\title{
WASP STUDIES AFIELD
}

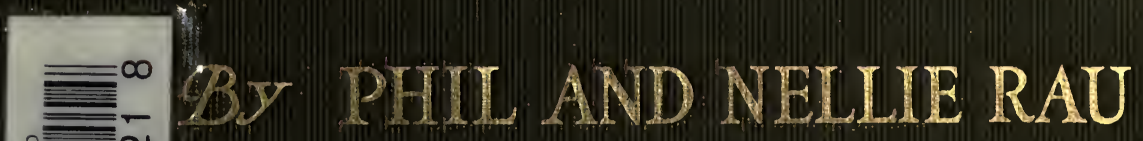







\section{WASP STUDIES AFIELD}


Digitized by the Internet Archive in 2007 with funding from Microsoft Corporation 


\section{Insecta.}

R.

\section{WASP S'TUDIES AFIELD}

BY

\section{PHIL RAU AND NELLIE RAU}

WITH AN INTRODUCTION BY

\section{WILLIAM M. WHEELER}

PROFESSOR OF ECONOMIC ENTOMOLOGY, HARVARD UNIVERSITY

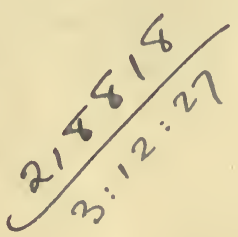

PRINCETON UNIVERSITY PRESS

PRINCETON

LONDON : HUMPHREY MILFORD OXFORD UNIVERSITY PRESS 

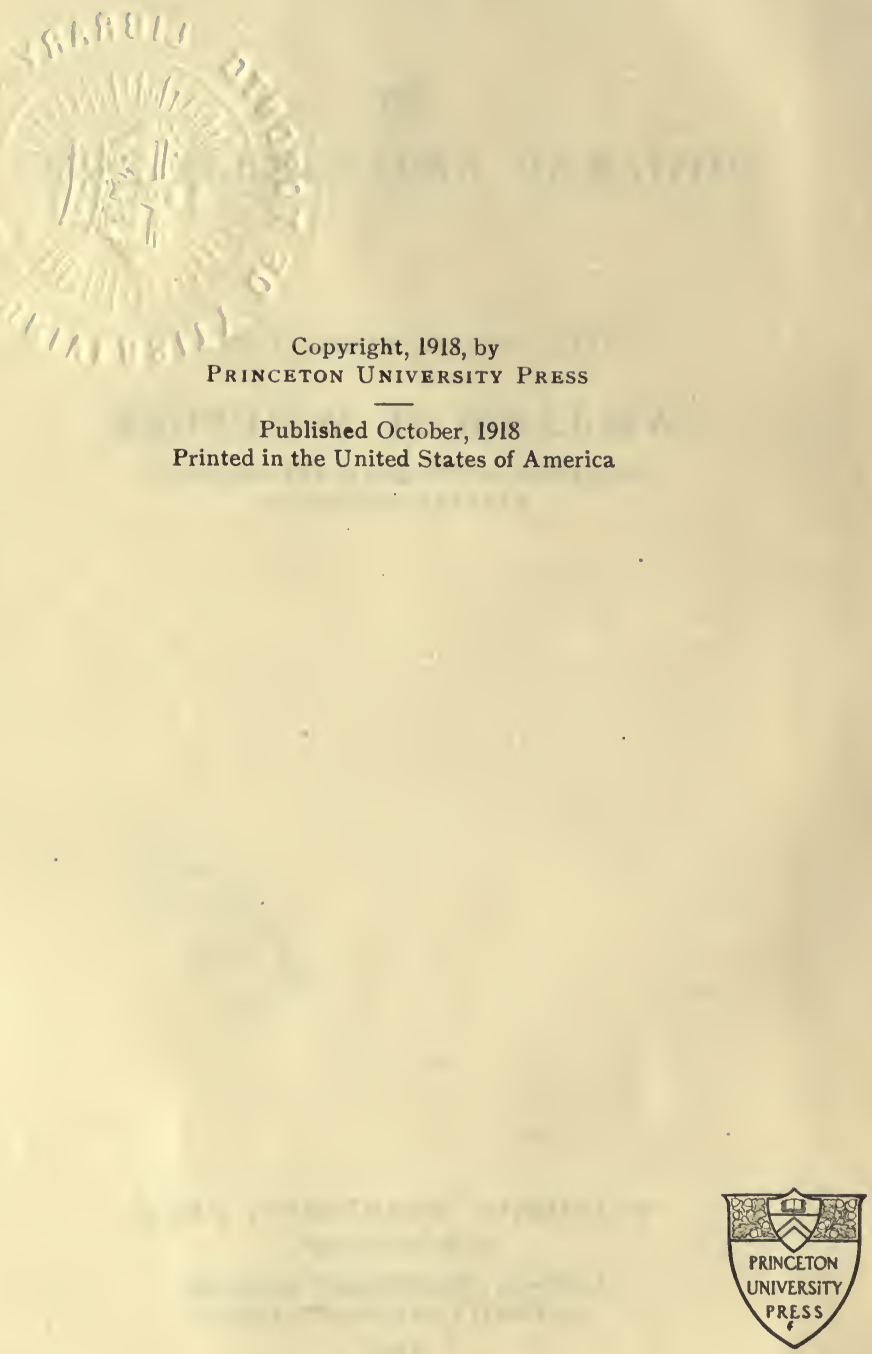
"Comparative Psychology is an as yet almost unexplored territory and but little understood, for want of approaching it by the best side, that is to say, by carefully made observations. It is involved either in metaphysical dogmas, *** or in shallow anthropomorphism which confounds inherited instinct and its automatisms with the plastic judgment of the individual, based upon memory and the association of memories or sensory impressions. $* * *$ Let us be thoroughly imbued with the truth that each species and even each polymorphic animal form has its special psychology, which should be especially studied, and which depends on the one hand, upon the development of its muscles and senses, and on the other, upon that of its brain."

-Forel, "The Senses of Insects." 



\section{PREFACE}
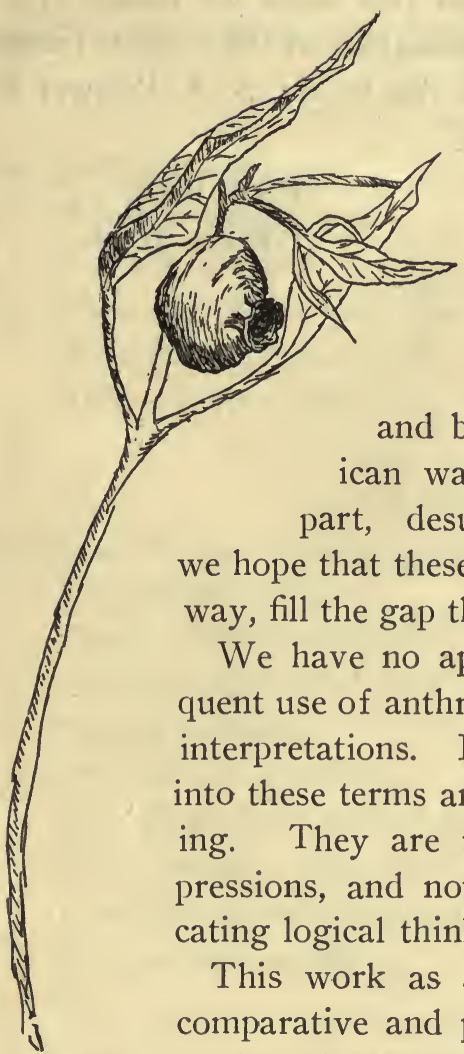

The present volume embodies the results of four years of out-of-door study of some of our most interesting and highly developed insects, in their native haunts, while pursuing their occupations in their own way. Biological and behavior work on the American wasps has been, for the most part, desultory and incomplete, and we hope that these chapters may, in their small way, fill the gap that exists.

We have no apology to make for the frequent use of anthropomorphic ideas, terms and interpretations. However, one must not read into these terms any subtle metaphysical meaning. They are used as apt descriptive expressions, and not for the purpose of predicating logical thinking to these creatures.

This work as a whole is descriptive; the comparative and philosophical, as well as the correlative, data have been reserved for a later volume.

- Unless otherwise stated, all of the observations were made at St. Louis or within a radius of thirty miles of that city. The sketches for the illustrations were made in the field and executed in their final form by Dr. Gustave Dahms. 
A debt of gratitude is due to Dr. C. H. Turner of Sumner High School of this city for critically reading the manuscript, and to Dr. L. O. Howard and the various specialists connected with the United States Department of Agriculture and the Smithsonian Institution whose names appear in brackets throughout this work we desire to express our thanks for the identification of the various insects. and especially is our gratitude due to Mr. S. A. Rohwer for much taxonomic information.

Saint Louis, Mo.

Phil Rau, Nellie Rau.

November 29, I9I7. 


\section{CONTENTS}

Introduction. By W. M. WheEler ........ I

Chapter I

Some Bembicine Wasps ................ 9

Bembix nubilipennis

Bembix spinolae

Microbembix monodonta.

Bicyrtes quadrifasciata

Sphecius speciosus

\section{Chapter II}

Behavior of Wasps Belonging to the Family Pompilidae 45

Pompiloides tropicus

Pompiloides marginatus

Psammochares scelestus

Pepsis dubitata

Priocnemis pompilus

Arachnophoctonus ferrugineus

Pseudagenia architecta

Pseudagenia pulchripennis

Pseudagenia mellipes

\section{Chapter III}

Some Fly-catching Wasps .............. 90

Hypocrabro stirpicolus

Hypocrabro chrysarginus

Paranothyreus cingulatis 


\section{Chapter IV}

The Enemies of Plant-lice ............... IO2

Xylocelia metathoracicus

Ceratophorus tenax

Chapter V

The Bee-killing Wasps ................. I09

Philanthus punctatus

Pseudanthophilus vertilabris

Chapter VI

Some Mud-daubing Wasps that Hunt Spiders ...... I I 8 Sceliphron caementarium

Chalybion caeruleum

\section{Chapter VII}

Some Wasps that Prey on Beetles ........... I26

Cerceris fumipennis

Scolia dubia

\section{Chapter VIII}

Some Wood-boring Wasps .............. I 33

Cerceris finitima

Trypoxylon tridentatum

Silaon niger

Trypoxylon clavatum

Trypoxylon johnsoni

\section{Chapter IX}

The Hunters of Small Orthoptera ........... I40 Alyson melleus

Tachysphex terminatus

Tachysphex fuscus

Tachysphex obscurus, and T. obductus

Notogonidea orgentata 


\section{Chapter X}

The Hunters of Large Orthoptera ........... I 59

Priononyx atratum

Priononyx thomae

The relation of Stizus unicinctus to Priononyx

thomae

Chlorion ichneumoneum.

A locust-hunter that makes twin cells

Chlorion cyaneum

Chlorion (Isodontio) Auripes

The prey of Ammobia bridwelli

\section{Chapter XI}

The Sand-loving Ammophila ............. 207

Sphex pictipennis

Sphex procera

\section{Chapter XII}

Some Social Wasps. Experiments on the Homing of

Polistes pallipes ................... 244

Polistes rubiginosus

Polistes annularis

Polistes pallipes

Polistes bellicosus

Vespula germanica

Vespa maculata

\section{Chapter XIII}

The Mining and Other Wasps of the Family Eumenidae 297 Odynerus geminus

Odynerus dorsalis

Odynerus anormis

Odynerus pedestris

Odynerus designatis

Odynerus foraminatus 
Ancistrocerus fulvipes

Ancistrocerus tigris

Ancistrocerus copra

Monobia quadridens

\section{Chapter XIV}

General Considerations ............... 355

Index .............................. 369 


\section{ILLUSTRATIONS}

FIG.

PAGE

I. Nest of the potter-wasp, Eumenes $s p . \ldots \ldots \ldots \ldots$ v

2. An attractive area for digger-wasps ......... Io

3. The burrows of Bembix mubilipennis ........ $2 \mathrm{I}$

4. Bembix mubilipennis filling her burrow ........ 28

5. Diagram showing the method of Bembix nubilipennis in sweeping the ground......... $3^{\mathrm{I}}$

6. The cocoons of Bembix mubilipennis ........ 35

7. The burrow of Microbembix monodonta ...... 40

8. A sandy area where Microbembix monodonta and Bicyrtes quadrifasciata abound .......... 43

9. Pompiloides tropicus transporting her prey .... 49

Io. The burrow of Pompiloides tropicus ........ 53

I I. Another form of Pompiloides tropicus burrow ... 56

12. Pompiloides marginatus dragging her prey up-hill 6 I

I3. The burrow and prey of Psammochares scelestus. 65

14. Priocnemis pompilus carrying her spider ...... 76

I5. Figure of female Arachnophoctonus ferrugineus. 79

16. The twin-celled nests of Pscudagenia architecta. 84

I 7. Psendagenia pulchripennis and her prey ...... 85

I8. The nests of Pseudagenia mellipes in the walls of a Sceliphron nest ............... 86

I9. A three-celled nest of Pseudagenia mellipes, and its maker ................. 87

20A. The mud cells of Pseudagenia, from which

Sphacrophthalma scaeva emerged ....... 88

20B. A mud nest of $P$. mellipes built in an oak-apple. . 89 21. The burrow and cells of Hypocrabro stirpicolus.. $9 \mathrm{I}$ 
22. The remains of a feast; cells of Hypocrabro stirpicolus ........................ 92

23. An elderberry twig containing the nest of Hypocrabro stirpicolus ................... 95

24. The nesting site of Paranothyreus cingulatis ... 97

25. Burrows of various forms made by Paranothyreus cingulatis ..................... 99

26. Figure of female Paranothyreus cingulatis ...... IOI

27. A clay bank where Xylocelia metathoracicus digs her burrows ................... Iо 3

28. The burrow and cells of Xylocelia metathoracicus 106

29. The burrow of Philanthus punctatus ........ I I 3

30. Nests of the mud-dauber, Sceliphron caementarium, and Chalybion caeruleum ............ I 20

3I. The opening to the burrow of Cerceris fumipennis 126

32. A Sceliphron nest remodelled to suit the needs of

Trypoxylon clavatum ................ I 36

33. Alyson melleus, her burrow and prey ........ I4I

34. The burrow of Tachysphex terminatus ....... I46

35. Notogonidea argentata, and her burrow ...... I56

36. Priononyx atratum .................. I60

37. Priononyx atratum filling her burrow ........ I63

38. Priononyx atratum pounding the soil with her head 164

39. Two burrows of Priononyx atratum ........ I7 I

40. Prionony'x thomae riding her locust home ..... I I77

4I. Priononyx thomae and Stizus unicinctus ....... I83

42. Cinders carried by Priononyx thomae ........ I 185

43. Chlorion ichneumoneum, her burrow and prey... 195

44. Twin-celled burrows made by an unknown locust-

huntress ...................... 199

45. The burrows of Sphex pictipennis ........ 208

46. Sphex pictipennis carrying a small caterpillar .... 2 Iо

47. The position of egg of Sphex pictipennis on prey. 21 3

48. A locality study by Sphex pictipennis ....... 220 xiv 
49. The cocoons of Sphex pictipennis ......... 235

50. Ammophila procera asleep on a dried stem..... 243

5I. The nest of Polistes ............... 287

52. A nest of Polistes anmularis among the branches. . 289

53. Vespula germanica thick as flies on a freshly removed rooster's head ............... 296

54. The turret over the burrow of Odynerus geminus 300

55. A burrow of Odynerus geminus ........... 301

56. A collection of mud-pellets carried out of the burrow by Odynerus geminus ............. 303

57. Five burrows made by Odynerus geminus .... . 308

58. Odynerus dorsalis, her burrow and her method of lowering the prey $\ldots \ldots \ldots \ldots \ldots \ldots \ldots \ldots \ldots \ldots$

59. The course of flight of Odynerus dorsalis to her water puddle ................... 3 I6

6o. The burrow of Odynerus dorsalis .......... 3 $3^{\mathrm{I}} 7$

61. Two burrows of Odynerus dorsalis .......... 3 I9 $^{\text {I9 }}$

62. An unusual Odynerus nest .............. 32I

63. The mandible-marks on the tunnel left by $O d y$ nerus dorsalis .................... 322

64. All that remained after O. dorsalis feast on Pholisora catullus caterpillars ............. 327

65. The nest of Odynerus pedestris .......... 333

66. Odynerus foraminatus and her home in a log... 335

67. The nest of Odynerus foraminatus in an elderberry stem ......................... 338

68. The burrows of a mining bee in a clay bank, some of the tunnels used by Ancistrocerus fulvipes . . 342 


\section{WASP STUDIES AFIELD}

\section{INTRODUCTION}

If any excuse were needed for welcoming another work in addition to the nearly three hundred books and articles that have been published on the habits of the solitary wasps, it would suffice to point to the fact that no other group of insects has so fascinated and baffled the student of animal behavior, the psychologist and the philosopher. When among contemporary generalizers we find an eminent psychologist, William McDougall, claiming for the solitary wasps "a degree of intelligence which (with the doubtful exception of the higher mammals) approaches most nearly to the human," and the illustrious Bergson using the same insects as paradigms of instinct in the sense of "intuition" as contrasted with "intelligence," there is surely need of a renewed presentation of facts already established, of the publication of new observations and of a serious attempt at dispassionate interpretation like that made in the present volume.

The solitary wasps comprise some 10,000 described species scattered over the torrid and temperate regions of the globe and representing a number of more or less closely related natural families of Hymenoptera. To the entomologist these wasps are of unusual interest for several reasons. First, they are in physical structure the most superbly specialized of insects, so that they bear to creatures like the beetles, flies, and grasshoppers, somewhat the same relation that the members of the cat family bear to the rodents, ruminants and insectivores. Even the social Hymenoptera seem to have a less 
perfected nervous and muscular organization and are certainly less beautifully formed and colored. Second, this unusual physical endowment is correlated, as would be expected, with extraordinary industries, or behavior. Certainly, with the single exception of the social Hymenoptera and the Termites, no insects show such a range of activities as the solitary wasps. Third, they are the lineal descendants of forms which gave rise to the social Hymenoptera. This seems to be so evident that Handlirsch actually derives the bees from the Sphegid, the social wasps from the Eumenid and the ants from the Scoliid wasps, and Roubaud has recently been able to detect in the genera Synagris and Belonogaster of the Belgian Congo a most interesting series of behavioristic transitions between the solitary and social wasps. And fourth, the ancestry of the solitary species themselves presents an interesting, though more debatable problem, owing to the fact that the group appears fully developed, at least so far as the families Mutillidæ and Scoliidæ are concerned, in the Baltic Amber of lower Tertiary age. Although no species have been found in older geological formations we must suppose, nevertheless, that the group goes back to the Cretaceous and probably even to the Jurassic or Triassic. Hence the evolution of the solitary wasps has extended over a period of at least four to six million years. We are not, therefore, greatly surprised to find that they exhibit such a diversity of habits, especially when we remember that the whole mammalian class, man, of course, included, has had a shorter evolution.

There is another peculiarity of the solitary wasps which is connected with their geological origin and history. The authors of this book repeatedly call attention, especially in their account of the Bembicids (Chapter I), to the fact that these insects are very strongly attached to their nesting sites and stick to them generation after generation. Such 
a habit has the earmarks of great antiquity and seems to indicate that the present type of nesting site is like the one in which the group originated. This is confirmed by the fact that the group as a whole prefers to nest in dry, sunny, sandy or gravelly soil and is therefore most abundantly represented by species and individuals in the deserts of North Africa, the Southwestern United States, Central Australia, etc., or in similar xerothermal localities of more limited area in other parts of the world (sand-dunes, pinebarrens, dry banks, roads, paths, etc.). Probably, therefore, the group originated during some period of the Mesozoic when there were large tracts of elevated, arid land in the interior of the continents, and this may account for our failure to find any fossil remains of the primitive ancestral forms. In this connection it is interesting to note that the work on the habits of the solitary wasps is mostly confined to particular countries in which the physical conditions are such as I have described. Thus the most important contributions to our knowledge by European observers such as Dufour, Fabre, Picard, Bordage, Roubaud and Ferton, have come from Southern France, Corsica and North Africa or from the tropics, and the more important observations of American investigators, such as Riley, Williston, the Peckhams, Hartman, Hungerford, Williams, Iseley, Barth and the Raus, have been made in the Middle Western and Southwestern States.

The fact that the solitary wasps have so many and such intricate relations with their inorganic and living environment renders their study in the laboratory impossible or, at any rate, very inadequate. A few habits, such as the method of constructing the nest among the mason wasps, can be observed in the laboratory, and sometimes with remarkable results as shown by Bordage's work on Pison and Trypoxylon in the Island of Reunion, but a knowledge 
of the complete cycle of behavior of any single species cannot be thus obtained. Field study is therefore indispensable and this demands acute powers of observation, much patience and no little mere physical endurance. Still the limitations of such study are obvious. The finding of the insects and their nests is a matter of chance and frequently only glimpses of their behavior are obtainable so that the whole cycle of behavior has to be pieced together from fragmentary observations and often requires the labor of several observers extending over many seasons. Hence the incompleteness of many accounts in the literature. A good example of this limitation is seen in the present volume in the interesting account of the extraordinary parasitic habits of Stizus unicinctus.

Another limitation in field study lies in one's inability to estimate the previous experience of the wasps under observation. Usually the insects are first encountered while engaged in some activity which may or may not have been repeated on some former occasion, such as making the nest or provisioning it, and as they undoubtedly profit by experience and form definite habits, what is evidently an important factor in the performance of the particular activity under observation cannot be taken into consideration. This lacuna is partially bridged in Chapter XII of the present book by a valuable study of individual experience in one of the primitive wasps, Polistes.

Even more serious is the limitation to the experimental method in the field. It is, of course, essential for descriptive and other purposes to ascertain by simple observation the course of the normal routine activities of the insect in its natural environment, but it is also of great importance to know what the insect is and is not capable of doing. This can be accomplished only by means of experiment; and experimentation in the field is a rather mild procedure 
compared with what can be accomplished under the rigorous and indefinitely variable control of the laboratory. Still results of considerable value have been obtained by simple field experimentation as will be apparent to the reader of the ingenious studies of Fabre, the Peckhams and the Raus.

Although the activities of only a few hundred solitary wasps have been carefully observed, we may be sure that every one of the Io,ooo described species has its own peculiar behavior. In the non-parasitic forms this appears as a complex cycle, the more important component minor cycles, or phases of which are the digging or construction of the nest, the capture and stinging of the insect or spider prey, oviposition and the sealing of the nest entrance. But the sequence and details of these cycles is subject to great specific and sometimes to considerable individual variation. Thus the sequence of the three first cycles in many species of Sphegids is nest-prey-egg, but in Psammocharids it is commonly prey-nest-egg, and in the Eumenids nestegg-prey. This is also the sequence in social wasps ( $\mathrm{Po}$ listes, Vespa, etc.). In parasitic species the behavior is, of course, peculiarly modified in adaptation to that of the host.

In their interpretation of wasp behavior the Raus agree essentially with nearly all previous investigators as could be shown by quotations from Marchal, Picard, Bordage, Adlerz, the Peckhams, Hartman and others. Most of the activities can be readily interpreted as chain-reflexes, or "instincts" in the usual biological sense of the term. They are relatively fixed or stereotyped and undoubtedly hereditary and therefore represent the most ancient and most solidified complex of the behavioristic cycle. But there stand out from this complex many activities which are much less mechanized and of such a nature as to demonstrate that the wasps possesss emotions and associative memory, 
that they exercise discrimination and choice, that they learn by experience and form habits in the restricted sense of the term and that they can modify their behavior adaptively in response to unusual stimuli on the basis of previous experience and therefore behave, to a limited extent, like intelligent beings. Such an interpretation will be accepted by any unbiassed student of the solitary wasps, and those who hold it may be classed as the moderates among behaviorists.

There are, however, three classes of extremists-the mystery-mongers, the simplicists and the humanizers-who fail to take account of all the facts and find support for their opinions in particular aspects of wasp behavior. Fabre may be classed among the mystery-mongers, because when he turned to the interpretation of the wonderful facts he had so carefully observed, his final appeal was always to some mysterious cause. This is best seen in his interpretation of the stinging of the prey as the expression of an inscrutable, intuitive knowledge of the prey's nervous anatomy-a view which Bergson incorporated in his philosophy of instinct. Fabre's treatment of the wasp's homing activities and of her method of finding her prey are similarly attributed to her possession of mysterious senses. This mental attitude was due to preconceptions to which I shall return presently. The simplicists are preoccupied with the reflex or tropistic, i.e., the mechanized behavior. At least one of them, Bethe, is also as much of a mystery-monger as Fabre. Loeb and Bohn have no first hand acquaintance with the wasps and are influenced by their knowledge of the lower invertebrates and insects whose behavior is so highly and consistently mechanized that evidence of its plasticity or modifiability are feeble or difficult to observe. The humanizers, who interpret animals like the wasps as if they were miniature men, are rarely met with at the 
present time, except among the writers of certain nature books.

The case of Fabre requires some further comment. Acquaintances, who are not entomologists but who read his "Souvenirs" with delight, frequently ask whether I regard him as a reliable chronicler of the habits of insects. I usually reply that, in my opinion, Fabre, Latreille and Réaumur are the three greatest entomologists, but that we must make due allowance in Fabre's writings for certain preconceptions, which, strangely enough, seem actually to heighten the merit and beauty of his work. He was trained as a physicist, chemist and mathematician and when he came to study insects he carried with him the point of view of the student of the inorganic sciences and was therefore interested in establishing clean-cut laws. Owing to this tendency and a belief in the scholastic conception of instinct he naturally stressed and schematized the normal course of behavior in the insects. Although he noted many variations in their activity, these evidently appeared to him as so many perturbations or accidents which were interesting only in so far as they helped to define his essentially static interpretation. They were, in other words, merely the exceptions that prove the rule. Hence his descriptions and discussions leave an impression of elegance and finality like a demonstration in mathematics or physics and therefore appeal more strongly to philosophers like Bergson than to the modern biologist who has been so often deceived by clean-cut theories concerning living organisms that he has grown timid and suspicious. Then it must be remembered that Fabre was unable to appreciate the variations of behavior because he was too set in his ways of thinking when the "Origin of Species" appeared to acquire any sympathy with evolutionary theories. If these considerations be borne in mind it is not difficult to estimate the value of Fabre's 
work. He is, indeed, so preeminent in the wealth and precision of his observations, in the ingenuity of his experimentation and in literary expression, that his "Souvenirs" will always endure.

The variations which to Fabre were more or less negligible necessarily at once assumed great importance when biologists became evolutionists. In fact, the variations in behavior, because they were considered to be the essential materials of evolution, became, if anything, even more interesting than the routine, mechanized activities. The first among entomologists to recognize the evolutionary importance of behavioristic variations was Paul Marchal in I887 in his study of a solitary wasp, Cerceris ornata, and since that time all students of insect behavior have focussed their attention on the variations. This is as apparent in the present volume as in the works of Marchal, the Peckhams, Adlerz, Ferton, Iseley and others, and could not well be otherwise, for all biologists are now thoroughgoing evolutionists.

In one other respect, also, the Raus have followed a commendable tradition in the presentation of their observations. Réaumur in his "Memoirs," published in I734 to I742, was one of the first entomologists to write on the behavior of insects in such a manner as to attract and instruct the general reader. Fabre adopted a similar method of presentation but greatly excelled his eighteenth century predecessor in literary power. That the American is as appreciative as the European public of this form of writing is shown by the success of the Peckhams' work on the solitary wasps. I feel sure that "Wasp Studies Afield" will meet with a like reception.

W. M. Wheeler.

Harvard University,

June Io, I9I8. 


\title{
CHAPTER I
}

\author{
Some Bembicine Wasps
}

Bembix nubilipennis Cress. [S. A. Rohwer].

The Bembix population burst upon us with a suddenness which startled us into full attention at once. We had crossed the field day after day, and, on that very day, June I6, I9I4, had passed by this certain bald, bare space in the field which the boys of the neighborhood had, for a number of years, kept packed hard for their Sunday baseball game (fig. 2); but all had then, only an hour before, been as quiet and lifeless as the grey earth itself. Now the very air above the surface of the bare ground seemed vibrant with the lowflying wasps, which formed a wavering, yellowish-green haze over the smooth, dusty earth.

Any estimate of their numbers was very difficult to obtain from the swiftly-moving swarm, but we suspect that at least one or two hundred were present. The ground was dotted with newly-opened holes, ${ }^{1}$ less than one-fourth inch in diameter, which seemed to go straight down and had no trace of excavated dirt around their mouths; this evidence led us to conclude that these wasps had all simultaneously emerged by these exits from their winter quarters, to mingle in this first.social frolic or dance. They remained in their unceasing flight at a uniform and constant height, all keeping, with

1 We counted forty-four holes in one area three feet square, but we could not be certain if all were holes of the emerging Bembix. 


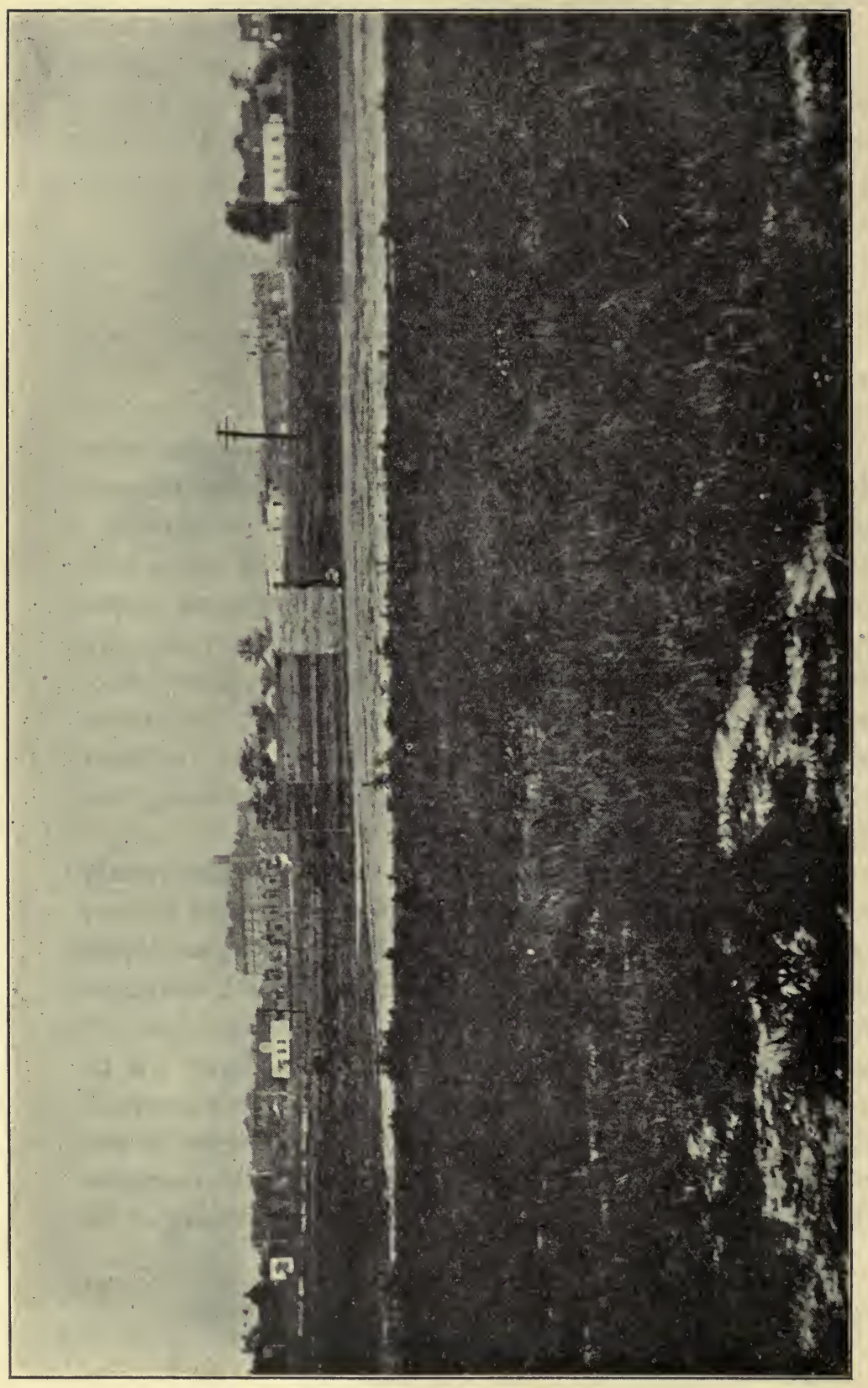

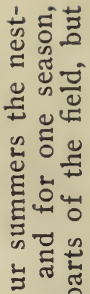
을 मे 으요 त 3 \% क స्ञ $\exists$ 공 - 0 क त् . ㄷ.? 0. 청 范焉. 던 $>$. on + 㱦 む怘完 के के

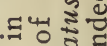
的芯。 के ङँ 궁 3 늘 E 년 - के 들 Ð ह क

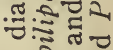
$=\approx$ సีミ 닌 ज. 플 조용 $\because 0^{\circ}$ E 0 ह फั त 0 व ن. LI bo. . 
surprising accuracy, on a level about one and one-half to two inches above the ground. No digging or any other enterprise could be seen; every citizen of the colony was mingling in the graceful sun-dance, doing his part blithely and heartily but not too obtrusively. The whole was not a helter-skelter commotion, but a merry whirl to the music of a faint, eerie hum of many wings, with every few moments a rather musical crescendo, which sounded like "zip!," when a whirling pair would suddenly dash off at triple speed on the wing, in the final fling of joyful abandon, for five or six feet, at a speed the eye could scarcely follow. But only for a part of a second did this shrill note come from the highly-vibrant wings; for then the pair separated and returned to the swarm and were instantly lost among their fellows, weaving their way in and out the maze, hovering back and forth in large circles or, with other partners, whirling once around in tiny circles.

In these wild dashes, in which two wasps invariably participated, they grasped each other as if in a violent embrace for just the instant, but we could not ascertain further details, for their movements at this point were so rapid that the eye could not follow them; in the twinkling of an eye they had returned to the common maze again. While we suspected that these embraces were acts of copulation, we had no actual proof. We at once called the performance a sun-dance, yet it must not be understood that they followed an up-and-down or vertical dancing movement; on the contrary, they flew with a rhythmical, gliding motion, like a skater taking one long, smooth stroke after another with scarcely a pause between them. They glided thus to and fro in the prescribed area singly, but frequently two would playfully or flirtatiously whirl around each other without touching (this movement we called waltzing), after which both would usually drop back into the glide with the 
others, although sometimes they would conclude with one of the wild dashes and embraces just described.

The liveliest part of the dance, when the participants were most numerous, occurred from 9:30 to Io a. m. By IO:30 they were fewer in number and droning wearily along, and by I I o'clock, when we were obliged to leave the field, both the activity and numbers were greatly reduced, although we could not discern whither they were disappearing.

Two days later we returned to the field at 7 a. m., eager to witness the continuance of this performance and learn more of its mysteries. The holes were all open, as before; but some minutes elapsed before the first drowsy Bembix appeared and took up the low, gliding flight of the day before. Presently others joined it and by $7: 30$ five were in the flight, gracefully weaving to and fro and occasionally resting for a moment on the grey earth. We did not detect whence they came. They limited their flight strictly to a bare area, which was perhaps fifteen feet in diameter, and did not venture out above the grass which surrounded it on all sides.

By 8 o'clock and during the hour following, perhaps half as many as on the first day were on the field, pursuing the same characteristic low flight, but to-day there was no perceptible hum of wings, no embracings, no "waltzes" and very few of the wild, flirtatious dashes. Instead, from time to time, many were settling on the earth and beginning to dig vigorously. In this digging, they paid no heed to the old holes from which we supposed they had just emerged; but they began energetically digging new burrows, each with a broader, spreading entrance and going down at an angle of approximately $30^{\circ}$ to $45^{\circ}$ with the surface. It seems that the old holes were merely direct channels of escape from the place where they had lain buried in the earth through the winter, and they did not turn to them at all as 
further domiciles any more than a chick returns to its egg-shell.

In the following year we took up a diligent watch early in June for this pretty phenomenon. Our expectations waned with long waiting, until we gave up all hope of seeing the frolic again. But on July 4 we were surprised by the outburst of wasps, as sudden as before. The cool months of May and June had probably retarded their emergence until this late date. Even this hypothesis seems almost incredible when we consider that they came from the eggs laid by many different mothers of the previous year from June to September, and that even their nests, which remain open until the larva is ready to pupate, were closed at widely different periods; yet we can now imagine no explanation for the phenomenon other than that the wasps which had come to their maturity simultaneously, or had been lying dormant ready to emerge at the fight conditions, had all responded to the dazzling sunshine and the rising temperature of this bright morning and had all dug their way straight out into the light, to mingle in this first social frolic or dance. None of the characteristic nesting holes of Bembix could be seen, but the clear-cut, vertical holes by which they had emerged were even more numerous than in the previous year. It was very noticeable too that the group was limited to precisely the areas where the mothers had nested during the previous few years, and where also the sun-dance of the last year had occurred. Thus, for generation after generation, they live and reproduce in the spot where they are born.

Strange indeed is the constancy of instinct in this dancing performance, which they are never taught and for which they have no further use; nevertheless it occurs year after year with each generation, and is in all details the same. In this the second year we were alert to ferret out 
the answers to the many mysteries which the first year had left us.

On the first day we arrived at the conclusion that there was a great predominance of males. In all the morning's dance we saw only three mating flights. In one of these cases, the united pair were in flight when they were knocked to the ground by two other males. A struggle ensued in which all the males were trying to gain access to the female. They were so intent upon this affair that we could easily get close enough to see all this. Even as we watched, more and more males left the flight and joined the struggling mass, and strove together on the ground before us for several minutes - or maybe it was seconds. So large an assemblage were they, and so intent upon their business, that we could have scooped up the mass in a handful, and the hand would have been filled to overflowing. Eventually the female and one of the males broke away from the mass and sped off on the wing. The train of admirers which followed them formed one of the prettiest sights we have ever witnessed in the insect world; the wasps extricated themselves, one by one, from the heap and followed the pair in unbroken succession, like the wool spun from the distaff, in a long, smooth line of glinting green and yellow, pursuing them so rapidly that before the fugitive female had gone fifty feet they had overtaken her again and formed the teeming mass around her. This struggle continued again for several seconds until one could not tell what had become of the female; but presently, one by one, they abandoned the conflict and returned to the dance.

As we have described for the previous year, their flight was low, near to the ground. The wasps were in motion for hours at a time, never resting; if one chanced to drop out or fall to the earth for an instant, another, perhaps mistaking it for a female, or for some other unknown 
reason, would immediately pounce upon it with a heavy thump and thus arouse it to return at once to the dance. The other two pairs that succeeded in mating made their speedy escape to avoid rivalry. This accounts for the wild dashes outside the area of the dance which we observed in the first year; the escape from the crowd has become so necessary a part of the act of mating that a dash for safety from the throng has become an integral part of every suggestion of mating or false mating.

In the midst of this pretty play we were driven from the field by the human proprietors of the baseball diamond, and when we saw the clouds of dust rise from the trampling of many spiked shoes, it seemed inevitable that the little Bembix would be driven from the homes of their ancestors. In the afternoon we returned, but found another set of ballplayers and many spectators doing their best to exterminate our pets. The next day at 8:30, however, true to their fatherland they were there and even more abundant than on the first day, although how they could have escaped extermination during the terrible trampling will always be a marvel. Wasps do not migrate far from the place in which they are born. This in a peaceful locality might show only indifference, but when even a noisy American baseball crowd cannot drive them from their home it proves persistence of a most surprising degree. Where these $\mathrm{Bem}$ bix had spent the night we know not. We certainly do not see how it would have been possible for any of them to locate their former holes from which they had emerged on the trampled and dusty earth, even if they had so desired. They may have slept on the grass and weeds surrounding this area, but in extensive studies of the sleep of insects in this field we have never found a Bembix asleep on the vegetation. The bare ground presented no newly-dug holes which they might have made for their sleeping quarters, 
but there were more of the vertical emergence-holes from which newcomers had probably issued.

It was soon apparent that there were more females present than on the previous morning. There was a noticeable reduction in the rivalry when a mating took place. A dozen or more matings occurred in the low flight near to the ground; since there was less rivalry, there was less need of a quick escape, and mating could go on with impunity. In only two cases was there marked rivalry where the mated pairs were knocked to the ground, but instead of the teeming mass of competitors which we had seen the day before there were only three or four pursuers.

The duration of copulation is brief. The time is hard to estimate, but it usually continues through about fifty feet of flight. The females are polyandrous, and all indications are that the males are polygamous. One certain female, which we could easily follow on account of her exceptional color, mated six times in a brief period. We are sure, from close observation, that all of these were cases of actual matings. In each case also the mating was spon- taneous, that is the female was not coerced by the eagerness of the males to mate, nor did the rivalry of the males cause the separation. Each time, after the union had been effected, the pair glided near the ground for the usual distance of about fifty feet and separated; the female returned at once to the dance and whirled in and out until she casually picked up another partner when the performance was repeated exactly. Thus with more females in the field on the second day the rivalry was much reduced, and we saw none of the extreme behavior of the males.

This also points to the habit of priority of emergence of the males, as we know occurs in other insects ( $c f$. Saturniids $^{2}$ ).

2 Rau, Trans. Acad. Sci. St. Louis 23: I-78. I9I4. 
At 2:30 in the afternoon of the second day all the excitement was gone, and all was quiet excepting a half-dozen or so females which were beginning to dig their nestingburrows. All of our afternoon observations show that the mating flights occur only during the morning.

Every morning, for ten days, we found Bembix in the field in the characteristic flight, but as the days passed, the number of those in the sun-dance became less and less while the number of females busily burrowing increased proportionately, until July I4 when the dancing behavior ceased. During the latter part of this period, only an occasional mating was to be seen. What becomes of the males? Do they fertilize the females once for all and promptly die, or do they hide away among the grass to be at hand when needed? We suspect that the former condition holds, for we have never found Bembix males in the grass or anywhere except for this one occasion, and I have never seen these wasps mate while nest-building.

Thus it seems that the one gala day which we so fortunately witnessed was not only the first but also the chief festivity of the Bembix year, for, although we saw a certain amount of this behavior on subsequent mornings, we never again saw the whole population give itself up to the dance as on this first occasion. After this had waned, only a few wasps were to be found above ground at a time. We do not know whether the males had migrated or perished, but we have every reason to believe that a large number of females were busy working in their underground nests or foraging for food for their young, so that now only a small proportion of the population at a time was in evidence above ground.

The work of most of our solitary wasps in nest building is characterized by an admirable constancy and zeal, but some labor with calmness and patience, and some even so 
cunningly that we can seldom spy them at their work. But there is no chance for doubt when Bembix is abroad; others may equal her in quiet diligence, but she works with unequalled commotion and bluster. Since these are solitary wasps working in communities and have a habit of robbing each other of prey, as we shall see later, they must work nervously. A wholly solitary wasp, or one which works in cooperation instead of competition with others, can afford to work much more calmly and deliberately. She alights upon a spot on the bare surface of the field-a spot without a trace of anything which we can discern to distinguish it from all the rest of the large, bald area several yards in width, yet this particular spot seems to be her choice, and there is something about it whereby she can remember it and distinguish it from all the remainder of the large area in returning to it again and again. Here she at once begins her digging. In this task she always works with an intensity which makes her appear to be driven by some fury. She cannot wait to calmly carry out load after load of dirt, as her sister species do, but, after having torn the earth loose with her mandibles, she scratches or kicks it back with her forelegs straight between her hind legs and far out behind her, in a spurting stream or jet. Much of the time, when she is working on or near the surface of the ground, she throws an almost unbroken stream of dirt out behind her as she digs, often hurling it as far as ten inches back of her. The front legs are provided with bristles which serve as brushes or rakes, with which she sweeps back the dirt. To do this, she is compelled to stoop forward; this gives her a comical appearance of "sweeping with her elbows," as the Peckhams suggest for another species of Bembix.

Often she seems dissatisfied with her location and makes several beginnings in as many different places, although we have never been able to see the slightest reason why the 
old place should have been abandoned, or that the new was in any way its superior. We watched one wasp begin one hole after another. Frequently others would fly down and alight with a thump beside her and violently bump her (but without actually seizing her). Thus disturbed, each time she arose on the wing at once and went off a short distance- $a$ few inches or a few feet-and began a new hole. After eight such interrupted attempts, she seemed to learn not to mind the intruders further, and continued to work on this hole while twenty-four others, one by one, flew down and butted her in this fashion, but finally she gave up this one also after it was well begun. After this we lost sight of her.

This case which we have followed in detail was no exception, but only a sample of the conduct of many of the swarm; some continued work upon their first or second hole, but all who attempted to dig were annoyed thus by the intrusion of others. The significance of this strange form of attention we have never been able to determine with certainty; but we have come to suspect that the intruders, seeing the owner of the burrow digging, suspected that she was entering her nest with a fly and pounced upon her to rob her of it. The Peckhams find the same habit in B. spinolae.

On two different occasions, when some of the B. mubilipennis were in a bumping mood, one swooped down upon a Sphex pictipennis that was carrying her caterpillar. A short struggle ensued, but both times when $B$. mubilipennis flew away, $S$. pictipennis resumed her walk. On one occasion a $B$. nubilipennis dropped a fly which she was carrying to her burrow, and, almost before it struck the ground, a sister wasp swooped down upon it and carried it away.

We do not know how long a time is required in which to dig the burrow, but we have one record of a nest that 
was begun on July I4, I9I5. When we excavated it on July 26 , twelve days later, it contained a larva three or four days old, together with four flies. Since the cell at the bottom must have been completed before the egg was deposited, this leaves eight or nine days for the construction of the nest and the incubation of the egg. This seems indeed a long time for so rapid a worker as B. mubilipennis. We have occasionally found her resting or loitering in her incomplete or newly-finished burrow, and we know that she does not work on cloudy or rainy days; so when we have made ample allowance of time for these indulgences, this may after all be a fair estimate of the normal time devoted to the making of a nest.

The normal burrow, three-eighths inch in diameter at the top, pierces the ground obliquely and continues downward, at an angle of about $30^{\circ}$ to $45^{\circ}$ with the surface, for five or six inches to its horizontal oval terminal pocket, which is one inch long by one-half inch in diameter. This cell is hollowed out more from the roof than from the bottom of the burrow. The tunnels are usually approximately straight, and only occasionally swerve to the right or the left; the slope of the tunnel rarely varies.

Most of the nests are normal, as the first two illustrations in fig. 3, but there are occasional exceptions. One nest went down at an angle of $60^{\circ}$; the tunnel was about twelve inches long, with the usual pocket one inch by one-half inch; another nest had a normal gallery, but a cell an inch and a quarter long and one inch wide. Another was normal at the entrance, but soon curved straight downward and then back under itself (lower illustration in fig. 3). But the most novel form of nest which we have yet discovered was one which started down and eastward, at an angle of $30^{\circ}$, for two inches; then turned sharply to the south and downward, at an angle of $45^{\circ}$, for four inches; then con- 


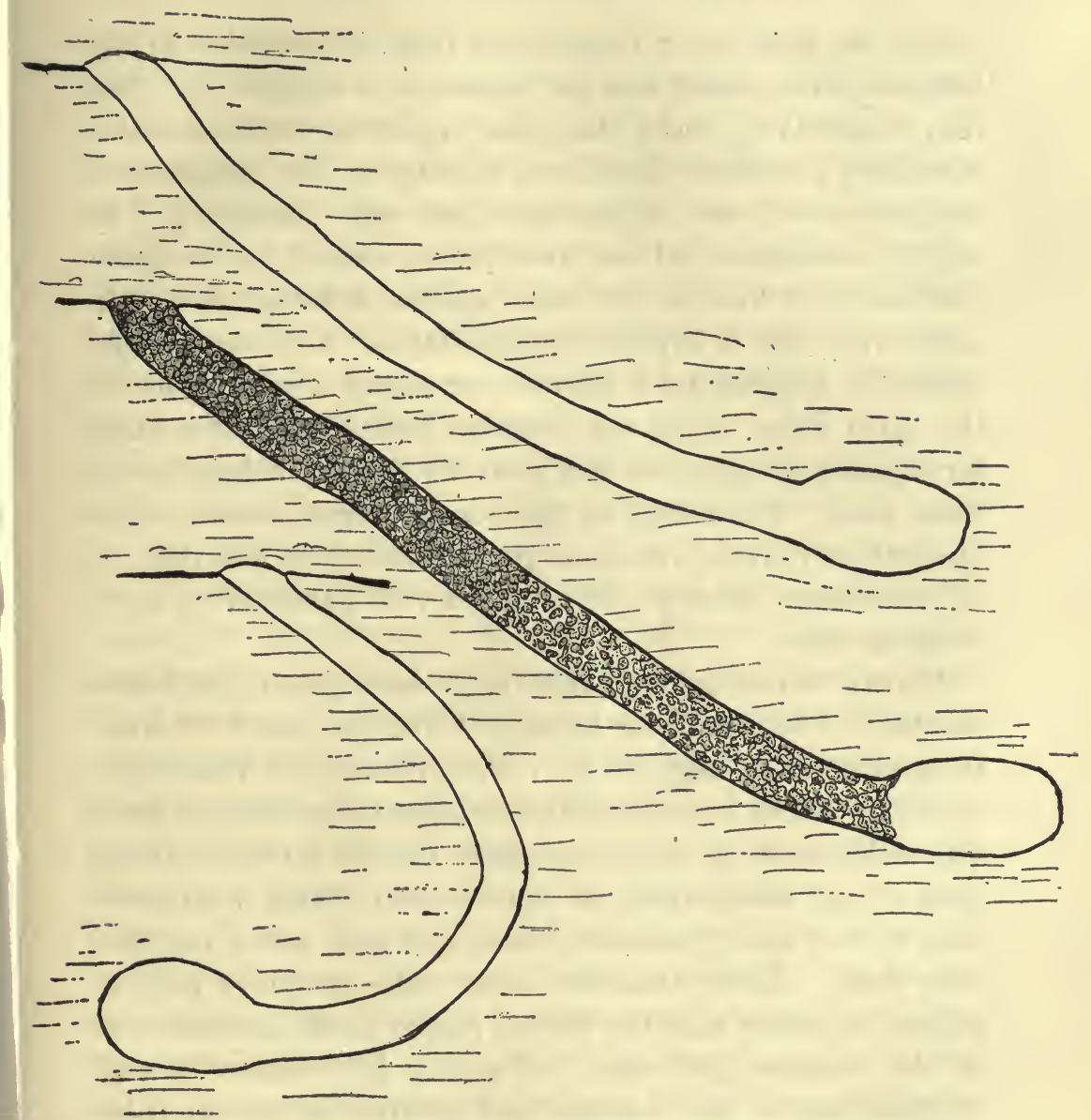

FIG. 3. The burrows of Bembix nubilipennis. Two-thirds natural size.

tinued south, at an angle of $30^{\circ}$, for two inches to the unfinished pocket where the owner was at work. It is strange that she should still be extending it after she had worked on it for several days and it was already beyond normal depth.

While we have opened many nests during the two years and found them in various conditions and of slightly varied 
forms, we have never found more than one chamber at the bottom of the tunnel and one immature wasp therein. The only nest having more than one organism was one which contained a medium-sized larva feeding on flies and a much smaller second one in the same and only chamber. The slight resemblance of the two larvae caused us to doubt whether they were of the same species, although the additional one was a Hymenopterous larva. On another occasion, in digging up a burrow we found a second one in the earth close beside the chamber that contained a large larva ready to spin, but this probably did not belong to the same nest. The wasps in their semi-gregariousness often build their burrows in close juxtaposition, so the cells of different nests seem to have only a thin partition of earth between them.

Parker, ${ }^{3}$ however, finds that his B. nubilipennis has habits similar to Philanthus, for he says: "The burrows *** enter the ground at an angle of $45^{\circ}$. At a distance of from eight to twelve inches from the entrance lateral branches are given off, which serve as brood chambers for the larvae. At the time of my observation no burrow was found with more than five of these chambers; most had four and a few had only three. In the chambers more than one larva may be reared, in which case the first is placed at the extreme end of the chamber and when full grown and encased a wall is placed across the chamber and another larva reared between this and the main part of the burrow. $* * *$ These observations were made on August 18 and I9, and although many burrows were opened only larvae were found. Many

3 Ohio Nat. Io: 163-165. Despite the fact that Cresson described the species in 1872 , this is the only paper that we can find which has biological data on this species, excepting Robertson, Trans. Acad. Sci. St. Louis 6: 458, 1894, who found the adults feeding on the flowers of four species of plants. 
of these had completed their growth and were encased in cells $* * *$ but in every instance an immature larva in some stage of development was also found in the burrow. In no case, however, was more than one developing larva found in any burrow. In one burrow with four branches three contained matured and encased larvae and the fourth, just newly constructed, contained two recently killed house-flies, on one of which was found an unhatched egg. From the data given above it would appear that the wasp rears only one larva at a time."

This interesting note recorded from Wilson, Kansas, which differs so widely from our observations on the number of chambers to each burrow, shows that the wasps of Dr. Parker's little colony of nubilipennis have acquired the economical adaptation of using their burrows for more than one chamber. It has been a matter of doubt whether $\mathrm{Bem}$ bix makes one burrow and carries that larva through its infancy before beginning the next, or whether she keeps up more than one domicile at a time. The Peckhams think, from some experiments, that $B$. spinolae takes care of only one nest at a time, and from our observations on the permanent closing of the nest early in the season with only a single young one within, we think it probable that, in our colony, the second burrow is constructed only after the first has been completed. When we consider (as will appear later) how poor the dissemination is in this species, we can easily see how a digression of making three to five chambers to a tunnel may easily become a habit and finally a family characteristic and may become constant in the colony. Dr. Parker states that these wasps had nested in this spot annually for a number of years.

Hence the establishment of a very pretty and economical habit. At the same time one must recognize a new habit, correlative of the multiplicity of cells, having arisen here, 
which, like the new habit just described, would go entirely outside the genus Rembix. We know that the digger wasps, Bembix, Ammophila, Priononyx, are essentially diggers, but Dr. Parker finds the Bembix in his colony taking up mason work also, building partitions to form new cells. "A wall is placed across the chamber and another larva reared between this and the main part of the burrow." It seems incredible that mubilipennis could build the wall of dry sand or dust, unless she too has acquired the watercarrying habits of certain Odynerus. The fillings of loose, dusty earth, such as she scoops into her holes here, could never be made to serve as a wall across the bulging middle of the chamber. It would be well worth while to make an effort to see how general this new habit has become.

We have so many times found the mother Bembix in her burrow when we opened it at any time near or after sunset that we have arrived at the conclusion that she sleeps in her nest, when she has one. We have also found her here safely hidden away on dark or rainy days, for Bembix loves only warmth and sunlight. The tunnel is always temporarily closed under these conditions. This is accomplished by the Bembix going down into the hole and pushing up loose dirt from below until the mouth of the burrow is completely closed. One morning we found that the dashing rain during the night had packed the soil hard and washed down the loose earth, leaving the hole open. We arrived just in time to see the mother Bembix cutting a small area about the opening and kicking the dirt thus loosened into her burrow until the aperture was closed. It seemed that this mother had remained in her burrow all night, with only the usual temporary covering over it, and that the rain had washed down this dust covering and she, unwilling to have herself and her nest exposed thus to danger, was hastening to cover her burrow again, even though she had to dig up 
the hard-packed earth with her jaws to obtain the necessary filling.

The same morning another Bembix alighted upon a particular spot which to us was absolutely indistinguishable from all the rest of the smooth-washed "diamond." She fell industriously to digging, and in a moment opened her tunnel and entered. She had evidently been away from home during the storm and found shelter elsewhere. Even this new condition of the soil about the nest did not confuse her. Some minutes later, upon returning, we were surprised to see the hole again covered, and the topography smooth, but about six inches from the hole (the place was marked or it would have been quite indistinguishable) was much loose dirt which had been swept well away from her door. On one occasion of exceptionally heavy rains the earth from the upper side of the area washed down and deeply covered every trace of their nests; but before evening about a dozen had worked their way out of their holes, none the worse for wet weather.

It was on July 2 of the first year of our observations, or just two weeks after the first emergence and dance of Bembix, that we dug out the first nest that was completed and occupied. The waspling was only a tiny larva onefourth inch long, and was feeding upon its first fly, a delicate little yellow-winged Dipteron. On many occasions thereafter, when we found a very tiny larva feeding, the prey invariably was a very soft, delicate little yellow- or green-winged fly-not the coarse, heavy kind such as houseflies, stable-flies or horse-flies, which the mothers bring in when the larva is stronger. Can human intelligence do better in delicate, maternal care? It was startling at first to see a tiny larva and fly fairly "rattling around" in so large a cavity; but it only proves again the maternal solicitude of Mother Bembix who, it seems, knows how to esti- 
mate the future needs of space for her growing infant, its food and the usual residue.

We have already stated that this wasp stays with her nest and daily brings in enough fresh flies to meet the needs of the young one until it reaches maturity and pupates. Just how many flies are brought in each day we have never ascertained with accuracy, but we suspect that the food supply varies with the needs of the infant. Also, as we shall see later, this instinct of the mother for providing the daily food for her young is sometimes defective and leads the mother to do various unprofitable things. However, what she does is so wonderful that we shall not presume to criticise her for occasional failures or erratic behavior.

When foraging and bringing in flies, they come and go with surprising rapidity, often making three or four trips in twenty minutes. They alight upon the nest with the fly so well concealed under their bodies, clasped between the middle legs, that we can hardly see it. They never waste a second's time in searching to and fro for their nests, but drop down from flight directly upon them every time. This homing instinct is truly marvellous when we consider that the bare area occupied by their colony is devoid of any apparent landmarks by which they could locate their holes amid the numerous holes of other insects. They work fast and furiously from the instant they arrive, probably to evade parasites, which soon shadow them if they are more than a moment in their work, or to escape attack from their sisters which are hot after them. In a fraction of a minute they dig through the temporary closure of the burrow and scramble in with the fly; in a few seconds they emerge head first, turn around at the brink of the hole, and reenter at once. For an instant this performance seems strange, but only for an instant; they enter just far enough 
to go past the loose dirt which has rolled down the sloping channel from the temporary closing, and pause to kick this dirt up in a heap (from within) which almost or entirely closes the hole just beneath the level of the ground. They gauge the strength of the kick with such remarkable accuracy as to throw the dirt to exactly the right point near the top of the burrow, but never out on top of the ground. They usually leave a tiny crevice at the upper side of the hole. This done, they later come squeezing and scrambling out through the loose dirt. Even as they draw their bodies out of the soft earth, they scratch the dirt back to close the hole completely but loosely. They do not leave it open an instant, or in any way give the parasites the least chance of slipping by them. This loose mound is so near to the top of the hole that a few more strokes usually suffice to finish filling it. We have seen the opening smoothly covered with only five strokes. In making these temporary closures, they give little or no attention to packing or smoothing the surface of the ground over the closed nest. Sometimes a wasp will pause a moment to sweep back the surplus loose dirt from around, the top of the burrow to a distance of six inches or more before flying away.

The Peckhams, who quote Bates on Bembix ciliata, say that this wasp sometimes leaves her door open when off on a fly hunt; she probably does this to save time. B. nubilipennis invariably closes her hole on leaving, but we fear she does not burden her soul with anxiety for the value of time, for we have often seen her scrape and scratch at the hard-baked soil about her nest until we thought she would wear her finger-nails off, working for more than an hour to raise a little dust from the hard-packed earth to fill in her burrow.

Thus the temporary closures of the burrows are made when the wasps are coming and going each day, bringing 
food for their young. In contrast to this we see the final or permanent closure which is made only at the end of the larva's feeding period. The contrast in the methods of effecting the two closings will be at once apparent.

When the wasp has finished feeding the larva, she emerges from the open hole but does not turn around and go right back in, head first, as previously. Instead of going in and kicking the dirt up from the lower part of the channel, she begins scratching and kicking the loose dirt from the surface into the hole behind her, moving forward as she does

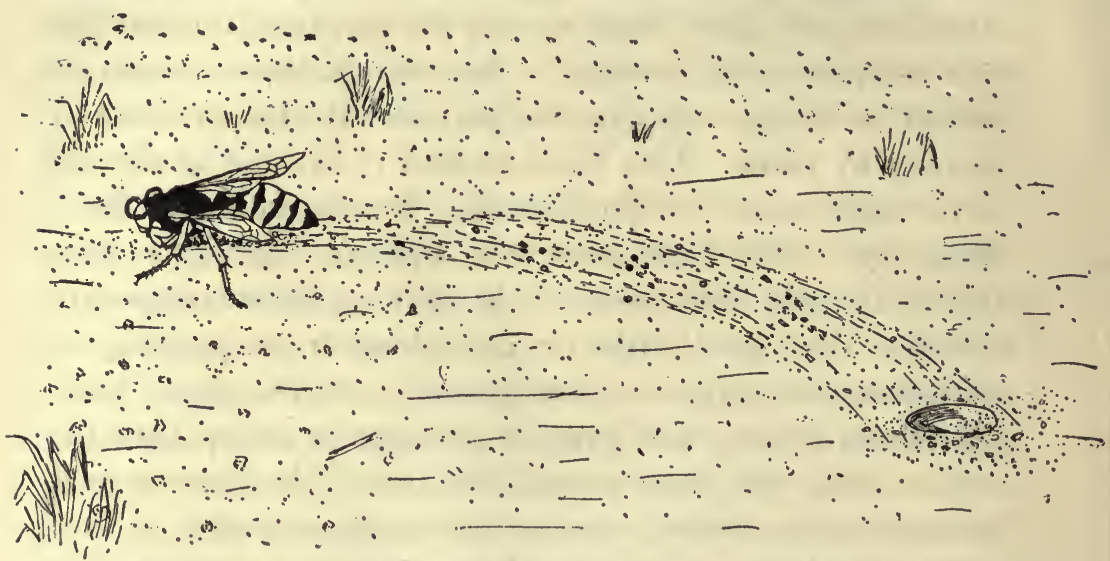

FIG. 4. Bembix nubilipennis filling her burrow. Note the brush-like forelegs sweeping the soil under the body, and the accuracy of her aim. Natural size.

so until she is two or three inches away from it. Then she runs to the hole, peeps in, turns around and backs in, kicking, scratching, clawing and crowding the dirt deeper down into the hole and out of sight. Then she comes out and exactly repeats the whole performance several times, each time beginning at the margin of the burrow to scratch the soil back in, and working gradually outward with her face away from the opening. (Fig. 4.) Thus she continues until the hole is filled so near the top that she cannot back 
down into it any more; then she assumes the same position backwards on the hole and crams and packs the dirt down with her hind pairs of legs and pounds, rubs and punches it down with her abdomen; then brushes more dirt back upon the depression and repeats the packing process two or three times, until the fill is brought up exactly level with the surface of the ground. Having finished tamping the earth she begins sweeping all around, as usual, to remove all traces of her nest from the surface of the ground. Her conduct at this point varies with the conditions; if there is a surplus of loose dirt near the site of the hole, she sweeps it well away and scatters it evenly over a considerable area; if it is bald so that traces of the filled hole may be seen, she sweeps other dust back over it from a distance until no trace of a scar may be seen. When sweeping away from the hole she begins at the outer edge of the patch of dirt, faces the hole and kicks the dust back of her as she moves from side to side and gradually nears the opening, all the time with a stream of dirt spurting out behind her; then she backs off to the periphery of the dusty space again before beginning anew, scattering it further and further from the nest. If, however, she is sweeping dirt toward the hole, she displays far greater skill in estimating the distance and the force necessary to throw the dirt in precisely the right spot. She always works with the hole squarely behind her, so she can throw the dirt back of her. She works fast and furiously in the hot sun, brushing lightly when near the hole and increasing the strength of her throw as she moves further away from it, and, with wonderful judgment of direction and distance of throw, hitting the region of the burrow with astonishing accuracy, from various distances. (See fig. 4.) She moves from side to side as she works, so that her path practically describes arcs of ever-widening circles the center of which is the burrow. When she has 
reached the limit of her distance from the hole, she does not wander aimlessly over the area, but always returns to the hole to begin a new series of arcs. This marvellous system of covering the ground is more easily made clear by the accompanying diagram (fig. 5 ). It is interesting to note that the wasp usually confines its sweeping to the area in front and at the sides of the hole, but is rarely seen working behind the hole. Of course this may be due largely to the fact that the loose dirt all lies in front of the burrow where it has been thrown during the digging.

Thus she sweeps, spreads and redistributes the loose surface dust for a foot or more, until, if we have not the exact location of the nest marked, we can seldom find it, so well is it concealed. Then she circles to and fro on the wing an inch or so above the area, surveying it carefully for several seconds, and goes whirling off flirtatiously with the other wasps, which, from time to time, have been dabbing down beside her and bumping her. One B. mubilipennis accomplished the permanent closing of her nest in twenty minutes, but they usually require a longer time to finish this critical piece of work.

When we see such highly developed instinct for the care and safeguarding of the young, we are surprised to find that these mothers are often guilty of committing gross errors in the most fundamental points. We watched one wasp working with great care and precision in closing her nest. After the last superficial trace of the hole had been carefully obliterated and the surrounding ground swept clean and she had departed, we opened the burrow in the full expectation of obtaining a mature larva, but we were shocked to find that the larva had pupated long ago and had been dead and rotten for some days at least. No fresh or uneaten flies were in the chamber; only the old débris. What she could have been doing there, or why she was so 


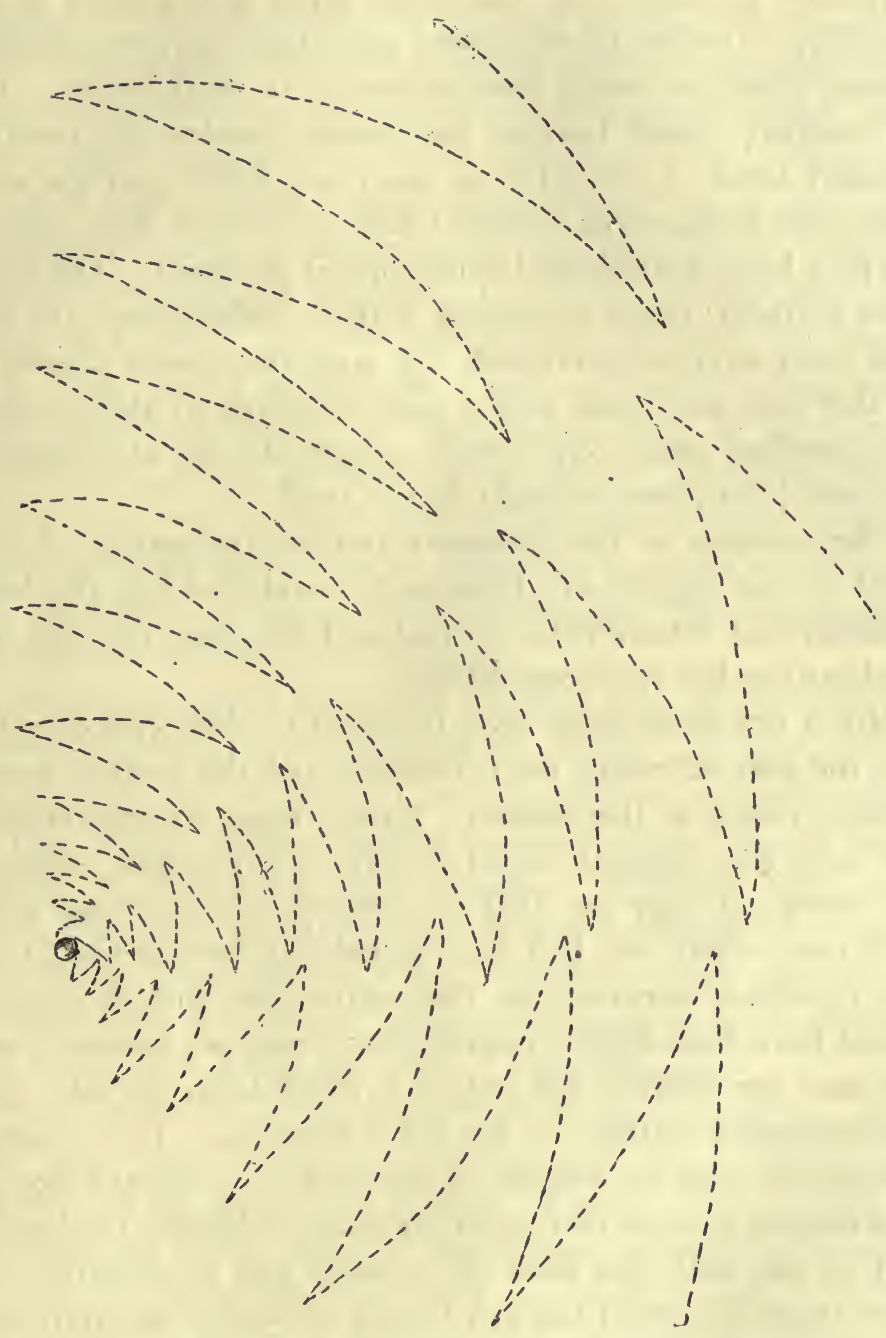

FIG. 5. Diagram showing the systematic method of Bembix nubilipennis in sweeping the dust back into her burrow for the permanent closure. 
particular in sealing up that dead larva will always be a mystery. Another mother spent equal pains in permanently closing a burrow which later proved to be stark empty. In yet another sealed burrow we found, besides the newlypupated larva, a spoonful or more of débris-wings and legs-and besides this sixteen whole untouched flies, showing how her solicitude had oversupplied the larva. The flies were all dead; never in dealing with $B$. nubilipennis did we find them alive or paralyzed, nor with the thorax crushed. In this nest we found also a pair of wings of the bee-fly, Spogostylum anale Say, which is parasitic on mud-wasps, but here it had been brought in for food.

The contents of the chambers and the occupancy of the holes by the diggers are little understood; ${ }^{4}$ as yet, the line of difference between the normal and the abnormal use of the burrows has not been drawn.

Not a few holes have been followed to their end only to find the nest all ready for occupancy and the mother wasp calmly resting at the bottom. Under these circumstances, the hole was usually closed, fairly firmly, from within. Of course, it may be that we chanced to interrupt her at a time when she had just completed her burrow, but this condition occurred so frequently that such a chance would have been highly improbable; hence we suspect that she uses her burrow not only for nidification but also, to a considerable extent, as her own domicile. To be sure, the gallery near the mouth of the burrow is always closed by a mound of loose dirt when the wasp is digging the lower part of the hole, but then the activity can be detected, at short intervals, when the dirt moves or humps up from the

4 On account of the frequent use of the field by the ball-players, it was impossible to keep in connection with one mother or her one nest long enough to get a connected story. Every effort was made to revisit marked nests, but in every case the boys with the spiked shoes obliterated them. 
pressure of the wasp pushing up from beneath, or occasionally the wasp itself will come pushing its way out backwards through the loose soil, emerging not a little dishevelled, and shake itself vigorously to free it from the clinging dirt, precisely as a dog shakes himself upon coming out of his bath. She then proceeds to dig out and sweep back the dirt she has brought to the top of the hole. But at these resting-periods mentioned above, no such movements are seen for days at a time, so we suspect that she is merely resting and enjoying the security of her home. But is she only gratifying a whim, or may she be waiting for the maturation of her ova or some other physiological phenomenon? The population diminishes at the end of the season; perhaps the old adults simply go off and die after they have completed their season of nidification.

On this occasion we might mention one other form of mortality which is yet unexplained. Early each year, when digging out the burrows of various species, we come upon a few subterranean chambers, which have never been opened, containing a dead Bembix. Whether these are young wasps which have safely arrived at maturity but have died before emerging, as often happens in other species, or whether they are parent wasps which have died while in the burrows, we had no way of ascertaining.

The contents of a few nests have puzzled us utterly. One hole $^{5}$ had long roused our curiosity as we watched and waited for its permanent sealing. Finally, one evening at twilight, we broke open its temporary closure and found therein $\operatorname{six} B$. mubilipennis ready to spend the night. Two of these were captured and proved to be females. Since we now know of the male priority of emergence and disappearance, we feel fairly safe in assuming that all of these were

5 The Sleep of Insects. Ann. Ent. Soc. Amer. 9: 240. 1916. 
females. On one occasion we saw a Bembix having much difficulty in keeping out a sister wasp, whose home it seems had been destroyed and who did not seem to care that it was not her own hole which she was entering. This gives us a possible clue to an explanation of the presence of six wasps in one burrow; perhaps they had returned to the field at twilight, found themselves homeless after the ball-game, and had found it convenient to crowd into the same opening for a night's shelter.

The Bembix do not seem to be so discriminating in regard to the choice of their prey as are some other wasps. So long as they can pick up flies, they do not seem to be particular about the variety. We have found in their burrows: Lucilia caesar Linn. [F. Knab], Spogostylum anale Say [F. Knab], Sarcophaga sp. [F. Knab], Sparnopolius brevirostris Macq. [F. Knab] house flies, stable flies and many more species which could not conveniently be identified.

The amount of food consumed by one of these youthful gourmands is quite astonishing. One which we brought up from infancy by hand consumed seventy-nine house-flies before it spun its cocoon. Another consumed the forty-nine house-flies and one large stable fly which had been given it, and then attempted to spin its cocoon. In the smooth tin box it made only a silky carpet (fig. $6 a$ ). After that, thirty-six more house-flies were introduced, and it devoured twenty-six of them in spite of the fact that it had already begun to spin. How many flies the mother provides for a single larva has never been ascertained; but after its pupation there is usually from a teaspoonful to a tablespoonful of legs and wings remaining. Occasionally we find that a mother has devotedly brought in more flies than the larva has been able to consume; but some of our work leads us to suspect that these gluttonous young are more often will- 
ing and capable of consuming even a larger amount of food than the mother provides.

The larvae kept in tin boxes or in vials were unable to spin the usual cocoon, owing to the fact that there was no dirt to blend with the silk. The pupal cases spun in the natural habitat are hard, tightly woven cocoons made of silk blended with earth. (See fig. $6 b, c, d$.)

In keeping Bembix pupal cases at home we often found

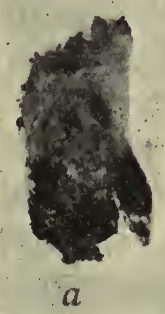

$a$

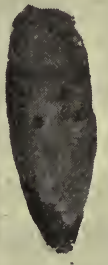

b

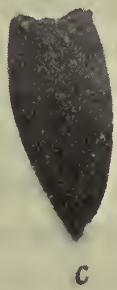

c

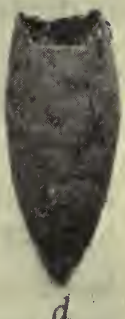

FIG. 6. The cocoons of Bembix nubilipennis. Exact size. a, abnormal cocoon; $b$, normal one; $c$ and $d$, empty cocoons showing apertures made by emerging wasps.

the organism within infested by the tiny Hymenopterous parasite Melittobia $s p$. These no doubt had escaped from some Pelopoeus nests in the same room, and very probably, under natural conditions, $B$. mubilipennis is not pestered by them. One Bembix burrow was observed which was normally filled in, but many ants were coming and going through the small passageway which they had made through the loose dirt. When this nest was opened it became apparent that they were after the débris of dead flies-wings, heads, legs, etc. The wasp larva had pupated, unharmed, but the musty débris was alive with two species of mites. Dipterous parasites shadow Bembix, and a small female Mutillid abounds in this area, but neither of these has been seen to actually enter their holes. 
Our present evidence indicates that there is only one generation per year of $B$. nubilipennis. From the time of emergence, in June or early July, the females go on with nidification until the middle of September. We do not know how many nests each constructs during this season, but they ought to make several in order to offset the high mortality and keep up so large a population. The numbers gradually diminish as autumn approaches; since we never see them elsewhere hereabouts, we conclude that the mothers gradually die off. They spend the winter in the pupal stage and, despite the fact that they reach this stage at different dates, they all emerge simultaneously when the warm rays call.

The persistence with which Bembix adhere to the one location which we have watched year after year is astonishing. Truly, their dissemination seems to be $\mathrm{nil}$. In regard to this species at least, one is soon ready to agree with the Peckhams in their opinion that wasps generally do not travel far from the place of their birth. Here the wasps of our particular colony have had at their disposal a pasture equal in size to six city blocks in which to choose their nestingsite, yet year after year they limit themselves strictly to two distinct corners of a base-ball diamond, in the middle of this field. Here they suffer weekly, and sometimes daily, persecutions under the spiked shoes of the boys; they are routed from their work in the middle of the day and their nests are obliterated in the powdered earth, and not a few must suffer death in the mêlée; yet not even this pressure causes them to move twenty-five feet to one side, where they might enjoy peace and prosperity. The fact that each successive generation should show the same choice and the same persistence is all the more astonishing. In another vacant lot a mile away was another colony which, to our knowledge, persisted in like manner on a small area for three years. Finally a building was erected on the site and 
the Bembix population must have been exterminated, for afterward the country roundabout was scoured in search of them, but no trace of their having settled elsewhere was ever found, although just across the road from the lot was a large tract of vacant land thoroughly suitable to their needs. In the two colonies in corners of the baseball diamond the numbers are becoming fewer and fewer, so if they do not migrate they will probably soon meet with extermination.

Bembix spinolae Lep. [S. A. Rohwer].

Other observers, notably the Peckhams ${ }^{6}$ and Parker, ${ }^{7}$ have already written upon the life of this species, so we offer no new data excepting a contribution of one or two eccentric circumstances.

One burrow which we discovered on Howard's Hill on September 25, I916, seemed externally a typical Bembix hole. It pierced the earth diagonally, and much loose sand was strewn about the mouth of the burrow. It went down thus for an inch and a half, then turned abruptly at right angles, and from there it continued downward in a spiral, so that the pocket was directly beneath the entrance. The total length of this spiral burrow was six inches, and the terminus was three inches below the surface. We saw no obstructions in the soil which would necessitate such contortions in the channel. In the normal nest (according to Peckhams) the tunnel goes down obliquely to a point from three to five inches below the surface of the ground.

At the bottom of the hole we found the mother Bembix together with a medium-sized, healthy larva, thirty large

${ }^{6}$ Bull. Wisc. Geol. \& Nat. Hist. Surv. 2: 58-72. 1898.

${ }^{7}$ Proc. U. S. Nat. Mus. 52: 127-I31. I9I7. 
living Diptera larvae, four adult bee-flies, Sparnopolis brevirostris Macq. [F. Knab], the remains of eighty-five more of the same, and the remains of one Lucilia caesar $\mathrm{L}$. [F. Knab]. Judging from the enormous amount of food remains when the feeding stage of the larva was as yet far from completed, and the presence of a healthy mediumsized Bembix, we can only conclude that the Diptera were not true parasites, since they had not attacked the larva of the Bembix, but merely inquilines or impostors who depend upon the mother Bembix to work extraordinarily hard to keep them, as well as her own young, supplied with meat. What a terrible toll, that she must provide constantly for thirty others in order that her own may live!

One wonders why the Dipterous larvae, so many in number, spared the Bembix larva, for it certainly would have made a fine meal. We do not wish to speculate excessively, yet it is probably only fair to breathe our suspicions on the subject. If they should devour the Bembix larva, it would satisfy them for only a short time, but with the demise of the mother's child their further supply of food would be cut off, since probably the rightful infant in the cell is the stimulus for the mother to continue replenishing the food supply for all of them as fast as it is exhausted. With these thirty-one mouths to feed daily, it is little wonder that the mother had to sacrifice all of her leisure that might have been applied to improved methods of domestic economy.

We do not pretend to say that the fly larvae knew the result of this action and behaved accordingly, and numerous other instances of the same kind would be required even to prove that this is a case of habit or blind instinct; yet if it were proved to be such, it would be no more wonderful than many of the delicate adaptations already known to exist in the insect world. 
Microbembix monodonta Say [S. A. Rohwer].

We saw this little banded Microbembix open her hole and enter, and close her nest preparatory to leaving, whereupon we captured her. The hole went down diagonally for seven inches, then turned at right angles and continued its downward course for six inches more, where it terminated without either pocket or prey. The end was six and one-half inches below the surface of the earth.

A second one was seen to leave her hole, after carefully covering it up. The illustration (fig. 7) tells better than words the nature of the burrow. The nesting-site was the semi-barren, sandy area (fig. 8) along the river at Lake View, Kansas. The total length of the hole was fourteen inches. The pocket was hollowed out from the ceiling of the burrow. Great was our surprise upon finding in here two beetles, Neoharmonia velutina [H. S. Barber] and Hippodamia I3 punctata [H. S. Barber], two tree-hoppers, Draeculacephala mollipes Say [E. H. Gibson] and Phlepsius irroratus Say [E. H. Gibson], one spider, a Xysticus nervosus Banks [C. L. Shoemaker], and one ant, Pheidole vinelandica Forel [W. M. Wheeler]. All six items of prey were dead, dried and hard. No egg was found with the food. We can hardly, indeed, call this collection by the term prey, because it was only a collection of dead carcasses which the wasp had garnered. Hartman too finds that $M$. monodonta takes home insects that are already dead. His list includes : slender red caterpillars, the leg of a grasshopper, small queen ants, large red ant, flies of various kinds, bugs belonging to five different genera, tree-hoppers, polistes wasp, freshly-killed grasshopper, a dry Mutillid and old Orthopterous pupal cases with dry, dead pupae inside. A lengthy and very interesting account of the mating behavior, the nesting-habits, food habits, etc., of this species is included 


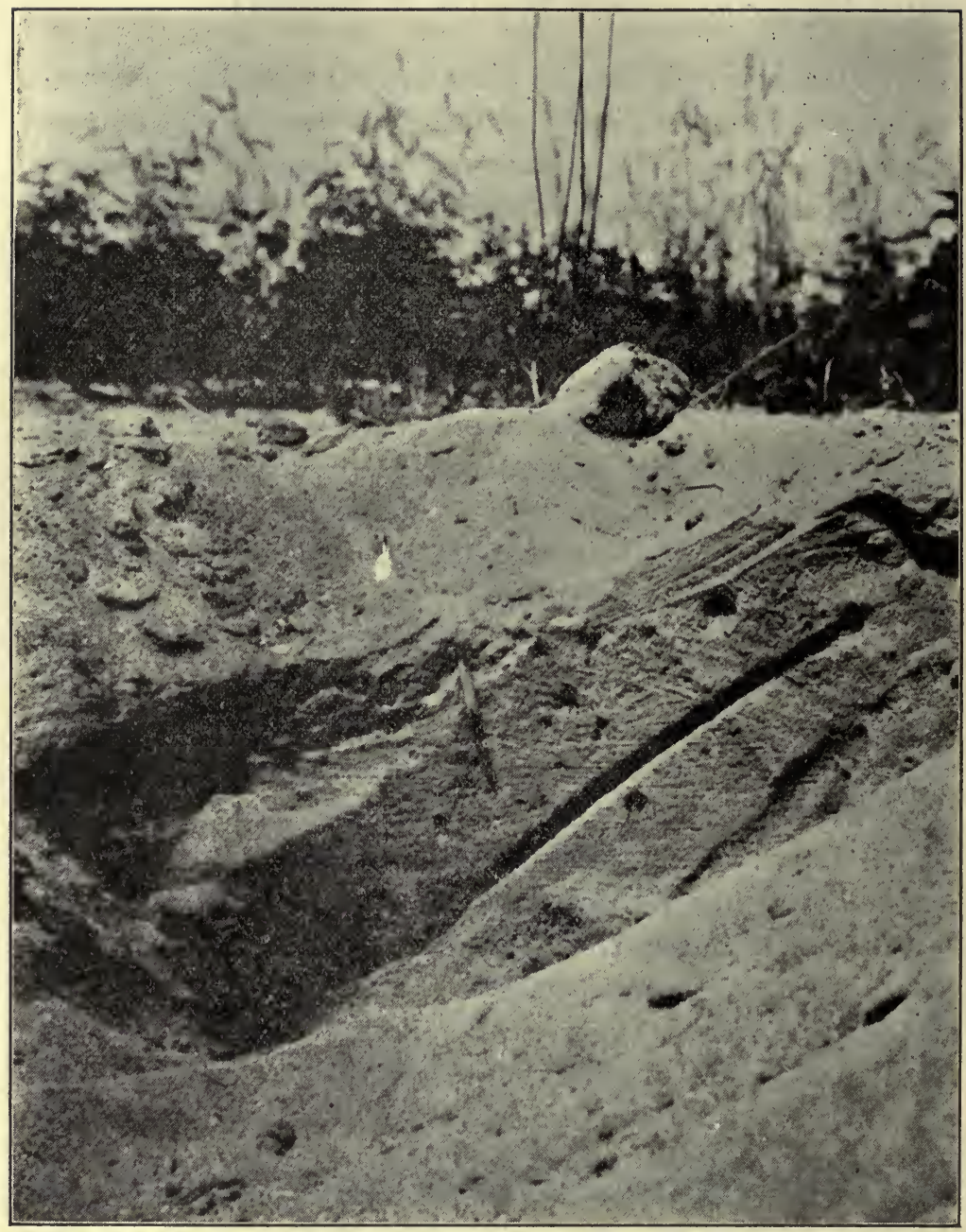

FIG. 7. The burrow of Microbembix monodonta

in the paper by Parker. ${ }^{8}$ His records of nest provisioning, based on several observations, differ from ours above. He 8 Proc. U. S. Nat. Mus. 52 : I34-I40. 1917. 
says that when the burrow is completed, a single egg is placed in the brood chamber, at the extreme end. This is firmly fastened in an upright position in the sand of the floor. No food is placed in the burrow until after the egg has hatched in the course of two or three days. Our single wasp had already provisioned the nest with six dead insects and had left the nest presumably for more, but a very careful search revealed no egg nor larva. Whether the Ohio wasps differ in their ways of housekeeping from the Kansas wasps, or whether ours was only an eccentric individual we do not know. The crooked nesting burrow described above seems also to be only an eccentricity. These points only show that wasps as well as other beings may express, consciously or unconsciously, their individuality.

Barth, ${ }^{9}$ in speaking of this genus and also of Bembix, says the "Larvae are fed from day to day, nests remaining open during excursions." This sweeping statement cannot apply to Microbembix monodonta.

Bicyrtes quadrifasciata Say [S. A. Rohwer].

In a semi-barren, sandy area (fig. 8) beside the Kaw River at Lake View, Kansas, we found our only specimens of $B$. quadrifasciata. Parker ${ }^{10}$ has described very well her manner of approaching her nest as she returns to it. She returns on the wing, flying high in the air, and poises in midair ten or twelve feet above the hole, then drops straight down, as if with a parachute, digs a moment at her very feet where she alights, and lo! her burrow opens. Truly, the students of animal psychology who are trying to solve the homing of insects have here an interesting problem.

${ }^{9}$ Bull. Wisc. Nat. Hist. Soc. 8: II8. I9Io.

${ }^{10}$ Loc. cit. p. I34. 
She follows the same method in departing from the nest or in starting homeward from the field when foraging. She rises straight up in the air, so high that it is difficult to follow her with the eye in the dazzling sunlight, then darts away horizontally above the heads of most living things.

We once watched one climbing in and out among the branches of a cocklebur plant, carrying her little bug snugly beneath her, resting once or twice on a leaf. All at once, without provocation, she leaped up into the air and flew straight upward, higher, higher, until we lost her in the dazzling sunlight, but in a few seconds she came down from her highway in the skies, straight down to a spot only ten feet distant from where she had started. Here she scratched on the ground at her feet, opened her hole and went in without letting go her prey. She remained within for about fifteen minutes, and closed the hole lightly behind her with loose sand when she came out before departing upward.

The prey which she brought into the nest was, in all cases observed, a small bug. She clasped it beneath her abdomen, and in the one or two cases which we have been able to observe minutely, carried it with the bug's ventral side toward her own. The four bugs found in one nest were all somewhat similar but of different species, all nymphs of Pentatomidae [E. H. Gibson].

The two holes which we dug out were unlike. They resembled a Bembix nubilipennis hole in general appearance, penetrating the ground at an angle of thirty to forty degrees with the surface. One was twelve inches long, and straight; the other was seventeen inches in total length, and the large, terminal pocket was nine and a half inches below the surface of the ground. The burrow curved irregularly, forming half a spiral. 


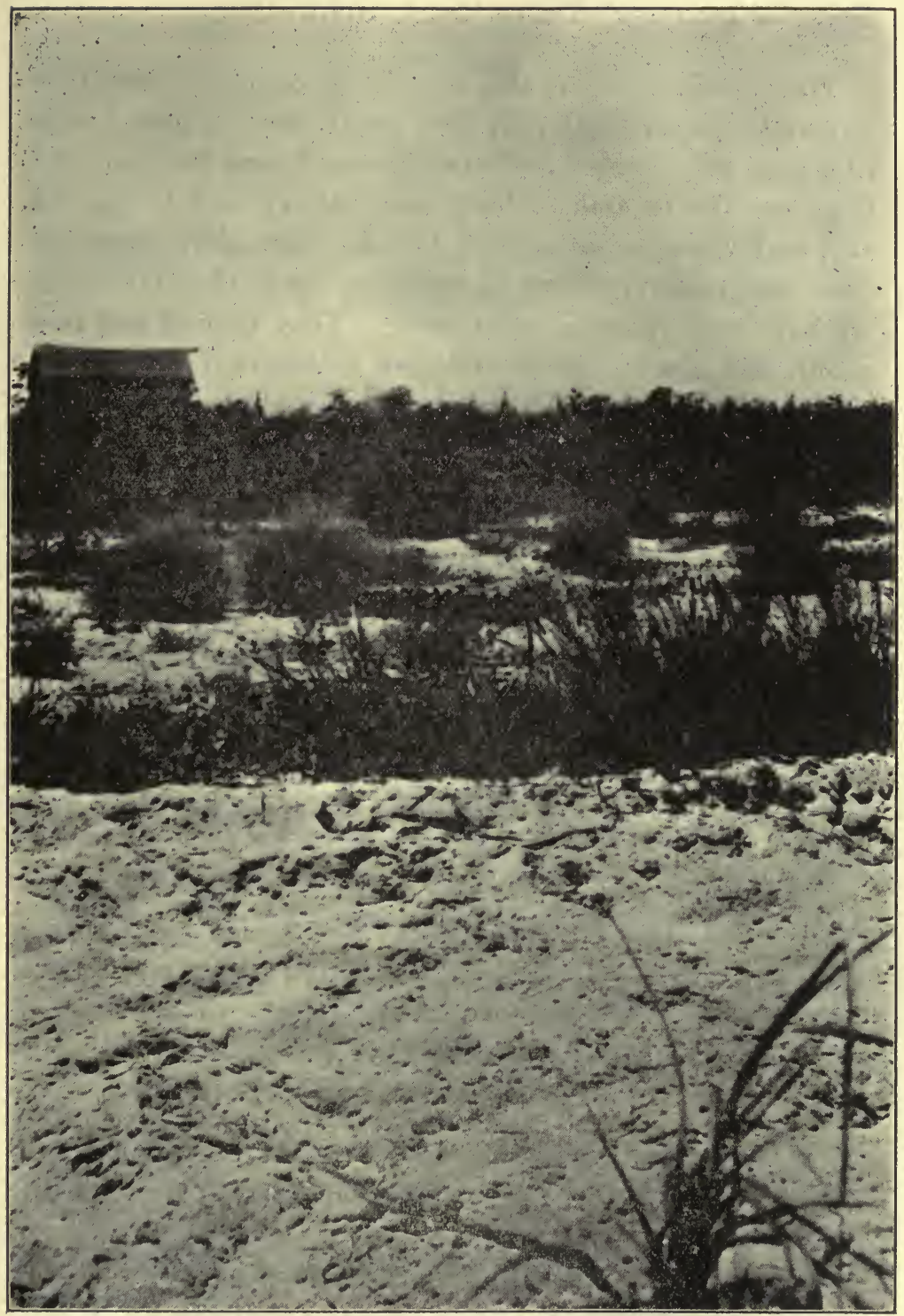

Fig. 8. A sandy area on the Kaw River where Microbembex monodonta and Bicyrtes quadrifasciata abound. 
Sphecius speciosus ${ }^{11}$ Drury [S. A. Rohwer].

Three individuals of this species, in company with Diptera and a Papilio butterfly, were busily feeding upon a mass of foamy sap that exuded from a wound near the base of a huge sun-flower stalk. They were determined to get the sap, and when we attempted to take them they expressed their indignation at being disturbed by the loudest noise that we have ever heard a wasp make. They buzzed and flew about, and always made attempts to return to their bacchanal. The sap seemed to have fermented in the summer heat, so perhaps like ensilage it was particularly exciting to animal appetites.

The next day we again found these S. speciosus attracted to the sap, greedily drinking their fill, and. boisterously buzzing, bumping and whirling around at intervals. Now they had for their companions several horse-flies, Tabanus exul O. S. [F. Knab], many smaller Diptera, one click-beetle, Ludius attemuatus [J. A. Hyslop], a half-dozen Polistes anmularis, one spotted cucumber beetle and one blue Papilio. Hence it seems that their pulque was popular in insect society.

Hungerford and Williams ${ }^{12}$ found that this wasp quarreled with Chlorion caeruleum for the sap oozing from the willows. Riley ${ }^{13}$ has worked up a beautiful account of the behavior of this species, a popular version of which may be found in Howard's Insect Book, pp. 22-25, or Weed's Life Histories of American Insects, pp. 157-160.

11 Of the sub-family Stizinae.

12 Ent. News 23: 246. I9I2.

13 Insect Life 4: 248-252. I892. 


\section{CHAPTER II}

Behavior of Wasps Belonging to the Family

PoMpILIDAE

Pompiloides tropicus Linn. [S. A. Rohwer].

One mild, sunny September morning we were walking across the field when we were startled to espy a telltale hole in the path. It was only the beginning of a burrow, but in a most hazardous situation, right in the beaten path over which hundreds of workmen passed daily, and also at its intersection with the wagon-road; yet, because the spot was void of vegetation and sunny, the wasp had proceeded to make her nest there, as if unaware of any danger. The ground was dry and hard enough almost to break a pocketknife to dig in it, while the surface had been ground by the tread of many feet into deep, fine dust. The hole was perhaps one-half inch deep; the spider, occasionally twitching, lay only an inch away. From this it is at once apparent that this wasp does not dig the hole first and then fetch her prey, for this hole was only begun, and the spider, an immature male Lycosa frondicola Em. [N. Banks], lay in front of it.

The black Pompilid, conspicuous against the grey dust, with its broad orange band on the abdomen, was seen hunting diligently all about the vicinity, eight or ten feet away. She returned to the hole once, but we had tampered with it, knocking in a lot of loose dust in trying to break through the hard crust of earth for her, so she left it at 
once and continued her search six feet to the west. She eventually came back and tried to dig in three or four places near her original location, but the loose surface dirt always rolled in upon her. She left again and wandered on foot down the road; finally after ten minutes she returned on the wing, found the spot without difficulty and again dug in a hole which promised to be successful. A caterpillar hurried by very near to her and seemed to make her uneasy, so she drew her spider back three or four inches. Again she departed for a while on an unexplained jaunt. Meanwhile we brushed the loose surface dust aside to give her access to the soil which was firm enough for her to dig in, and, with a knife, began a new hole. Her spider still lay near by. A parasitic bee-fly, which had been hovering about inquisitively from time to time, hovered over our hole the same as over hers. The wasp came back thrice but did not seem to recognize the area.

Round and round the dusty margin the wasp searched anxiously, and finally ventured to cross the area (six inches in diameter) from which the dust had been removed, peeped once into the hole which had formerly been hers, and scuttled away-frantic. During her absence we replaced some dust around the hole; still she did not recognize it nor her spider, one inch distant. She came within a few inches of it on several occasions, but always searched over the dusty periphery and avoided the open area with the artificial hole exactly where her own had been. We finally placed the spider on the dust in the region where she searched most. She returned to the familiar spot where she found it, looked at it for a moment but showed no particular agitation, dropped her excited manner, walked straight to the hole and began digging inside it without a moment's delay, and as calmly and business-like as if nothing had gone wrong! After digging out a neat little pile of dirt she came and 
examined her spider once more, pulled and turned it around, legs up, and went back to her digging. Presently she returned again to the spider and proceeded to bite it on the ventral side of the body between the second and third pair of legs; we could distinctly see her palpi move and we suspected that she was sucking the juices. When she withdrew after about a minute she stood "licking her chops," repeated the performance and then left promptly with such a strange flight of abandonment that we doubted if she would ever return. We inspected the spider and, sure enough, the body wall was broken at the point mentioned and a large drop of clear juice had exuded.

The morning passed and we saw no more of her. Whether she became disgusted with the hard soil or offended at the disturbance we know not. But it was interesting to see how she was determined to get some good out of her spider by at least having a meal before abandoning it. ${ }^{1}$

The tiny parasitic fly had been hovering over the holenot over the spider-during this entire performance, and was still poised in the air over the burrow when we left the scene, long after the wasp had given up the enterprise.

The spider was taken home. At ro o'clock that evening it responded slightly to stimulus, but by the next morning it was dead.

On another morning, as we were walking across the field past a spot from which all the grass had been trodden, we suddenly scared up from the edge of the grass a $P$. tropicus. She had been engaged in carrying a spider, Lycosa frondicola Em. female [N. Banks], not quite mature, but larger than herself. After a quarter of an hour she appeared

1 It is a question whether Pompiloides tropicus does not live entirely on animal juices, for while Robertson found many species of Pompilidae feeding upon the nectar of various flowers, he has not one record as far as we know of $P$, tropicus coming to the flowers. 
searching vaguely in the general region, but most of the time six to twelve feet distant from her spider. She searched by walking a few inches, then hopping and flying a foot or two, occasionally taking a circle on the wing just above the grass-tops. She seemed to gain no headway in her search, so presently she went over to a small patch of cockleburs, which was six feet from the spider, and hopped and circled over the plants with an air of getting her bearings. Her behavior made us wonder if she had originally found the spider near these plants and had gone back to retrace her steps. Then she started out in the direction of the grass-plot, but missed her prey, so she went back to the cockleburs again, repeated the performance, and this time went almost directly to her spider. She pounced upon it viciously, as if she thought it necessary that it be attacked vigorously, and got a good grip, grasping it by its ventral side back of the third pair of legs.

She dragged it thus a foot or so, walking backward and pulling like a dray-horse; then poised it in some grasses and went back to hunt a place for a hole. She found a depression in the earth, a place where we had dug with a trowel the day before. The ground was dry and hard, with much dust on top. She tried spots here and there in the side-walls of this hole, scratching and biting furiously in eight different places, but she found the ground too hard and the surface dust fell in on her. After trying thus a long while, she went straight back to her spider two feet away and brought it nearer, then returned to dig, as if satisfied that this place was as good as she could expect to find. Then she seemed suddenly to decide upon her spot, and, after just a few strokes of digging, for the first time she swept the dirt back from the space immediately in front of the hole. It was hard digging, so while she was gone to visit her spider again we pierced the firm surface crust 
BEHAVIOR OF POMPILID WASPS

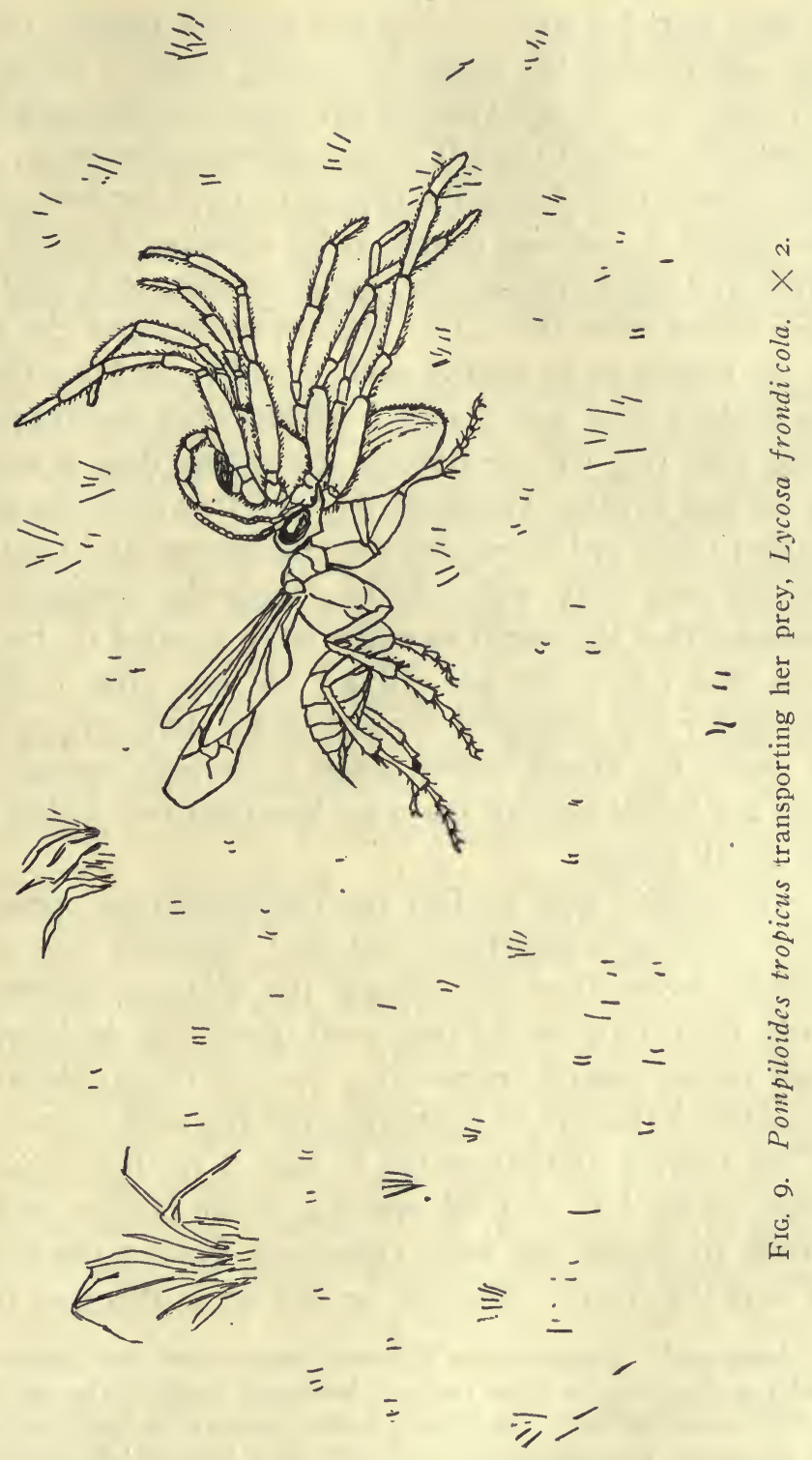


to help start her nest. After this she dug rapidly, coming out and visiting her spider six times while it lay in this position. We do not know if she examined the spider frequently in order to see if it was behaving properly, or to gain an accurate idea of the required size of her hole. Next she lugged it one foot nearer to the opening, dug out more earth and again moved the spider nearer, to a spot only nine inches from the hole. She always grasped the spider by the middle of its ventral surface and carried it vertically, the spider's hind legs dragging behind while the front ones hung limp (fig. 9); she did not at any time drag it sidewise by the legs as other Pompilids do. Furthermore, she always walked backward when she had the burden and could not see her way very well, so she constantly struggled over obstacles that she might as easily have avoided if she could have seen where she was going. ${ }^{2}$ At one time in moving her spider she struggled through grass and over a tangle of weeds for fifteen inches, when a perfectly smooth clear path lay beside her, all the way, less than two inches from her at all points.

She seemed now to feel the enthusiasm of seeing her work nearing completion, and dug furiously for a few minutes more; then she brought the spider very near and hung it carefully on the tiny weed nearest to the hole, only four inches distant, removed a few more mouthfuls and kicked back the dirt, then dragged the arachnid to the mouth of the burrow and attempted to take it in; but it was too large, so she left it at the opening of the burrow and proceeded to deepen the hole, vigorously kicking the dirt out all over the spider. She dug on and on in this way for an

2 Another $P$. tropicus, in a different locality and year, moved her spider in precisely the same manner, holding it vertically by the middle of its ventral surface. She always walked backwards, galloping lightly up absolutely perpendicular places, and even backing up overhanging spots without evident difficulty. 
hour, only occasionally kicking or sweeping a little dirt off the spider. We suspected that she did this, not for the sake of keeping her spider cleared, but merely to follow her habit of occasionally clearing away the débris around her doorway. Some tiny ants hung around a bit inquisitively; the wasp came out of the hole and bit at them, kicked at them and curled up her sting at them menacingly until they withdrew.

Once when the wasp had swept the dirt off the spider it stirred, scrambled to its feet and walked away three inches, whereupon she promptly pounced upon it and the pair rolled over in a tumble-she probably stung it-then as it lay quiet she calmly mounted its back and precisely curled her abdomen around its body and planted a deliberate sting in the ventral part of the thorax, just in front of the last pair of legs; then she took it back and laid it up-sidedown with care, at the mouth of the hole and resumed her digging and kicking dust all over it. So, to try her, when she was deep in the hole we drew the spider back two inches and turned it right-side-up. When the wasp emerged she saw it but paid no attention to the fact that its position had been altered. On her second appearance it began to wiggle its legs; she pounced upon it ferociously and tumbled over, probably stinging it, as the spider did not resist further; then she casually stung it again, as if for good measure, between the third and. fourth pairs of legs; then as it lay on its back she most deliberately placed her sting between the second and third right legs, near the center of the body, and left it there for several seconds, while the spider convulsively drew up its quivering legs and stirred no more. Tiny drops of juice oozed out of the wounds; she paused and seemed to drink this. Then she marched away with a most triumphant and self-satisfied air.

By this time she had apparently learned that she could 
not profit by keeping her prey lying at the mouth of the hole, so she carried it to a spot five inches away and proceeded with her digging, visiting it often, as if to see that it was behaving properly. She worked by digging up the loose dirt in the hole and then backing out, pushing it up in a mound behind her. But, we asked ourselves, why did she dig so deep and not make the hole wide enough to admit the spider?

Time dragged by-perhaps she spent another hour in enlarging the hole. At last! for the first time she came pushing her way, head first, up through her mound of loose dirt. Once more she visited the spider and shook it enquiringly by the left leg, went in and pushed out the last bit of loose dirt, emerged head first again, grasped the spider by the left coxa and, with much labor, dragged and tugged it in. Thus we see that she made her exit head first only when the nest was ready to receive the provisions. The spider fitted in the hole so tightly that its legs were all doubled straight back. At the last her economy was better than we had judged, for the hole was wide enough after all, with no wasted space, and the spider fitted in the hole so snugly that it could not possibly use its legs to kick or work itself free. After the prey was in the hole she continued pushing up loose, fresh dirt, evidently clearing the way as she moved it back in the gallery. The passage must have been of greater diameter below the surface, however, in order to allow both her and the dirt to pass beside the spider. After ten minutes she had thrown up enough fresh dirt to completely close the mouth of the burrow, so we could see no more of her doings. She did not come out on the surface any more, since her property was no longer outside.

The quarter-hours passed, yet she did not reappear. Thrilling indeed! Two rational human beings squatting in 
the burning sun, watching a motionless spot of earth!-But how consoling that the poet who best knew patience has said :

"He also serves who only stands and waits."

At-length we were preparing to dig her up, when suddenly a speck of the loose dirt in the middle of her mound quivered and a tiny hole appeared; she was hollowing it out from underneath and slowly packing it firmly back into the channel as she came up, until now the door was falling in. She emerged gradually, slowly, packing the loose dirt back into the hole with all her legs and punching it down with the tip of her ventrally curved abdomen. She filled it in tight to the top, swept the dust back over it loosely and departed so promptly that we had trouble in intercepting her.

When we dug out the burrow the spider kicked so vigorously that it seemed it would dislodge the egg. The long,

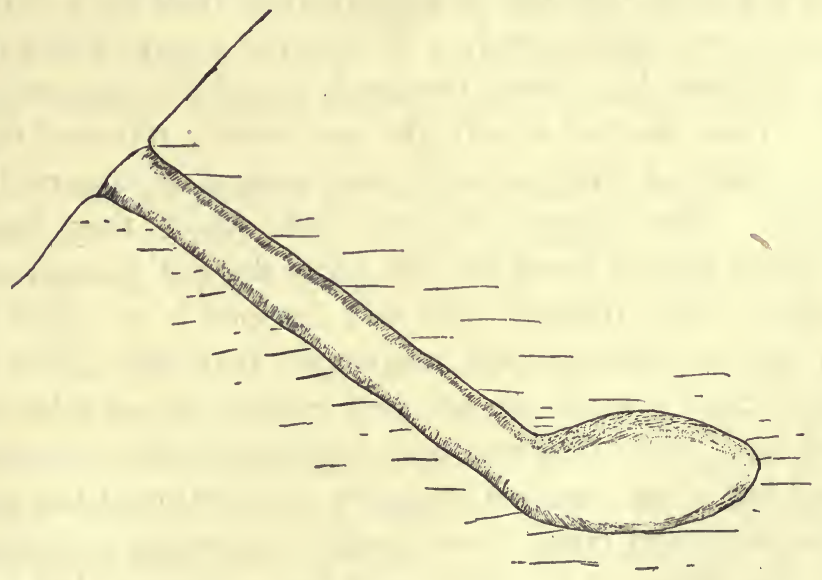

FIG. 10. The burrow of Pompiloides tropicus. Natural size.

white egg was slightly curved and fitted nicely to the side of the abdomen where the larva would be in position for the juicy, tender part of its food first. 
The hole (see fig. Io, exact size), one-fourth inch in diameter, went downward at an angle of 40 degrees with the surface level, for about two inches, and terminated in an oval, horizontal chamber an inch long and a half-inch wide.

From these observations we may be sure that the egg was deposited and the spider entombed at about II:45 a. m. At Io o'clock that evening the spider was active and would make the characteristic threatening spring back when touched. The legs could move actively but not coordinately, and were unfit for progression; the mandibles attempted to close, but could do no more than quiver, when tickled with a straw. After this activity we were surprised the next morning to find it dead. By the following day we were quite certain that the egg too was dead.

One mid-September morning we saw a lot of dirt thrown out of a hole in the side of a depression made by a horse's hoof. As we came nearer, a P. tropicus emerged and flew away in alarm, but slowly returned, found the spot and entered. Thus she fled in affright and timidly returned three times, when we tried to come near enough to observe her activities. She jumped into the hole which then lacked only a half-inch of being full, bit away the soil from around the edge of the irregular hole and dropped it in. Still the wasp was so nervous and suspicious that only with the greatest caution could we get near enough to see what she was doing. She often flew out, frightened, then nervously flapped her wings, walked in again and continued her task. At last we could creep close enough to see her smoothing down the filling in the hole with her abdomen, but in a strange way quite new to us. The abdomen was curled under the body, making the dorsal surface of the tip appear ventral; this convex portion, pressed against the ground, proved a very efficient sad-iron, smoothing and at the same time compressing the loose soil. 
When the filling was packed into the hole up to within one-eighth inch of the surface level, she kicked in some dust from the tiny embankment overhanging the nest-not the yellow dust that had originally come out of the hole. (The surface earth here was grey and the subsoil yellow.) She then kicked all of the little clods of grey earth in a heap on top, went a few inches away and made another neat pile of exactly the same kind, then kicked more loose dust over the hole, completely covering it, and also flung in any stray lumps, large or small, that lay near. When they were too large, she carried them in her jaws and loosely dropped them on the site of the nest. At no stage did she attempt to compress the mass on top with her abdomen; it seems that this treatment is reserved for interior work. Just when we were happy to think that the two piles of grey clods were placed there to deceive any enemy that might come near, $P$. tropicus, as if forgetting herself, kicked half of the second pile over the hole, so all notions of actual rational deception being practised by this Pompilid were shattered.

When she considered her work finished, she flew to a spot fifteen feet distant. There she deliberately and restfully made her toilet for five minutes, then flew high in the air and away.

We opened the burrow and found it as illustrated (see fig. II), with the bottom of the chamber three inches below the surface of the ground. The maximum diameter of the chamber was one inch. The spider therein was very active, moving the legs and mandibles violently and giving good promise of recovering from its abusive treatment. The white egg adhered to the dorso-lateral surface near the basal part; it never hatched. Eleven days later the spider, Lycosa carolinenisis Walck. [C. R. Shoemaker], was dead. During the same week two $P$. tropicus, in company with 


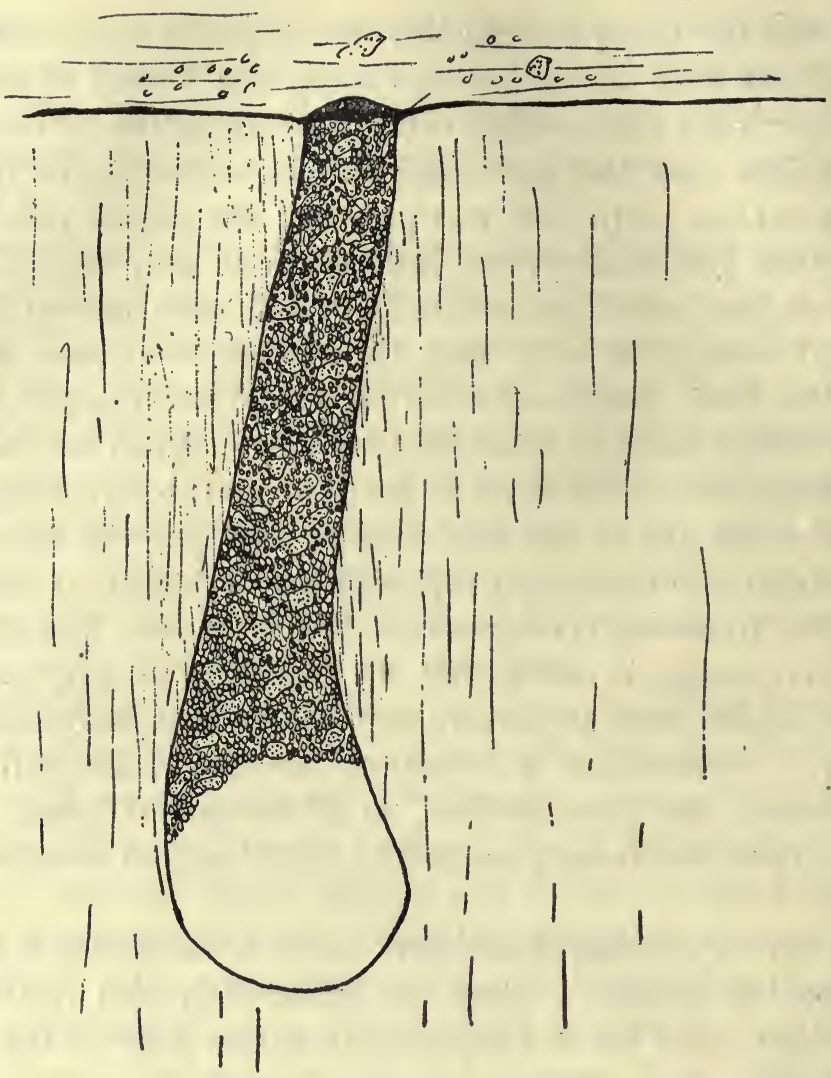

FIG. II. Another form of burrow made by Pompiloides tropicus. Natural size.

two individuals of a much smaller species of Pompiloides, were discovered out foraging. We watched them for an hour or more as they walked along on the ground somewhat nervously, examining with particular care the base of all clumps of short grass.

A month later we chanced to see a $P$.tropicus foraging more actively. She alighted boldly upon a large spider-web in the grass (one of the spreading kind with a den or lair 
in one corner) walked over it with wonderful lightness and rapidity and entered the lair. She came out at once without the spider, however, walked without the slightest entanglement to the edge of the web and flew off. Perhaps the spider spied her and escaped, but it was surprising that the Pompiloides was not ensnared in the web, as so many of the larger insects are, especially since this is the whole purpose for which the web is constructed. We have elsewhere remarked that dead Chalybion caeruleum and Eumenids are often found in spiders' webs.

Others were seen in other regions and at other times, apparently foraging. Some were out in the grassy fields, and others in barren, clay-covered areas. They seem to be generally distributed, whereas Bembix mubilipennis and other wasps are found only in specific places.

It seems, from what we have noted, that the primary sting is insufficient to paralyze the spider and that whenever $P$. tropicus is aware of any activity on the part of her prey, she re-stings it.

One record shows that a spider may recover from the sting. A small female $P$. tropicus in alarm left her spider, a medium-sized specimen of Pellenes coecatus Htz. [N. Banks] at our feet on June I2, I9I6. This tribute was cherished, even though it appeared to be dead. It was daily stimulated, but it was not until four days later that the stimulation brought forth the slightest movement of the legs. Every day the spider was mildly stimulated with the same sort of response, but it was not until the fifteenth day that the spider showed tendencies to revive. On that day, June 27, it moved the legs more actively and jumped slightly. On July 4 it was so lively that, when the box was opened, it jumped out. It had also just spun a web in the box. The next examination, July Io, found it very active, as did also the inspection on July 20 , so it was released in the 
garden, apparently fully revived and capable of carrying on all the duties of spiderdom. Of course we must not forget that the spider revived only after fifteen days, and had he remained buried with the wasp's egg upon him, he would have been devoured long before the days of his resuscitation.

The fluid of the sting must have had some preserving influence, because without being stung, it is doubtful if the spider, would have lived five weeks without food, under like conditions.

\section{Pompiloides marginatus Say [S. A. Rohwer].}

We followed this little black and orange-spotted Pompilid on the ground for a half-hour; she appeared to be foraging. She kept close to the ground amid the sparsely growing grass and only once or twice climbed the grassblades for a few inches. The twitching wings showed that she might easily be aroused to anger, although the head was kept close to the ground, in a very intent manner, often moving from side to side as if in search of something. At one time in particular, it seemed certain that she could not be bent upon any other mission than the quest of prey, for when she came to the small turret of a young spider she became very much agitated and lingered about the place for some time, possibly waiting for the spider to come out, and several times violently rammed her head against the turret. Finally, seeing the fruitlessness of her wait here, she continued her wanderings. Hancock ${ }^{3}$ records finding $P$. marginatus in the tube of the castle-building spider, Lycosa domifex.

An hour later we watched another of the same species going through exactly similar foraging behavior.

We found one on the sunny afternoon of August 3I,

${ }^{3}$ Ent. News 10: 29. 1899. 
digging in an old hole of some larger insect (wasp, spider or beetle), which had been closed by a recent rain, but not tightly packed, so there was still a marked depression on the surface of the ground. She stood head downward, worked the dirt loose and burrowed down through it, and only carried out a chunk occasionally, when it crowded her too much. She was rather clumsy or indifferent about clearing away the débris, and did not dig as neatly and scientifically as most wasps do; the dirt was constantly falling back upon her as she worked, and, even when she carried out a clod at a time, she usually laid it down on the sloping earth at the side of the hole so it promptly rolled in upon her again. We watched her carry out one lump five times, and each time she laid it in the same place on the side of the funnel-shaped depression so it rolled down and bumped her again. She did not work systematically at all, but scratched first on one side of the hole, then on the other, and occasionally paused to clean herself for a while. Finally, after ten or fifteen minutes of this, she left the place indifferently and performed similarly, but for a shorter time, at another old hole near by, but soon abandoned that likewise.

We dug up these holes but found nothing in them. Was she seeking for prey in them, or was she prospecting for an easy place to dig her own burrow? We could find no spider near. Others of this genus use spiders which they catch before they dig their burrows. She remained in this immediate vicinity, and later commenced to dig, for only a moment, in two other old covered holes. She moved and worked very indifferently, almost stupidly.

It may be possible that this one was merely looking for a spider for her own food. One which we saw in the grass a little later in the afternoon was chewing at a small spider, the remains of which were identified as a young specimen 
of Phidippus sp. [N. Banks]. She munched and sucked at it as if heartily enjoying her meal.

Hartman $^{4}$ describes the nest-building of $P$. marginatus in this way. She had chosen for the home of her offspring the middle of a much-used path through the sandy woods. "Here she began to dig with vim and in a few moments had dug a hole an inch or more in depth and was bringing out sand at regular intervals, which increased in length with the increase in depth of the nest. The sand was pushed up in loads with the hind legs and the end of the abdomen. The wasp did not appear with a load each time, but often five or six loads wculd be allowed to accumulate at the entrance when the whole pile would be pushed out and scattered away from the entrance more or less carefully."

We discovered another one October Io, just in time to witness it doing a marvellous feat of strength. She was walking backward dragging a spider, a Trochosa avara Keys [N. Banks], much larger than herself. She was holding the spider in a vertical position, grasping it by having her mandibles inserted in the ventral surface of the spider between its legs. It was remarkable that the little wasp could move such a huge victim at all; but when she proceeded to drag it up a bank eight feet high, part of which was actually vertical and a small portion slightly overhanging, we could hardly believe our eyes, and cannot yet understand how it was possible (see fig. I2) ; yet the little wasp seemed not at all disconcerted abcut it.

This method of transportation of prey, as illustrated, does not seem constant. While Hartman says the wasp grasped the spider by one of the coxae, which would probably make the carrying position very near to that illustrated, the Peckhams describe one as "going backward carrying a medium-sized spider," and another "dragging a small

${ }^{4}$ Bull. Univ. Tex. 65: 52-54. 1905. 


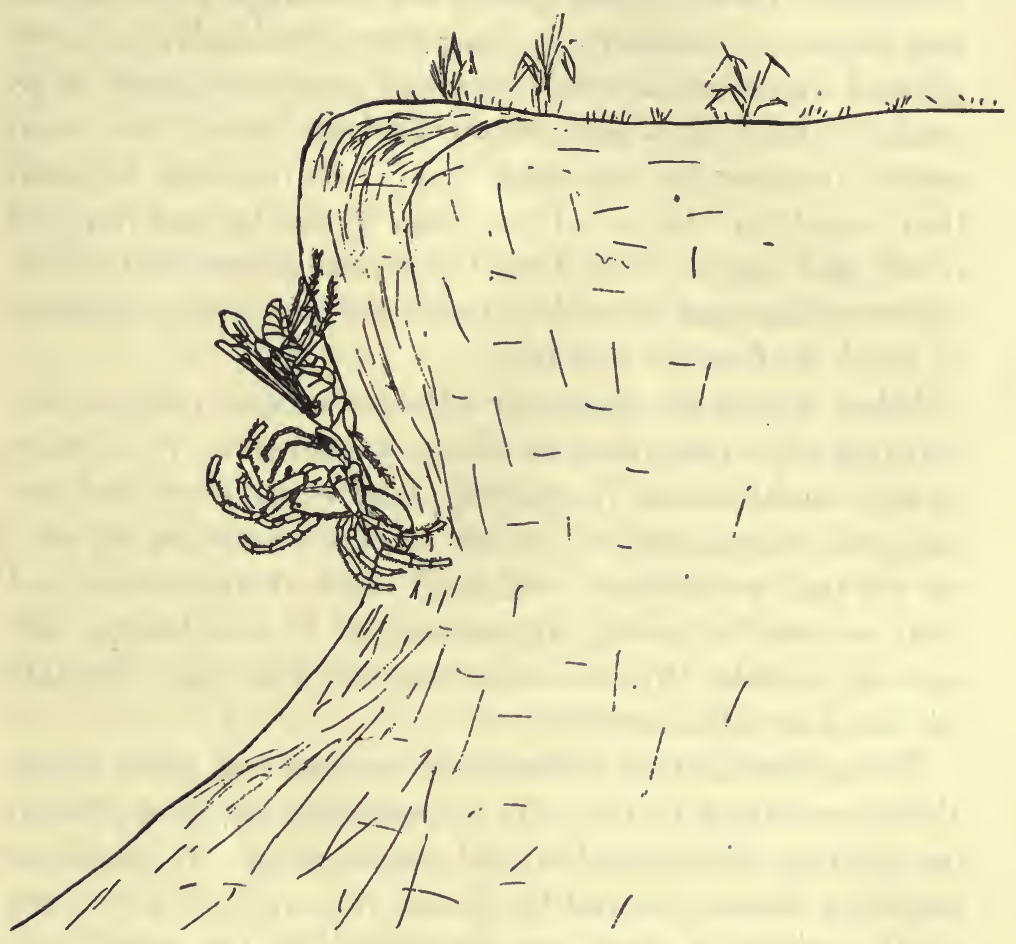

FIG. 12. A marvellous feat of strength: Pompiloides marginatus dragging her prey up-hill. Two times natural size. 
Thomisid $* * *$, the spider was so small that she held it in her mandibles well above the ground, and we speak of her as dragging it only because she walked backward and acted as though she were obliged to exert herself. Quite often the spiders taken by this species are too large to be carried and then it is necessary to drag them; this habit is so ingrained that when it would be much more convenient to go straight ahead, they stick to the ancient custom, and seem unable to move in any other way." On another occasion they found that she seized the spider by one leg and dragged it off, and again: "We have twice seen a marginatus pick up her spider and fly with it backward for a long distance, as much as four or five feet."

When we see the constancy of some wasps in the way of carrying their prey, such as Priononyx atratum, $P$. thomae, Bembix nubilipennis, Ammophila pictipennis, Odyneris dorsale and others, each of which species transports its prey unvaryingly according to the fixed ways of the species, and then we see the variety of methods of $P$. marginatus, one can only wonder if natural selection will some day eliminate the less favorable methods.

The spider figuring in the above incident was taken home. When examined the next day it appeared entirely unaffected by the sting, but jumped up and walked away. Its abdomen had been bitten into and the juices removed, so it was not at all surprising when, on the third day, the spider was dead. Thus it would appear that marginatus sometimes indulges in animal food, although Robertson finds that it frequents the flowers of Solidago nemoralis. We have often noted that the prey of the Pompiloides exhibit a good deal of energy and activity, after they recover from the first shock of the sting, and soon afterwards succumb suddenly. Hartman finds that the spider is stung to death, while the Peckhams record that the spider of this wasp, which they 
dug up after two days, was alive, as was shown by the quivering of the legs; four days later this quivering was scarcely perceptible, and it died two days after. They also mention one instance where the spider was stung to death.

The one characteristic that is constant for both Hartman's and Peckhams' wasps is their method of concealment of their prey in among the blossoms, under a lump of earth, or on a leaf high above the earth, while the nest is being dug, and the habit of visiting it at short intervals while the work is in progress.

One interesting record of the Peckhams ${ }^{5}$ we beg leave to quote, since it seems as though practical judgment or some other intellectual faculty must have been involved.

The spider was hidden, and then began the usual hunting performance, which soon resulted in the discovery of a cavity which had a very small opening. The wasp crept in, remained a minute and then came out and brought this spider to its new hiding-place. The head went in easily, but it took a great deal of tugging to get the rest to follow. At last both spider and wasp were out of sight, and everything remained quiet for a long time. When the wasp came creeping out, she went on an extended tour. She doubtless selected another halting-place, for when she returned it was to try to get the spider out of the hole by pulling at one of the hind legs. The task, however, was not an easy one; she exerted all her strength so that they expected to see the spider torn to pieces, but still it did not come. At last she seemed to realize that there was more than one way to accomplish her end, and turned her attention to cutting away the earth to make the opening larger. After a few minutes' work she tried again and although the passage was still much too small for convenience the spider was at length dragged forth.

- 5 Loc cit. p. I5O. 
Psammochares scelestus ${ }^{6}$ Cress. [S. A. Rohwer].

On October 7 this wasp was found carrying an immature spider, a Dolomedes sp. [C. R. Shoemaker]. She did not hold it vertically, but drew the spider's middle leg conveniently under her body, grasped its tarsus in her mandibles, and while she walked forward, dragged its body along bumpity-bump over sticks and stones. After travelling this way for a short time, she hid the spider under a clod and flew about over the sandy bank for some little time, where she probably found a suitable spot or hole; then she returned to her spider and again, in the same way, attempted to pull it up hill. This time, however, she failed to get a firm foothold and both rolled down to the ledge below. Here she carried it to a small depression and left it. When she failed to return after an hour, we took the spider, which was then motionless. By the next day it had regained its vigor to such an extent that it could slightly move the body sidewise. Three days after its capture, while it could not move its body, the legs responded to stimulus. The next day it was so active that it could hop for some distance with surprising agility, but on October I3, six days after its capture, it was dead.

One day, in searching for insects, we dug a little cave several inches deep into a bank, near its base. Two days later, October 5, this black wasp was at work digging a hole at the extreme end of this little dugout. The hole must have been deep or large, for already there was a goodly pile of fresh earth thrown out about the orifice. It was rather dark back in this little cave, but with the aid of light reflected upon the wasp from a mirror, we were able to follow its maneuvers. The wasp went into the hole head first, remained inside a good many minutes, and, when

${ }^{6}$ This wasp is the same as Pompilus scelestus (fide Rohwer). 
finally she appeared, she brought with her, under her body, an astonishingly large load of dirt. One could easily spell out her method: during her long stay in the hole she loosened the soil and kicked it under her body, then on coming out of the hole backwards she had only to spread her forelegs in such a way as to make a fence or rake, and by passing out she would automatically drag out the loose soil. When one sees the slope of the burrow in fig. I3, one

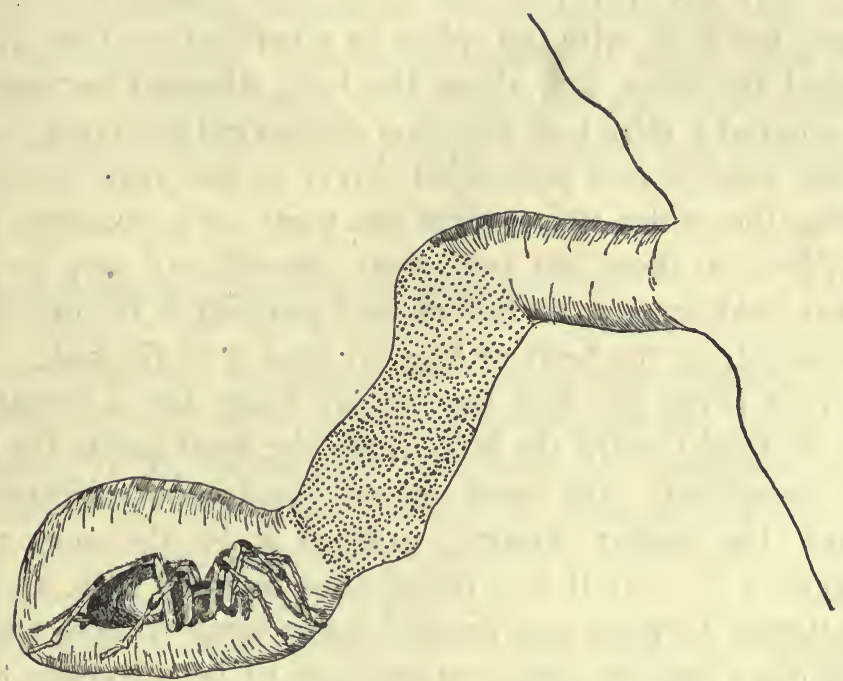

FIG. 13. The burrow and prey of Psammochares scelestus. Natural size.

realizes her tremendous task in pushing her load up-hill backwards. Sometimes the load was so large that the wasp had to force her way with much effort out through her doorway. Occasionally the loose earth at the top of the- 
gallery was kicked out, but no attempt was made to clear away the débris from her own door.

We looked for a spider which we suspected she must have near by, but found none. Once when we intruded too close she fled to the top of a bank some fifteen feet away, but soon returned to her hole. After a few minutes more of digging she flew again to the same place on the top of the bank and picked up the prey she had deftly concealed among the vegetation. She at once grabbed it by its ventral center, where the legs join the body, and walked backward toward her hole, with the spider in a vertical position. She reached the ledge just above the hole, dropped her spider and entered a false hole but soon discovered her error, took up her burden and proceeded direct to her own burrow, leaving the spider twice while she went on to examine the nest; but, on these last two visits, she did not stop to get a firm hold upon it as before, but grasped it in any way convenient, by the head or legs, to drag it to the hole. At the very brink she laid her victim down for a moment, with its head toward the hole, while she went inside for the final inspection. She came up and slowly and deliberately turned the spider around, grasped it by the anus and dragged it in. As it was pulled thus into the hole, all the legs turned forward and pressed firmly against the body of the spider; then we could see the logic of her choosing that position. But what impressed us most was the deliberate and careful manner which the wasp displayed in turning the arachnid around, so that the rounded and appendageless part could be grasped. It was no accident, but a deliberate act.

She remained within for one hour. When we opened the nest, we found the spider resting still with its head toward the exit (fig. I3, exact size), and on its right side was the wasp's egg. The wasp's last hour had evidently been spent 
in closing the hole, from bottom upward, but she had not yet reached the surface. The spider was motionless. The next day it showed faint response to stimulus; then it died. On more than one occasion we have noticed that the prey of this species of Pompiloides are so severely stung that only after two or three days do they show the faintest signs of reviving.

The Peckhams in both of their wasp publications have a splendid account of the behavior of this wasp, under the name of Pompilus scelestus; in several details our notes substantiate theirs. No other biological notes have been located in the literature, excepting that the insect inhabits mountains at or above an altitude of 5500 feet (fide Slosson).

Pepsis dubitata Cress. [S. A. Rohwer].

The following paragraphs are merely a description of the efforts and difficulties of a $P$. dubitata on her homeward journey; if the recitation of the trials and struggles seems wearisome to the reader as he sits at ease; let him consider how much more wearisome was the reality for the little Pepsis under the midday July sun.

We first discovered her at I p. m., July 29, walking nervously about on the ground in irregular circles, as if seeking something lost. Suddenly she dropped into a tunnel in the earth, made by some rodent. We watched at this hole for twenty minutes but she did not reappear; when we gave up the vigil and walked about thirty feet away, we found her where she had emerged from another point in the tunnel. She was intensely at work dragging a spider. These insects are rarely met with, so we turned all attention to following every detail of her behavior.

It was now $\mathrm{I}: 20 \mathrm{p} . \mathrm{m}$. She had a huge spider by the 
head, probably five times as heavy as herself, and was walking backwards, dragging it over sticks and stones, green and dried grass, up logs and down.

After four minutes the wasp stopped dragging the spider, and for five minutes she rested and cleaned her antennae, body and legs. Twice during this interval she left her spider and went under a leaf near by, but each time she returned to keep watch again in front of its prostrate form, while she made her toilet. But we were mistaken in thinking that her burrow was under this leaf; for at I :29 she grabbed her property and continued her journey, in the same manner as before, for six minutes. Twice she left the spider, walked about in circles with the same nervous, jerky gait, but in a moment she seized it and hurried on again, making good time over a bit of smooth road which chanced to be in her way. She certainly seemed not to trouble herself to find a smooth way. One of the spider's legs was seen to quiver several times.

At $\mathrm{I}: 35$ the wasp enjoyed a perfect rest near her prey, for a half-minute. The spider's second right leg still quivered occasionally; but the wasp was not perturbed by it, but calmly rubbed herself down. She cleaned her abdomen with her hind legs and her antennae and head with the forelegs. For nine minutes she loitered about, making her toilet most of the time, and occasionally moving her position for a few inches, sometimes behind, or to the right or left of her spider, but always near enough to keep a watchful eye upon it.

The spider's right leg gave a more marked twitch. The wasp darted at once to her position at the right of the spider's head. At I :44 she left it and went under a dried leaf, as if reconnoitering. After a few seconds she came out and dragged her prey under the leaf with her, the legs of the spider protruding. We followed eagerly but 
cautiously, thinking that here she would bury it. But no, she could be seen, through a rent in the leaf, quietly at rest before her spider. The wasp occasionally walked about slowly under the leaf; apparently she only wanted a more sheltered spot wherein to rest and loiter. Up to this point she had travelled about sixty feet.

Two o'clock came and there was no change; the sun beat down hotly and our patience was strained. With the forceps we gently pulled the spider out by its leg for a halfinch. This instantly aroused the wasp to action; she snatched the spider by its head and dragged it under the leaf clear to the extreme opposite margin, paused a moment, as if undecided, and then impetuously seized her prey and resumed her journey in earnest. There was much difficulty in following her, owing to obstructions, vegetation and poison ivy. She showed by her actions that she now felt anxious and skeptical in our presence; from $2: 06$ to 2:I2 she remained at rest, but this time holding the spider in her jaws all the time. Finally she regained enough confidence to lay it down while she made her toilet for three minutes. We should be glad to know if she purposely laid down her prey so often in order to clean herself, or if she only rubbed herself for a pastime when she paused to rest. We have also wondered if all this was for the purpose of personal daintiness, or if a part of this practice served as a massage or an athletic rub-down of the tired muscles after the strain of labor.

At $2: 15$ the wasp made a very graceful attempt to climb a log which lay over her path. How the insect became aware of its presence without facing it to see it, or bumping into it we cannot imagine, but she seemed somehow to sense the location precisely. She backed up near to it, dragging her spider until she came within reach of the log, when she lifted her hind pair of legs high up in the air until they 
came in contact with the rough bark; then she continued backing up until soon she had all six of her legs in action. Just as she reached the top with her heavy burden, however, she grasped a fallen leaf which lay loosely upon the log, and leaf, wasp and spider rolled to the ground. Finding her lost prey after a few seconds' search, the wasp resumed her travels in another direction, this time up a steep hillside. She resorted to no diagonal inclines, but pluckily struggled straight up the steep slope, pausing only once, for a few minutes' rest, when half-way up the hill. Presently she slipped and fell and rolled part way down the hill. This seemed to discourage her a little, and she left her prey and strolled a dozen inches away, then back to it thoughtfully, and settled down to spend the next ten minutes in resting, toilet-making and short, jerky walks.

At last she resumed her wanderings, carrying the spider still further up the hill, and reached an area blackened by a recent fire, where there was no green vegetation and the ground was literally full of the holes and tunnels of rodents. But nothing here seemed to appeal to her, and again she took up her burden and went down the hill beyond, for ten feet, and then up the next hillock, always walking backwards and holding the spider by its head. About this time she dropped her spider two or three times and made short side-trips, looking over the vicinity, returning to it as though to continue the trip. Suddenly and without warning she disappeared with her prey into a rodent hole. We watched and waited long, and wasted much effort in digging up the tunnels and a considerable portion of the surrounding country, but could discover her no more.

Over the very roughest country this wasp had dragged her burden for a hundred yards. Since she seemed to have an especial liking for rodent holes, one wonders why she did not use for her nesting-place the first tunnel wherein 
she found the spider, and thus save herself the labor of dragging such a load for three hundred feet over rough roads, or at least choose one of the many which she passed by in the burnt area.

After following this wasp mother through the details of her prolonged trials and difficulties, we respect her for her faithfulness and pluck in continuing her heavy task to the end. And yet we have a lurking feeling (which we regret to express) that this type of faithfulness may have been an exhibit more of brawn than of brain. However, we must not judge the species by this one female which may have been very individualistic in her behavior; perhaps her sisters would have shown as fine instinct and economy as is found in any of the other species.

Priocnemis pompilus ${ }^{7}$ Cress. [S. A. Rohwer].

Verily, if boils were sent to try the patience of Job, then Priocnemis pompilus must have been created to try the patience of naturalists. One sees an animated little black wasp darting nervously here and there in a hot, sandy field, and one follows eagerly, confident that some interesting activity will ensue at any moment. She runs in this direction and that, absolutely without any system or general direction, peeping into every crevice or behind every obstacle, often hopping and twitching the wings nervously. Thus she lures us on and on almost interminably, until our eyes feel strained with watching her in the glaring sun. Sometimes she plunges into a crevice or a mole's tunnel, and we wait until she comes out empty-handed, or she may walk about the tunnel and emerge far beyond, and leave us watching for ever so long at the place where she entered,

${ }^{7}$ This species is listed in Dalla Torre's Catalogue as Salius pompilus (fide Rohwer). 
before we discover that we have been deceived, scramble to our feet and go scurrying after her again. Or perhaps she darts under a grass-blade and there she sits, and sits, and sits, occasionally scratching a bit at the ground or peeping out as if to make sure that her secrets were not being spied upon, and eventually darts out without doing a thing and resumes her crazy journey. Probably these are foraging trips, but in the summer months we have never seen their activity lead to anything more than this vain search. It may be because of the scarcity of spiders of adequate size at that time of year, or due to the sexual immaturity of the wasps. Later in the season, September and October, their work seems to be more purposeful and their efforts lead eventually to some results.

On the afternoon of October 3, I916, we met with one such instance. A Priocnemis pompilus was rushing hither and thither over a small area of broken ground. We had so often seen this species wandering about on the bare ground inspecting crevices, and had been so constantly disappointed in seeing them do nothing that we paid no attention to this one. Upon returning an hour later, however, and finding apparently the same wasp running about in the same small area, we suspected that there must be spiders in the many depressions in the earth, so we sat down and waited.

The retina of one's mind, as well as the retina of the eye, grows dull when weary of gazing at one thing, so our thoughts were far away when, perhaps a half-hour later, suddenly there was a great commotion-hurry-tumbletopsy-turvy! The wasp had her spider and was stinging it. The shock was so great, and the work was done so quickly, that we could not see just how it was done. The wasp left her victim, ran around like wildfire for several seconds, returned, stung it again and dragged it some distance away, 
left it and, in the same wild manner, looked for crevices, went from one to another and eventually carried the spider to a shallow cne. Not satisfied with this the wasp dragged her burden further and, in an uncertain way, wandered about with it. Presently she lost her prey, but continued roaming about, possibly looking for it.

Being unable to wait longer, we took the wasp to make sure of the species. While the story here is incomplete, these observations show that these wasps are persistent in remaining in a spot, when they are suspicious that their prey lies hidden thereabouts, and that they get their prey first and then hunt for a suitable crevice wherein to deposit it.

Even later in the season than this, October 26, the active $P$. pompilus were more abundant than at an earlier date. While these wasps had frequently been seen before in search of game, on this day four were discovered with spiders, on a clay bank. One in particular was followed and watched. She had a medium-sized spider in her mouth and was nervously and quickly moving with it. We say moving because her gait has no name; she was walking and flying without lifting her legs from the ground and doing both equally well, either pushing her burden forward or going backward and dragging it with her. She would often leave her prey to explore the region for suitable holes. At last one was found on a perpendicular bank, eighteen inches from where the spider lay. This bank was almost straight up and down, and we wondered how it would be possible for the wasp to carry the prey up to the hole. It seemed for a time as if it were not possible, for in the twenty or more attempts that she made walking backward and climbing up the bank, invariably both fell down; either she tumbled down holding to her prey or she dropped it and flew down after it. She made a few examinations of other nearby holes, as if considering the advisability of a change 
of plans, but for some reason she always returned to the one of her first choice.

Eventually she mastered the art needed and her perseverence was rewarded with success; at last she got the spider up to the hole. However, the ledge in front of the hole was so narrow that it would tumble off just as fast as she got it there: It seemed that she had an aversion to dragging the spider into the hole without first going in herself, and this seemed impossible. She later learned to place-or better to say succeeded in placing - the spider just over the mouth of the burrow, and there it hung while she very dextrously wedged her way into the hole, to see if all was right, before entering with the prey. But here new disaster came; she could let the spider lie on the outside over the hole while she squeezed herself in, but when she came out her head butted against the spider and down it went again into the valley below. Her patience and strength seemed inexhaustible; we had long ere this lost all estimate of the number of times she had skilfully carried her spider up this precipitous bank. Three times in succession this last mishap occurred, when finally (and this may have been accidental, but we shall always hold it as a case of profiting by experience), she took up her spider, carried it some distance to a point where the bank sloped gradually, and climbed up, walking backward and pulling the spider with her; then she dragged it back horizontally and let it rest on a ledge three inches directly above the hole. Next she went into the nest, examined it once more, and came out and got her booty. Here we thought the insect showed wonderful intelligence; it would be easier to carry her spider down three inches to the hole than up eighteen inches and still it would be within easy view while. she went for her final inspection of the hole, which she deemed so necessary. This arrangement, we thought, would obviate that examination and the subsequent sliding down of the spider into the chasm below. 
She emerged from her burrow and walked directly up to where the spider lay and dragged it down to the hole very easily. She did not immediately take it in, as we had expected, but squeezed in alongside it exactly as before for that supremely important final examination. Then, alas, she came out and as usual bumped against the spider so hard that it plunged down the eighteen inches, and she went tumbling after. The instinct of unnumbered generations of always examining the depths of the nest while the prey is at the door was not to be undone, even if she must go only three inches from the hole since the last scrutiny.

Her next scheme was to drag the spider up the steep declivity under the hole, then a little to one side and let it rest in the crotch of a protruding root while she again entered the hole.-Now there is really and truly a limit to the patience of a naturalist, so we helped her, and glad she seemed to receive the aid. When she stepped aside again to get the spider, we pressed a notebook against the bank to form a shelf just beneath the hole. When the little wasp came with her ponderous prize she found that it would rest securely and exactly flush with the hole. She went in, as always, to examine the bottom of the burrow, came up and protruded only her head, grasped the spider and attempted to bring it in. Alas! the hole was not large enough to admit it! Is it not remarkable that, through all her dogged determination to examine the hole immediately before taking her prey in, it had evidently never occurred to her that the hole was far too small to admit the spider at all? This is very different from the accurate methods of many other species discussed in these pages. She did not seem at all disconcerted, but shoved out her spider, removed several mouthfuls of dirt at the opening and then had no trouble in getting it in.

Both disappeared in the depths. After more than an 
hour's weary waiting for the wasp to emerge, we stirred her out with a probe and dug away the earth to explore the nest. It went in horizontally about six inches (it had probably been a beetle's hole); then the channel or crevice was lost. The prey was not found. Probably her last hour was spent in filling and packing the hole within up to this point, much after the manner of other Pompilids mentioned.

This species of wasp uses a variety of spiders. We have at various times and places found it carrying off the following species: Pardosa minima Keys [N. Banks], sp. of Lycosidae, immature [N. Banks], Lycosa helluo Walck (young) [N. Banks], Pardosa nigripalpis Em. = P. cana-

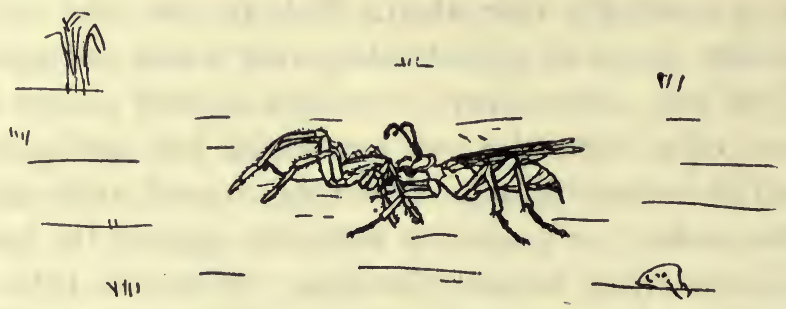

FIG. 14. Priocnemis pompilus travelling backwards and dragging her prey. Twice natural size.

densis Blk. [N. Banks], and Clubiona abbotti Koch [N. Banks].

It scon becomes apparent that in many of the affairs of wasp life, $P$. pompilus is not such a stickler for conventionality as are many of her sister species. She takes such prey as she can get, and does not reject good spiders because they are not of the species which Habit specifies as proper for her; she uses such holes as she can find in the moment of need and modifies them to suit her needs; if she cannot ascend a precipitous slope directly, she will in time contrive some indirect way to scale it. In fact, like most individuals who go outside the pale of convention, while she may at 
times seem bizarre, yet her action contains an increased portion of refreshing multiformity and resourcefulness. And so also in her way of carrying her prey, she has not one fixed way, but a variety of ways. She seems, in fact, to be entirely without any fixed habit in this point, excepting that she grasps it in her jaws. This is really the only way possible for her, since she is so small that she could not possibly straddle spiders of the size she catches. Her most common mode of locomotion is to walk backward, pulling her prey (fig. I4), but she also sometimes walks sidewise, dragging her burden at right angles to her own body. Her method of half-running and half-flying with the feet on the ground, while she either pushes or pulls her spider, has already been described. In making ready to drag her prey, she seizes it by any of its members that may offer themselves as a convenient handle at the moment. Each place of insertion of her jaws in the spider's anatomy gives it a different aspect. For instance, when she grasps the spider by the base of one middle leg, this stands the body on its side; when she grasps it by the middle of the ventral side of the thorax, the ponderous abdomen bobs up and down as it passes over the rough ground in a way that must be annoying to the little worker. Another of her favorite methods is to seize it by the palpi. The loose sand often gives way under her feet, and both captor and prey roll headlong.

Another species of Priocnemis ( $P$. flavicornis) according to Needham and Loyd ${ }^{8}$ transport their prey by flying above the surface of the water and towing the load too heavy to be carried. Out onto the surface of the water the wasp drags the huge limp spider, "and, mounting into the air with her engines going and her wings steadily buzzing, she sails across the water, trailing the spider and leaving a wake

${ }^{8}$ Life of Inland Waters, p. 330 . 1916. 
that is a miniature of that of a passing steamer. She sails a direct and unerring course to the vicinity of her burrow in the bank, and brings her cargo ashore at some nearby landing."

Arachnophoctonus $^{9}$ ferrugineus Say [S. A. Rohwer].

This large red wasp ${ }^{10}$ was observed on July 7, I908, walking up the perpendicular stone wall of the abandoned ice-house at Meramec Highlands, near St. Louis. She was walking backwards, dragging a very large Lycosa spider, much heavier than herself, straight up the wall. She held the spider's head between her mandibles, and was making very rapid progress. Thinking that she was climbing to some height in order to fly down to her nest (in this conjecture we were probably mistaken), we captured her and her prey before she should get beyond reach. The spider had a long gash surrounded by a large swelling on the dorsal side of its abdomen, but we had no way of knowing whether this was a wound inflicted by the wasp's sting or a cut from her mandibles, or only a laceration from the stones over which it had been forcibly dragged.

While looking for mud-daubers' nests about the stone foundation of another abandoned building in this vicinity, we frightened another specimen of this formidable-looking species out of a crevice. The cracks between the limestones of the foundation were filled with well-weathered mortar. She flew to the ground near by and crouched low under some grass; when we attempted to examine her, she

${ }^{9} \mathrm{Mr}$. Rohwer writes that this generic name is one of Ashmead's divisions of the old genus Pompilus.

10 This wasp is comparatively rare in this region; besides the few mentioned here we have seen only five, four females and one male, in five years. 
flew further, but she was recognized immediately by the bright red of her abdomen and, in the bright sunlight, her bluish-tinted wings. Her brilliant coloration and her nervous, defiant manner certainly render her a formidable looking creature (fig. I5). In cabinet specimens of this species, the red of their bodies looks far more dull, and the wings,

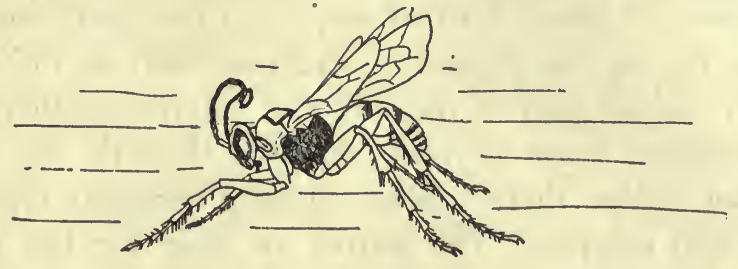

Fig, 15. The Pompilid wasp, Arachnophoctonus ferrugineus Say. Exact size.

which are a conspicuous royal blue when vibrating in the sunshine, are but a smoky color with a slight blackish-blue tinge at the base.

After having frightened her away, we proceeded to examine the loose mortar for her nest or prey. We were attracted to a pile of loose, dry plaster-dust on the damp earth; this pointed up to the third tier of rock, probably eighteen inches from the ground, where a large Lycosa spider lay in the crevice, about an inch from the opening. It was removed and found to be fresh, limp and motionless; it was probably dead, so we replaced it and waited. After fifteen minutes the wasp flew into the vicinity again, but became shy upon seeing us there. After another ten minutes she ventured near again and alighted on the stone wall at a height of six feet, and east of the nest; then walked down and westward, entering and examining several holes. and remaining in some of them for a few seconds. She eventually found the crevice containing the spider, entered and examined it so intently that we, wondered if she 
recognized that it had been tampered with. Then she turned her abdomen toward the spider and held it thus, hugging it closely for some seconds; we suspected that the wasp was stinging it again, but she was so deep in the crevice that we could not see distinctly. She then went deeper into the cavity between the stones and flung out another halfdozen kicks of dust. Unfortunately, at this point she spied us lying flat on the ground to scrutinize her, so she darted away to another part of the wall and entered another niche, and remained there so long that we thought she would carry her spider there. She suddenly emerged from this retreat and escaped. We waited an hour for her return, but she seemed shy, so we wandered away, returning every three or six minutes to look for her.

While thus loitering about waiting we took a trowel and, at a point in the wall about thirty feet away, idly removed from the foundation the hard, black cement which covered the soft mortar beneath, thinking thereby to make an attractive spot for other wasps. After a time, we lost patience, however, and decided to work elsewhere. We knew the species of the wasp, the place where her spider lay was marked, and we knew where she had dug her cavity in the mortar, so it was decided to leave her in peace and return later to get the spider with the egg on it.

Upon returning in a half-hour, imagine our surprise upon finding the spider gone. It seemed scarcely probable that another had come along and purloined it, because, from her previous actions, it appeared that she was going, to change her nesting-place. Now it was a task to find the spider, and for another half-hour we dug into the mortar in various suspicious-looking places in search of it. Suddenly a passing gleam of color caught our eye; the wasp flew past, ignoring her old location and alighting on the wall thirty feet beyond. We watched her carefully as she 
tried to find her new apartment. She accomplished this with difficulty; twice she had to fly away and return on the wing to the same spot to get her bearings. Eventually she located her hole and entered - the very one we had, only a short time before, begun in order to attract some wasp! We were almost too astonished to believe the story ourselves, and yet the evidence seems sufficient to warrant the surmise that it was the same wasp. We knew that she had become dissatisfied with the place that harbored intruders, and that no others of this species were seen all that day. Her actions indicated that she was looking for a new abode, and we are sure that this second hole could not have been there for more than a half-hour-the exact time since the first nest had been deserted-because it had been accessible only since we pulled away the hard outer cement.

She went in and remained about fifteen minutes, when she was captured in a vial placed aver her hole. We worked for a long time trying to dig out her spider and egg; but the probe showed that the crevice between the rocks was eight inches deep, so we were obliged to give up the quest without getting her prey or learning anything more about her nest or egg.

This also solves the problem of seven years previously, when an $A$. ferrugincus ascendèd the old stone wall of the ice-house, walking backward and dragging her Lycosa. No doubt that wasp also was directing her course to a chosen crevice in the old stone wall.

In other species of Pompilids, as previously noted, when the wasp is digging her burrow, she often leaves her work to examine her prey and frequently moves it closer to the hole. The notes that follow will show that $A$. ferrugineus does not drag her prey along until she comes to a suitable spect, but in transporting her prey she has a very definite notion of where she is going. 
On August 19, at 4:30 p. m., one was discovered dragging a large Lycosid spider by one mandible, walking backwards with a jerky motion, travelling without much difficulty over the long, fallen blue-grass in the front yard. She carried the spider right-side-up and brought it about fifty feet after being discovered. Twice in that time she left it and took a quick, circling flight, as if exploring, over to the old log smoke-house with plaster-chinked crevices; then she returned, without difficulty, to her spider and coritinued her course very directly, as if she knew precisely what she was about. When finally she got it to the bald area a few feet in front of the smoke-house she paused, left it again and flew to the wall, alighted on it and took a quick, surveying gallop over the two lower logs and their interstices; then went right back and got the spider, took it hastily over to the wall and hid it deep in a crevice in the foundation. She then took on a very nervous attitude, running and flying all over the two walls, examining nooks and crannies everywhere, with wings and antennae nervously vibrating; finally she sat down for five minutes' rest and "meditation," then resumed the chase and search. We cannot believe that the wasp travelled from the spider to the smokehouse so often to see if the smoke-house was still extant, but we think perhaps that was her way of ascertaining whether she was travelling in the right direction; she knew where she wanted to go, and retraced her steps often to see that she was going there.

Presently the wasp disappeared in one of the crannies. Meanwhile the spider was examined. It was limp, but responded to stimulation by slight movements of the legs, although it was so completely paralyzed as to be almost dead.

After a half-hour in hiding, the wasp again apppeared and made her way to the spider and rested in the crevice 
beside it. When we intruded too near, she flew to the log above, rested, made her toilet and visited the spider for a few seconds. Then she went forth on another tour of inspection of the log walls clear to the very top and down again, by a circuitous route, examining every crevice on the way. Once more she rested a while and made her toilet, then went to the original crevice and carried her booty into a nearby cranny, which she had just passed with casual notice, and dragged it far in out of sight and beyond our reach.

This wasp, then, seems to have a propensity for building nests in the crevices of stone walls, and the propensity probably had its origin in the days when the loose stones of bluffs or hillsides was the only place for the species' abode.

Pseudagenia (Agenia) architecta Say [S. A. Rohwer].

Under the loose bark on a log, tangled in a mass of spider-web, was a pretty little two-celled nest of mud. It was treasured until $P$. architecta emerged from it, revealing its authorship.

Later in the season several similar cells were found at Cliff Cave, near St. Louis, Missouri. They were always in pairs (see fig. I6), neat, thin little cells joined end to end like sausages.

The Peckhams ${ }^{11}$ found a similar dainty mud nest hidden away in the folds of a flag when they unfurled it on July 4. Each cell contained a dead spider and a wasp larva. They spun their cocoons on the 7 th, 8th and 9th of July, and on July 29 a male emerged and on August 2 two female adults appeared.

Wickham $^{12}$ found one in Iowa dragging off a spider, a

11 Bull. Wisc. Geol. \& Nat. Hist. Surv. Ser. I. 2 : 165-166. 1898.

12 Ent. News 9: 47. 1898 . 
Trachelas tranquilla Hentz, which was much heavier than herself. The spider's legs had been bitten off at the junction of the coxae and trochanters. She dragged it with its

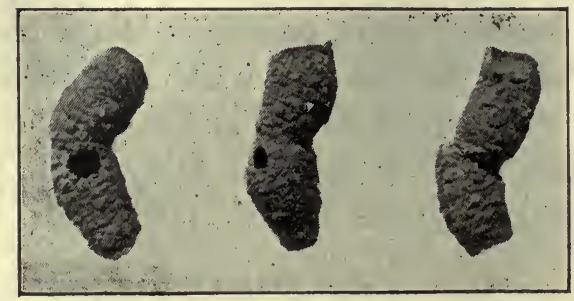

FIG. 16. The twin-celled nests of Pseudagenia architecta, showing the holes made by the emerging wasp. Exact size.

smooth, rounded back downward, to prevent friction, and grasped it with jaws near the tip of the ventral surface of the abdomen.

Ashmead, ${ }^{13}$ in citing Walsh and Riley, says that the thimble-shaped cells occur under bark, logs or rocks, and are parasitized by Pteromalus sp. and Osprynochotus junceus $\mathrm{Cr}$.

Pseudagenia pulchripennis Cress. [S. A. Rohwer].

This medium-sized black wasp was found walking along a path at Creve Coeur Lake on October 7, carrying a spider, Phidippus andax Hentz [C. R. Shoemaker]. The wasp was holding the spider by one of its chelicerae and walking sidewise, the combination of spider and wasp forming a right angle (see fig. I7). It moved in a very strange manner, walking sidewise. This was the first wasp we had ever seen travelling thus. Night was approaching and traintime was drawing near, so we were obliged to abandon 13 Psyche 7 : 66. I 896. 

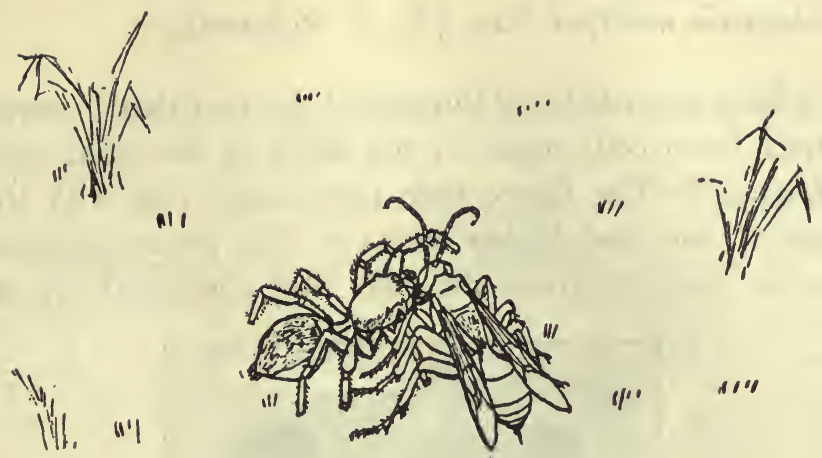

$11:$

FIG. 17. Pseudagenia pulchripennis escorting Philippus andax to her burrow. Two times natural size.

further observations on their free behavior and take both. The spider showed signs of life for three days.

Long afterward, another wasp was found actively engaged in running about on a fallen log. Suddenly it leaped to the ground and chased a medium-sized spider. The arachnid made one leap and escaped. The wasp became frantic; the sight of the spider and the fact that she had been fooled so excited her that she acted as though mad, walking, flying, running about the ground in indescribable directions until she tumbled headlong into a mole's hole. After a few moments she emerged from the burrow carrying a spider by its anus. She walked forwards, backwards or sidewise over the ground or low vegetation, in a manner indicating intense excitement, and eluded us many times before we finally captured her. All this occurred, not in the hot sunshine where most Pompilids choose to work, but on a path in the cool, shady forest. 
Psendagenia mellipes Say. [S. A. Rohwer].

We have recorded and illustrated the fact that $P$. mellipes emerges from cells made in the walls of the mud nest of Sceliphron. ${ }^{14}$ The figure here reproduced (fig. I8) shows the nest of the mud-dauber with two hilly protrusions which were cut down to show the cells that contained the pupal

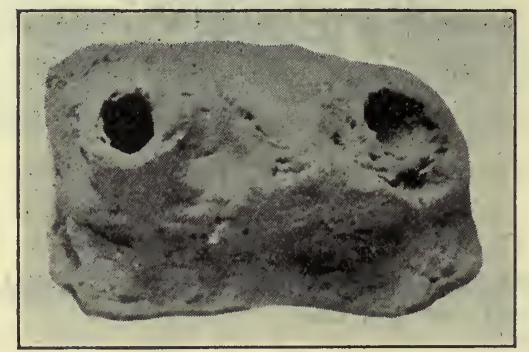

FIg. 18. Two protuberances on the nest of Sceliphron which gave forth adults of Pseudagenia mellipes. Natural size.

cases of $P$. mellipes. Elsewhere on the nest, mandible marks were in evidence, so we suspect that mellipes dug out a small cavity and then carried mud bitten from other parts of the nest and built up and around it until the cell was completely enclosed and hidden from view.

This, we find, is not the only method of nidification of this species. At Moselle, Missouri, on June 30, 19r6, while breaking away some loose bark from a fallen tree, we found a little three-celled nest, very beautifully constructed, which we carefully guarded since we expected some species of Agenia to emerge therefrom. We were surprised when on July 8 and II two adults of $P$. mellipes emerged. The nest did not adhere to the wood, but lay loosely under the bark. The accompanying figure (fig. 19) shows this nest and also the builder (exact size).

${ }^{14}$ Journ. Animal Behavior 6: 27-63. 1916. 


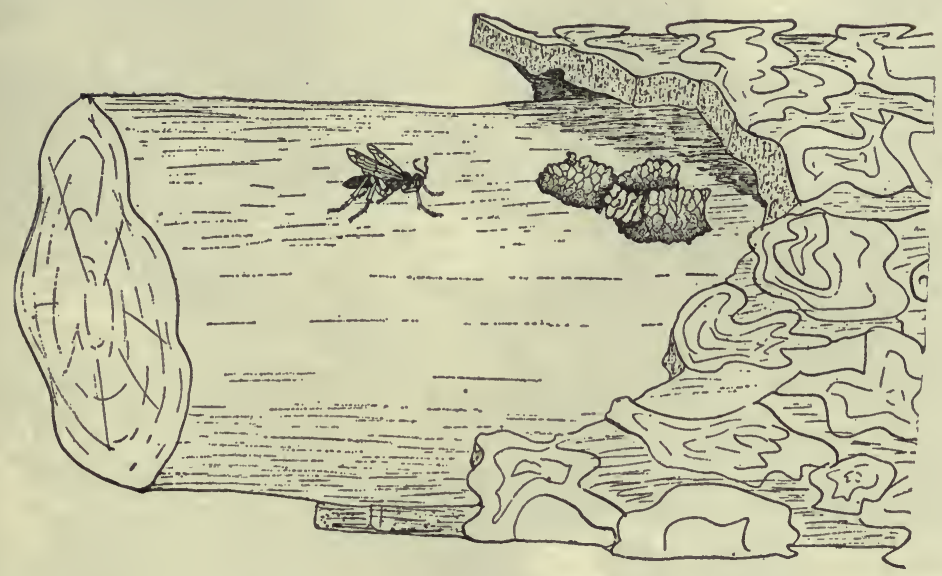

Fig. I9. The three-celled nest of Pseudagenia mellipes under loose bark, and its author nearby. Both natural size.

An old oak-apple taken from the tree on June 20, I9I7, had the four-celled nest within it. (See fig. 20B). Two cells were sealed and two unsealed. The unsealed cells were perfect; this goes to show that this wasp does not fill each cell as it is finished, but makes several before hunting for prey. The apple was perforated by a small, round hole, one-fourth inch in diameter, through which the wasp had entered and departed. The big, brown oak-apple had made a most comfortable home. On July Io, one male P. mellipes emerged.

How many other places of nidification mellipes has remains to be discovered. Ashmead, citing Walsh and Riley, ${ }^{15}$ 


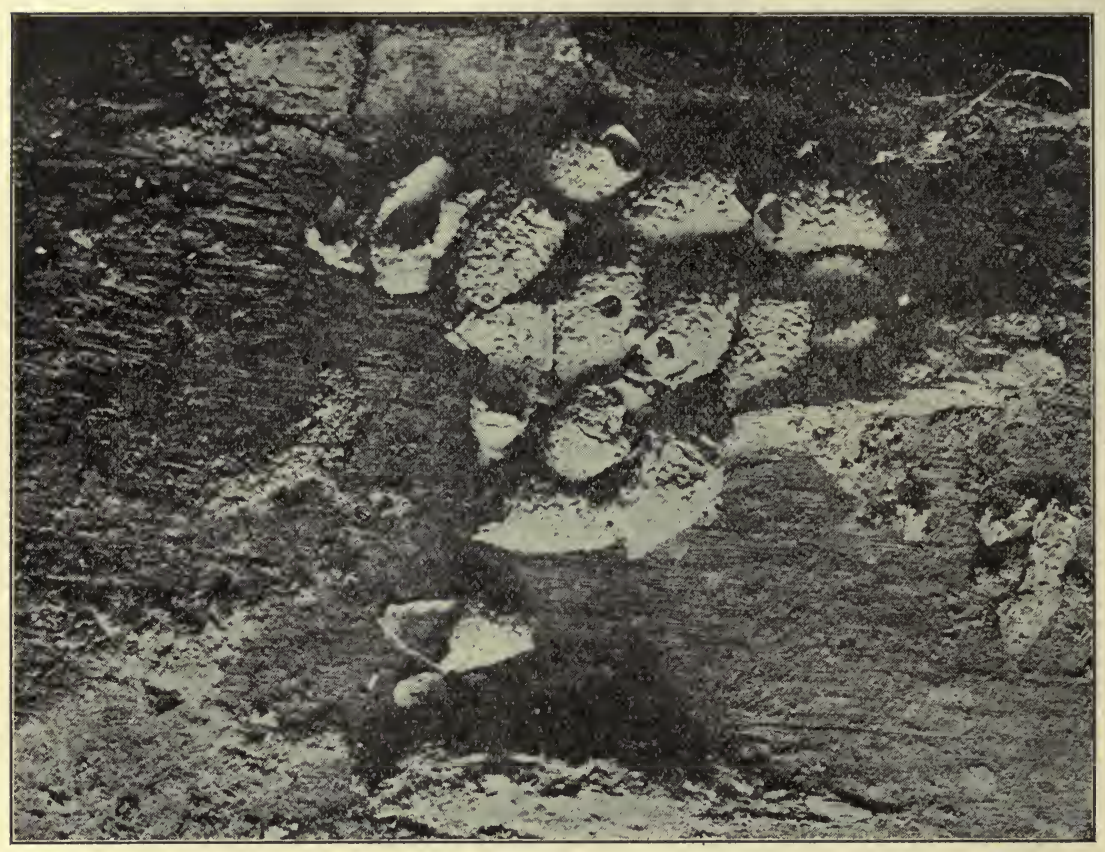

FIg. 20 A. The mud cells of Pseudagenia sp. from which adults of the Mutillid wasp Sphaerophthalma scaeva emerged. Natural size.

says that Agenia mellipes makes thimble-shaped cells under bark, logs and stones, and that they are parasitized by Pteromalus sp. and Osprynochotus junceus Cr. The cells here illustrated can hardly be called thimble-shaped.

A collection of Pseudagenia sp. mud cells was found under the loose bark of a tree (fig. 20A), and another

${ }^{15}$ Loc cit. p. 66. 


\section{BEHAVIOR OF POMPILID WASPS}

group of identical cells was found under a plank which covered a depression in the ground. Both lots, however,

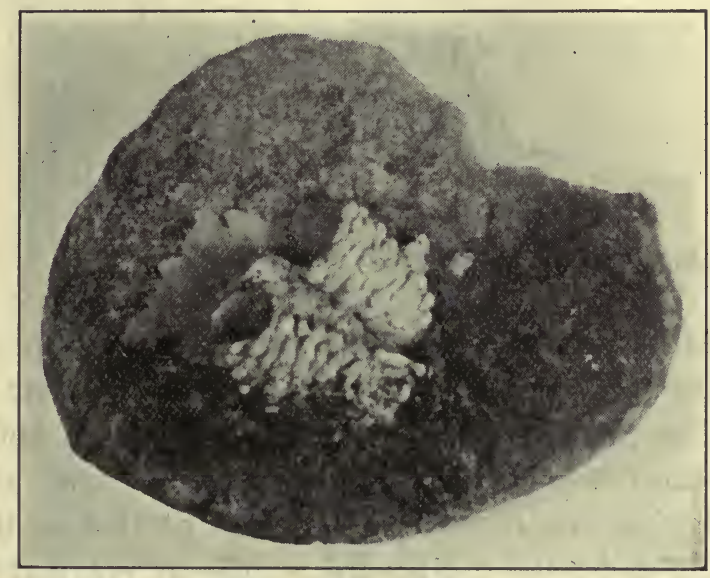

Fig. 20 в. A mud, nest of Pseudagenia mellipes within an oak-apple. Slightly enlarged.

gave us not Pseudagenia wasps, but both sexes of the parasitic cow-killer, Sphaerophthalma scacva Blake [S. A. Rohwer]. 
Hypocrabro stirpicolus Pack. [S. A. Rohwer].

An old railroad tie lay half buried in a heap of dirt. Under the protruding rotten end was a miniature hill of sawdust, or rather particles of wood bitten out, and above this a clean-cut hole pierced the log. We found after we began digging into it that only a small portion of this was rotten, and under the surface the wood was very hard. The long tunnels leading in from the surface aperture were made in the softer, decayed part of the wood. This tunnel led to a series of three cells which were five $\mathrm{mm}$. in diameter and were partitioned to make neat cells fifteen to eighteen $\mathrm{mm}$. long. Another tunnel branched off from the main channel, and, going into a lower stratum of wood, there branched into four similar cells as shown in fig. 2I (slightly enlarged), each containing a definite successive stage in the development of the young. The material used for partitions was the sawdust tightly packed to a thickness of ten $\mathrm{mm}$., so it made a remarkably strong wall.

The prey in these cells was two-winged flies of several species. Two cells that were filled and had very small larvae had four flies each, and another had four flies plus one head. In some cells were many heads, wings and thoraces of flies. One cocoon was of a dark brown color, and all the débris in the cell had been shoved to one end before spinning (fig. 22). Two adults emerged on July I and 3 . 


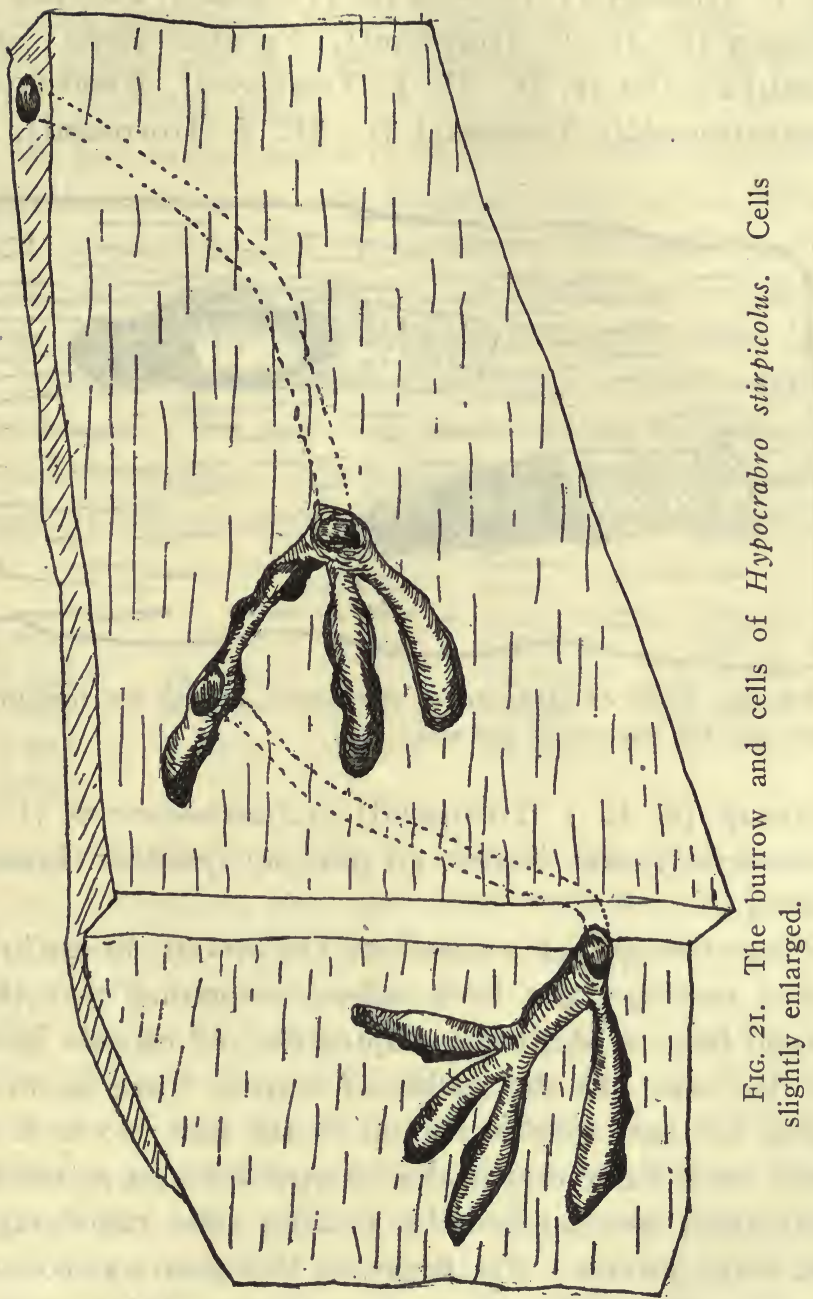

A variety of flies are used by this wasp. Those found in these and other cells are: Atrophopoda singularis Townsend [C. H. T. Townsend], Ravinia quadrisetosa Coq. [C. 
H. T. Townsend], Phorbia sp. [F. Knab], Phormia regina Meigen [C. H. T. Townsend], Psilopus sipho Say [F. Knab],Lucilia sp. [C. H. T. Townsend], Emphanopteryx eumyothyroides Townsend [C. H. T. Townsend], Sarco-

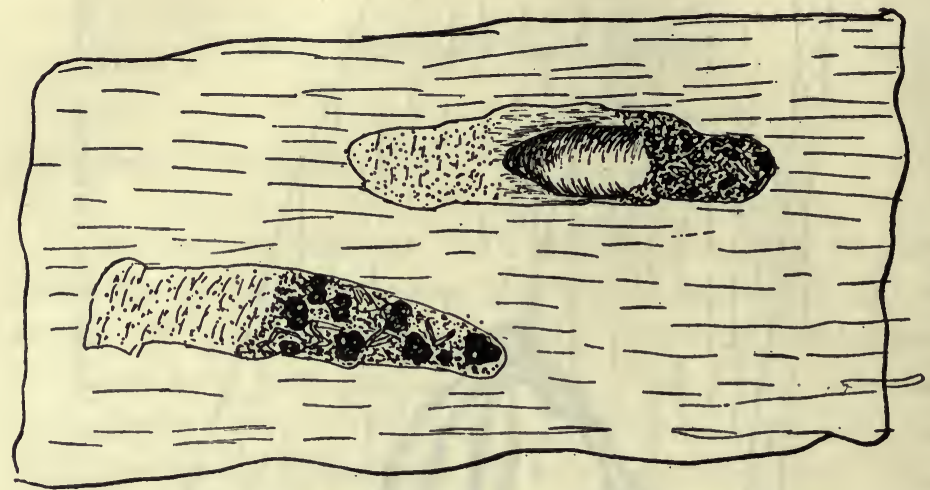

FIG. 22. Cells of Hypocrabro stirpicolus, having the remains of the feast and the cocoon in one cell.

dexia sp. [C. H. T. Townsend], Achaetoneura sp. [C. H. T. Townsend], and Solva (Xylomya) pallipes Loew, [F. Knab].

Since this species is elsewhere known only to use brambles for a nesting-place, it is indeed surprising that this one should have so skillfully adapted the old tunnels in the log for her use. In the stalks, of course, there is no lateral space for individual variation in the nest; so it is all the more remarkable that in this exceptional nest so much good adaptation was applied, by making cells ramifying from one main burrow. Furthermore, this nest was constructed horizontally, while all other nests recorded have been in upright stalks.

On one occasion an elder twig was broken off and examined for twig-dwelling insects, but it was unoccupied. In less than five minutes we passed by this spot again and 
found a $H$. stirpicolus boring into the soft pith. It had in this brief time made a hole one-sixth inch deep. Another was found still at work burrowing in the pith at so late a date as October 25.

One fine nest in an elderberry twig was found in November. The burrow in the pith chamber was thirteen inches long and one-fourth inch in diameter. The gallery was not at all points in the center of the stalk, but oscillated from side to side. Perhaps the wasp in digging it out had merely followed the line of least resistance and had chosen the softest spots. The partitions were made of the soft pith firmly packed together. The thickness of the partitions and the length of the cells were variable, as the following table shows :

$\begin{array}{lclc}\text { Partition. } & \text { Cell. } & \text { Partition. } & \text { Cell. } \\ \text { I } 3 / 8 \text { inches } & 3 / 8 \text { inch } & 3 / 8 \text { inch } & 1 / 2 \text { inch } \\ \text { I inch } & 1 / 2 \text { inch } & 1 / 4 \text { inch } & 3 / 8 \text { inch } \\ 1 / 2 \text { inch } & 3 / 4 \text { inch } & 1 / 2 \text { inch } & \\ \text { I/4 inch } & 5 / 8 \text { inch } & & \end{array}$

The upper five inches of the tunnel was open and unused. All the six cocoons in the cells rested with the heavy end toward the bottom, leaving the thin, easily opened covering on the top. We do not know, however, whether these wasps habitually emerge by boring through the side of the twig, or by struggling through the pith to gain the top exit. In another series of cells in a twig eight inches long, the partitions in the upper half were broken and crumbled, as if the occupants of the nest might have escaped by that way. Of course, if they emerge by the open, upper end of the stalk, the priority of the lower inmates offers difficulties. These nine adults emerged during our absence, from April 12 to 28. Another neat nest very similar to this is illustrated, exact size, in fig. 23. This had fourteen cells and eleven 
cocoons. The cells varied in size from 2 to $6 \mathrm{~mm}$., and the cocoons fitted nicely into them. There was no fly débris remaining; every evidence of the feeding proclivities of the tenants was gone.

Packard $^{1}$ says that they avail themselves of plants whose stem has a pith which they can readily excavate, and Cresson $^{2}$ found their nests in blackberry stems. The Peckhams found that this wasp uses the stems of plants; in fact, this is the famous insect that worked for forty-two consecutive hours with only a ten-minute intermission. They found all tunnels of this species to be from thirty to forty centimeters in length, and the completed cells contained flies of four different species, all dead. Our notes show that the species uses various species of flies. Perhaps Packard was mistaken in stating that the females of stirpicolus provision their nests with caterpillars, aphids, spiders and other insects.

Cresson $^{2}$ says that the Hymenopteron Diomorus hatched from the nest of $H$. stirpicolus.

Hypocrabro chrysarginus Lep. [S. A. Rohwer].

A log of wood was lying on the ground, and just beneath it a heap of fine sawdust. This cone-shaped mound pointed to a hole in the log directly above. Presently a black-andyellow $H$. chrysarginus flew into this hole and remained therein until we lost patience. Among the sawdust on the ground were four flies, apparently dead but quite fresh,

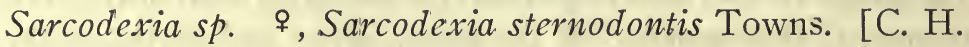
T. Townsend] and Anthrax lateralis Say. [F. Knab]. There was no way of determining whether the wasp had dropped them as she entered the nest and had abandoned

${ }^{1}$ Guide to the Study of Insects, p. I58. I889.

2 Psyche 2: 189. 1878. 
them, or whether she had left them here only as a relay station in bringing in the food. Since the wasp gave no promise of coming out, we opened the log and got her. The entrance-gallery pierced the hard wood for one and a half inches. It had evidently not been made by this wasp, but must have been cut by some beetle during the life of the tree, because the wounded surface was all healed over. Where this previous burrow had reached the rotten wood beneath, the wasp had continued the gallery. The length of this tunnel was seven inches, not exactly straight but oscillating a little, while following the same general direction. The tunnel came to an end and a little to one side of the terminus was a completed pocket containing four flies, 3 오's and I $\delta$, of Promusca domestica L. [C. H. T. Townsend].

Neither egg nor larva was found and we could not tell, upon rudely chopping open the log, whether this cell was connected with the gallery, or even whether it was sealed. We suspect that the wasp was only storing this cell.

Barth has found this wasp nesting in an old log in company with Crabro obscurus, $C$. montanus and $C$. sexmaculatus. The adults are nectar feeders, as recorded in the papers of Banks and Robertson. All of these records appear under the generic name Crabro.

Paranothyreus ${ }^{3}$ cingulatis Pack. [S. A. Rohwer].

In a steep, sandy bank, perhaps fifteen feet wide and twelve feet high, near the margin of the lake, was a fairly large colony of these black-and-yellow wasps. There was no vegetation on this sandy area (fig. 24), but at some recent time a large pile of straw had been dumped and

${ }^{3}$ The generic names of this species were formerly Crabro and Thyreopus, fide Rohwer. 


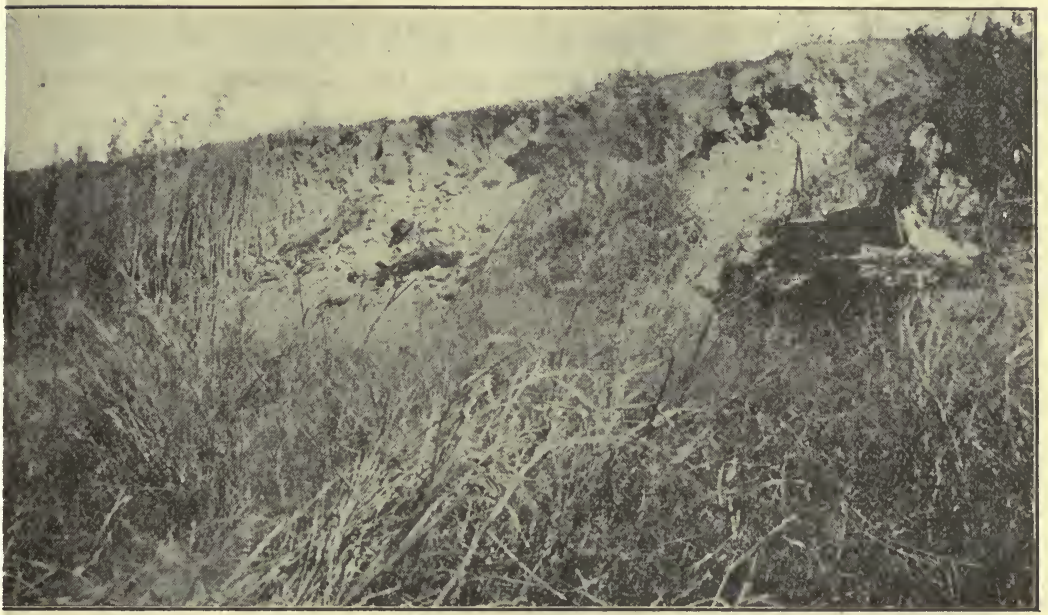

FIG. 24. The bare portion of the sand bank was inhabited by Paranothyreus cingulatis.

burned there. This is mentioned merely to show that the smoke and flames had been unable to put the insects to rout. A survey of a large part of the shore revealed no other colonies of these wasps. While the community was large, nothing in the way of communal life could be discovered. Each wasp conducted its own home independently.

The open holes were conspicuous because of their form. While the burrows themselves were round, the entrance was shaped like an arched dourway with a flat bottom, and was one-eighth inch larger than the inner hole. The wasps were coming and going, each bringing a Dipterous morsel under her abdomen, darting into the hole with it, without stopping at the entrance or leaving it at the doorway until an examination of the interior could be made.

Several of the wasps were enlarging their nests. The method was to bite out and loosen the sand, and rapidly kick it out under the body, through the doorway, where it 
rolled down the slope below. When biting out the earth from the sides or ceiling of the nest, they turned around, sometimes quite upside down, and the abdomen squirmed as they forcibly attacked each bite. In many cases the nests were under, and sometimes concealed by, a little natural hood or projection of the earth (fig. 25, burrow in the upper left-hand corner).

The nests were found, when excavated, to be of various shapes. The accompanying illustration will give an idea of the diversity of form and their general nature (fig. 25, onefourth natural size).

We have never seen lateral cells directly connected with these channels, but have often found from two to eight isolated cells near by. Perhaps they had been made as branches, but when the short, lateral galleries leading to them were closed, the connection could not be distinguished in the sand. Whether or not this wasp digs a long burrow and makes several cells from the main gallery, we cannot say with certainty. In nests excavated later the cells were sometimes found to be so numerous that we could only suspect that other wasps were responsible for them. The burrow in all the nests was about one-eighth inch in diameter, and the entrance one-quarter inch wide. When the mother was found within, with some flies at the bottom (showing that the nest was being provisioned), it was seen that no perceptible chamber or cell had been excavated, but the completely filled and closed cells which we came upon in the sand were of very pretty oval form, one-fourth by one-half inch. In one such case we found fourteen flies forming a pretty heap, all piled up like cord-wood, one atop the other, all with the head laid in the same direction. In two other cells close together, twenty flies each were taken. Others contained from eleven to twenty flies. All of the flies used by these wasps were Paralimna appendiculata 
Loew. [F. Knab]. All which we took from the nests or from the wasps in transit were dead.

The following week we again visited Creve Coeur Lake and further studied the contour and contents of the burrows. It was strange that, in one mass of homogeneous material like a sand-bank, with no roots, stones or other

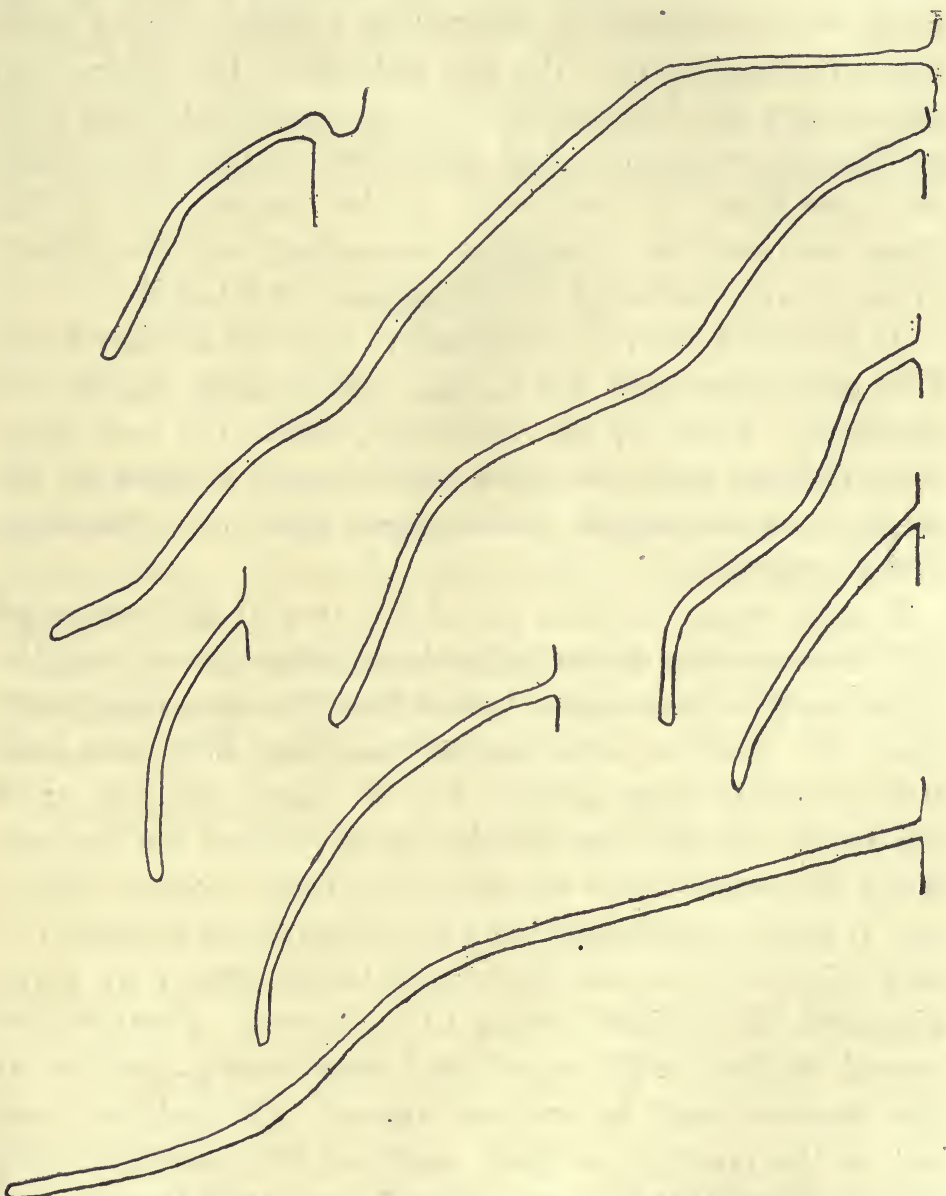

FIG. 25. The burrows of Paranothyreus cingulatis. One-fourth natural size. 
obstructions, no two burrows were alike. Of course there is some reason for Philanthus and Xylocelia metathoracicus making a tortuous gallery in a clay bank which is full of rocks, roots and rubbish; but here this extreme variety in habit makes one think that either there is instability of the species, or that so far as natural selection goes this point is of no consequence to the species; hence a fixed habit would be superfluous. We like to think of the staple form of nest that all Ammophila pictipennis make as being fixed by Natural Selection-that this form of nest is in some way best fitted for the needs of the species-but in this group no form has a particular advantage over the others, so none are eliminated and thus none is selected.

At noon (October 2) the mothers were all in their holes. This may have been due to the cold autumn nights and mornings. Later in the afternoon, when the sun shone more directly upon the bank and warmed it, two of the wasps were carrying in flies, hugging them under the body in the usual way.

In many cases we have found the prey at the bottom of the burrow where it was being deposited as it was brought in, but we have been unable to find out if the wasp completely closes this burrow after the cell has been filled and then makes another long burrow for the same purpose, or if she makes and fills one chamber at the end of the burrow, closes this and extends the burrow to form another, and so on. It seems improbable that a new channel can be made for each cell, for in the two days spent in this colony we never witnessed the surface closing of a burrow. Furthermore several finished cells were found suspiciously near to an open burrow, and, in one nest opened, one such cell was just at the point of a sharp angle of the burrow, which would indicate that they are dropped down from the tunnel.

One interesting item about this species is the tenacity 
with which they cling to the fly. We have caught them in a test-tube, and only with the hardest shaking could they be induced to relinquish their hold. At the time when we were afield we never thought of the probability of their holding the fly by the aid of their sting. The figure (26), drawn from a pinned specimen which was placed in the cyanide jar with the prey and later shaken loose, shows clearly the position of the abdomen and sting, and reveals how it is possible for the fly to be carried on the under side of the body, with the curved abdomen and sting holding

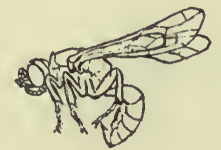

FIG. 26. Paranothyreus cingulatis. + . Twice natural size.

the prey like a hook. This detail, however, needs further clarification. Parker finds that a near relative, Oxybelus quadrinotatus, enters the nest with the fly firmly impaled upon her sting.

The only biological note on this species is recorded from Washington State by Kincaid, ${ }^{4}$ who saw it flying about clumps of Lysichiton kamtschatinse.

4 Ent. News II : 358. 


\section{CHAP'TER IV}

\section{The Enemies of the Plant-lice}

Xylocelia metathoracicus ${ }^{1}$ Mickel. [S. A. Rohwer].

The picture herewith (fig. 27) will give the reader an idea of the physical features of the site of the only colony of Xylocelia metathoracicus which we have observed. This perpendicular bank, six feet high, was the side of a gully which had been washed through a vacant lot by many rains. The wall at this point faced directly southward, where the sun beat down with burning glare, and not a breath of breeze could enter the hole walled in by dirt and tall vegetation.

On September 3 we came here in quest of large game, but found instead a swarm of these tiny black wasps dancing in the sun on the face of the bluff. We were startled to find them here in so great numbers, for none had been in evidence when we had visited the place only the week before. At that earlier date, however, in digging out a Philanthus burrow in this same bank, we had exhumed a tiny cocoon from which emerged one of the $X$. metathoracicus, the first we had ever seen. This one incident leads us to think that the normal time of emergence of these wasps was September I, and that the entire population had come forth at this

1 This wasp has been only recently described by Mickel, Ann. Ent. Soc. Amer. 9: 349. I9I6. Mr. Rohwer writes that Xylocelia is the correct name for Diodontus in the Pemphredonini as treated by Fox. 


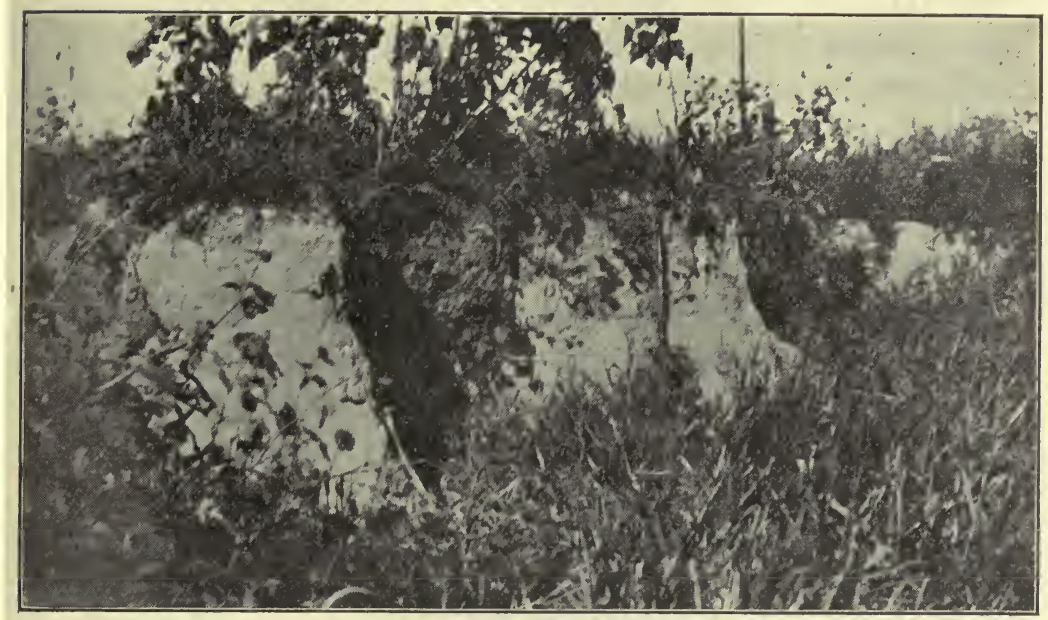

FIG. 27. The clay bank where Xylocelia metathoracicus build their burrows.

time, in the same manner as Bcmbix and other wasps, to participate in a sun-dance at the opening of their season of activity.

They did not wander far from the general region; neither did they keep in a strictly defined swarm as some insects do, but wavered lightly and leisurely to and fro in front of the face of the bank. As they hovered and flew they always kept their heads toward the wall. Occasionally they sat down at the foot of the bank to rest and rub their abdomens. Frequently, while one was resting thus, another dashed down and bumped against it, or pounced upon it and stirred it into flight again. Only twice on these occasions did we see real matings accomplished. One mated pair on the wing was soon lost to view; the other remained in copulo, the male surmounting the female, for five minutes before we lost sight of them. The pairs seemed to be equally at ease walking, resting or flying. While at rest, 
however, they were disturbed frequently (eight times in one brief resting-period), by other males eager to mate.

Presently we realized that the size of the swarm (or rather colony, for it was not unified enough to be called a swarm) was gradually diminishing; occasionally one wasp would alight on the bank and slip quietly into a tiny hole, so small as to be almost imperceptible. The holes must have been of their own making, for they were so neat a fit for the insects and of a very uniform size. We dug out some of them to a depth of two or three inches, but at this early date found no nest. They usually slipped into their holes without any confusion, alighting on the very spot where the opening was. Sometimes they almost flew into the burrow.

Their flight was a lazy, droning flight, poising and wavering to and fro in the air more than dancing. It all seemed the more wonderful because the wasps, burrows and all were so tiny; the adult wasps were only a little larger than gnats.

The foregoing observations were made between I I and I 2 o'clock; it was $3 \mathrm{p}$. m. when we returned to the place the next day. By that time the wasps were behaving not at all as they did on the first day, but this difference may have been due to either the hour or the day. Other wasps which indulge in these sun-dances in the morning of their lives usually dance only in the morning of the day, and then turn their attention to more serious occupations after the second or third day and in the afternoons. (See account of Bembix nubilipcnnis). It may well be that these wasps were already in the second or third day of their existence when we found them.

On this day mest of them, when they approached the bank, would fly into these burrows. The apertures were temporarily closed from within, and the wasps spent only a few secouds there, when they would come out and fly away. 
The holes were quite inconspicuous, and they were perceived only when the wasps entered them. If the openings were as inconspicuous to their enemies as they were to us, there was little need for their closing them.

None of these wasps seemed to be making burrows. It is possible that these were the holes from which they had originally emerged. We see no reason why they should not serve perfectly well as places of nidification as well. To be sure, the wasps may have dug them before they were discovered, but we saw none of them digging at this time.

On the second day, instead of dancing or digging, all were busy carrying in prey which consisted of aphids, Aphis setariae Thos. [J. J. Davis]. These they carried in their jaws. The wasps clung tightly to their booty, and even when taken in a test-tube and violently shaken they would not release their hold.

The bank was of "made" or "filled in" ground, with pieces of glass, crockery, cinders, etc., strewn thickly through it, so it was impossible, at this stage, to trace out the delicate burrows to the end; but some that we followed for a distance showed that they were usually very crooked and gradually wandered downward in their course.

From time to time, until the end of September, we visited these tiny black wasps in the dirt bank. While they continued plentiful, they were by no means so abundant as they were on the first day, when they performed the sun-dance. This might have been due to the elimination of the males. The specimens present later and those entering the holes were all the larger ones, probably females, and at no time did we again find the mating behavior; hence we suspect that $X$. metathoracicus mates once for all time.

Approaching autumn did not seem to cause their industry to wane. On October 6 many of them were out. They were all females, coming and going busily at their nests, 
carrying aphids as usual. No males were present, and the sun-dance seemed quite forgotten. The dance is no doubt a sign of their having just emerged, so probably the date we have recorded for that event might be accepted as approximately the date of the first appearance of this species.

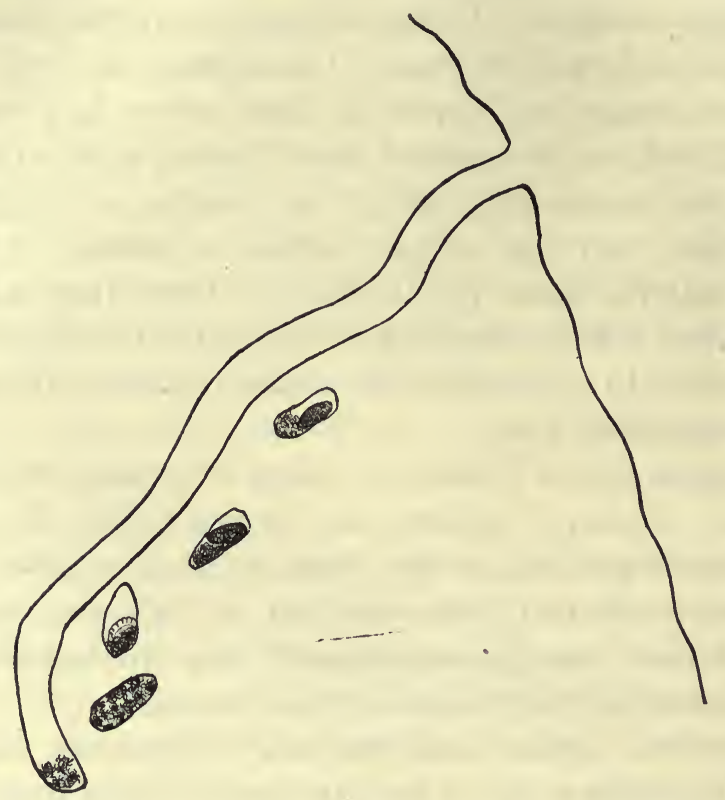

FIG. 28. The burrow and cells of Xylocelia metathoracicus. Enlarged.

We succeeded at last in tracing one hole to its terminus. The opening and gallery were about three $\mathrm{mm}$. in diameter. The channel was tortuous, owing partly to the rocky condition of the soil, and its total length was less than four inches. At the bottom of the gallery (fig. 28) were four aphids. Doubtless the mother was carrying in prey when we intruded. A short distance to one side in the earth was a little cell, sealed off; this was completely packed with fortyeight aphids, all of the one species, Aphis setariae. They 
were all dead. It was with difficulty that these delicate organisms could be removed, and if the minute wasp-egg was among them we failed to notice it. Just above this was another cell, also disconnected, containing a full-grown larva, but the food-supply had been exhausted. Still further up, in line with the gallery and nearer to the opening, were two cells, evidently older, since in them the pupal cases were already spun.

Hence we see here that the wasp probably uses one tunnel throughout its life, and that it digs a little channel turning sharply downward at the end, fills the end of it with prey and an egg, seals it up, thus forming a cell, and continues the burrow further into the earth in such a way that the little cells are always dropped beneath the gallery. Thus, as we progress inward, we find the young in earlier and earlier stages of development. As the season advanced these galleries and the row of subjoined cells became more nearly complete, while the mother continued, at least in several marked holes, to work in the same nest week after week.

Until the middle of October they were industriously at work on every day that was warm enough for them to venture out, and even on November 3 several dared to come forth as if attempting to continue this work.

No notes on the behavior of this species have been published. A moment's comparison with the ways of allied species may give the reader a more comprehensive idea of the ways of this group.

Westwood $^{2}$ says that Diodontus gracilis and D. corniger provide aphids for food for their progeny, carrying them in the mouth to their cells in the holes in posts. Morley ${ }^{3}$ finds $D$. tristis V. der Lind. flying to nests in sand banks.

2 Introduction to Modern Classification of Insects 2: 195. I840.

${ }^{3}$ Entom. 31: I4. 1898. 
Ashmead ${ }^{4}$ says $D$. tristis Dahlb. and D. minutus Fab. burrow in sand, while D. americanus Pack. burrows in hard clay and makes burrows of "considerable depth." On D. americanus, one of the "tiniest of all the wasps," the Peckhams ${ }^{5}$ have given us a very interesting account, and the only record extant heretofore of an American species of Diodontus. They find for this species that in most cases the aphids are killed by squeezing the neck repeatedly between the mandibles; in other cases the disturbance to the prey is so slight that they are able to walk about as soon as released. The wasp never uses the sting. The nests are in the ground, with some grains of dirt irregularly heaped around the edges. It takes the wasp about an hour to dig the nest; she carries the earth out in her mandibles and front legs, backing from the hole. The nest is not closed until the provisioning is completed. The number of aphids in each of six nests varied from five to forty, and sometimes the aphis served as food for the mother also.

Ceratophorus ${ }^{6}$ tenax Fox [S. A. Rohwer].

At Valley Park, Missouri, on June 26, we broke off an. elder stem and found this wasp in the hollow within. The lower portion was crammed with twenty-five aphids, Macrosiphum rudbeckiae Fitch [J. J. Davis]. The partitions were of the pulverized stem. It was $4 \mathrm{a}$. m., when dawn was just breaking, and we suspect this mother had spent the night asleep in her nest. Another elder stem taken near by had a few loose aphids of the same species in the top cells and two pupal cases beneath. On July 20, two adult $C$. tenax emerged from these.

4 Psyche 7: $46 . \quad$ I896.

5 Bull. Wisc. Geol. \& Nat. Hist. Surv. 2 : 99-106.

${ }^{6}$ Commonly known as Pemphredon. 


\section{CHAPTER V \\ The Bee-Killing Wasps}

Philanthus punctatus Say. [S. A. Rohwer].

The Philanthus punctatus is a faithful little creature, but her task of nesting is so prolonged that we have never been able to watch the entire process in a single case. By putting together the parts of the story as we have gathered them, we may be able to get some idea of this shy wasp's way of living.

We discovered one burrow, already begun, August I, at 8 o'clock. A lot of loose dirt was rolling down a tiny embankment by the roadside; the dirt was freshly kicked or pushed out, and we ascertained with a probe that the burrow underneath it went into the bank horizontally for about one inch. We could not remain with the wasp then, but the next morning we were pleased to find that she was still at work. A good deal more dirt had been pushed out. We knew that this must have been done very recently, because heavy rains during the night had tamped down the previous lot. That evening, too, when we passed by, we were certain that she was still at work.

Knowing that it would be impossible to watch her further, and desiring to know whether she spent the nights in her burrow, we dug her up. The hole went horizontally into the embankment, an inch below the surface level of the ground above, and toward the south for two inches; then 
it turned at right angles and went westward and downward at an angle of forty-five degrees, for ten inches, the course of the channel being broken at one point by a rather sharp kink, without any obstruction or cause that we could see. It then turned at right angles again and went directly down into the earth for two inches. Here, at the end of the tunnel, was the female $P$. punctatus, probably ready to spend the night. The monotonous details of the channel are mentioned here because it certainly was the crookedest one we ever saw in the work of wasps. No larva nor provisions were present-there did not even seem to be a terminal chamber-so we suspect that the burrow was still in course of construction. If this is only a part of her work, what must be the extent of her finished project! The entire length of the burrow was about fourteen inches, and after its many convolutions it terminated about eleven inches below the surface of the ground.

The burrow was already begun when we found it, and it seemed still to be incomplete; nevertheless, we know that the insect was at work digging for two whole days. The wasp is comparatively small, and when we think of the small burrows of some of her larger cousins, we marvel at the amount of work that she does. It is truly wonderful that this little creature should delve so deep into the earth to find safety for her offspring, which doubtless she will never see. Since the top of the hole is always covered with the loose dirt, and since she is never seen out-of-doors, we suspect that she keeps pushing the dirt upwards with her head and cut at the orifice, thereby keeping her house constantly closed to intruders.

Later in the summer, September I9, we found one insect hovering over her nest, which was temporarily closed. She seemed to be performing her flight of orientation, calmly poising in the air and deliberately swinging, pendulum-like, 
to and fro, in semicircles, with her head always toward the hole. The arcs or semicircles of her flight gradually grew wider, and suddenly, with a dash, she flew off across the field.

On the same day we found, on the firm, bald margin of the boys' baseball diamond (fig. 2), a little mound of very fine dirt, almost indistinguishable from a small ant's hill. It was neither of pellets nor of dust, but of dirt which was granular like corn-meal. A tunnel five inches long led down under this at a slope of forty-five degrees. The hole was not under the center of this mound, but under one edge; the dirt had been thrown out in a neat pile in front of the bore-not thrown about indiscriminately like the Bembix pile, nor carried to a distance like that of Ammophila.

We dug it out. The larva had just pupated, but was injured with the trowel when it was unearthed suddenly. The length of the burrow was about twelve inches.

In the same location, another $P$. punctatus flew about and settled upon a characteristic hill of loose soil. The wasp kicked the dirt from the opening, entered and closed the hole by casting up the loose dirt in the tunnel. She stayed in about ten minutes, came out head first by working her way through the loose soil, which fell in and closed behind her, covering the hole. She flew over the nest for a few seconds with a jerky motion (probably the flight of orientation) and then flew away. After some minutes she returned with a bee; this she concealed so well that we could not see it until we got down on all fours to watch her as she opened the nest. She kicked the loose soil away as she did before, and by close scrutiny one could see that she held the bee tightly to the ventral side of her body with the middle pair of legs, while with the first pair she dug out the dirt, and with the hind pair kicked it back. She remained within for about five minutes and left, after closing 
the hole behind her. But at this interesting climax the boys came romping across the diamond ready for their game, so we were obliged to relinquish the field to them.

For about seven days we had kept our eyes on another burrow and had known that activities were going on inside it, and a few times we had caught sight of the female or had seen some fresh earth thrown out. On September 24 we opened the hole and found its entire length to be about twelve inches. It followed a somewhat irregular slope of approximately thirty degrees, so the end was five inches beneath the surface of the ground. The mother was in the burrow. Near the terminus was a short branch gallery or neck, leading off at a right angle from the main channel; this led to a chamber which was oval and a trifle more than a half-inch long. This neck was snugly filled with soil, and the chamber contained a white pupal case and some heads and wings of bees. Another burrow of an identical general plan, although with the main channel a little more crooked (fig. 29), leads us to think that the mother Philanthus digs a long main burrow, then makes, near the end of this, a branch with a pocket which she provisions and seals, and that she then proceeds to extend the main burrow further, with a view to making more cells on the sides. If this species uses one burrow for several young, she is more economical than Bembix, which probably digs a new burrow for each larva.

Another of these nests was discovered on July 23. It pierced the side wall of a little depression, and a large quantity of loose earth lay scattered beneath it. One of us chanced to be near when the Philanthus came to her hole at 8:30 a. m., brushed out the loose dirt with her forelegs, kicking it backwards under her body in a way very similar to Bembix, and darted into the hole. Once inside, she 


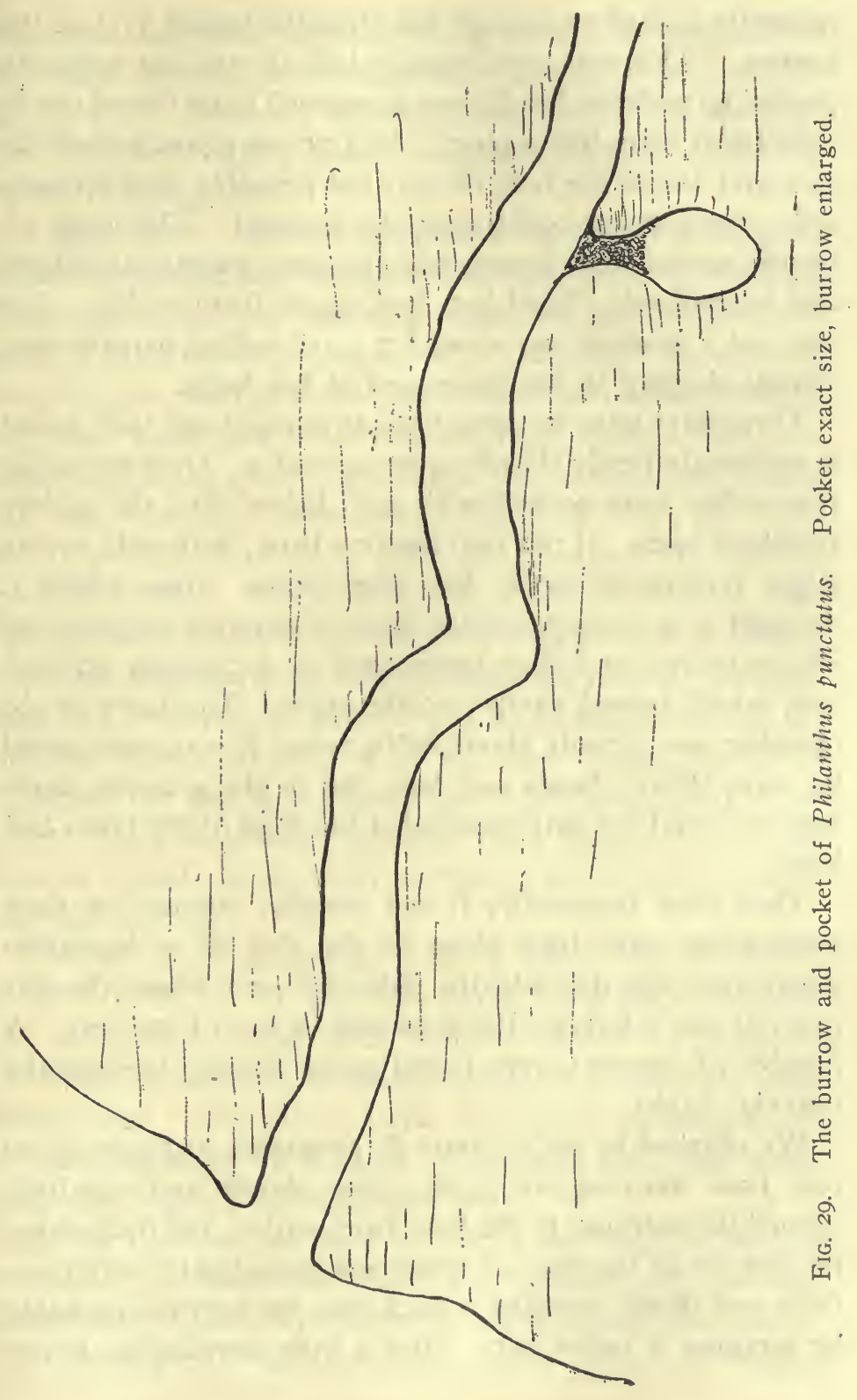


promptly pushed up enough soil from the tunnel to close the burrow. This was not roughly kicked out, but probably pushed up with her head, since it seeemed to be forced out in cylindrical form like a plug. At 2:30 we again visited the spot and found the hole closed; but probably only temporarily, for a probe could easily be inserted. The wasp returned and entered, in precisely the same manner as before, and immediately closed her door again from within. She was not a moment too soon, for a red-bellied parasite was already digging in the loose sand at her heels.

Three days later we came back at twilight and then found it apparently firmly closed, so we opened it. Only the upper few inches were packed with soil; below this, the gallery remained open. It ran into the tiny bank, with only a very slight downward slope, for four inches, after which it dropped at a steeper incline, about forty-five degrees, for eleven inches, and then terminated in a chamber an inch long which turned sharply to the right. The larva in the chamber was already about half-grown; it was surrounded by some débris, heads and legs, but in the growing darkness we could not determine what the food of the larva had been.

Thus they frequently, if not usually, choose for their nesting-site some little slope or the side of a depression where they can dig into the side-wall, and where the dirt cast out can roll down the slope and be out of the way. A number of burrows were found going directly horizontally into clay banks.

We chanced to see a sleepy $P$. punctatus just getting up one June morning at 7:20. She slowly and carefully opened the entrance to the hole from within, not by pushing the dirt out as she does on other occasions, but by very carefully and slowly working it back into the burrow, probably by scraping it under her. First a little opening no larger 
than a pinhead appeared, then this grew, as if by magic, until the round face of the Philanthus was quietly and intently gazing at us. Presently she slipped out through the opening; the loose earth lightly closed behind her and she flew away on the morning air.

$P$. punctatus seems to experience as little difficulty as Bembix in finding her nest upon returning to it. She alights from flight upon the very spot where her hole is concealed under a little mound of loose dirt. Only once we saw one in error; she entered a hole in the bank and came scuttling out, then tried once more and emerged again. Then she began digging at a spot right beside this hole and uncovered her own nest only one-quarter inch away from the other hole, the domicile of some other insect, which she had entered by mistake. It is little wonder, however, that she committed the error, when her neighbor's door stood invitingly open only one-fourth inch from where her own lay covered. Repeated observations have taught us to expect to find the mistress within the burrow if the door stands open, but if during the day it is closed, she is probably away from home. Since she makes chambers from time to time alongside her tunnel, she probably alternates the work of excavating and hunting.

The bees, Halictus sparsus Robt. $q$ [J. C. Crawford], $H$. versatus Robt. \& [J. C. Crawford], H. pruinosus Robt., and various other species of Halictus, which we found in the wasps' possession, in the burrows, or in the cells were always dead. We saw no marks of violence on them to tell. us the manner of their death. Ashmead finds that these wasps prey upon Halictus disparalis $\mathrm{Cr}$.

On one occasion we tried to offer a bee with the thorax crushed to a Philanthus which was finishing her burrow. Repeatedly we laid it at the mouth of the burrow, but just as often she carried it back and discarded it. A second Philan- 
thus did exactly the same, but when finally she returned to her hole with a bee of her own she seemed to become confused at the sight of ours lying there, hesitated and dropped her own and flew away.

The Peckhams have some very interesting notes on the stinging habits and general behavior of this wasp. They also illustrate a.nest which, in shape, is unlike anything we describe here. They find that the males of this species construct lodgings in the sand, and return to them night after night to sleep.

\section{Pseudanthophilus vertilabris ${ }^{1}$ Fab. [S. A. Rohwer].}

On the afternoon of September I6 a little pile of dirt, about two inches in diameter, appeared to have been newly excavated and lay covering the mouth of a hole. A P. vertilabris alighted on the pile, carrying an insect snug beneath her body, and walked about as if seeking a place to enter. She dropped her prey for a few seconds while she explored the mound; this gave us the opportunity to see that it was a little bee all yellow with pollen. She soon picked up her property again and, carrying it between her legs to a precise spot on the opposite side of the pile, began excavating and kicking the dirt up behind her, all the while keeping a firm hold upon her precious bee with her middle legs while the forelegs dug up the soil, and an instant later the hind legs flung it back. Her method of proceeding with her work seemed to be: after she had gone inside the channel, to leave her insect in the part of the gallery already cleared, retreat to the opening and kick out the dirt, go back and excavate some more and move the insect down to the new clear spot.

- 1 This wasp is gencrally known as Philanthus ventilabris or P. vertilabris: 
After a minute or two of this work, she came ont and began vigorously kicking in the soil. At this point we had to take her or run the risk of losing her identity. Upon opening the burrow, we found the top two inches filled in loosely and the remainder empty. The hole sloped downward at an angle of forty-five degrees, first toward the southeast for ten inches, then it turned west and then reversed sharply and went directly east. We could not accurately follow the sharp curves of the channel, but at the end were found a pupal case and a larva, both surrounded by bits of black chitin. It was one of the longest wasp tunnels that we have seen. It was little wonder that the abundant soil on the surface made a conspicuous mound. Is it then the custom of these wasps to continue using the same hole for several offspring? It certainly appears so, since this burrow already contained two babes of different ages. We do not know whether the bee which the mother wasp was bringing in was intended for food for the larva already in the' nest, or to be a host of another egg.

The Peckhams have a short note on $P$. vertilabris, wherein they tell how she takes bees of several genera and species into a ground nest. She carries her prey with her second pair of legs, and closes the door whenever she leaves the nest.

Robertson finds the adults feeding on the flowers of various species of Solidago. Packard figures this species in the American Naturalist, I : 77, I868, and his Guide, p. I 58, I885, where he mentions this as "our most common southward form."

The Peckhams tell us how $P$. punctatus males make holes in the sand wherein to spend the night, and we found a male of this species, $P$. vertilabris, hiding one evening at deep twilight, in the burrow of a cincindela beetle. 


\section{CHAPTER VI}

Some Mud-daubing Wasps That Hunt Spiders

Sceliphron (Pelopoeus) caementarium Drury.

In a former study ${ }^{1}$ of the contents of the nests of this species we included many items on the behavior of this insect. We present here a few notes on the biology of this species, not included in those pages.

We learned in the previous observations that the mother sometimes fails to supply sufficient food for the growth of the young, but we did not inquire whether the larvae could assimilate more than the normal amount of food supplied by the mother. The number of spiders most frequently supplied by her is six or seven. In the one case in which we experimented upon this point, we added three more spiders; these were promptly devoured, so we added one more. By the next evening this too was gone, so we gave the young wasp four more fat ones. Two of these were eaten, and the larva was found dead. Whether its gluttony produced its death we do not know, but in the five days it had eagerly consumed six extra spiders.

During the latter part of June we had the good fortune to discover three Pelopoeus larvae in the act of pupating. This enabled us to learn accurately the duration of the pupal period at that time of year. One of them emerged nine-

${ }^{1}$ Journ. Animal Behavior 6: 27-63. 1916. Also Journ. Animal Behavior 5 : 240-249. I9I5. 
teen days after pupation, and the others twenty-two days after spinning.

The Peckhams gauge the quality of the sting of wasps by the longevity of the victim, but in our opinion the size, vitality and species of the spider should be taken into account. The Pelopoeus or Chalybion may give a sting of standard size to all of her prey, regardless of their size. It remains unknown whether the larger spiders live longer than the smaller ones. We found great variation in the longevity of the spiders from one new Pelopoeus cell. The wasp's egg was still new and unhatched, so we knew that the spiders had not been entombed more than one day at most. On the day of discovery, August .II, they all moved their legs actively, but their vigor gradually waned; on August i9 the first one died, after having lived 8 days after being stung, and the other seven lived respectively 8 , IO, I4, I4, I4, 25 and 32 days.

Our actual observations have confirmed Peckhams' suspicions that the choice, tender abdomens of the spiders are first eaten by the young larva, and later, if there is need for more food, the legs are served for a second course.

A completely melanic specimen of male Sceliphron caementarium was seen getting nectar from the flowers of smartweed. When taken up in the hand, it pretended to attempt to sting by curling and passing its abdomen over the finger, much in the manner of a more formidable female.

One July day we were startled to see a Pelopoeus leisurely flitting from flower to flower, with the entire abdomen gone, only the basal segment remaining. She seemed lively enough, and just as happy as though she were all there. We took her home. The next day she appeared the same, but we could not see how she could escape misery, so conisigned her to the cyanide bottle. Packard ${ }^{2}$ records a female Pelopoeus

2 Psyche 2: 18. 1877. 
coeruleus that lived more than twelve hours after it was beheaded.

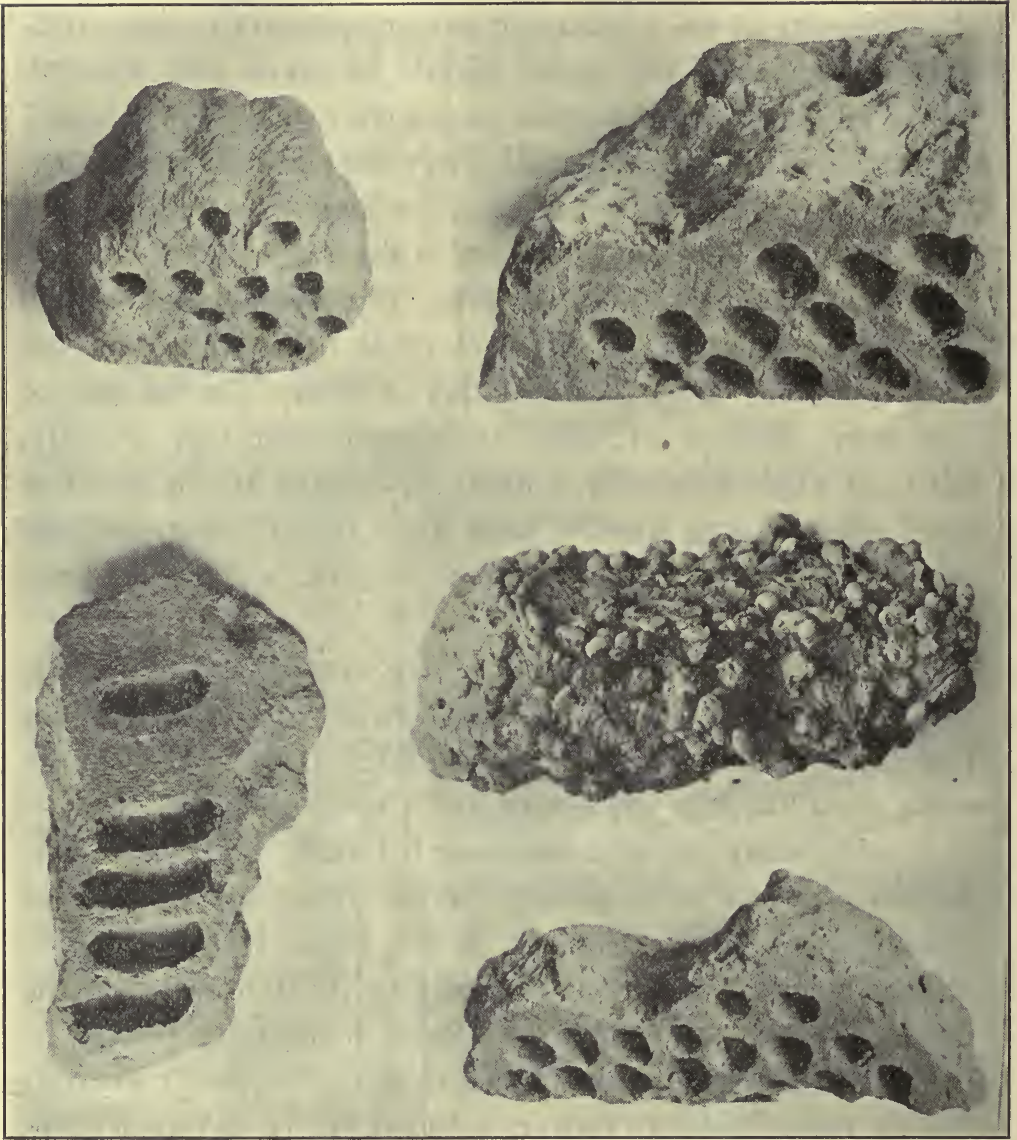

Fig. 30. Nests of Scclipliron cacmentarium or Chalybion caernleum. Interior and exterior views. Two-thirds natural size.

One often pictures the male wasps of this species as lazy, good-for-nothing fellows, while the females are incessantly busy, bringing in mud and spiders and making the nest; but 
the females too like to loaf sometimes. On September I6, I9I4, we observed one mother at work during the afternoon. At 3 : I 5 the cell was completed but unsealed and unfilled, and the wasp was bringing mud to reinforce the nest, by spreading it thin all over the outside. Up to 7 o'clock she was still thus occupied without paying any further attention to the unfilled cell. Until noon the next day the wasp was absent, possibly loafing. At 4 o'clock when we returned to the nest we found that the cell had been filled and sealed in the interval, but further work for the day had been discontinued. We watched for her the remainder of that afternoon and all the next day, but there was no return whatsoever to the nest. On the following day also we lay in wait for her, and were about to give her up as dead, lost or stolen, when she returned for an hour at midday and finished another cell, after which she seemed to consider herself deserving of another afternoon off. Unfortunately we could not watch her beyond this time, but we have often wondered if this was an unusually indolent individual, or if such is about the usual rate of progress of the work of these wasps.

The nests of this mud-dauber and those of Chalybion coeruleum are identical. Figure 30 illustrates the exterior and interior of their homes. Some nests show nicely the details of architecture (upper figure), while in others these details are obliterated by the decorations of mud pellets (see middle figure).

A six-celled nest of a $P$. caementarium was found hanging firmly to a root only two $\mathrm{mm}$. in diameter which ran along its longitudinal axis. It reminded us of the mode of attachment of the potter wasp's cell to the twigs of plants. This was the root of an overturned tree on the top of a sandbank; the soil was washed away from the roots, and on one of these strands of exposed rootlet this nest was very deftly 
attached. Since this root was so small, it must have required a great deal of deftness on the part of the mother to attach her first cell to it; of course with this one well anchored for a foundation it was easy to build the others. But if this sort of site was generally used by primitive caementarium - and this undoubtedly must have been necessary before. people provided them with barns and shedroofs-then we think, in those days of pioneering, a deal more of ingenuity was necessary than in the life of ease and convenience of today. Campers had built fires in the hole under the roots of the tree, and the smoke had blackened the nest, but this did not affect the contents of the cells.

On another occasion we found a four-celled nest hanging to a thread-like vine which grew into the shed through a crack in the wall. Despite the fact that there was hundreds of feet of board surface upon which this wasp could have built, it chose this frail vine. These facts, together with the fact that these nests have often been found plastered to nails protruding from the walls, on umbrella ribs, cornhusks and other unlikely places, suggest that probably the primitive instinct was to build in such places.

At Lake View, Kansas, a fine, large nest was being built on the outside of a schoolhouse. It was structurally complete but the mother was busy daubing mud all over it to strengthen it. In taking it down it became slightly broken, so we left it. The next day the mother had plastered mud all over the broken parts. Some would say: "A wise mother!"; but in this case there was, we believe, no wisdom or intelligence at all; she was daubing mud all over the nest at the time when the accident happened; hence nothing is more natural than that she should continue to spread mud all over the broken places as well. In our opinion it would have shown real intelligence if she would or could have interrupted her momentum of spreading mud all over the 
nest and constructively repaired, ring by ring, each injured cell. This she did not do. However, we once saw a case where, when the cell was broken while under construction, the wasp did repair it so. Here too it was probably instinctive work, as she was already occupied with the task of ring-making.

We have every reason to believe that Pelopoeus suffers at the hands of many impostors. The appalling toll of parasites has been reported previously. We find also, in the laboratory, that mice carry off mud nests or open them on the spot and eat the contents. One wasp was seen dead in a spider's web, and a second one was actually being devoured by a spider, Theridium tepidariorum Koch. [N. Banks]. The Peckhams say that this wasp goes in and out of spiders' webs for prey, and it is surprising that it should get trapped in the game.

Pelopoeus is, sometimes at least, a flower feeder. We have seen her eating at the flowers of iron-weed and a pinkflowered wild pea.

These wasps do not congregate at night, but sleep individually on the flowers. ${ }^{3}$

Their cocoons differ from those of their near relative, Chalybion caeruleum as illustrated in our previous note. ${ }^{4}$ Other life history details are very interestingly told by the Peckhams. ${ }^{5}$

Ashmead $^{6}$ writes that this wasp is distributed all over North America. Blackburn and Cameron ${ }^{3}$ find that this species, introduced by man's agency to the Hawaiian Islands, is now a common species. Cameron ${ }^{8}$ finds, too, that

3 Rau, Ann. Ent. Soc. Amer. 9: 227-274. I917.

4 Psyche 12: 62-63. 1915.

${ }^{5}$ Bull. Wisc. Geol. \& Nat. Hist. Surv. 2: 176-199. 1898.

${ }^{6}$ Psyche 7: 65. 1894.

${ }^{7} \mathrm{Mem}$. Manchester Lit. and Phil. Soc. 10: 233. 1886.

8 Proc. \& Trans. Nat. Hist. Soc. Glasgow II. I: 264. 1885-86. 
the specimens taken from the Marquesas Islands are identical with others which he has from the Sandwich Islands. Ashmead finds this species parasitized by two species of cuckoo-bees, Chrysis coerulans Fabr., and C. perpulchra $\mathrm{Cr}$. Robertson ${ }^{9}$ and Cockerell ${ }^{10}$ have written on its flower-frequenting habits. C. H. Turner ${ }^{11}$ has gathered some very interesting experimental data on the homing habits of this species.

Chalybion caeruleum Linne.

While breaking open the mud nests of these wasps at 9 p. m. on July $2 \mathrm{I}$, we were startled by a buzz. We traced the noise to our very finger-tips, and there in one of the cells we spied the insect's jaws protruding from the pupal sack; the young wasp was furiously biting an opening and all the while spitting much saliva about the point of attack. In less than five minutes the new fledgling was free and flying about the room in circles. We wonder if they sometimes normally emerge at night, or whether our rough handling caused the wasp to make its exit at this unexpected hour. It would be interesting to know, too, if the abundant saliva is of use in breaking down the heavy mud seal of the nest.

Howard, in the Insect Book, records the observation of Schwarz. He found C. caeruleum "was engaged in capturing a certain kind of spider which hid itself so carefully that it was most difficult to find. Instead of spending the time in fruitless searching, the wasp would entangle herself in the web of the spider, when the latter would immediately dart out from her hiding-place, thus exposing herself to the

9 Trans. Acad. Sci. St. Louis 6: 453. 1894.

10 Nature 48: 438. I893.

11 Biol. Bull. I5 : 215-222. 1908. 
wasp, who would easily free herself from the web and chase the spider to its retreat." We have never witnessed this method of almost human cunning and deception, but we are sure that not every wasp could easily extricate herself from the web, for in four instances, at different times and places, we have removed from spiders' webs the dead remains of C. caeruleum.

We noticed one $C$. caeruleum flying and buzzing from place to place on the barn wall. We lost her for a moment, but when next seen she had a small spider in her mouth and had her abdomen flexed to sting it. She alighted near by and it seemed she was turning it over and over in her mouth, perhaps eating it, or adjusting it for stinging. She eluded close watching, so we could not observe the details of her habits.

The season for C. caeruleum is long. The extreme dates on which we have thus far observed them cut were May 20 and October I3. They were seen in July and August, feeding on the flowers of Pimpenella.

A more complete account of the work and behavior of this wasp may be found in our paper on The Biology of Mud-daubing Wasps, ${ }^{12}$ with a description of the cócoon made by the larva recorded in a separate note. ${ }^{13}$ Figure 30 illustrates the interior and exterior of their nests.

These wasps, while they are solitary in their mode of life by day, are gregaricus at night, and congregate, night after night, at a chosen spot for the purpose of commingling in sleep. The full account of this strange habit may be found in our paper on The Sleep of Insects. ${ }^{14}$

12 Journ. Animal Behavior 6: 27-63. I9I6.

13 Psyche $22: 62-63$. I9I 5.

${ }^{14}$ Ann. Ent. Soc. Amer. 9 : 227-275. 1916. 


\section{CHAPTER VII}

Some Wasps That Prey Upon Beetles

Cerceris fumipennis Say [S. A. Rohwer].

A Cerceris fumipennis at Lake View, Kansas, had chosen a hard-packed highway for her nesting-site. The hole went straight down for about two inches and then turned at an angle. How far it continued we do not know, for the road was so hard that a trowel could not pierce it. There was a quantity of loose soil about the opening (fig. 3I). The wasp . was evidently digging the cell; she went in to dig for a little while, came out head first and dropped her load at the same time turning around to go in again, and so continued. When we crowded too close to see the details of her work, she would pause in emerging and hold her yellow face against the aperture as she solemnly eyed us for a moment, then slowly retreat and cautiously remain within for a long time.

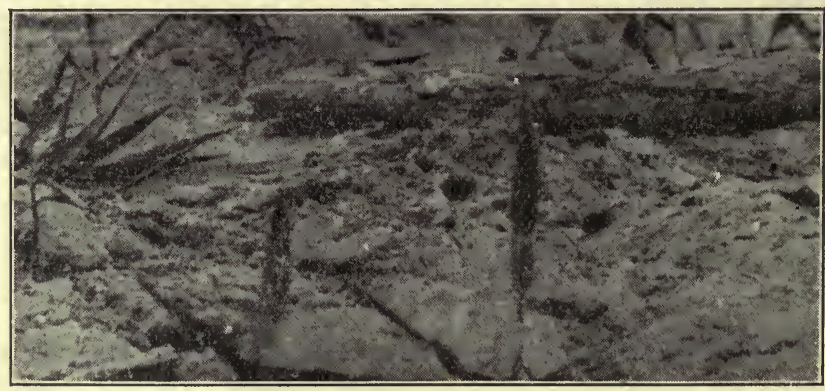

FIG. 3r. The mouth of the burrow of Cerceris fumipennis. 
A second, and a little later a third, wasp of this species attempted to enter this nest.

Another C. fumipennis, at St. Louis, alighted in a hole in the ground made by a peg. Immediately she began to bite the dirt in the side and throw out the soil thus loosened, all the while struggling to force her body into the new hole. From the time the bore was deep enough to admit hali of her body, she began working on the sides and top. In this task she twisted herself around to work from all directions alike, and sometimes turned herself completely upside down. While in these difficult positions, she would brace herself in a variety of skillful ways by pushing with her legs. . After only ten minutes digging, the hole was deep enough to conceal the entire body, and a pretty mound of fresh earth was accumulating beneath it. Probably her work progressed much faster in this case because the burrow was a horizontal one and the dirt was merely pushed out instead of being carried out load by load. She did her work so well that we were more than usually sorry to see her destroyed a few minutes later, under the heels of the baseball players.

We came upon another hole in the ground which stood open. It ran sloping into the earth, so that while the tunnel was about five inches in length the chamber at the terminus was only about three inches below the surface of the ground. The burrow, while it was open on top, was closed loosely with soil for about one inch, just before it reached the chamber. In the chamber were five beetles, all of one species, Argilus objectus Horn [E. A. Schwarz].

The site was badly torn up after we had finished examining it, but we decided to linger near and watch the spot for the returning owner of the nest. After an hour we discovered her digging, head first, into the earth that had been dug up, at the precise spot where her nest had been. Close 
beside her, almost touching her, lay another beetle of the same kind, the sixth one, which she had just brought in and dropped. The site was so thoroughly mutilated, with no entrance visible, that it was wonderful that she could recognize the spot at all, and far more so that she should persist in burrowing into the dishevelled earth in an attempt to reach the chamber. The appearance of the place was completely altered, and yet she unfalteringly delved into the heap of fresh earth at precisely the right spot to reach her old nest. Hence, unless the sense of smell was a factor, it was indeed mysterious how she could, without any reconnoitering, locate the precise spot in this large barren area.

To show how individual temperament enters into the homing problem, and how one cannot lay down hard and fast rules for the species as a whole by observing a small number of cases, let us cite the interesting notes by Hartman ${ }^{1}$ on the behavior of this wasp. He found one carrying a weevil (Conotrachelus neocrategi) into her nest which was situated on the edge of a five-foot embankment, under a bush about two feet high. The next day he returned and cut the bush off at the roots and placed it three feet to the right. Soon fumipennis returned and flew not to her nest but to the bush which had been placed to one side. "After discovering her mistake she flew away to get another start, came down again from between two trees and flew to the bush. Since she repeated this performance at least a dozen times without finding the nest, it is safe to conclude that it was the bush that directed her flight. Moreover the wasp always flew down from the same direction, showing that earlier in her course she was directed by other objects, especially trees."

1 Bull. Univ. Tex. No. 65: 66. 1905. 
The six beetles taken from our nest were watched over carefully, but no signs of life were visible, with all the usual methods of stimulation. The conclusion was that $C$. fumipennis kills her prey outright, although it might be possible that these beetles feign death when stimulated.

The Peckhams, according to Wheeler, ${ }^{2}$ find that other species, like the majority of European Cerceris, prey upon weevils, but that $C$. fumipennis preys upon a Buprestid beetle, Chrysobothris 4-impressa "which it kills outright," while Ashmead, ${ }^{3}$ citing Hubbard, says they provision their cells with Chrysobothris deutipes, and Grossbeck ${ }^{4}$ finds that they use three species of Buprestids for prey: Dicerca punctulata, Buprestis lineata and Chrysobothris floricola. He also says that their mounds resemble conical ant hills which are about two and one-half inches in diameter, the depth four and one-half to six inches, and there is no widened cell at the terminus. His statement, however, that at the bottom of some burrows paralyzed Buprestids were found shows that it is still an unsettled problem whether C. fumipennis paralyzes her prey or kills it outright.

Scolia dubia Say. [S. A. Rohwer].

While we had been examining Howard's Hill ${ }^{5}$ several times a week all summer, we had neglected to penetrate one small corner near the stables. Here we discovered Scolia dubia on September 15, 1915. Whether these wasps had come here late in the season, or whether they had been there for some weeks is not known, but this much is certain: if they had

2 Journ. Animal Behavior 3: 383. I9I3.

3 Psyche 7 : 60. 1896.

${ }^{4}$ Journ. N. Y. Ent. Soc. 20: 135. 1912.

5 A large tract of land situated in the southwestern part of St. Louis. 
been there for any considerable length of time, they had kept very close to their own particular habitat where we found them, for all other parts of the field had been thoroughly scanned repeatedly. Further observations will be necessary to show whether they disseminate over the field or keep strictly to a limited area of peculiar characteristics.

A strip of ground by the roadside, perhaps five feet wide, some twenty feet from the barn, was thickly overgrown with pigweed, smartweed and bulrushes. This ground sloped down into a depression which, at that time, was a stagnant mudhole. At the end of this strip was an old manure-pile covering a large area, partly overgrown with vegetation. Just above these plants and along the roadside a number of these wasps were flying. They were doing nothing in particular that we could see but flying idly to and fro along this strip of ground. Their flight followed a zig-zag course, in and out; they seldom rested, and, if one tried to follow them with the eye, they seemed to disappear among the vegetation, but one could not trace them. The wasps are very conspicuous in flight; their reddish abdomens with the two blotches of yellow on one of the segments make a brilliant showing. There were probably thirty or more of them in flight. We watched them for over an hour and saw only two of them sipping the nectar of the flowers of smartweed and pigweed, and one the snakeroot, but to them the sunflowers near by did not seem at all attractive. This strange flight could not have been a search for food, and we hardly think it could have been a preliminary of mating, since they did not seem to chase one another, although both sexes were present.

Again and again, on other days, we watched them in this vague, monotonous flight over the weeds; we watched in various kinds of weather and at different hours of the day. Sometimes there were more, sometimes fewer of them, but 
we have never been able to catch them doing anything that would explain the mystery of this lazy flight, with an occasional disappearance into the weeds. This place must have been in some way peculiarly adapted to their needs or liking, for while they were plentiful here they were never seen more than one hundred feet away.

Since they lingered persistently near stable-waste, and since Scolia's young are known to feed upon beetle larvae, we suspected they were there because the manure-heaps furnished the habitat for their prey. Examination of the manure heaps revealed hundreds of larvae, probably Cotinis nitida Linn., large, medium and small. A half-dozen Scolia dubias were also seen flying about in the same place. We spread the manure attractively and waited an hour, but saw none of the wasps oviposit therein. We took a large number of the beetle larvae home, hoping to rear from them adult $S$. dubias, but never found any evidence of their being so infested.

Many long vigils were spent at this place, but the summer came to a close without our having been able to learn one whit beyond mere conjectures of the reasons for their mysterious flight and their presence in this spot.

The following year we early began our watch around the site, in an effort to solve some of the mysteries of their presence there, but they did not appear until August r9. We could not tell whether they emerged $c n$ the spot, or came to it. This year as previously, they occurred only in the limited area where foul horse-bedding was piled near the stable. Most of the weeds were this year supplanted by sun-flowers. Here about the flowerheads were ten S. dubias, flying about in the same meaningless manner as before, resting occasionally for long periods. They have the greatest propensity for resting that we have ever witnessed in the wasp world. One flew about for only a few seconds 
and alighted on a leaf, and rested as long as we were willing to watch her; our willingness extended to one hour, and so likewise did her repose.

As the season advanced, the behavior seemed exactly the same as previously. During August the males and females commingled in the lazy flight to and fro over the manurepiles, but they did not pay any heed to each other. At one time during August we dug up the manure-heaps thoroughly, but then found no beetle larvae.

In September, only the females were present; thus it seems that in the species $S$, dubia, as in many other insect species, the males both appear and disappear in advance of the females. By this time some of the females had scarred and worn wings, showing that they had probably been active for a goodly time.

The majority of them were lurking about the oldest manure-heaps, that had lain undisturbed the longest time. Since, in previous experience, we found the beetle larvae only later in the season, we can only conclude here that these $S$. dubia were lingering about these promising heaps waiting for the larvae to become mature or abundant in order to oviposit, and that they felt so secure in the favorable prospects of the situation that they would not even go forth and seek other places, but waited.

We can find no literature on any biological aspect of this insect, excepting that Ashmead ${ }^{6}$ says: "Very little is known on the habits of our forty-four species of Scoliidae. They are parasitic on various scarabaeid larvae, mostly of the family Scarabaeidae."

${ }^{6}$ Psyche 7: 78. 1896. 


\section{CHAPTER VIII}

Some Wood-Boring Wasps

Cerceris finitima Cress. [S. A. Rohwer].

This little creature seems, in her behavior, rather paradoxical. We have three records, made in widely different times and places, of finding her digging in sand and entering holes in the ground in a very familiar way. From these observations we had just arrived at the deduction that she is a ground burrower, when we found one in the pith-chamber of a weed-stalk. This was open at the top, where it was broken off, and she was about four inches down. Probably she was preparing to make another cell, since one was already completed. This first one was composed of a layer of mud next to the pith wall, a chamber one-third inch in length containing a pupal case, and another layer of mud for a closing wall. Only ten days later, September 9, this pretty wasp emerged from this cocoon, thereby proving that the mother had been there by no mere accident. Despite the fact that the stem containing the pupa was already split open on one side, the wasp bored a neat hole on the other side by which to gain its exit.

Since some species of Cerceris use burrowing bees for prey, we may take the liberty of suspecting that she was foraging where we found her peeping into holes in the ground.

The adults are nectar feeders, fide Robertson and Smith. 
Trypoxylon tridentatum Pack. [S. A. Rohwer.]

A burrow in the pith-chamber of a certain elder twig at Lake View, Kansas, must surely have been an attractive resort-although inconspicuous to us-for it had evidently been used twice as the cozy domicile of insects.

The burrow in the twig was six and one-half inches in total length. It had evidently been made and used by another insect previous to the present one, for the lower three and a half inches was tightly packed with débris of the former tenant. At that point a mud plug was firmly fitted in to wall up this refuse. A little way above this was another mud partition making a cell three-fourths inch long, and a third plug was inserted to make another such room. There may formerly have been more cells-we do not know-for a mowing machine had cut the stalk off smoothly just above this point, leaving the gallery open. The neat little cells contained tiny cocoons. It was brought in from the field on August I, and on August I5 an adult $T$. tridentatum emerged.

Although this species was described in 1867 , no literature could be found on the biology of this wasp.

Silaon niger ${ }^{1}$ Roh. [S. A. Rohwer].

An elder stem with a little hole in the top aroused our curiosity. On opening it we found, in the pith-chamber, some small pellets of mud, a few bits of dried leaves thrown in promiscuously, and then long partitions with four cocoons at intervals among the débris of dried leaves, little pieces of mud, small stones and little pellets of excrement.

${ }^{1}$ This belongs to the family Larridae, and is the same as Niteliopsis in Fox's and Williams' articles, fide Rohwer. 
All were so small that only with the aid of a magnifying glass could we determine what they were.

In each case the cocoons were very brittle, and when an injury was by chance made with the forceps, the inmate walked out as if quite ready to emerge. They were all ready to come out into the light of day, but whether they would have emerged normally this season (the date was August I I), or whether they would have remained dormant to emerge the next spring we do not know.

We can find in the publications no biological notes on this species, and only very few on its near relatives. Williams finds that the sister species, Niteliopsis inerme Cress. ${ }^{2}$ made a burrow in a small area of bare, clayey soil and filled the hole with pellets of earth. "The tunnel was neat and round, almost vertical and one and one-half inches long and cohesively silk lined for half its length," which causes him to suspect that its original inhabitant must have been a spider. The bottom of the hole was not enlarged into a cell. It contained five immature green Hemiptera (Caspidae), one of which had a large egg secured at the cephalic end and behind the first pair of legs. On the authority of Rohwer, he states that $N$. fossor was taken with an Orthopterous prey, an immature Oedipode. We see varied behavior here, and the amazing feature is that one of its species should be twig-inhabiting, when the family Larridae is essentially a group with digging propensities.

Trypoxylon clavatum Say. [S. A. Rohwer].

While we have previously ${ }^{3}$ classified these wasps as tenants of the abandoned cells of the mud-daubing wasps, and we

${ }^{2}$ Kans. Univ. Sci. Bull. 8: 208. r 1913.

${ }^{3}$ Journ. Animal Behavior 6: 27-63. 1916. 
here illustrate the interior (fig. 32 ) of an abandoned cell of the mud-dauber partitioned and resealed and containing two clavatum cocoons, we have also long suspected that they adapt and use in the same manner the holes already made by other insects in logs and fence-posts. Knowing from our observations that she frequently makes her nest in old borrowed cells, our surprise was great when we found that T. clavatum can also deftly tunnel into wood and make her own burrow. This shows a greater diversity in activity than is often found in wasps. It is indeed wonderful that so high a degree of specialization should be associated with such diversity of accomplishments or habits as we find in this wasp.

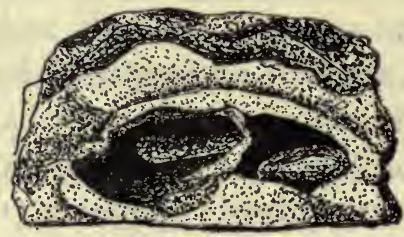

FIG. 32. The abandoned cell of a mud-daubing wasp remodelled to suit the needs of Trypoxylon clavatum. Pupal cases'in situ. Natural size.

They work when burrowing in a very characteristic and mechanical manner. Of course we could not see their method of cutting the wood, but they get their load of sawdust in the depths of the burrow, emerge backwards and fly away backwards a few inches from the mouth of the hole, hover or poise on the wing for some seconds until they drop the load, ofttimes going mechanically straight to the hole again, and sometimes turning the body slowly around and flying in a circle, which of course makes a very stiff and ungraceful movement, and then returning to the hole.

A number of these little wasps were found living, in a 
semi-gregarious way, in a wood-lot. While they were fairly numerous about the half-dozen long rows of cord-wood, there was only one spot at the end of one row where from five to eight individuals congregated at a time for play. They would fly about the top of the pile of wood at a height of five feet, chasing one another on the wing for an hour or so at a time, doing nothing in particular but to play thus in the sun. Both sexes were present, so we thought it might possibly be a coquettish behavior preparatory to mating. A certain scar on one of the logs, where a branch had been cut off, was the one and only place where they would rest. One at a time they would select this spot, ignoring all the similar ones at hand, and remain there quietly until discovered and put to rout by the others. The latter would chase her (it was usually the females who sat down to rest) back into the crowd. During the afternoon we saw five groups there, in turns, frolicking in the sun; but the behavior never varied, the location never changed, and the cut end of this one log never seemed to grow less attractive. Yet during all this performance we saw no attempt at mating.

Trypoxylon johnsoni Fox. [S. A. Rohwer].

For our knowledge of this species, we must depend largely upon mere surmise or regular detective methods. We have seen it active only once, when, at Lake View, Kansas, on July 27 , it entered three holes in a clay embankment. What its errand there was we did not ascertain, whether searching for a domicile or hunting prey.

A year later we got our next clue to her ways of living. A stem of some soft wood was found, near to the ground $7 / 8$ inch in diameter and $\mathrm{I} 3$ inches long. It had been hollowed 
out and contained mud partitions at intervals of $3 / 4$ inch, $\mathrm{I} / 2, \mathrm{I} / 8,2 \mathrm{I} / 4,3 / 4, \mathrm{I} 3 / 4, \mathrm{I}$ and $\mathrm{I}$ inch. There were also indications of former mud partitions which had been removed. There were also six holes in the stem along one side. These clearly showed, by their large, rough and asymmetrical form, that they had not been made by the insect emerging from the interior, but must have been made by a stout-jawed or -toothed creature from the outside. These openings were on the outside irregular and varied from $1 / 4$ to $3 / 4$ inch in length, while on the inside they were $\mathrm{I} / 8$ to $3 / 4$ inch in length. We can only suspect that a wood-pecker or some foodhunter of like habits had broken into the nest when it was first used, and devoured the occupants, and that thereafter this wasp rented the house in spite of the leaky walls. At the bottom of the cavity was a dried mass of spiders' legs and parts. Whether the mother wasp had filled the lower cell with spiders and then forgotten to lay the egg, or whether in renting and clearing the house she had shoved back all the débris, as does $T$. clavatum, we do not know. Since there were no shedding-skins or other rubbish with the spiders, it seems safe to say that these spiders belonged to the latest occupant.

Just above this compartment full of spider remains were two cells each containing a good pupa, which later gave forth adults of $T$. johnsoni.

Next above these was a solid mud partition or plug which was unbroken; this she had evidently put in for her roof. One of the side-holes had served as her doorway. It is evident that this had been the upper terminus of her nest, for this heavy partition was unbroken, while all those above this were perforated, as if the emerging insects had escaped by the top of the stem, and the upper cells were empty.

Thus, only by virtue of detective methods, but without having been a witness to the deeds, we suspect that this 


\section{WOOD-BORING WASPS}

wasp nidifies in a hollow stem or other cavity which she finds already dug out and which she repairs and partitions with mud, and that she probably uses spiders for her provisions. 


\section{CHAPTER IX}

The Hunters of Small Orthoptera

Alyson melleus Say. [S. A. Rohwer].

The experience of the summer's field work in different places has taught us to find these delicate creatures only in the peculiar environment that seems best adapted to their needs. We have never found them elsewhere than in a cool, damp bank of mud or sandy clay, near to a body of water. They may be very near to the dry earth or the hot, sandy areas, but they scrupulously avoid such regions.

The first ones that we found were at Moselle, Missouri, on June 30, I9I6. They were seen carrying green insects under their abdomens and entering holes in the mud bank. Their burrows were invisible to us because of a number of little wet pellets of mud that lay over the mouth of each hole, but the owners found their way in somehow. After the wasps were captured, the holes were exposed by brushing away the pellets covering them. Sometimes the little lumps, or rather shapeless mouthfuls of mud, were strewn or heaped, without any arrangement, over and around the mouth of the burrow; in other cases they were piled dextrously about the hole to form a crude little chimney or canopy over the orifice on the sloping bank.

Their little burrows were about one-eighth inch in diameter and went straight into the bank, at right angles to its sloping surface, then curved slightly downward. They varied 
in length from one and one-half to four inches; the few that we found completed terminated in a little oval pocket (see illustration, fig. 33), which was merely the end of the channel slightly widened into oval form.

We did not chance at any time to find a cell already filled

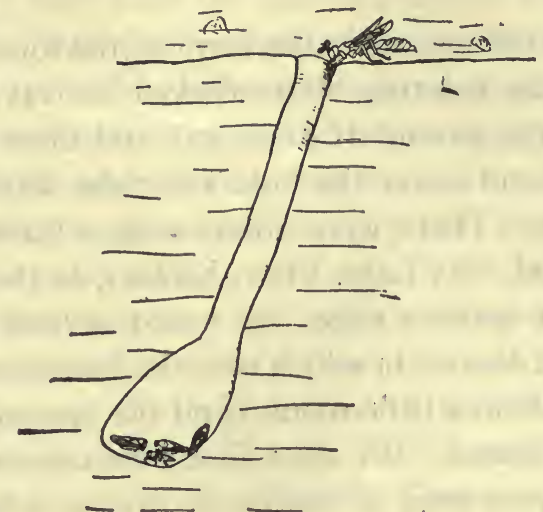

Fig. 33. Alyson melleus, her burrow and prey. Natural size.

with provisions at the end of an open burrow, but in the earth nearby we found, on more than one occasion, little cells whose connection could not be traced. These were the terminal cells of other nearby nests whose channels had been closed. The first of these isolated cells was packed tightly with a number of leaf-hoppers. There were about a dozen of these frail creatures, so delicate that we could not handle them everi with forceps, but with a straw we gently brushed them into a vial. They exhibited no signs of lifeand truly we cannot see how such frail organisms could survive even the handling of the wasps, much less their sting. Twenty hours later, when we examined the hoppers, which we had placed in a sealed vial, every one was shrivelled and hard, so desiccated that a delicate larva could hardly derive any nourishment from them. This discovery suggested a 
clue to the probable reason for this wasp persistently choosing a damp, cool place for her nest: only in such surroundings could the food be kept fresh and moist. The wasps continued to be seen during all of the season up until October 7 . in widely separated places, but always in permanently damp situations.

Some variation occurs in the form of the tops of the nests. At Moselle, the entering wasp worked its way between the pellets of a little mound of loose soil, and these would again fall together and cover the hole after the wasp had disappeared within. There were others with a little chimney or canopy of mud. At Lake View, Kansas, in the sand a few feet from the water's edge, we found several nests under scattered dead leaves, in which case the loose sand was piled behind the hole in a little mound and the opening was in the side of this mound. We even found two nests at the base of a hillside, very steep at this point, twelve inches above the level ground. Here the holes went in horizontally, at right angles to the surface, for a little way and then turned downward. Much loose soil had rolled down the steep incline beneath the orifice, and two beautiful canopies made by the wasps projected for one-fourth inch above the holes. We were surprised to find $A$. melleus in so dry a place as this was, but when we dug down to the chamber we found the earth very damp and gummy.

The group of them at Lake View, Kansas, on a plot of wet sand near the the lake shore, conducted themselves in a way that puzzled us. They were all running this way and that, with heads close to the ground, as if anxiously searching for something. They looked more like a group of large red ants in confusion than wasps. All this activity was confined to a space less than four feet square, and it went on for over a half-hour while we could remain to watch them, yet they did not find what they wanted. At one time one 
found a hole with a little mound of sand on top, but the opening was visible. She entered, and came out fifteen minutes later empty-handed. We opened the burrow and found that it went down for three inches into wet sand and ended abruptly. It may have been a nest which she was constructing, or it may have been the nest of another wasp. A little later, another was seen peeping into cracks in the mud. What they were so busy about remains a mystery.

At noon, none were in evidence, but at $5: 50 \mathrm{p}$. m. perhaps fifty were on the sand. This condition was noted repeatedly, that, unlike most wasps, which love dry heat and work chiefly at midday, these are seldom to be seen in the heat of the day but become most numerous and active at about $5 \mathrm{p} . \mathrm{m}$.

Their prey which we have thus far been able to confiscate has been of the four following species of leaf-hoppers: Athysanus exitiosus Uhl. [E. H. Gibson], Thamnotettix clitellarius Say [E. H. Gibson], Empoasca mali Le B. [E. H. Gibson] and Agallia novella Say [E. H. Gibson]. From four to twelve occurred in a nest.

There are in the literature no biological notes on any member of this genus, so far as we have been able to discover, excepting a paper by Hartman ${ }^{4}$ on this same species. Herewith are some of his details which show the similarity and diversity of the behavior of this species in two distinct and remote localities. He says that the nest of melleus is always left open day and night, the sand is loosened with the mandibles, scratched back with the forefeet and kicked out with the hind feet. The work of digging the nest is done at once, although some dirt is brought up from time to time after the provisioning has been begun. The prey, carried in. the mandibles, is a leaf-hopper, Tettigonia bifida Say. One specimen of melleus fell prey to a spider which was a perfect mimic of the sand. On digging out a nest he found it "to.

4 Bull. Univ. Texas 6: 4I-42. 1905. 
extend downward in a gentle slope for a distance of twelve inches to a chamber one-half inch in diameter," which contained seven leaf-hoppers.

Tachysphex terminatus Smith [S. A. Rohwer].

This energetic wasp goes about its nest-building in a manner very similar to that of Bembix nubilipennis. It digs in sandy places; it attacks a spot furiously and digs down rapidly with the forelegs, flinging the dirt out under the body and behind it. Occasionally it backs out of the hole to sweep back the accumulating sand in front of the door. It seems to have little difficulty in digging in sand; the work goes on quickly and somehow it contrives to keep the roof from falling in. We have watched many Bembix spinolae commence holes, work them for three or four inches and then abandon them, but not so with this species; where she starts work she holds her own and seldom changes her mind. There are exceptions to this rule of course. We saw one attempt twelve different holes in a small area where our footsteps had already loosened the sand, so of course her roof would not hold firm; but as soon as the roof caved in she would start in another place. This however was not the fault of her careless work or her fickleness.

They dig with remarkable speed and skill when working in sand, and contrive to make a simple but shapely burrow; but when working in harder soil or clay, they dig very differently. We presume this difference in habit is due to the difference in soil, and not at all to the locality. The sand diggers were not more than forty miles distant from the clay diggers. The latter which we observed seemed just as intense in their work as those just described, but seemed to experience more difficulty in accomplishing their 
task. ${ }^{5}$ They would often begin digging several places in succession before they carried a burrow to its completion. They would usually begin to dig in some little depression or shallow hole, where their hard work was already begun for them. Here they kicked out the loose dirt and then enlarged the hole sufficiently to receive their stock of provisions. The resulting burrow was not of any definite form or dimensions, however, but of any shape and size that the wasp could best excavate in the hard earth. Sometimes her burrow was barely sufficient to get her ill-arranged mass of prey under cover. She attacked the hard soil in much the same manner as she would loose sand; hence it is not surprising that she was not very efficient here. She had no refined methods for smoothly cutting out the hard earth, as has Odynerus or Anmophila. May it not be that the habit of digging became fixed while the species inhabited sandy areas, and that her old habits hampered her when she wandered to a different environment and attempted to carry on her work by old methods?

The burrow, when completed, is merely a short, curving channel going into the sandy earth aslant; it is about three inches long and the terminus is about an inch and a half below the surface of the ground (fig. 34, slightly enlarged). There is no real pocket or cell. These wasps are very wary about the intrusion of human beings, so it is difficult to draw near enough actually to observe their ways without frightening them away. ,

The nest is soon prepared, and the wasp ready to begin carrying in the Orthopterous prey. When at last the nest is provisioned, she closes her burrow with locse sand in a way very similar to $B$. mibilipennis; she emerges kicking the dirt under her into the burrow and, after it is fully

${ }^{5}$ The Larridae, to which this wasp belongs, are diggers in sand. 
closed, takes great pains to kick plenty of loose sand over the hole to conceal it completely. When one proceeds to dig it out, one finds the sand so loosely packed in the channel that it can readily be tickled out with a grassblade. One mother carrying home her prey experienced some difficulty in finding the depression where her nest was located.

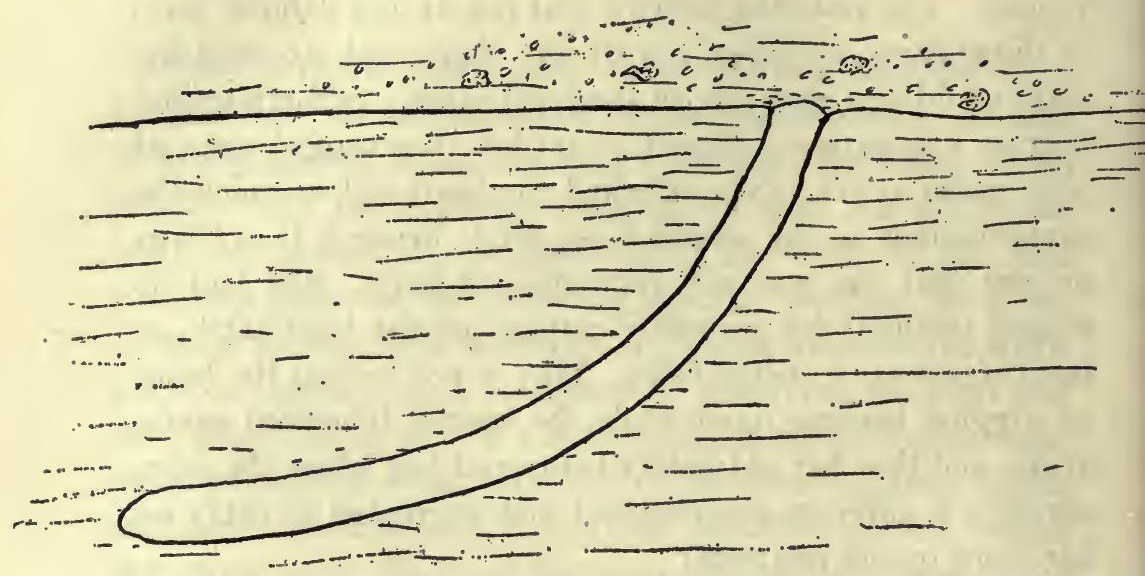

FIG. 34. The burrow of Tachysphex terminatus. Slightly enlarged.

She laid down her Orthopteron while examining spots on the ground, but would always pick it up when flying about getting her bearings; this she did several times (she seemed afraid to leave it lying exposed on the ground while she went far away), carrying it under her abdomen and flying swiftly and smoothly as though, she were not so laden and once, on the way, even engaging in a fight with a $B$. spinolae. At last she dropped her burden in the depression of her nest, kicked out a few strokes of dirt, entered the hole and dragged her hopper in after her.

For some time we had suspected that they build more than one nest in a place. We had been watching the progress of a certain nest for most of the day. Late in the 
afternoon, the work ceased and the mistress did not appear for a time. At about 6:30, however-at an hour when all honest wasps are abed-a Tachysphex terminatus, probably the same individual, was excavating a hole right beside this nest. Our suspicions of her identity were strengthened when she left the new hole, went to the site of the old covered one and for five minutes hovered directly over it, alighted and caressed it with her feet, then returned to her digging at the new burrow.

The next morning at $8: 28$ we found her already bringing in her first Orthopteron. She carried it on the wing directly to the hole, as before, laid it down on the brink while she kicked out the sand, went in and turned herself around ready to pull it in after her. She remained inside only onehalf minute when she came out, covered the hole with a few kicks of sand, and sped away on the wing. In barely five minutes she was back with another hopper and repeated the performance exactly, only taking time to shy off cautiously several times on account of the camera which stood focused a yard from her nest. When her pretty work was nearly finished, however, it came to a sad end. A $B$. spinolae had been regarding the identical spot as favorable for a nest, and when we came back an hour later, a good-sized B. spinolae hole occupied the space, and the eight fine green Orthoptera lay kicked out in the sun to dry.

On this the evening of the second day, it was cloudy and dark at $6: 30$, yet the plucky little wasp was digging only two inches away from her former nest, the one acquired by the Bembix. She seemed to be getting it in readiness for the morrow's provisions. It was too dark to work longer at $6: 45$, and the wasp must have completed her burrow or at least dug it to a sufficient depth, for she kicked some sand into the mouth of the channel, crept in between this mound and the roof and then completely closed the aperture from 
within. Thus she was ready to spend the night. And so our suspicions were confirmed that $T$. terminatus makes a burrow in the evening, sleeps in it that night, fills it the next morning and before evening makes another for her next night's shelter, and so on. The problem of where she sleeps at other times than in the nesting season remains unsolved. In digging in another locality, we accidentally ran across another series of five cells, one right after another and about one inch apart. This also lends strength to our belief that she builds a chain of nests. This may account also for the fact, which we have mentioned before, that she makes no flight of orientation; with so many nests in one locality she soon becomes so familiar with the region that she needs no special study of its landmarks.

The prey of this wasp is Orthopterous insects. They are usually of the species Syrbula admirabilis Uhl. [A. N. Caudell], small and medium size nymphs. In other cells, however, we found one Oedipodid nymph [A. N. Caudell] and one small Dichromorpha viridis Scud. [A. N. Caudell] nymph in the first stage, Acridean nymphs, and nymphs of Melanoplus sp. [A. N. Caudell]. From five to nine insects are usually used to provision a cell.

Whether or not there may be any color relation between the wasp larva and its food cannot be declared absolutely, but we were interested in observing that one young larva on a brown hopper was itself brown, while another on a green food was as green as its host. It has been suggested that this color is probably due to that of the juices of the insects consumed.

Sometimes the larva was found adhering to its foodinsect between the second and third pairs of legs, on the ventral side; in other cases they were on the under side of the neck where, in making their attack, they had promptly severed the head from the body. 
The hoppers, as a rule, survive the maltreatment of the wasp only feebly. Many of them, the majority of the small ones, are killed outright, while only the most vigorous survive a day or so, and they can respond but very feebly to stimulation.

Ashmead, treating of this species under the name of Larra terminata, finds that they prey upon Chortophaga viridifasciata; Williams took one of these wasps with a young Tryxalid. Banks finds they frequent the flowers of Ceanothus.

\section{Tachysphex fuscus Fox [S. A. Rohwer].}

It was late in the season for wasps to be active, yet this little grey $T$. fuscus was very busy on this morning of September 30. She flew to an abandoned building and alighted in the mortar between the rocks of the foundation. She had previously commenced her hole there; now she vigorously kicked back the loose mortar and it fell to the earth below. After about five minutes of this arduous work, she walked a few feet away and cleaned herself. Then she turned to another spot on the ledge of the foundation and began to dig in the loose soil lodged on this, kicking the fine earth backwards under her body, as she had done in the other instance. One large lump of something impeded her progress, so she snatched it up bodily, carried it some distance in her mandibles and threw it away; she then flew a few feet, sat dawn and cleaned herself again and presently started to dig anew, in the third place. After only a few seconds here, she moved again and commenced a fourth hole. It seemed that she could succeed in digging into only the stratum of loose dirt, and when she struck the hard 
cement she gave up the project and started anew. She worked away here for over an hour, kicking the dirt behind her and, as the hole deepened, occasionally coming to the opening and kicking it further back out of the way. She often emitted a sharp, squeaky buzz while she was intent upon her work in the hole. Two trains passing near by, though they made a great uproar as they entered a tunnel under the hill, did not disturb her in the least. When we returned in the afternoon we found that this hole, too, had been given up, and despite the long time and arduous work expended upon it, it was only three-quarters inch deep. We saw her no more.

A second wasp of this kind was discovered about noon of the same day, just commencing her burrow. She chose a strange spot, an ant-lion pit, at a point half-way down the sloping side of the funnel, and dug in horizontally. After having witnessed the astonishing persistence of the first wasp in working in the plaster of the old wall we had supposed that some similar site was absolutely necessary to their happiness, so we were surprised to find another. using so different a kind of place. Evidently $T$. fuscus is a versatile little creature. We longed to stay and watch her, but traintime was approaching, and the completion of the story had to be left for another time.

Tachytes obscurus Cress. and T. obductus Fox. [S. A. Rohwer].

This small $T$. obscurus was found struggling with a shorthorned locust. She mounted it and dragged it a few inches, grasping the hopper by its antennae. She tried to hold it with its back against the earth, but had difficulties in keeping 
her position against the wind. Finally she opened her wings and made an attempt to fly, whereupon we seized her and placed her and her prey in a vial, lest she should escape without our knowing her name. Still she clung to the hopper, even after this rough treatment, so we released her, hoping that she would proceed to her nest with her prey.

She resolutely mounted the hopper in the same manner as before; then apparently changed her mind and paused, still resting astride her victim, and calmly made a very complete toilet, cleaning her legs, antennae and abdomen. Meanwhile the grasshopper worked over on its side. Once more refreshed, the wasp seized the hopper and righted it, the dorsal side to the earth, and flew away. But she was flying against a strong wind with her burden, so it was not surprising that after she had gone six feet she lost it, seemed to give up the project, and sat down on a plant to rest. We must not be hasty in calling her faithless, since we do not know how long she may have been struggling with her burden before we chanced to find her.

Williams ${ }^{6}$ has taken this species once with her prey, a very small acridian.

A Tachytes abductus was seen to enter several holes in the sand, at Moselle, Missouri, on September 23, but pop right out again. She remained in one hole longer than usual; this aroused our curiosity, so we dug it up. At the bottom was a spider,Trochosa cinera F. [N. Banks]. It was probably no more than coincidence, since most of the members of this group of wasps use Orthopterous prey. For this species Williams says: "They frequent the muddy shore of the Solomon River in Kansas. A few were searching for immature Tettigidae. On two occasions the grouse locusts were small and easily borne on the wing."

${ }^{6}$ Kans. Univ. Sci. Bull. 8: 199. I913. 
Notogonidea $a^{7}$ argentata Bve. [S. A. Rohwer].

The appearance of Notogonidea argentata early in the spring has long puzzled us. On the morning of April 7, I9I5, we saw at Cliff Cave perhaps two dozen of them on the sunny side of the bluffs, apparently doing nothing in particular, resting, strolling or flying about in a sheltered spot in the sunshine. A little later in the day, we found the same behavior in a group in a sunny southern exposure. It was surprising to find them out so early, and we still wonder whether they had hibernated or had emerged so early from their original burrows.

But although they were seen thus in groups in the first days of spring, they do not continue the gregarious habit, but work singly during the summer months.

On July 25 we fell to watching one as she was walking and running in and out among the short grass along the roadside in an open field. She soon darted into a hole in a small sloping bank. The burrow was shallow, for we could see her little black-and-grey body only a little way beyond the aperture. As she worked, she occasionally pushed out the loose soil behind her and it fell out of her doorway and rolled down the miniature hillside. Presently she left her work in the burrow and walked to and fro around its opening; it was not long before we realized that she was not making her hole, but was at work filling it up. She did not try to put back the dirt that had been pushed out, because that had rolled down the slope, nor did she carry it back in her mandibles. Instead, she picked up pellets, fragments of stems, dried leaves, and any available débris that lay about, and dropped them into the hole. All of these she

${ }^{7} \mathrm{Mr}$. Rohwer writes that the name Notogonia by which this wasp is generally known has been changed to Notogonidea, since the former name has been used for mollusks. 
gathered within a radius of twelve inches from the nest. The great majority of them were taken from either the right or the left side of the hole, where she could work on the same level; a few times she brought a fragment from above the hole, but only once or twice did she attempt to bring anything from beneath the burrow. Occasionally she would tug away at something too large or too heavy for her, but she would soon let it go. She appeared nervous and discriminating, and seemed to have a hard time in finding just what she wanted. Fearing to lose her and her identity, we took her when the hole was nearly filled.

Upon opening the burrow, we had some difficulty in accurately following its contour because of the entanglement of grass roots. The hole seemed to be about two and onehalf inches deep. The lower third was a chamber containing three crickets of two species, Gryllus pennsylvanicus Burm. nymph [A. N. Caudell], and Nemobius fasciatus DeG. [A. N. Caudell]. Above this the gallery was all packed with soil. The wasp must have used all the available dirt for the hole at the time when we arrived upon the scene. Only the upper one-third of the bore was filled with débris. When we first opened the chamber and found the lively lot of crickets, we thought we had made an error and had broken into a crickets' nest. Soon we spied the wasp's egg, white and slightly crescent-shaped, fastened to one of the crickets where the leg joins the body, and curving around the right side until it was visible from the dorsal side. The crickets were active when stimulated in the legs, antennae and mouth-parts, and, while they could not actually hop. they could walk for a few steps when prodded. All three were males. In all probability the egg was deposited at about $2: 30$ p. m., but we could not tell whether it had been deposited on the first, second or last cricket brought in. By the next morning, they had all walked some distance from 
where they had been placed in the jar; even the one bearing the egg had wandered away. All responded actively to stimulation. By 7 o'clock of the second morning, the egg had hatched, even though its cricket host was still persistently active. The larva was a delicate little yellow creature, not very fat. In spite of its small size, it was a little gourmand, and, by the second day of its life, it had devoured almost all of the first cricket. The other two crickets were still alive and we wanted to keep them to test their longevity, so we substituted for them another and larger specimen of the same species. We crushed its head before placing it with the larva, lest by its activity it might do some injury to the latter. By 9 o'clock that evening, the larva had devoured the contents of this one also, leaving only a thin, dry shell. The infant grew well and seemed to thrive on this, so that night we gave it another newly-killed cricket of the same kind. This one was larger than the others - almost full-grown - so, lest the integument would be too tough, a few incisions were made in the abdominal wall before serving it. The larva was placed thereon and it fell to at once, greedily devouring the juices. By this time the smaller cricket, which had constituted the original prey, had grown quite feeble, but the larger one was still active.

With the introduction of the last cricket, the larva had had three, the number originally provided for it by its mother; but two of these were much larger than those which she had supplied. We did not presume to interfere further with the mother's provision by offering it more food, once it had consumed this, yet it failed to pupate and eventually died, after three days more, probably because its nursery was not properly equipped or regulated. The other two crickets which had been stung and buried lived four days.

Almost a month later, August 22, we were scouring a 
field for wasps when an open hole on a gently sloping little bank, with a number of little chips of earth on the slope beneath the hole, betrayed the presence of a nest of $N$. argentata. The mother wasp soon appeared upon the scene; she had probably been frightened away by our approach. She had already begun closing the hole, but we were happy to have discovered the nest in time to see her put in the dirt filling. She worked by kicking in the loose soil near the mouth of the hole with her front legs, and then, with the ventral part of the abdomen, she would tamp it down and rub it smooth with a slow, grinding, circular motion. Before the hole was quite completed we took her, lest she should escape and we should lose her identity, so we did not see the final ceremonies of the closure of the nest. Another N. argentata in closing her hole first fetched a small cinder and took it down into the burrow, and then repeatedly kicked loose dirt in upon it until the hole was full. We should like much to know whether these wasps usually finish off their burrows with bits of rubbish, or whether the individual previously described modified her usual habit and carried débris because her loose dirt had rolled away where she could not get it. Perhaps her work was rendered more difficult in that case by the gummy condition of the earth after a heavy rain.

The opening of the hole was about three-eighths inch in diameter; it went down for one inch and terminated in a chamber one-fourth inch in diameter. This contained four cricketts, all Gryllus pennsylvanicus $\delta \mathrm{s}$, three large and one small, although all were mature. The wasp's egg was attached to the one nearest the top, probably the last one brought in. It was fastened to the ventral side of the thorax, nestling very nicely between the first and second pairs of legs. We could hardly believe that the crickets had been stung when we saw how they hopped out 
of the nest as soon as it was opened, and even at ten o'clock that night all of them could walk or hop with alacrity upon slight stimulation. Judging from the fact that the egg was on the top cricket and the wasp was closing the nest when

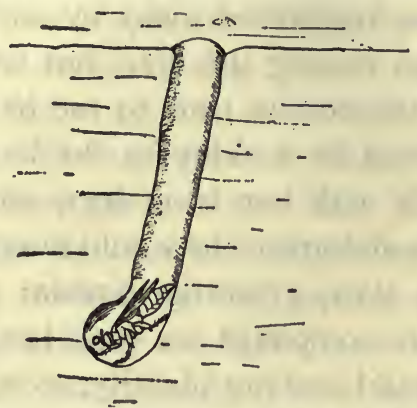

FIG. 35. Notogonidea argentata and her burrow. Natural size.

we arrived, we can safely estimate that the egg was laid between $\mathrm{I}$ and $\mathrm{I}: 30 \mathrm{p}$. $\mathrm{m}$.

On the evening of the next day, the crickets were all astonishingly lively; the one bearing the egg ran and hopped clear across the table when the box was opened. After four days imprisonment, they were a little subdued and seldom walked about in the box. By the evening of the 27 th, five and a quarter days after the closing of the nest, the smallest cricket was growing lethargic, and by the 29th all but the largest which bore the egg were dead, and it too seemed almost gone. The egg never hatched.

Ashmead $^{8}$ says, under the name of Larra argentata, that in the south this insect stores as many as six immature crickets, which she completely paralyzes. The way the crickets here jump out of the nests when they are opened readily shows that the Missouri wasps very incompletely paralyze their prey.

Figure 35 shows another nest in course of construction

8 Psyche 7: 63. 1896. 
which we opened. The mother was at the bottom of the burrow.

Williams $s^{9}$ gives some interesting data on the biology of this species. He records that one soon rendered helpless a small Gryllus by a sting under the thorax, malaxated it on the ventral side of the neck, and carried it toward her nest, ventral side down. The wasp made little runs and short, flying jumps with her burden, and after she entered her hole, remained there for five minutes. In filling up her tunnel, she gathered little lumps of earth and other material such as twigs, thorns and grasshopper excrement and dropped them in. None of the material, he says, was tamped down. She did not use her feet in filling up the hole; the feet of Notogonidea are not armed with brushes to assist in such work, and the heavy black earth in which she was working did not readily permit digging with the feet.

In the first argentata that we observed, we found precisely this behavior, carrying and dropping into the hole pellets, fragments of stones and leaves. Upon opening the burrow, however, we did find the gallery just above the chamber well packed with earth, which she surely must have compressed, not in the usual way in which wasps pack down the soil but, as our second wasp showed, with the veritral part of the abdomen moving in a slow, grinding, circular motion. While we did not witness all the filling of the hole of the second wasp, we did see this one scraping in loose dirt with the front legs. A third one, to, as we have shown, used her legs to scrape in the soil.

Since we have recorded individuals of this species very early in the season, one would expect that their vegetative and reproductive functions would soon be over and they would die off. But this is not so, for we have one record of

${ }^{9}$ Kans. Uni. Sci. Bull. 8: I9I. I9I3. 
having seen a dozen of them out foraging on October 6, at St. Louis, and others as late as October 28, at Clifton Terrace, Illinois, evidently still in quest of prey. The nights at the latter time were very cold. We wonder if this insect does not hibernate in the adult stage; if so, we may find them producing more than one generation a year-a condition which is unusual for the wasps of the group to which this one belongs.

We have yet discovered no enemies of this species. After a heavy rain on August 20, however, a few of the wasps were found dead in the field; they seemed somehow to lack the means of protection from the assaults of this kind of weather. 


\section{CHAPTER X}

The Hunters of Large Orthoptera

\section{Priononyx atratum Lep. [S. A. Rohwer].}

The morning of September 4 was clear and sunny, with a temperature of about $72^{\circ}$. As we walked across the field at 9:30, we scared up a $P$. atratum. She circled about in alarm above the grass in the vicinity, but in a few minutes her excitement subsided and she turned to looking for the nest which she had so hastily left. She seemed sure of the general region and did not wander far away from it in her searches, but seemed to be without any clue to the exact location of the hole. May it be that, in leaving the spot in sudden alarm, she had failed to go through her usual ceremonies of getting her bearings; hence the great trouble in locating it? For an hour she searched diligently to and fro in the immediate vicinity, examining every ant-hill and depression, until at length she found it - or rather, seemed to stumble upon it. The hole was about three-fourths inch deep; the bottom was concave and firm, so we could not tell whether she was digging or filling and packing it in. A little loose dirt lay at the mouth of the hole. The bitings were of characteristic size and shape for $P$. atratum, not pellets nor dust, but tiny chips of almost uniform size.

The moment she spied the hole, the wasp joyfully pounced upon it and, with a few rapid strokes, filled it up-scooped the dirt all in loosely almost before we knew what she 


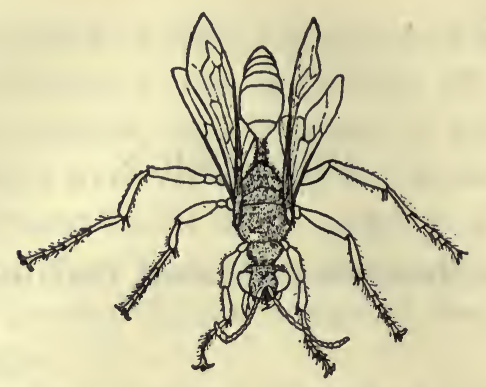

FIG. 36. Priononyx atratum, expressly drawn to show the wonderful legs, capable of scraping and carrying soil, as well as being long enough to gracefully straddle and ride home a large grasshopper. Natural size.

was about. That done, she took a careless, free flight of about eight feet, looked around for only a minute or two, and began industriously digging. In about five minutes she had dug to a depth of one-third of the length of her body; then, quick as a flash, she jumped out and, with half a dozen rapid scoops, whipped all the dirt back into the hole and heaped it neatly on top. Then she tried a third place less than a foot away, but deserted that also after a few mouthfuls had been taken out and replaced. She began the fourth burrow, six feet from the last, after walking about ten minutes; she dug a hole the length of her body in a very business-like manner, then jumped out and kicked the dirt in again. Next she walked about for ten minutes, taking out a few mouthfuls in other locations, but putting the dirt back with the same ultra-precision as before, and at length flew away over the grass and across the field for some distance. But she seemed faithful to her original purpose; after ten minutes or so she came flying back, alighted on the bare spot and doggedly began another hole. In seven minutes it was as deep as the length of her body; then she went off across the grass, leaving it open. In about five minutes she came trudging back with a huge 
hopper; we do not know whether she had just caught it or had had it there somewhere all the time during her many attempts at digging in this region; but, from what we saw later, we judge the wasp undoubtedly had the hopper in hiding. She carried it fully three feet beyond her hole and hunted for five minutes before she rediscovered her burrow. She then resumed digging earnestly, going in and out mechanically, like a toy wound up, and coming out two or three times to kick the dirt further back from the mouth of the nest. She worked earnestly, as if the work was now full of meaning to her.

Disturbed by a passing boy, she flew around, came back and examined her prey and returned to more digging, brought the hopper a foot nearer and propped the thing up in a tuft of grass and went back diligently to digging, lugging out in her jaws loads of earth as large as her head. She held the masses of soft dirt up against the mandibles with her front legs as she carried it out backwards, to keep the load from falling to pieces, so it looked as if she were carrying a double armful up to her chin. As the burrow grew deeper she backed away from it further, to perhaps a distance of two inches or more, before dropping her load, and occasionally paused to sweep the whole pile back with her forelegs.

We examined her grasshopper, a Dissosteira carolina Linn., and were astonished to find that its hind legs were gone. Evidently they had been carefully bitten off, though probably not by atratum, for the cut was smooth, and not lacerated as the wounds would have been if the legs had been torn off.

The same day we found another hopper in the field with the jumping legs neatly cut off. Both of these mutilated hoppers displayed all normal activities except jumping.

After about ten minutes more of digging, this one brought 
her prey nearer, to within one foot of the hole. She carried it by straddling it right-side-up, grasping its antennae in her mandibles, clasping her forelegs around its neck, and struggling over the ground with her two hind pairs of legs. The wonderful modification of the legs of this species, as shown in figure 36 , shows how capable they are of scraping and carrying the soil, as well as long enough gracefully to straddle and ride home a huge grasshopper. After another brief period of digging, the wasp moved the hopper to the very brink of the hole and swung it around so it was directly facing the sloping burrow, although it had formerly been behind the hole. She went in, turned around and reappeared at once, head up, seized the grasshopper's antennae and dragged it in out of sight. The hole was a close fit for the prey; it was with difficulty that she squeezed it in. For only one brief minute she remained inside the chamber with her booty; then she scrambled out and scooped in a few armfuls of dirt, arranging each load slightly but packing it little. As the channel filled, she tamped the dirt down more. She scooped in each armful of earth with a circular stroke, cutting a crescent-shaped area out of the tiny hill, smoothly and systematically like a workman carefully scooping sand away from one side of a heap (fig. 37). Such precision rather startled us, since we were accustomed to Bembix' way of scratching over the whole region.

With her head she packed it constantly tighter as she neared the top. When the depression was nearly full she stopped taking the loose earth, but bit up chunks of firm, fresh dirt which she carried in her mandibles and broke to pieces on the site, just as Sphex does with little clods, rubbing and pressing down the soil with them until they were ground pieces and became a part of the firm pack of pulverized earth.

Just as she appeared at the mouth of the hole after having 
dragged in her grasshopper, a little parasitic Dipteron arrived and hovered about the place, like an evil spirit. It poised persistently over the hole, and tried to get in whenever the wasp's back was turned. The wasp would occasionally whirl suddenly around, glare and jump at it defiantly and it would dart away, only to return at once as teasingly as ever. Such persistence! Such perfect adaptation! On the spot as sure as fate and as inevitable!

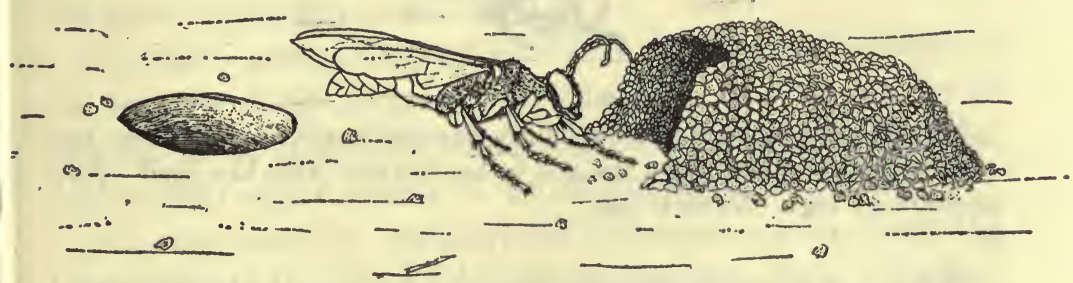

Fig. 37. Priononyx atratum filling her burrow. Natural size.

The wasp pounded and buzzed and labored for fourteen minutes, packing dirt in the depression until the ground was so hard and smooth that no trace of a hole remained. She stood squarely on her head, pushing downward so hard that twice she started to turn a somersault and just saved herself with difficulty; after that experience, she ingeniously altered her position for pounding, with her hind legs braced against the dirt and spread to their fullest extent, and one middle leg (the left one) thrown clear over above her head to serve as a prop and keep her from turning a somersault (fig. 38). She showed much mechanical skill in spreading her hind legs and bracing herself by placing one middle leg forward, to hold her balance and yet get more power for her work. When the closing of the hole was completed, she straightened up and took one look at it, then in a flash arose in the air and dashed away across the fields so swiftly the eye could not follow her, and was lost in the distance. Even. 
one unfamiliar with wasps' ways would have said at a glance that her interest in the spot was forever at an end.

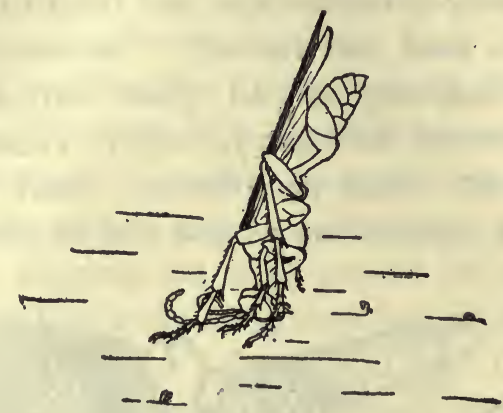

FIG. 38. Priononyx atratum deftly bracing herself to hold her balance while pounding down the soil in her burrow with her head. Note position of legs. Natural size.

Then we went back and dug up the first hole for which she had hunted so long and earnestly, expecting to find what she so carefully sealed up in it. It was stark empty! Why had she been so very particular to put the dirt back into all of these empty holes?

Let us add here that this persistent habit of closing up the abandoned holes is not constant. We have one record of an atratum which commenced six holes before she was satisfied with a location, but made no attempt to kick back the earth.

The last nest, to which our wasp had given such careful attention, contained the hopper with the wasp's egg cemented, in its usual position, on the hind leg and curved around the side of the body. But the Dipterous parasite mentioned above must have been too quick for the mother wasp after all, for fifteen minutes after the egg was laid, it and the host were already teeming with tiny Dipterous larvae. There is a possibility, of course, that the hopper may have been parasitized as it lay in hiding, but this chance 
is slight because usually the adult parasites stolidly ignore the prey of wasps while it is left lying idle, but take an interest in it when they see, with surety, that it is going to be buried properly.

The next day at 5:00 p. m., the hopper could still move its mouth-parts and legs, and when stimulated it could flutter its wings. In the interval, the parasites had devoured the egg and were entering and feeding upon the body of the grasshopper at the point of attachment of the wasp's egg, at the base of the left hind leg.

We have never found more than one hopper stored in the burrow of $P$. atratum. Williams ${ }^{1}$ found their prey in Kansas to be a mature Aulocara, Mermiria neomexicana, Melanoplus differentialis $q$ or $M$. lakinus.

On one occasion we were so fortunate as to catch the $P$. atratum in the act of selecting her nesting-place. On that morning, August 30, at ro o'clock, we found her searching to and fro in the region of her grasshopper, which lay, already paralyzed, on the grass. We should much like to know whether she had brought it here from some distance or whether she had killed it on this spot. We might add here that the Peckhams are evidently mistaken in surmising that the species first prepares the nest and then catches the wherewithal to fill it. In every case when we saw the wasp at work digging, we found the paralyzed hopper near by. This wasp did not come directly to her prey, nor did she at any time wander further than four feet from it. Judging from her manner of hunting here and there over the region, we thought she was seeking her lost quarry until, after examining one bare spot closely for five minutes, she began to dig. This spot was only about eighteen inches from her hopper, but in selecting the site she did not return directly to her prey at any time.

1 Kans. Univ. Sci. Bull. 8: 230. 1913. 
The earth was moist and she dug rapidly, carrying out large mouthfuls of dirt as she emerged backwards from the hole, dropping it near the brink and flinging it back under her body and out of the way with her forelegs. When the dirt had accumulated near the hole so as to form a slight obstruction, she would come out and kick the whole pile away to a distance where it would cause no further annoyance. During the next period we timed her; she usually took out five loads of earth a minute, and occasionally six.

After ten minutes of her faithful digging, the hole was deep enough to include her whole body; then her mind turned back to her hopper and she started out in quest of it. Her manner of locating it was interesting to watch; first she walked in the direction of the prey but a little to one side and missed it; when some distance beyond it she turned and came back but passed it again. Then she took a short flight but went too far and landed beyond it again; then another return flight brought her only slightly past it once more, and from there she walked a few steps to it. She mounted it and trundled it half-way to her hole, where she left it on top of a thick clump of grass, and resumed her digging for another quarter of an hour. Once more she moved her hopper nearer to the hole; this time she had no trouble at all in finding it, but walked straight to it. When she brought it near to the hole, we felt sure that she had the burrow almost ready for it; for these wasps have a way of gradually moving their booty nearer and nearer as the work on the burrow progresses, until it arrives at its destination just as the hole is completed. Why do all of the Priononyx persist in digging awhile and then bringing their prey closer, several times before its final burial, when they might as well bring it all the way at one trip? Do the wasps grow anxious about the welfare of their prey? Hardly, or they would bring it at one trip clear to their place 
of work, where they could keep a watchful eye on it. Do they rest themselves by a change of work? Or do they want to compare dimensions and get a more exact estimate of the required size of the burrow in course of construction? Or do they judge in terms of their weariness, i.e., after a long time of digging do their tired muscles (not their "heads") tell them that the hole must be large enough; then when they have tugged at the heavy caterpillar or grasshopper until their backs ache and their legs quiver, do they decide from their muscle-sense (not by their visual estimate) that the varmint must be larger than they had thought and they must dig the hole larger, etc., alternately until they arrive with the prey at the hole?

True to our expectation, this wasp worked at excavating just two minutes longer; then she moved the grasshopper to the very brink of the hole, wheeled it around so it was in position to slide down the sloping entrance head-first, went in to turn around and promptly reached out and dragged it in by the antennae. After only one minute, she reappeared and began at once to fill in the hole by first kicking in a small amount of dirt and then getting into the hole and working this earth down solid with her head, buzzing shrilly as she rammed it down. Sometimes she would break off clods or chunks of earth to fill in; these were not carelessly dropped but crushed to powder and packed tight with the head. She finished her burrow just one hour after she had commenced it.

On another occasion there was a small sandy area on Howard's Hill, where a load of sand had once been dumped and left to disintegrate. Here and there on top were streaks of grayish-white fire-clay and a few cinders, which had been washed over the sand by heavy rains. On one of these claycolored areas was a very conspicuous spot; a little mound of moist red sand was surmounted by a tiny monument of black 
cinders thrown out on top of this smooth white surface. It was clearly the work of a Prionony $x$, in all probability $P$. atratum, since the only other member of that genus found here is $P$. thomae, and none of them had yet been seen in this vicinity. The gallery of this burrow was about an inch and a half long. It was tightly packed near the mouth with the material which had been excavated. In form and slope the burrow conformed in every way to the standard specifications of Priononyx; hence we may conclude that she finds the same scheme adequate, whether working in sand or firm earth. The adult hopper in the cell, a Dissosteira carolina, was active in all its members, kicking vigorously with all of its legs, moving its mouth, antennae and abdomen, and occasionally fluttering its wings. During all of this activity the egg, which was glued at the base of the right hind leg, was not dislodged, although it was badly shaken and occasionally received a full blow from the middle leg. Hence, it was not in the least surprising that the egg never hatched and that three days later it was shrivelled. The hopper was at that time fairly active, moving the hind legs, mouth and antennae; only the first and second pairs of legs seemed helpless.

The site of the nest was particularly conspicuous because of the contrasting colors of the mound and the adjacent soil, while the tiny black cinders laid on top of the gray clay made the contrast only the more striking. In covering and finishing off her burrow in this way, the Priononyx had merely followed her usual custom for effecting its concealment, but she had failed ludicrously, by picking up material of sharply contrasting colors. Surely, if this behavior was not blind instinct, at least it was colorblind.

In I9I4, while walking along a country road in Kansas one August morning, we noticed a hole in the side of a wagon rut. In a moment the proprietor, a $P$. atratum, re- 
turned and claimed it. About twelve inches away and facing the hole was a grasshopper, a Melanoplus differentialis Thom. \& [A. N. Caudell], lying in the very natural position of one at rest. When it remained there without moving we decided that it, too, was a participant in the drama about to take place.

For fifteen minutes the wasp enlarged the hole, all the time working out the dirt with her mouth and forelegs. The mandibles brought out the big clods, while the legs rapidly worked the dust out behind her. Once she paused to examine the hopper and when she found it resting perfectly quietly except for the pulsating of the abdomen, she at once resumed her work. For eight minutes more she worked at the excavating before she again examined her prey. She had more difficulty in finding it this time, and walked around in an irregular circle twice and a part of a third circuit before she stumbled upon it. She straddled it as it lay, grasped its antennae in her jaws, stretched her legs over the sides of its body, and thus trundled it along (just as in fig. 40). At a point about four inches distant from the nest, she left the grasshopper, went to the mouth of the burrow, poked her head in, turned back and once more scrutinized the prey and immediately took out two loads of dirt, one from each side of the entrance, thereby enlarging the opening. It was difficult for an observer watching this exact work to throw aside the conviction that actual judgment was a guiding factor in such little details of behavior as this. Then she continued deepening the cavity. A buzz, similar to the shrill buzz of a fly ensnared, was occasionally audible; it seemed that each buzz was simultaneous with the energetic pressing of her head as she strove to loosen a pellet of earth. At 9: $5_{5}$ she started for her hopper, mounted and grasped it the same as before, excepting that this time she clasped its thorax with her front legs 
and struggled forward on her four hind feet. Thus they progressed to the burrow. There she laid it down, with its head at the very brink of the opening; but she left it for only a moment while she stepped inside, turned around and poked her head out just far enough to grasp the hopper by one antenna, and dragged it in. After a brief time, perhaps one-half minute, she came out and immediately commenced to fill the hole, pausing only to chase a Dipterous parasite that hovered about while she was filling it in. How strange it is that only the filling of the tunnel seems to stimulate the fly's desire to enter; she had had abundant opportunity to enter ere this, or even to deposit her eggs on the grasshopper as it lay wholly unprotected, but she seemed to take no interest in the hopper until she was sure the wasp had finished with it.

While filling and packing in the earth, the wasp stood on her head and pressed down the soil, producing with each stroke the shrill buzz. Next she brought large pellets from a distance and dropped them on the depression. Then, in scratching the dirt back, she worked gradually sidewise, with her face away from the hole, so her path formed a perfect arc of a circle the center of which was the nest. Often she would have to go back to the original spot to get her bearings and estimate exactly where to direct her kicks. While thus occupied, without ceremony or warning, she arose and flew away in a straight line. It was then $9: 30$, or forty-five minutes after the time we discovered her.

We opened the nest. The length of the tunnel down to the grasshopper was five inches. The chamber was no wider than the rest of the burrow and lay horizontally. No earth was in this chamber, and the hopper, with its head to the wall, had ample air space around it. We dug it out and took it home for further observation. It was still alive, but seemed severely stunned, and for the remainder of that 


\section{HUNTERS OF LARGE ORTHOPTERA I7I}

day moved its legs and antennae only upon stimulation. By the forenoon of the following day, it had recovered enough vigor to move spontaneously, but the powers lasted for only this one day, when they again waned. During the next two

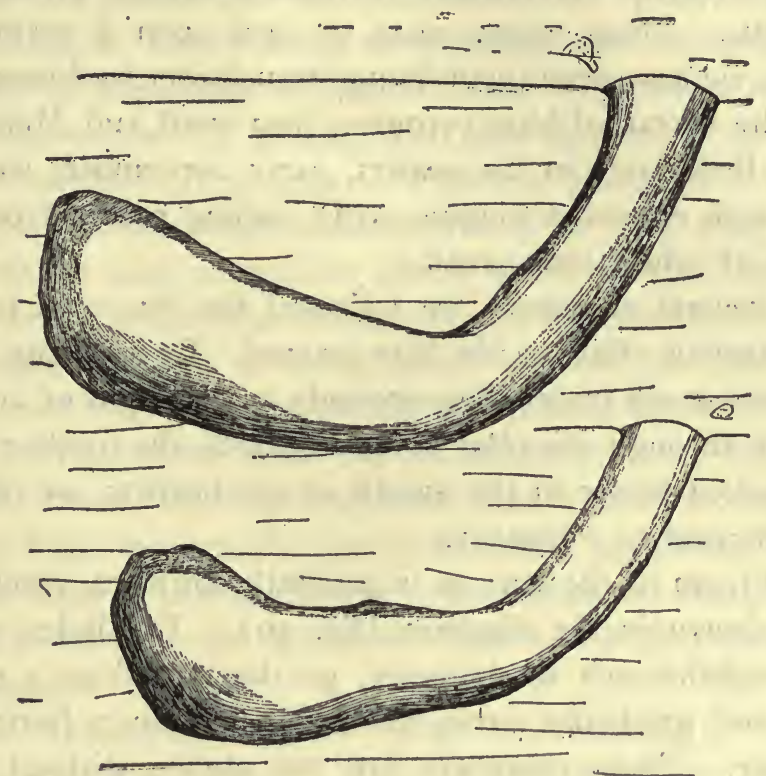

FIG. 39. Two burrows of Priononyx atratum. Natural size.

or three days, it moved in response to stimulation and voided excrement, but gradually grew more sluggish until, one week later, it was dead.

In four instances, we found a $P$. atratum nest well covered, and the hopper within being speedily consumed by Dipterous larvae. These parasites destroy the egg as well as the locust, and since they seek to enter the body of the hopper at its softest point, i.e., where the wasp egg or larva is attached, the egg is usually destroyed before it has a chance to hatch. 
-Adams ${ }^{2}$ finds the Tachinid fly Metopia leucocephala Rossi hovering over their burrows.

To see a Priononyx intent upon the herculean task of making her burrow and burying the grasshopper, one can hardly imagine her blithely refreshing herself among the blossoms. These wasps seem to feed upon a variety of plants; we have seen them flying from flower to flower, sipping the nectar of blue veronica, iron-weed and Melilotus, and a little later in the season, early September, we saw them with extended tongue, lazily sipping nectar from the florets of white snake-root.

On several occasions, we followed the clue of a pile of characteristic chips on the bare ground. By scooping away the surface soil under these mounds to the depth of an inch or two, through the plug of earth which the mother wasp had packed firmly in the mouth of the burrow, we discovered the nest of Priononyx.

The form of the burrow is generally uniform, similar to those shown in the diagram (fig. 39). The holes, about three-eighths inch in diameter, go downward at a gentle slope and gradually curve until they end in a horizontal chamber. These chambers are not always distinct; frequently they are little more than a continuation of the gallery. The burrows are three and one-half to four inches in total length, and, at the deepest point, about one and one-half inches below the surface of the ground. We have never chanced to find a Priononyx burrow of the form described by Williams; ${ }^{3}$ a distinctly L-shaped nest about two inches deep and two and a half inches long. There has been very little variation in the form of the fifteen nests which we have excavated.

The Priononyx nests which have come under our observa-

2 Bull. I1l. St. Lab. Nat. Hist. I I : I95. I9 5.

${ }^{3}$ Kansas Univ. Sci. Bull. 8: P1. 33, fig. 2. 
tion have always contained one of three species of 'grasshoppers: Dissosteira carolina Linn. nymphs, Arphia corinata Scud. $q$ large nymphs, or Melanoplus femuirrubrum DeG. ${ }^{4}$

The first named was the most abundant. Riley, Packard and Thomas ${ }^{5}$ record them as pursuing and capturing the nymphs of the Rocky Mountain locust, Coloptenus spretus, and Adams (loc. cit. p. I95) also says they use Melanoplus femur-rubrum. The prey was always placed in the oval terminal chamber, with its head toward the wall, away from the exit-a wise precaution which would prevent the hopper's escape in case the stinging should be imperfectly done. The upper portion of the channel was always filled with earth, and near the surface this was packed so firmly as to be indistinguishable from the surrounding soil. The horizontal chamber at the end was not filled with earth, but contained only the grasshopper surrounded by plenty of air space. May it be that this terminal chamber is made in this form so that the dirt will not roll in and pack around the grasshopper?

The faithfulness of these wasps in returning to the unfinished nests is variable. We have described above the case of one wasp which spent a whole hour in diligent search for an unfinished hole, only to fill it up and desert it the moment she found it. On one other occasion, we disturbed a wasp as she was making her nest, and found the next day that she had returned and finished it. In another instance we met exactly the opposite behavior: the wasp with her prey, a large Dissosteira carolina, right beside her, was putting the finishing touches to her burrow when our footsteps frightened her away. She returned and found the hole again before we passed on, but when we came back that afternoon
${ }^{4}$ All kindly identified by Mr. A, N. Caudell.
${ }^{5}$ U. S. Ent: Comm. $1877: 318$. 
to dig up the finished product, we were surprised to find that she had deserted it just as we had left it that morning. The nest remained slightly unfinished, and the hopper nearby was being dismembered by ants.

Two other unfinished and deserted burrows of Priononyx, probably atratum, were found. One was evidently ready for the closing; even the hopper, a Melanoplus femur-rubrum, was in place at the bottom, but the owner was gone, the dirt was dry and the locust was being carried away in bits by ants. The other was almost as far advanced; the prey, an Arphia corinata $q$, lay directly in front of the hole and facing it-the last position before the wasp drags it in-but this too was being plundered by ants. There is, of course, a possibility that both of these failures had been caused, not by the faithlessness of the mother wasp, but by some tragedy which had overtaken her. We might add here that the mothers themselves are not exempt from enemies, for Pierce ${ }^{6}$ records this species as being stylopized by Ophthalmochlus duryi, and in one instance where a male parasite emerged three days after the death of the host.

On one August morning we were interested in watching the courtship of a $P$. atratum. At 8:42 a black female was seen at rest on a small Melilotus. After a few seconds a second insect appeared, flew directly to the first, mounted. and tried hard to effect a union, and flew off. During the next fifteen minutes this performance was repeated about a dozen times; occasionally the male would fly to a distance of fifteen feet, rest for a second and then return to the female and resume activities, but more often the flights were short. The male would hover to and fro in a space of about three inches in the air in front of the female before mounting; then he would curl his abdomen beneath hers. Mating probably occurred during this coquettish performance, but if so,

${ }^{6}$ Bull. U. S. Nat. Mus. No. 66: 38. 1909. 
it must have been instantaneous. Finally the male flew away permanently and the female remained on the same plant, apparently waiting for him to return. Our approach caused her to seek another plant, where she assumed the same position. We watched her for some time, but no suitors appeared.

Priononyx thomae Fabr. [S. A. Rohwer].

In a vacant lot adjoining the brick-yard, where the ground was well covered with cinders, we saw this red-bellied Priononyx nervously walking about at $4: 35$ p. m. on July I4. From her manner, we at once suspected that she was looking for a nesting-site. One may imagine the difficulties which confronted a little creature trying to dig her hole in a surface-soil composed largely of cinders; one would hardly think of trying to dig in such material with a pocket-knife.

She already had her grasshopper, a Dissosteira carolina Linn., which was in its last nymphal instar. Twice while hunting for a location, she returned to her hopper to see if it was safe. On each visit, she straddled it and carried it a short distance, then wandered away again looking for a site. In two places she seriously attempted to dig, but abandoned the spot on account of the bad cinders. Both of these were at so great a distance from the place where she had left her hopper that we doubted whether, if she remained there, she could ever find and fetch it.

Her third and successful attempt was begun in the rough cinders somewhat nearer to where her hopper lay, but still at a distance of about fifteen feet. The cinders were harsh and heavy, and how she tugged at big lumps in getting them out of the hole! We often thought that if the rough cinders hurt her legs as much as they did our hands and knees 
as we watched her, she deserved our highest respect for faithfulness to duty.

Her method of digging was similar to that of $P$. atratum; she would plunge into the hole head first, grab a lump of dirt or a cinder, back out and drop her load a few inches away. When the bore was about half completed, she found her hopper with little difficulty, mounted it again, grasped its antennae in her mandibles as usual, and away she went (fig. 40). ${ }^{7}$ She did not exactly fly, but she made such rapid speed that she must have aided her progress by beating her wings. She left the locust about twelve inches from the hole until she enlarged it. Then she returned again to lier prey, and, despite the fact that she was very near to it, she found it with more difficulty than on the previous occasion. It took her one minute to discover it, and at one time she passed it when only one inch from where it lay. In the usual manner, she mounted it, grasped the hopper's antennae in her mouth, and dragged it to within three inches of the burrow. Here she evidently decided that it was a trifle larger than the hole would yet admit, so she laid it down and removed three more mouthfuls of dirt. She then carried the prey to within one inch, went into the hole once more to make sure that all was ready, came out again and dumped it, head-first, half-way into the opening; then she herself crowded in ahead of it and dragged it in after her. She remained in only one-half minute, came out and began to fill in the dirt. After this, for many minutes she carried large cinders and placed them over the site. The heavy cinders were moved with the mandibles with comparative ease. Sixteen minutes later she stopped piling cinders and for two minutes walked and took short, low flights about the nest, surveying the situation; then she came back to the

7 Throsgh an error in the figure, the middle leg fails to reach the ground. 
very spot and critically added more cinders, took a few more last looks and finally, at 5:29, she flew off and rested on the grass some distance away, as if all her interests were now in the future and the past was a closed book. It had taken

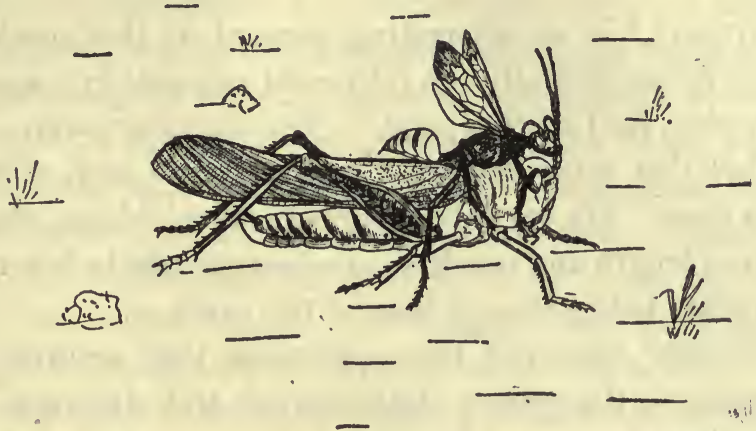

Fig. 40. Homeward bound Priononyx thomae transporting her locust to the burrow. Exact size.

her just fifty-four minutes to dig her burrow, bury her prey, lay the egg, and conceal the spot.

After she had gone, we opened the nest and found the hopper with its head to the wall. The chamber was only one inch underground and one inch long, of no definite shape, but it was as well constructed as it could be in such rough material. We found the brown egg on the right femur, near where it joins the thorax. We took the egg and its host home and guarded them carefully. The next morning, July I5, at 7 o'clock, we found the legs, antennae and mouthparts of the hopper active and excrement had been passed, but the femur upon which the egg rested was immovable. With what delicate accuracy the little mother-wasp had done her work! By the following day the egg was slightly enlarged and had changed from brown to green. The morning of the I 7 th found a larva, fat and large, still clinging to the femur of the hopper and eating away the thorax near the joint. 
July I9 revealed a light-brown cocoon just completed; the hopper had all been eaten. On August I5, scarcely one month later, a perfect adult female emerged. This shows that in this species there is more than one generation each year.

Hartman, ${ }^{8}$. in an interesting account of this species, tells of how he accidentally ran into eight nests all in a space "not larger than half of this page." The chambers were so close together that some had but a quarter of an inch of wall between them. He says the chambers were oblong, about two inches in length and one-half to seven-eighths inch across and two inches below the surface of the earth.

Williams ${ }^{9}$ observed two specimens that secured locusts belonging to the genera Amphitormus and Aulocara.

Another chapter in the life of $P$. thomae, the hunting of the provisions, must be taken from another individual.

A terrific commotion in the low grass attracted our attention. An adult grosshopper, Arphia xanthoptera Burm. [A. N. Caudell] lay on its back violently flapping its wings against the earth, as if in great distress. A little red lump on the ventral side of the thorax explained the mystery; it was the abdomen of a $P$. thomae with its sting buried deep in the hopper's thorax; the rest of the body of the wasp was curved around the grasshopper's side. The struggle was more violent than that of an insect on its back trying to right itself; besides, a grasshopper seldom has' much difficulty in turning over if it happens to become inverted-in fact they are seldom so clumsy as to get into that predicament. The point is, this action was simply an aimless and conclusive muscular contraction, a writhing resulting from the sting of its enemy. A grasshopper is so seldom seen in this position that the wasp must have either attacked it on

${ }^{8}$ Bull. Univ. Tex. No. 65: 64. 1905.

${ }^{9}$ Kans. Univ. Sci. Bull. 8: 227. I913. 
the wing and made it fall, or attacked it on the ground and caused it to roll over in its agony. We should like to witness the initial attack of the wasp. It is doubtful if the hopper's movements were really an effort to rise or to shake off the enemy. Nevertheless, it is certain that the wasp had much difficulty in clinging to the hopper during this shake-up without removing her sting. The sting was inserted between the head and the thorax, at a point just in front of the fore-legs. She did not make several thrusts as Ammophila does, but when we saw them her dagger was already inserted, and there she calmly and firmly held it for over one minute while her victim writhed and fought; how long they had struggled thus before our arrival we do not know.

At the end of the minute the wasp suddenly darted away on the wing to a snakeroot plant ten feet away. Judging from the suddenness of her departure and the absence of any flight of orientation, we suspected that she had fled in alarm and would not return.

We then watched the hopper as it lay on its back violently beating its wings against the earth. Gradually the beating grew weaker, until it was a throb and a quiver; this in turn gradually waned until, at the end of five minutes, the hopper lay motionless on the ground with its wings outstretched. Of course this made us ask at once: "If the wasp returns, how will she right the hopper and close the wings to make its removal easy?" At that moment the wasp appeared on the field, seeking her victim. By a series of walks, jumps, skips and short flights, she attempted to locate it, but she had left it so hastily that she had difficulty in discovering it; although in her fifteen-minute search she came within a few inches of it four times, she could not find it; she evidently knew the general vicinity, but had memorized no familiar landmarks by which to locate it, so presently she flew away permanently. 
After waiting in vain for her return, we looked at the hopper again; it had somehow righted itself and sat on the ground with its wings closed. Closer examination showed that it was powerless to use its legs, but it moved its wings in response to stimulation. It tried to walk, but the only result of its efforts was a slight quiver of the left hind leg. We picked it up, a little later, to examine it more closely on the open hand. Imagine our surprise when, with the first puff of wind, it spread its wings and flew a distance of forty feet and was lost in the vegetation. Evidently the legs had been properly paralyzed, but the wing nerves and muscles were unaffected. This condition is usually sufficient by reason of the fact that hoppers cannot normally use their wings for flight without first leaping into the air by means of their jumping legs. As prey they may occasionally escape by some unusual circumstance, as in this case, but such cases are so rare that there is no need of the wasp burdening herself with either the instinct or the task of paralyzing the wings of her prey. As to this hopper it probably lived and grew fat, even if it was unable to use its hind legs, but we should like much to know whether the injured members fell off. We have seen healthy hoppers with the hind legs so neatly trimmed off at the basal joint that we wondered how they came so; may it be that $P$. thomae or $P$. atratum had once had them?

The Relation of Stizus unicinctus Say [S. A. Rohwer] to Priononyx thomae. Fabr.

While Chlorion cyaneum was working on the cinder-bed, as later described, a Priononyx thomae appeared, reconnoitering in the same field. She at once went to work energetically and dug a hole a half-inch deep, then deserted it 
and attempted another at a spot ten feet distant and abandoned that also; a little later she commenced a third burrow about five feet from the second. This last location seemed to offer more favorable conditions. Here the wasp worked diligently among the cinders, and in ten minutes had dug a hole the length of her body, with an opening one-half inch wide. This was good work, considering the difficulties of digging in packed cinders. It seems that this species has a liking for cinders, for the other that we saw worked in the same material despite the fact that only a small proportion of the available area was covered with it.

The blue wasp, C. cyaneum, which was foraging under a brick-pile near by, annoyed her twice by entering her open burrow; but since she entered every hole and crevice in the brick-pile and cinders, this was probably only an accident.

This $P$. thomae followed the same technique in her work as $P$. atratum: she would carry up the soil, cinders, etc., with her mouth, back out with the load and drop it near the orifice without turning around, and run in again, head first, soon to emerge in the same mechanical manner, like a little toy wound up with a spring. When the débris had accumulated so as to be annoying, she paused long enough to rapidly kick and brush it all together, in a neat little heap, some distance away.

After she had dug down about the distance of her own body-length, she turned to a horizontal direction and excavated the chamber. Thus the ceiling of the chamber, when completed, was only about a half-inch beneath the surface of the ground. The opening was large enough to permit us easily to see her moving about inside.

After a half-hour's arduous work, she came out of her burrow and slowly walked about in the immediate vicinity of her nest. We thought she was getting her landmarks preparatory to bringing her booty home. Her slow and 
deliberate actions indicated this, but presently she changed her mind and again went into the hole to make certain improvements in view of the coming storage, removed a few more mouthfuls of dirt and again strolled slowly about her nest. Then she flew off for her hopper. During this period of her work, we had made a diligent search for her prey, which we were certain she had in hiding somewhere near. But now, without hesitation or uncertainty, she walked directly to a brown brick on the ground at the side of which lay her hopper, almost indistinguishable against its similarcolored background.

Once, while she was at work in the hole, a red-banded Stizus unicinctus had poked her head in and walked away without further intrusion; but now, while she was gone, the same meddler returned and wandered about the vicinity, with a "looking for something" manner.

$P$. thomae straddled the hopper, grasped its antennae in her mouth and struggled on her way over the rolling cinders. It was with considerable difficulty that she rode the hopper; besides the grasp on its antennae she gripped the hopper's neck with her forelegs; so she walked with her hind legs, while the middle legs attempted to assist, but, owing to their shortness or the thickness of the burden, they seldom reached the ground. The hopper itself often assisted in their progress in this way: as thomae dragged her prey forward, the tarsi of its hind legs would cling to the rough cinders, and, while the heavy body was being pulled forward, the hind legs would thus be stretched out to their fullest extent; of course this process would lift the rear part of the grasshopper and make the body pitch forward. When the legs had reached their full extent, they would snap shut and the process would be repeated, pushing the heavy body slightly. forward each time, thus at least avoiding hin- 
drance by friction, if not positively aiding the struggling wasp.

She thus carried the hopper to a tuft of grass about ten feet from her hole and there left it, returned to the burrow and dug for ten minutes more, again went direct to the locust and carried it, in the same fashion, to a spot three feet from her hole and once more resumed the digging. At this point in her work she was again visited by $S$. unicinctus, but this time the bold Stizus actually entered the new burrow, where, after a brief tussle, she was chased out by the owner and angrily pursued for a distance of three feet (see fig. 4I). Thomae's wrath soon cooled and she devoted her-

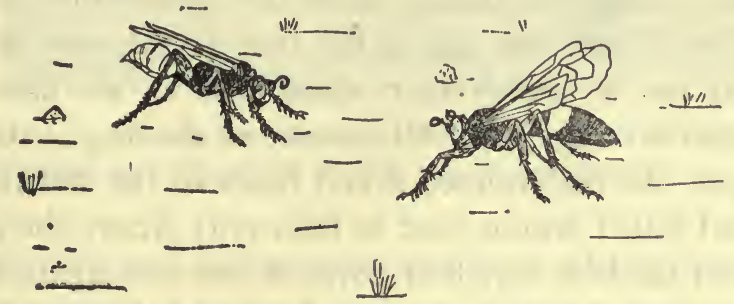

F.G. 4I. Priononyx thomae and Stizus unicinctus. Exact size.

self to digging for about five minutes, and again visited her prey and brought it, in precisely the same manner, to within six inches of her hole, where she left it in a clump of short grass and resumed her task of adding the last critical touches to the future nest of her offspring. During her visits to the hopper, we watched carefully and found that no other stings were given to it, although its hind legs sometimes quivered. She dug for ten minutes more, then got the prey and carried it directly in front of the hole, went in for a moment as usual for one final survey to see if all was in readiness, then reached out and seizing the hopper's antennae, pulled it in. Just a short time previous to this, we had looked into the burrow and had seen a large cinder, which she had failed 
to remove, projecting into the gallery; this now obstructed the way so she had trouble in getting her property in, but she worked strenuously inside the hole, and, with our assistance on the outside, worked her locust in after five minutes' labor. Again Stizus was seen lurking about in the vicinity of the nest.

$P$. Thomae came out and filled her hole carefully, first by carrying in mouthfuls of soil and precisely arranging it on the inside, and then kicking more dirt in and going in after it to pound it down, making a loud hum as she pressed with all her strength against the tightening soil. In getting dirt to fill in, she first took that nearest the hole and when this was gone, instead of taking all of the earth which she had kicked into a hill, she dug at the foot of this tiny hill and hollowed out a semicircular space just as we have seen $P$. atratum do (fig. 37). Of course, as she dug at the foot of the pile, she undermined it and much of the dirt tumbled down and rolled into or near to the cavity where she needed it. When the hole was half covered, she was again visited by Stizus, but she at once gave chase and the meddlesome intruder fled. The task of filling and covering was continued, and when this was done, several cinders, large in size but of light weight (see fig. 42, exact size), were brought in the mandibles and placed over the spot. A collection of twelve such cinders was taken from her mouth, with the forceps, as she brought them to the place; this shows how tame she was or how accustomed to our presence she had grown. She surrendered the cinders to us peaceably and without defiance; however, we did not pull them away from her but merely held them firmly with the forceps so she could not move them further. So she gave them up, or she may have merely thought that they were too heavy or too tightly lodged for her to move. After a few more kicks, she abruptly flew away. 
HUNTERS OF LARGE ORTHOPTERA I85

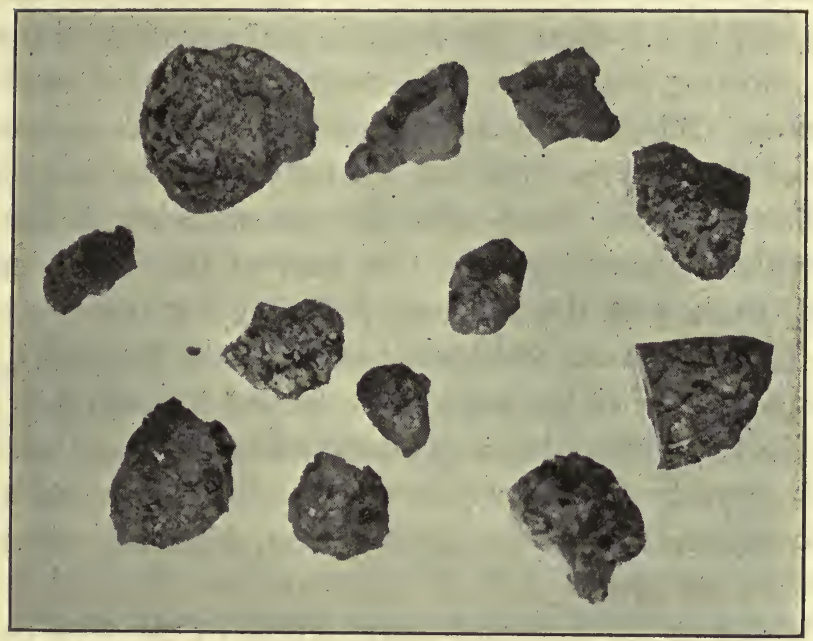

FIG. 42. A collection of cinders, exact size, carried in the mandibles of $P$. thomae and deposited on the top of her burrow.

Our flesh and bones were weary of sitting on all fours on the cinders for two hours and it was growing late, but still we were eager to see if Stizus would show any further interest in the nest. We waited for five minutes and she did not reappear, so we began to dig up the nest and had removed enough soil to expose one of the hopper's tarsi when behold! Stizus appeared upon the scene. We slipped back and she came nearer and nearer to the nest by walking zigzag, following almost arcs of circles around the hole, with her head close to the surface and antennae vibrating, until she came to the nest. She located it apparently with less difficulty than wasps sometimes experience in locating their own nests. She approached in the manner of one familiar with the situation and having business there. She kicked away much of the filling until she had removed the hard plug and arrived at the loose material beneath; then she 
worked her way into the nest at the right side of the hopper, remained in for about five minutes and emerged at the left side, showing that at least she could turn around inside the chamber. She went in again and this time we removed a little of the soil, yet could not see fully what she was doing; but this much was clear-that she was standing on the hopper with her head near the fore part of the insect, quietly sitting there with the abdomen pulsating for over five minutes. She came out and kicked in all of the loose dirt, then dug up more with her mandibles, kicked it under her body into place, and picked up and placed a few more bits until the hole was once more nicely covered. She then went a few feet away and calmly sat down to rest, when she was taken to secure her identity.

We dug up the nest and found a hole of the type usually made by both $P$. atratum and thomae, only the chamber was unusually long in this case. The hopper lay there with its head to the wall. The egg of thomae was in its usual position on the right femur, at the base of the abdomen, but lo! it was only an empty sac! Evidently Stizus had mutilated the egg by malaxation, or had sucked the contents for food. We found no Stizus egg; but it is probable that, in the difficulty of opening the nest in a harsh cinder bed, it was knocked off by crumbling walls. We know that Stizus did not deposit an egg during her second stay in the chamber, for we could see her abdomen all the while, but we suspect that she was then mutilating the egg of thomae, after probably having laid her own.

We wonder by what sense Stizus found the nest. To be sure, she had returned to the spot while $P$. thomae was at work sufficiently often to get the landmarks of the vicinity; but considering the remarkable way in which the nests are covered and concealed we wonder how she could find the 
exact spot under normal conditions. In this case it may have been easier than usual, since we had already exposed the tarsus of the grasshopper.

After having observed this startling conduct, we were alert for other Stizus. On August 3 I the morning was bright, dry and sunny on the diamond. When a S. unicinctus appeared, foraging after her manner, we followed in eager pursuit. She was flying lightly from place to place, peeping and examining every spot where the bare surface ground (fig. 2) was a little roughened, such as by ant-hills, or little breaks in the bald smooth ground made by hoof or heel. She made no pretense at alighting on smooth or unbroken spots, but flew lightly from one to another. We followed her and watched her for six minutes; in this time, she alighted ninety-one times on the roughened spots and peeped under the clods, but only twice did she alight on the smooth, unbroken earth, although by far the greater portion of the area was smooth. Was she trying to find a Priononyx hole by this method? She flew out over the grassy portion of the field bordering the diamond a part of the time; there, in about three minutes, she made twenty stops. When out over the grass she alighted only at long intervals-whenever she came upon a little bald spot among the grassbut here she alighted on every bare spot she found whether smooth or broken. While on the diamond, where all was bare, she paid attention to only the roughened spots. On one occasion, she appeared to be particularly suspicious of a certain hoof-print and examined it all very minutely; she paused and scratched at five different places in the crescent, and once burrowed so deep that her head was out of sight.

An hour later, on the same morning, we followed another Stizus for a few minutes, as she flew from place to place 
over the grassy part of the field, examining bare or roughened spots just like the one described above. She moved calmly and without haste or agitation. After examining about ten spots in a couple of minutes, she arrived at a certain inconspicuous pile of loose earth, in outward appearance very similar to all the others. Instantly her manner changed. She became greatly excited, nervous, quivering with eagerness. She probed here and there in the pile until, in a fraction of a minute, she had located the filled-up hole beneath one side of the pile, and then eagerly began digging. She burrowed steadily and rapidly in the freshly-stirred earth, and pushed and flung the loose dirt out between her legs and under her body. She worked with the furious eagerness of a dog digging out a rabbit; surely, if she could have barked or snorted, she would have done so. In a minute or so she was through the plug of earth and disappeared into the cell. We waited breathlessly, knowing that this was the time when she was probably crushing the Priononyx egg and laying her own-but we nearly fell on our backs when she came out at once, washed her face thoroughly, rubbed her legs vigorously and unceremoniously flew away, leaving the hole wide open! There was no indication of her returning or giving any more attention to the place, so we dug it up to see if it really was a Priononyx hole, and if she had done anything. The case was quickly explained: the hopper in the $P$. atratum chamber was reeking with parasite larvae, but bore neither Priononyx nor Stizus egg. Wise Stizus! The Diptera larvae had probably devoured the Priononyx egg, and the Stizus knew at a glance that the same fate would befall her babe if she left it there, so she fled from the place at once. Where will adaptations and interrelations cease!

A few minutes later we noticed several parasitic Diptera 
hovering around the wreck of the tunnel, although both hopper and wasp were now gone. How did they know? It did not any longer look in the least like a P. atratum hole, all dug up as it was. Did some Priononyx odor remain on the dirt which she had handled, by which the parasites, and also Stizus, could detect the location?

On one other occasion we opened a carelessly closed, or, as we later concluded, a newly opened burrow which we took to be that of a $P$. atratum, but were surprised to find, beneath the rumpled earth-covering, a freshly-killed hopper and in the chamber with it a live Stizus. What business she had there we can only surmise.

To be sure, the above cases give only circumstantial evidence, which is generally not accepted as proof in the courts of law. Yet we think that the evidence here is strong enough to justify our indicting Stizus as a cow-bird wasp, and one highly skilled in her profession. In this suspicion we are not alone, for Williams also has suggested:

"While the evidence at hand is incomplete, it seems more than probable that the common red-banded bembecid wasp, Stizus unicinctus Say, plays the part of a burglar and uses the locust captured by Priononyx atrata as food for her own young. Unicinctus is a rather compact insect, somewhat inferior in size to and less powerful than the sphecid. . . . In Stanton county one of these wasps was observed to hover about a freshly-made tunnel, apparently that of a Priononyx, which it entered while the sphecid was away. The latter had brought an Aulocara near this burrow, which, being occupied by Stizus, was finally deserted by the disgusted Priononyx.

"In Morton county, July 7, I9II, I came upon a Stizus unicinctus engaged in smoothing over a spot with her feet. I unearthed what proved to be a filled-up burrow, which in 
form and dimensions resembled that of a Priononyx. In the single cell lay a Melanoplus. But where the Priononyx egg was to be expected on this egg was only a small bit of soft matter, probably the remnant of a sphecid egg destroyed by the Stizus, while cephalad of these remains was a short wasp egg, doubtless that of Stizus.

"Certainly the short-legged Stizus unicinctus does not appear to be a sufficiently powerful insect to capture and subdue locusts of the size and vigor of those which serve as the prey of Priononyx."

If we consider this idea tenable, it may throw some light upon the circumstances which obtained when once we found, in different places, three open holes, apparently of $P$. atratum. We opened them further; one hopper had been almost all carried away by ants, another was heavily parasitized by Diptera larvae and nearly riddled, and the third had both ants and parasitic larvae. Had Stizus opened these and left them open like the one described above? We have at other times also been mystified by open Priononyx holes or their grasshoppers ruined by ants. Some such cause must be behind this waste, for it is too frequent to be attributed to mere accident. Furthermore, when Priononyx closes her hole, she does it so thoroughly that it takes a sneak-thief to get in.

Stizus undoubtedly opens the nests for the purpose of laying her own egg. True, we have not found her egg there, even though the Priononyx egg had been destroyed, but this may well have been due to our faulty manipulation in digging. It seems hardly possible that the taste of Stizus can be so perverted that she, cannibal-like, goes into the nest only for the purpose of sucking the contents of the egg, for we find she is a nectar-feeeder. We have often seen her feeding upon the flowers of white snakeroot. 


\section{HUNTERS OF LARGE ORTHOPTERA I9I}

From the above observations we see that Stizus unicinctus has two ways of locating her host: by inspecting all breaks in the surface of the earth where Priononyx nests are likely to occur, in order to locate the nest when closed, and by shadowing the Priononyx while she is storing her prey and closing the hole. This evidence shows that Fabre's ${ }^{10}$ idea in regard to Ammophila, that the insect is endowed with certain marvellous and mysterious powers, an unknown sense, which draws her to her subterranean prey, cannot apply to Stizus, although we are sure that, from a literary standpoint, Fabre's chapter on An Unknown Sense will live. True, her powers are wonderful, but it seems to us after witnessing the above, that she finds her host, not by magic, but by energy and persistence. Here again, "genius is only the capacity for taking infinite pains." We ourselves usually find Prionony $x$ holes by examining the piles of dust or earth-clips which look to us suspicious; so does she.

True, she may possess a delicate sense of smell or other faculty, which may help her to detect the presence of the Priononyx nest when near it, for she must be highly skilled if she can inspect a mound of dust and determine, in five seconds or less, whether or not a securely-covered Priononyx hole lies beneath it. But in the case described above of the Stizus opening up the parasitized nest, it seems incredible that the scent alone could have attracted her to open up this spot. It was natural that the Diptera should be attracted to the hole after the earth that had lain next the decaying hopper had been thrown out on top of the ground, all nicely saturated with hopper scent. Since the flies appeared so promptly when the tainted earth was thrown out, it is evident that they must have been plentiful in the field at that

'10 Chapter on An Unknown Sense, in The Hunting Wasps, 371384. $1915^{\circ}$ 
time, so why did they not come about before the hole was opened? Probably just because the flies could not scent the hopper through an inch or more of well-packed earth. So if the fly, with its highly specialized offactory organs, cannot scent the contents of the nest when it is closed with earth, how can we have the audacity to suspect that unicinctus finds her way to the burrows by the sense of smell alone? Of course, you may say, it is possible that mother Priononyx, when carrying out the earth, leaves her taint upon it. Perhaps so, but even if she does, in this case the condition of the hopper and parasites showed that the nest had been sealed for at least three. days, and surely any taint that Priononyx could leave at her doorway would, in three days of wind and weather, have been reduced to a minimum. Granting that Priononyx does leave an odor, we would again have to prove that Stizus has the power to perceive it in so delicate a degree. It is hard to believe that she locates the nest by the grasshopper .odor, for the field is at that time of year constantly overrun by hordes of grasshoppers, and certainly she cannot by scent pick out a buried one which is just like all the others except that it is paralyzed.

Thus it seems, from the evidence at hand, that the greater part of the responsibility in discovering the hidden nests falls upon the sense of sight, although it is almost beyond belief that any one sense could be developed to such a degree of sensitiveness.

The highly specialized instinct of Stizus to get the hopper only after it is buried is worthy of note. The hopper lies fully exposed for a long period awaiting burial, during which time Stizus ignores it, but suspiciously visits and revisits the hole. Would it not have been less complex if her instinct had been so developed as to lead her to seek 
the hopper as it lay and deposit her egg, and then and there get it out of her system both physiologically and psychologically? But no, the chance of injury to her egg in the transportation of the hopper for burial, and the question of the survival of her young one in a tussle with the infant Priononyx proves her way safer after all, and she is right in wanting to see the food safely in place, the atratum egg destroyed and the host devoid of parasites before she will take any chances with her own young.

\section{Chlorion (Proterosphex) ichneumoneum L.}

While walking over the sparse grass on a clayey plateau, we scared up a large sand wasp, Chlorion ichneumoneum. It created a great commotion, buzzing about our heads in threatening manner until we withdrew. It then returned to its burrow, which was near by, and resumed its digging. The hole was already nearing completion; it went straight down into the ground from an opening one-fourth inch in diameter. About four inches distant was a large pile of pellets of earth (fig. 43), which had been taken from the hole.

Presently she stepped aside to get her prey, which she was from time to time bringing nearer to the hole; it was a long-horned green grasshopper. Then, after the usual manner of certain wasps, she laid it down and went inside once more for the final survey of the pocket, came out and brought the hopper to within one-half inch of the opening; she went in head first, turned around and poked her head out just far enough to grasp the hopper's head and then dragged it down out of sight. A minute later she appeared at the surface for just a moment and at once went down and remained inside the burrow for three minutes. 
When she emerged again, she flew away directly, leaving the hole wide open. This was at $12: 30 \mathrm{p} . \mathrm{m}$. We thought she had gone for another hopper; but when she did not return by 3 o'clock, we opened the nest. The hole went straight down into the hard soil for seven inches, then it turned at a right angle and in the direction just opposite to the pile of pellets, continued for three inches and terminated in an enlargement or pocket (see fig. 43, one-third natural size). (The pocket in this one was somewhat larger than that illustrated by the Peckhams.) In it were four green, long-horned grasshoppers, Orchelimum vulgare, one of which bore a young larva which appeared to be a Dipterous parasite. Another female nymph, which was larger (body-length five-eighths inch), bore a yellow, slightly curved egg three-sixteenths inch in length. The other two hoppers were males measuring nearly three-quarters of an inch in length. They were not active, but were still able to move the antennae and mouth-parts when stimulated.

By the evening of July 28 , two days later, the wasp larva had grown enormously. It had eaten the contents of three of the green hoppers and was greedily working over the garbage, a few heads and legs, and actually eating the softer parts of the integument, so we gave it the fourth grasshopper. Shortly after this it spun a weak and incomplete cocoon. Two weeks later we found that this had been ravaged by that pestiferous intruder, Melittobia.

On the same day and in the same place, a second burrow was discovered near the first. This had the same external appearance, a hole five-eighths inch in diameter running straight downward, and a large, neat pile of loose dirt and small pellets four inches away. The wasp soon returned from her flight of alarm and resumed her digging. She would walk in head first and come out backwards and continue to 
HUNTERS OF LARGE ORTHOPTERA 195

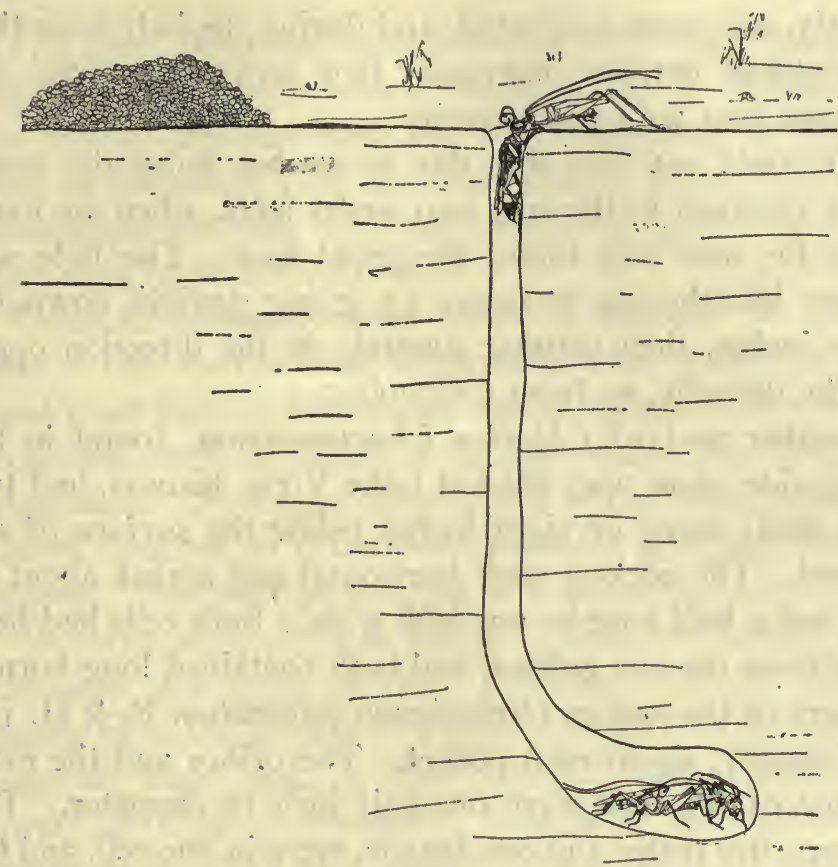

FIG. 43. Chlorion ichneumoneum, her burrow and prey. One-third natural size.

walk back until she came to the dumping-place, where she would release her load and go in at once for another, without looking to the right or left. These trips to and fro were repeated with all the mechanical air of clockwork. The load of dirt was carried in the mouth while the front pair of legs helped to hold it in place. She dug out a big mouthful of the loose, crumbling soil for each trip, and would probably have lost much of it on the way if she had not supported it in her jaws with her fore-feet. After carrying out and dropping several loads with mechanical precision, she would pause to clear the path of any débris and to brush up the pile with her legs. Although she worked 
intently, she seemed agitated, and during the half-hour that we watched her, she nervously flew away five times, for no cause that we could perceive.

We could not wait that day to see her finish the work, so we returned to the spot two weeks later, when we excavated the nest and found the pupal case. The hole was exactly like the one in figure 43, going straight down for seven inches, then turning squarely in the direction opposite the dirt-pile, to form a chamber.

Another nest of Chlorion ichneumoneum, found in the sunny side of an open shed at Lake View, Kansas, had two cells about seven or eight inches below the surface of the ground. The pockets were horizontal and sealed, about an inch and a half long by one inch wide. Both cells had been made from the one gallery, and both contained long-horned hoppers of the species Orchelimum calcaratum R. \& H. [A. N. Caudell], six in each pocket. The orifice and the main burrow of the hole were one-half inch in diameter. The hoppers, five males and one female, were in one cell, and the egg was fastened to one, ventro-laterally, between the first and second legs; in the other cell were three males and three females, and the egg was on the ventral side of one. Barth ${ }^{11}$ finds that this wasp has several cells leading off at right angles to the main passage, and that it stores its nest with as many as twelve grasshoppers.

For this species, Hancock' ${ }^{12}$ notes substantiate the observations of the Peckhams. In addition, he found the prey to be females of Orchelimum delicatum and $O$. vulgare and both sexes of Conocephalus attenuatus. He found one wasp to weigh 5 grains and four hoppers weighed 7 , IO, I I, and Io grains. One wasp made-two nests in succession close together.

11 Bull. Wisc. Nat. Hist. Soc. 6: 134.1908.

12 Nature Studies in T'emperate America, p. I95-20I. I9II. 
The prey from our two nests survived their sting and imprisonment equally well. The next day, in one cell, one had rotted, one had died and four responded to stimulation; in the other cell, one had rotted, one responded to stimulation, and four were motionless, but apparently living. Four days later, all were dead.

These $C$. ichneumoneum also are annoyed by various pests. The ever-present Melittobia were found in their pupal cases kept at home, although in nature, when the underground nest is closed, it is improbable that they can reach them. A hopper taken from one of their nests had a larva attached to it that was probably a Hymenopterous parasite. Our attempt to bring it to maturity failed.

We have noticed these wasps feeding on flowers, both goldenrod and sweet clover. Robertson records them as feeding upon the flowers of various species of Solidago, and Cockerell finds that, in New Mexico, they frequent the flowers of Cleome serrulata. Folsom in his Entomology figures an insect of this species with pollenia of milkweed attached to its legs. Fernald ${ }^{13}$ finds that they visit the flowers of sumach, clematis, asclepias, mint, etc., and says that the species has probably the widest distribution of any of the Chlorioninae in America. He has seen specimens from various states in the United States, and gives references of their occurrence in Brazil, Guatemala, Nicaragua, Costa Rica, Panama, Guiana, Venezuela, Cuba, Jamaica and Santo Domingo. Howard ${ }^{14}$ says that this species is gradually extending its northward range.

Pierce finds this insect to be the host of the twisted-wing parasite, Strepsiptera. Adams says that the larva of this species is probably devoured by the parasitic fly, Metopia.

13 Proc. U. S. Nat. Mus. 31 : 402. 1907.

${ }^{14}$ Cir. Bureau Entom. 97 : 2. 1908. Footnote. 
Howard gives a good figure of this wasp in The Insect Book, P1. 5, fig. 18.

Davis ${ }^{15}$ found the following prey in the nests which he opened: Atlanticus dorsalis, three in each of two nests and five in another, and elsewhere he saw a wasp carrying a Conocephalus triops. Packard, in his Guide, says they use Orchilimum vulgare or $O$. gracile. Our records mention only Orchelimum in their nests. All of these are the longhorned grasshoppers, for which they show a preference.

\section{A Locust-hunter that Makes Twin Cells.}

All summer long we had scoured this bare spot in the field almost daily (fig. 2), yet it was the middle of September before we discovered the first burrows of an unknown wasp. The mouth of the hole, open, is about three-sixteenths inch in diameter, clear-cut, and might easily be mistaken for a beetle's or spider's hole, while the neat little mound of dirt nearby is almost indistinguishable from the dainty little ant-hills which abound in the field. Sphex pictipennis carries out and piles up the dirt in the form of little chips; Priononyx and Bembix kick it out as dust, but this species brings it out and piles it up in granular form, only a trifle coarser than that of the tiny ants. She must understand the art of keeping herself modestly inconspicuous, and must work without all the bombastic commotion in which Bembix indulges, for we have never been able to catch her at her wọk.

One of these piles of granules aroused our curiosity on September 15. We examined all the earth about it carefully, but could detect no trace nor scar on the ground where the soil had been disturbed, so with the trowel we shaved off

${ }^{15}$ Journ. N. Y. Ent. Soc. 19: 218. I9I I. 


\section{HUNTERS OF LARGE ORTHOPTERA I99}

the surface of the earth for several inches around. This at once revealed a hole, newly refilled, which went down to a depth of less than an inch, when it expanded into a pocket, one inch long and three-eighths inch in diameter, lying almost horizontally. At the far end, this chamber contracted into the channel again with its diameter of three-sixteenths inch and a length of about one-fourth inch; this portion also was filled in with a compact plug of fresh dirt. Beyond this, the hole again expanded, forming another pocket exactly like the first. Each of these cells contained a grasshopper, Melanoplus femur-rubrum, neatly tucked in with its head toward the rear wall. Each hopper carried an egg fastened to the femur, near the abdomen, in the precise spot where Priononyx attaches her eggs. We took them home but were unable to rear them.

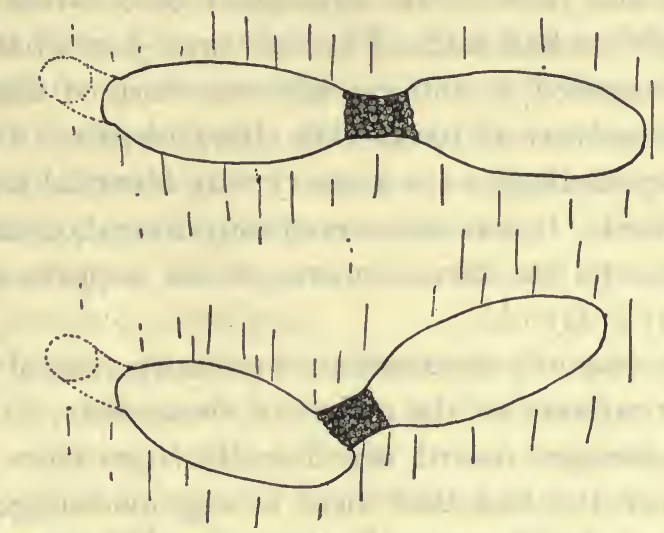

FIG. 44. The twin-celled nests of an unknown wasp. Exact size.

A few feet distant we found another pellet-pile similar to the first. Only by the same method of search, scooping off the surface earth, did we discover a second nest almost identical in form with the first: two cells lying horizontally with a constricted part between them filled with dirt (fig. 
44), and in each cell a hopper bearing an egg in precisely the same position as before. One of these eggs hatched two days later, September I7; by the next day it was developing rapidly. The other egg was probably injured by the crowding of too many hoppers in a small tin box. Two of the hoppers died three days later, and one died after six days. The larva which hatched devoured its food speedily, leaving only the hardest parts of legs and integument, and it grew with astonishing rapidity. Just nine days after the discovery of the egg, the larva began to spin. It made a small area of brown silken carpet under itself, but had difficulty in forming a cocoon in the small tin box, which was quite different from its natural earthen cell. We tried to shape a little nest of cotton around it on which it might get a hold, but it could not adapt itself to its strange surroundings and died in the attempt at cocoon-making.

Although we had learned by this time just what to look for, we succeeded in finding only one more of these nests, during the summer of I9I 5. The characteristics of this nest and its surroundings were in every way identical with those just described. It was discovered only four days later than the others, and the larva on one of the hoppers appeared to be about a day old.

Another season's observations were unsuccessful in clearing up the mystery of the maker of these nests, so we give forth this meager record which really is no more than to make known the fact that there is a ground-digger, probably a wasp, which makes horizontal twin cells and stores them with one locust each.

Chlorion cyaneum Dahlb. [S. A. Rohwer].

We hereby enter our protest against Chlorion cyaneum: we spent over fifty hours during one summer intently 
watching and following members of this species foraging, without once seeing them do anything more than hunt. One could seldom spend even a little while in the field adjoining the brick-yard without seeing one or more of these blue Chlorions foraging among the cinders, but without getting anything. It seems probable that they detect their prey only by the sense of sight, that they prowl about, in their characteristic manner, entering holes and crevices for the purpose of finding prey, and that they are not attracted to certain holes by other powers, such as scent, hearing, etc.; else they would not waste such a vast amount of time on hopelessly fruitless areas. The prey of these wasps is crickets, and the habitat of crickets is never in beds of cinders, some of them freshly dumped and still hot. Yet these wasps go on prowling about every accessible crevice and continue searching long after one's patience and endurance have been exhausted. Sometimes they enter the same hole many times without finding anything. This would lead one to conclude that they hunt more or less stupidly and that each detail of their actions is devoid of psychological significance; possibly they are attracted to the cinders by the large number of inviting crannies, and not by any indication of the presence of crickets.

Two years ago an entire afternoon was spent in watching the similar behavior of these wasps at the foot of a strawstack. Although they did not, to our knowledge, have the good fortune to capture any crickets, they were more justified in seeking them under wheat straw than in dry cinders.

One warm morning in Kansas we found a $C$. cyaneum in a sandy plowed field, hurrying homeward with her cricket, probably a Gryllus abbreviatus Serv. [A. N. Caudell]. She travelled briskly, her cricket apparently no burden, and laid it down only once for a moment. She carried it, head forward, under her body, and at one time flew with it for about 
three inches. She moved in a manner that indicated that she knew where she was going, and yet we are not certain that she was going anywhere in particular. She went straight across the field for thirty feet until she arrived at a deep furrow down the side; then she turned at a right angle and followed directly down this for twenty feet more and plunged into a mole-hole. She may have used it without hesitation simply because it happened to be in her path, but she travelled with all the precision and familiarity of a man walking home from his office and turning in at his own door. She remained in the hole nine minutes, then emerged hastily and soared off to the woods again. We tried to dig out the burrow, but our searches in the loose sand were all in vain.

While, in this instance, we found $C$. cyaneum dragging her cricket across the field, this method seems not to be constant. Hungerford and Williams ${ }^{16}$ write that in Greely County; Kansas, one was observed climbing a clay bank, carrying a mature female of Centhophilus, evidently striving to reach an altitude sufficient to enable her to fly to her nest. and the Peckhams find that one, after running a little way, arose and flew lightly, for about eighteen feet, to a hole on the bare hillside. Here, too, Peckham's wasp differed from ours in that it had its hole in readiness on the surface, while ours, if she had a hole, had it concealed in a rodent burrow. The Peckhams illustrate a very pretty burrow of this wasp in which one egg was deposited amid seven crickets, Gryllus abbreviatus Linn. From their later observations, they find she does not make a new nest for each egg, but she provisions a number of cells leading from one gallery. They $\operatorname{record}^{17}$ a very interesting incident which gives one the im-

16 Ent. News 23: 247. I9I2.

17 Bull. Wis. Nat. Hist. Soc. I : 85. 1900. 
pression that she is attracted to a favorable spot for prey by her auditory sense. She "stood in the doorway, turning her head now to this side, and now to that, as though listening, and now we became conscious of the fact that a cricket was chirping loudly nearby. Perhaps she was getting the direction from which the sound came, for, after a little, she flew to the top of a tall weed, then dropped and entered a hole below, from. which she issued a moment later, with a very limp specimen of Gryllus abbreviatus." Of course it remains entirely possible that this wasp, which seems to be possessed of a mania for peeping into all holes and crevices anyway, was not attracted at all by the cricket's song. Furthermore, this implies that she has auditory organs on the head just because "she turned her head now to this side and now to that." In fact, it has never yet been positively demonstrated that they have auditory organs anywhere.

\section{Chlorion (Isodontia) auripes Fern. [S. A. Rohwer].}

We have never yet seen this wasp catch its prey, but we place this account of certain aspects of its behavior in the chapter, "The Hunters of Large Orthoptera," for two reasons: first, that Fernald ${ }^{18}$ places this, as well as the two preceding species, in the sub-family Chlorionini; and second, that Davidson ${ }^{19}$ finds that a sister species under the name Sphex elegans, now called by Fernald Chlorion (Isodontia) elegans, uses tree crickets for the nests containing young.

One July morning we saw on the barn door a wasp carrying a piece of excelsior about three inches long. It was such an unusual sight that we ran to observe it, but, without warn-

18 Proc. U. S. Nat. Mus. 3I : 356. 1907.

19 Ent. News 10: 179-180. 1899. 
ing, the wasp quickly flew out the door and escaped. A few nights later, at twilight, one of this species, possibly the same individual, but without her burden, was flying about the inside wall of the barn. Eventually, she settled in one of the holes in the wall. Thinking that this was her nest and hoping to get more of her story, we did not take her then. But on the morrow, we sorrow fully learned that this was only her sleeping-quarters and not her nest at all. One more fleeting glimpse of her some days later carrying a large wheat straw only tantalized us and whetted our curiosity. So when, many days after, the twins came running to the house shouting, "It's there! It's there! the wasp with a stick in its mouth!," the family broke in disorder and ran to the spot. Like the populace rushing forth, craning their necks skyward, to view the first modern aircraft to appear above a village, so we ran hither and thither watching the maneuvres overhead of our grass carrier wasp. She wheeled and circled about, and finally landed at her burrow in a log in the corncrib. It was an old carpenter-bee hole, completely stuffed with grass. It seemed that the straws had all been drawn in by their middle, so the ends protruded from the orifice in a broom-like tuft. We removed this material, and found nothing but grass. However, we could not reach to the bottom of the burrow with the forceps.

This nest was the counterpart of several which we had seen about that time. All of them seemed to be old bee or beetle burrows in logs or timbers, and all were similarly filled with this material, tightly crammed into the hole. These nests did not appear until near the end of our sojourn in the country, so we did not learn, first-hand, the use or purpose of these straw structures, so like a bird's nest.

On the morning of our last day with them, we saw one out gathering her grasses. She alighted on a leafless branch 
of a plant and tried her jaws on it, but apparently it was too tough. She turned to a blade of green grass, which bent and swayed under her weight when she alighted on it. As she bit the blade off with her jaws, I expected to see her tumble when it severed, since she was sawing the branch on which she was sitting. But while the cut portion was hanging by a mere thread, she spread her wings and flew away, breaking it off as she flew. On her next trip, she flew far away and returned after four minutes with a long timothy stem protruding four inches from her body. These wasps always carry their grasses under their bodies, grasping the anterior end in their mandibles, and alight and enter the hole without shifting their burden. When we visited them on October 3, three were at work all the forenoon, busily carrying dry grass into their chosen bee-holes, and even at $4: 45$ p. m., when it was quite cloudy and dismal, one was still faithful to her task. Thus the season ended without our having ascertained whether they use this material for bedding, for food or as a plug to close the orifice.

We are not alone in this observation, for Packard ${ }^{20}$ finds the same insect, under the name Sphex tibialis St. Fargeaur. behaving somewhat similarly. He says Mr. J. Angus, who reared this species, sent him a larva in a cavity previously tunnelled by Xylocopa virginica in a pine board. The hole was six inches long, and the oval, cylindrical cocoons were packed loosely side by side where there was room, or one a little in advance of the other. The interstices were filled with bits of rope, which had perhaps been bitten up by the wasp itself. The end of the cell was filled for a distance of two inches with a coarse sedge arranged in layers, as if rammed in like gun-wadding. The cocoons are 80 to 90 hundredths of an inch long, oval, lanceolate, somewhat like

${ }^{20}$ Guide to the Study of Insects, p. I68. I889. 
those of Pompilus. They consist of two layers, the outer very thin and the inner, parchment-like. The larvae hibernate and turn to pupae in the spring, appearing in summer and autumn.

A similar type of behavior has been reported by Davidson for a sister species, under the name of Sphex elegans: "For nesting sites they prefer the larger stems, first gnawing through the thin partitions opposite the leaf insertions which naturally divide an otherwise hollow stem. The parent wasp first packs the bottom of this tube with very fine grass-like fibers, which on investigation prove to be fine strips of the loosely fibrous bark of Audibertia polystacha, from one-fourth inch to one and one-fourth inches in length. On this is laid the larval food supply, which consists, on an average, of from seven to eight tree crickets. The egg is laid on the breast of one of the crickets, a wad of bark fiber is placed on the top which forms the base of the next cell, etc. A copious wad, sometimes three or four inches in depth, protects the topmost cell."

The prey of Ammobia bridwelli Fernald. [S. A. Rohwer].

Late one August afternoon, at Meramec Highlands, Missouri, this wasp was seen entering her burrow in the soft, loose earth, under an open shed. Since it was impossible for us to remain there, we captured the wasp and dug up the nest. It was well provisioned with the long-antennaed Orthoptera, Camptonotus carolinensis Gerst. [A. N. Caudell]. They were eight in number, three males and five females. The earth was so loose that we could get no idea of the shape of the burrow. 


\title{
CHAPTER XI
}

\author{
The Sand-Loving Ammophila
}

Sphex (Ammophila) pictipennis Walsh. [S. A. Rohwer].

When the time comes for Sphex pictipennis to respond to the impulse for nidification, she proceeds about her important business quietly and without much commotion. She appears not to be especially exacting in the choice of a location, as do some species of wasps, although occasionally she is seen to abandon a place where she has begun a hole, and seek another. Usually, however, she alights upon a suitable spot, a bare area in a sunny, open field, and begins her excavation in a matter-of-course way. With the mandibles she cuts out the firm soil in the form of little chips; walks to a chosen spot about four inches away, and piles these chips up, load by load, in a nice heap. So faithful is she to this habit of piling her fresh dirt at a precise distance from her hole that often only that has served as our clue in locating a completed nest. These characteristic piles of chips are easily recognized, even when the holes are perfectly concealed. By scooping off the surface soil in a circle of about four inches radius around this pile, the burrow is almost invariably brought to light. Only once have we seen an exception to this habit of carrying the dirt to some selected spot: in that case the ground was so dry that it was easily pulverized, and as the wasp bit out each load of dirt, she stepped back an inch or so from the hole, in this direction or that, and threw it 
into the air, where it made a little puff of dust as it blew away in the breeze.

She digs her hole straight down for an inch or an inch and a half, then fashions an oval, horizontal pocket or chamber about three-fourths inch long and one-half inch high (fig. 45 ). She works without either haste or hesitation, but with precision. When at length the last mouthful of dirt has been carried out and she feels that the burrow is ready for use, she comes out and hunts for a little clod. She usually finds something suitable within a few inches of the hole, but she is very exacting in her selection and will not be satisfied with anything which falls short of her specified requirements, even though she must seek for some time. This clod must be just large enough barely to cover the mouth of

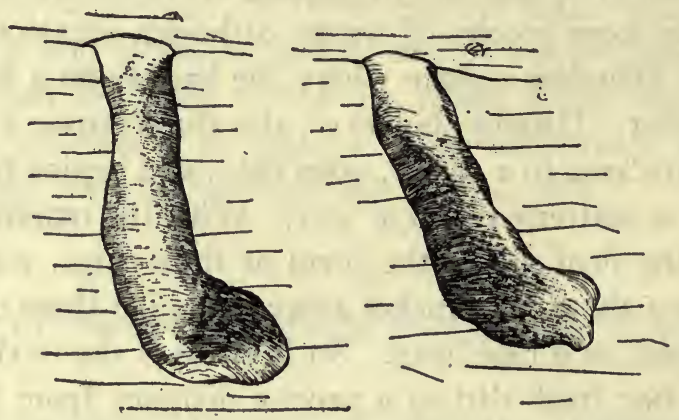

FIg. 45. The burrows of Sphex pictipennis. Natural size.

the hole, or to fit into it like a plig, but it must not fall into the burrow. We have seen her use a bit of stem of just the right size. This she places carefully over the entrance, to close it to intruders during her absence. Sometimes she throws one or two kicks of loose dirt over and around the spot, more completely to disguise the place. Then she goes off on the wing in low flight over the grass and weeds in quest of prey. 
The duration of her absence varies. Sometimes she meets with early success in her foraging and returns with her caterpillar in an hour; sometimes she is out as long as six or eight hours, presumably in her search for prey. We have never been so fortunate as to witnèss this part of her work. We have seen her out foraging in the field, to be sure, hopping from leaf to leaf or flying over the grass, scanning the weeds as she lightly passes over them, but we have never seen her at the critical moment of the capture of her prey. But, sooner or later, she comes trudging home with her burden, which often is a grey cut-worm. At this part of her task she is, naturally, more conspicuous and more easily discovered than at any other time. We must not be surprised that she sometimes has some difficulty in progressing with her load; rather we must be astonished that she can move with it at all. The caterpillar is very often four times her own weight, or more, yet she brings it through grass and roots, clods and gutters. We have never seen an $\mathrm{Am}$ mophila give up a caterpillar because it was too heavy for her. Sometimes, however, the prey is so small that she can drag it with ease or even lift it clear of the ground and make rapid progress. She practically always carries it in the same manner; she turns it on its back so the smooth, rounded back will slide on the ground like a sled-runner; then she stands astride it, grasps the skin at the sides of its throat until it is drawn to look like a tight collar around the caterpillar's neck, lifts the anterior end a little so only the rounded dorsum will touch the ground or obstacles, and away she goes on all six feet. Once or twice we have seen her grasp it by the middle segment instead of by the throat, and lift it clear of the ground (fig. 46). On one occasion, when a wasp was in grave difficulties in getting her caterpillar through a tangle of grass, she managed it very ingeniously by lifting one end of the burden and prop- 
ping it, almost vertically, in the fork of the grass, then lifting the other end to a slightly higher point. Thus, lifting

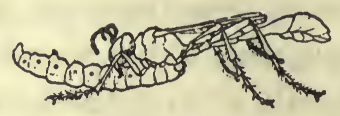

FIG. 46. Sphex pictipennis carrying a small caterpillar. Natural size.

the ends of the caterpillar alternately, she hoisted it out of the chasm in the grass-thicket into which it had fallen, exactly as a man, working alone, would hoist a heavy timber little by little. Our $A$. pictipennis always walks forward with her prey beneath her, as did the Ammophilas observed by the Peckhams, in contradiction to Westwood who says that Ammophila, when she has captured her prey, walks backward.

In this point of her behavior we see the grossest error in economy committed by Ammophila. She spends an enormous amount of energy and time in trundling her heavy caterpillar from a considerable distance, we know not how far, and then dragging it all over the region in the vicinity of her hole while locating the burrow. Since she uses but one caterpillar, she might save all this needless waste of time and energy by doing as Priononyx does, digging the hole conveniently near to the prey after it has been captured. The topography about the nest is usually very similar in nature to the environment of the prey and she seems not to be very particular about the location. To be sure she has a preference for beaten paths and sunny bald areas, but she as often uses any little bare spot between the weeds and grasses for her nesting-place. So why should such a stupid habit persist, entailing frequent loss, danger and expenditure of effort, while all of her other methods of work have become so refined and highly developed? The only explanation that we have to offer is that 
many other members of this genus use more than one caterpillar, and naturally have to return to the hole repeatedly. Perhaps in pictipennis this habit is a vestige of the time when she too used more than one caterpillar and must therefore have an established nesting-site.

After she arrives in the general region of her nest, there often ensues a long search for the exact location. She wanders here, there and yonder, dragging her booty with her. She seldom lays it down or leaves it; perhaps this is to guard it the more constantly from the parasites which are usually following. But occasionally, when her search has gone on in vain for a discouragingly long time, she will leave it while she hunts for the burrow, after which she usually searches as clumsily again for her caterpillar. Sometimes she hunts for an hour or more for her burrow, and occasionally she is utterly unable to find it and gives up, abandoning both prey and nest.

When finally she arrives at the nest all in readiness and waiting, it takes her only a moment to remove the plug and enter backwards, dragging the caterpillar after her. There is none of the monotonous performance we see in some species of wasps of digging at the hole a few minutes, then going and examining the prey, then digging more, etc. Many times it appeared to us that the hole was surely too small to receive so large an object; but the wasp judged better than we, for in every case it was large enough, with only one exception. This case of abnormal behavior is perhaps interesting enough to warrant narration.

We came upon the scene of an unusual performance in the life of Ammophila - the wasp had left the caterpillar lying beside the hole while she was digging the burrow deeper. It was a large caterpillar, and very fat. At length she essayed to take it in, but it was too large for the opening. She tried various ways, and yanked it this way and 
that, but each time when it would not go in she would lay it aside and dig the hole deeper, or at least enlarge the chamber at the bottom. At last, in another attempt, she dragged it in after her, but it became lodged when only one-eighth of it was protruding-hence she could neither push it out nor herself escape. We waited for a time and saw that the situation only meant death to her, so we came to her assistance. (Thus our humanity! If she had been alone with Nature she would not have left any posterity perhaps to perpetuate her stupidity!) We pulled it out with forceps-but already the Dipterous parasites which had been lurking nearby had done their deadly work, for a half-dozen squirming larvae were at the neck of the caterpillar. As it was pulled out, some of these were brushed off and fell down into the hole. She showed neither anger nor surprise at the assistance that had been rendered to her, but she appeared satisfied with the disposition of her property. She came out and picked up a large, firm pellet, took it down into the hole with her and remained quite a while, brought it up for a moment, then returned with it and remained inside for another period. Then she came out once more, threw this pellet aside and gathered a half-dozen other smaller ones, which she took down into the burrow. Oh, if we but could have seen what she was doing with them down there in her dark chamber! Did she use the first large one to kill the parasites which infested her nest? Or did she instinctively feel that it was now time to bring in material for the partition or plug at the entrance to the chamber? Hardly the latter, because when she emerged, she promptly dragged her caterpillar in again as if nothing had happened. This time she succeeded in getting it a trifle lower, so the rear end was level with the surface of the earth; then she seemed to encounter the same difficulty as before. Five minutes elapsed, and she could move it neither down nor up. 
Unfortunately, we had to go then, so we dug up the nest. We watched carefully for the tiny Diptera larvae, but if they were there they were lost in the digging.

Two minutes is all the time the wasp requires for adjusting her prey and ovipositing, and sometimes she is through in less time. (Figure 47 shows the position of the egg on the caterpillar.) Then begins the task of filling the hole, and in this she works in a most calm and purposeful manner, disturbed of course if one crowds too near, but with no silly

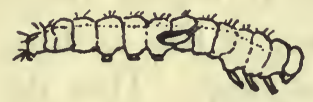

FIG. 47. Position of egg on caterpillar. Natural size.

nervousness. She emerges head first and immediately gets some small clods, usually about three, and takes them down to the bottom. We suspect that she arranges these to serve as a partition between the chamber and the burrow, to prevent the loose soil from being packed down around the caterpillar or crowded upon the delicate egg. Then she jumps out nimbly and scratches and kicks the loose dirt nearby into the hole, goes in and stands on her head, pounding and packing it down. With each ram of the head, she emits a shrill buzzing sound. How this buzz is made we do not know, nor do we know whether it is an expression of pleasure, or of labor, or a mechanical part of the effort. Thus she brishes in and packs down several layers of loose dirt, until the hole is filled almost to the top. If she uses all the loose dirt lying nearby, she is not in the least disconcerted, but simply bites some more loose, with her mandibles, from the surface of the ground and uses that. When the depression is yet about one-fourth inch deep, she fetches a large, firm clod, sometimes as much as five times as large as her own head, and throws it into the hole. At first it 
appears that she is using this method as a quick way to fill up her hole. But no, she settles herself for work again, grasps the clod firmly in her mandibles and, for a minute or so, she rubs and grinds it fiercely against the bottom of the depression, with a rotary or side-to-side motion, until, under the pressure and wear, the clod crumbles and is worn to dust and becomes part of the compact filling. She then turns round and round on top of the hole, sweeping to the center the dirt which has been pushed out at the edges of the saucer-shaped depression, fetches another clod from somewhere within a distance of two or three feet from the hole and repeats the performance. Thus she uses sometimes as many as ten or twelve clods, grinding, beating and biting them to pieces, until the top of the fill is level with the ground. In this way she works the fill down much tighter, for we have often seen her use several pellets and pound them in after the hole appeared level full.

In her next selection she seems to be more particular. She goes here and yonder, pausing at clods and tiny pebbles, sometimes lifting them or turning them over. When finally she finds one which suits her fancy, usually a pebble a little larger than her head, but sometimes an unusually hard clod or bit of wood, she brings it in her mandibles and, grasping it firmly, she rubs, pounds and hammers down the dirt on the top of the hole until all traces of the fill are obliterated. When she has finished, we ourselves cannot discern the spot. Her task, so skillfully done, is now at an end; she throws her tool aside a few inches and flits away with an utterly careless air, as if she had forgotten all interest whatsoever in this place-and quite probably she has. It is interesting to note that she cannot be persuaded to use this tool before the precise time for it. Once we tossed her a tiny pebble while she was yet busy grinding to pieces her clods with a pestle-and-mortar motion, but she only took it, without ado, 
and laid it back on her rubbish-heap, where an annoying bit of stick and a troublesome cinder had already been placed. Later on, when she was ready for her hammer, she went directly and, to our great delight, got our pebble which she had so stolidly spurned only a few minutes before. If, in grinding up the clods for filling, one does not readily go to pieces, she does not leave it in the hole for filling but takes it out and throws it away.

Thus she finishes her task with characteristic precision, and leaves it beautifully done. In accomplishing the closing, she devotes about forty minutes of careful attention to a task which wasps of many other species finish in a few minutes.

Here we have not only the record of a tool-using habit of an insect, but also, what is equally rare and valuable, a possible clue to the probable origin of this habit or instinct. We see her using first the loose earth, then clods with which to pack the earth tighter and more tight, and finally using some object one degree harder which will pack down the remaining dust on top of the hole, but will not go to pieces and leave more litter of its own on the site.

This is not the first record of the tool-using behavior of Ammophila. The Peckhams have observed one instance in A. urnaria, and Williston ${ }^{1}$ records the same for A. yarrowi, while Hungerford and Williams ${ }^{2}$ found an Ammophila sp. that used an Acridiid leg for a tool in pounding down the soil. Hartman ${ }^{3}$ finds that with $A$. procera, at the end of the operation of closing the nest, it sometimes happens "that a piece of wood is pressed down tightly, then pulled out and pressed down again, and this repeated several times,

1 Ent. News 3: 85. 1892.

2 Ent. News 23: 244-246.

${ }^{3}$ Bull. Univ. Tex. 66: I7. 1905. 
so that one might suspect that the wasp were here improvising a tool with which to tamp down the sand."

Considering that our tool-using insect described above would have nothing to do with the pebble until a time when it was needed for tamping, and in view of what is to follow as the result of very close observation by the two of us on another pictipennis mother closing her nest, we do think that they actually have highly plastic intellectual powers. Morgan says, ${ }^{4}$ in speaking of the interesting observation of the tool-using Ammophila of the Peckhams: "Here we have intelligent behavior rising to a level to which some would apply the term rational, for the act may be held to afford evidence of the perception of the relation of the means employed to an end to be attained, and some general conception of purpose." But Holmes takes exception to this interpretation of Morgan by saying: "But in estimating the psychic aspect of the performance we must bear in mind that the act is one which borders closely upon the normal instinctive behavior of the insect. The seizure of pebbles in the mandibles and the packing in of dirt are parts of the instinctive process of filling the hole. The wasp combines two features of its hole-filling instinct in a rather unusual way. Does she really perceive the relation of means to end? I am not sure that she does." Whether Morgan's or Holmes' interpretation is the correct one we hope the details given below will convince the reader. In this connection it may not be amiss to relate exactly the conduct of another of these wasps, through this part of her task.

The wasp, when discovered, was carrying her caterpillar. It was a smaller worm than usual-so small that she carried it in her mandibles by grasping it in its middle, and lifting it clear off the ground, so she could use all her legs freely for progression. She made a pretty sight carrying

${ }^{4}$ Holmes, The Evolution of Animal Intelligence, p. 204. I9Ir. 
her prey in this new-fashioned way. After carrying it for ten feet she dropped it and started to remove the lid off her nest. In our eagerness to see all, one of us pressed too close and she flew away a short distance in alarm. In a moment she walked back to the cut-worm, examined it and gave it a reproving sting on its under side near the pro-legs, but we could not distinguish which pair. She then straddled and seized it in the manner already described, and carried it off, making a very perfect circle about three feet in diameter, and dropped it at the identical spot from where a moment before she had indignantly taken it. A strange way, this, of responding to disturbance! She then gave it two impressions about the head with the mandibles, then passed the tip of her abdomen on its under side as it lay, ventral downward, and felt-or rather probed-in a halfdozen places, sliding her abdomen continuously backward until she reached a spot just in the rear of the last pair of pro-legs; there she thrust in her sting and let it remain for several seconds. We had thought at first, when she felt the integument with her abdomen at a number of places, that she was stinging the caterpillar, but when we saw the way she deliberately thrust in her sting and let it quietly remain there for some time, we decided that these former touches had been only of a testing or probing nature. She then resumed her work where she had left off, and opened her hole by removing one mouthful of clods. She darted in and reappeared almost instanter, carried in her cherished prey, remained inside two minutes, came out again and immediately began to fill the hole. While she was inside, we took the opportunity of observing the site closely. There was very little loose dirt or dust about the hole; all that had been taken from the hole had been carried five inches away, across a tuft of grass, and piled up neatly-in spite of the difficulties of always clambering through the tangle of grass- 
stems. She came out head first and carried in, one at a time, three clods of earth; these we suppose she arranged to form a plug in the angle of the "L"-shaped nest. After that, for a few seconds, she kicked loose dust into the burrow. She also kicked a straw, six inches in length, over the hole; this she carried a few inches away, and later, when it got in her way a second time, she carried it in her mandibles and flew with it for some distance and cast it away. She kicked in more loose earth, and after each portion, went in to ram or pack it down, humming in a discontinuous way - that is, it sounded as if with each ram of her head she notified us with a sharp buzz of like duration.

Thus she used all the loose dirt that lay near at hand; the region was hard and clean. There was yet about one-fourth inch of the burrow to be filled, when she came with a hard clod about five times as large as her own head, threw it into the hole and went in herself as far as possible. We thought this would be an easy way to fill up the burrow, and were surprised to see her grasp it in her mandibles and continuously, for three minutes, press down the earth in the depression with this tool, rubbing with it in a circular motion. But our surprise was greater when we saw her throw out this hard clod when she had tamped the dirt down sufficiently; the easy way of filling a hole was not her way. A much smaller clod was then thrown in and beaten to dust with her head and face. This was plainly to be seen, and this later clod must have been intended for this purpose since the mandibles and head were used to break it up, and no attempt was made to swing it in a circular motion. It is quite likely that this small one could also have served as a tool if she had wanted to use it to that purpose, and we feel sure also that the former one could have been bitten and pounded to pieces with her stout mandibles, had she wished to do so. But she had done the necessary pounding; filler 
was now needed and she made it. The question confronted us of how she would get dust to fill in the rest of the hole. That troubled her not at all; with her strong mandibles she dug up the hard earth nearby and kicked it in until the depression was full, and packed it again with her head. To accomplish this she almost stood on her head, bracing herself with her hind legs. In our eagerness we crowded too near again, whereupon she flew off and walked around for three minutes; then she returned and resumed the work, exactly where she had left off under disturbance, and finished the pounding with her head. She next found a hard piece of clay a few inches away and, using it as before, packed down the loose earth. After rubbing with this for five minutes she left it in the hole, dug up some more earth and kicked it over the site, quite covering this last tool, so she went back to the hole and with her mandibles fished out this same clod and again used it for one minute to pack down the last layer perfectly smooth and level with the surrounding earth. Then she laid the useful clod to one side. The interesting fact is that she should have remembered just where her tool was last left. After an additional few seconds of dust-kicking, to make the spot look exactly like the rest of the field, she flew carelessly away, her task done.

This is the method of work generally followed fairly uniformly, by Ammophila, in her nidification. However, the members of this species show much individuality in their behavior, and meet emergencies in such varied and interesting ways that it will be of interest to note some of their digressions from the usual method.

In the manner of departing from the finished burrow when starting out on a foraging trip, these wasps show so much variation that it has been quite impossible for us to ascertain which is the normal and which the abnormal conduct. We are inclined to believe that, if they are frightened 


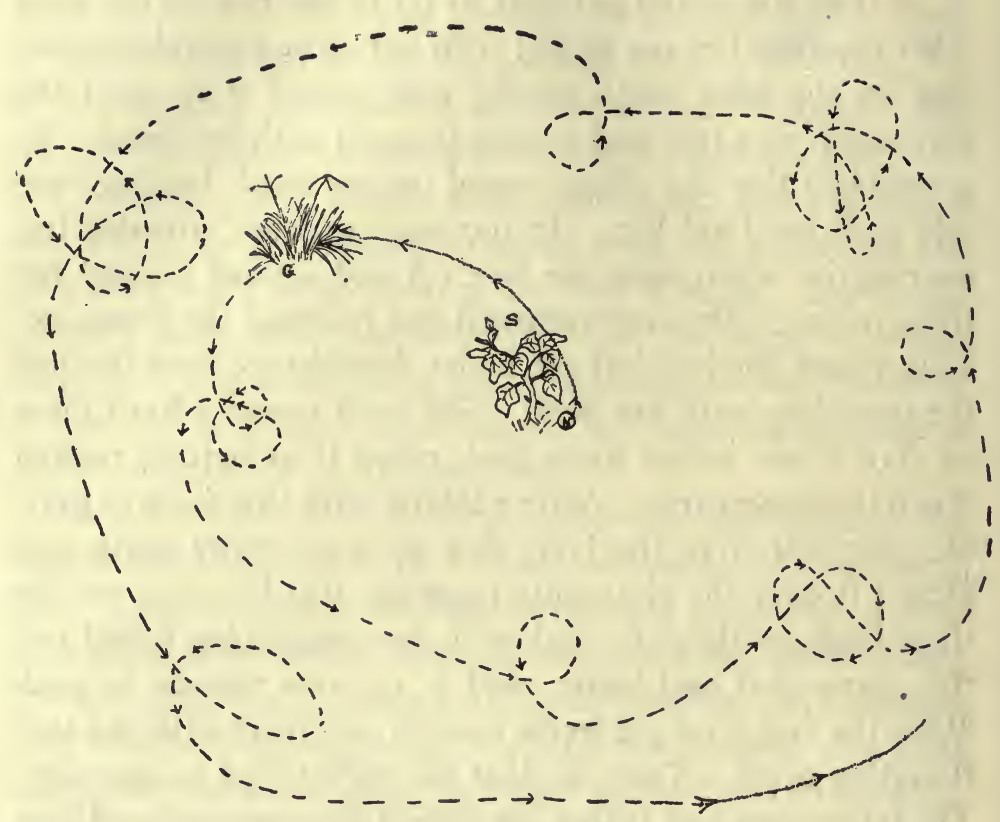

FIG. 48. Diagram to show the way one mother S. pictipennis studied the landmarks about her nest.

away from their burrows, leaving suddenly without getting any landmarks, they have grave difficulties in returning to their nests. Occasionally one departs on the wing from her incompleted burrow, without any appearance of examining the region. More commonly, however, they go around the covered nest in widening circles, first walking near the hole, then running, hopping and at last flying in larger circles, and finally soaring off to the fields in quest of prey. One wasp which we stealthily watched seemed unusually precise in her manner of examining the location before departing 
for the hunting-grounds. The hole was finished, and she had brought three pieces of dirt and carefully covered it. She flew to a leaf a few inches away. From this perch she descended three times to do some unnecessary scratching over the hole. By these maneuvers she may have been getting her landmarks (see fig. 48) -in fact, we suspect that she was, for she walked all over this small Solanum ( $S$ in the figure) which overhung her burrow $(N)$, examining it all the while, and as she came to the leaf directly above her nest she usually peered down and sometimes descended to do some scratching, then returned to continue her examination of the weed. Then she turned her attention to a small tuft of grass $(G)$, the object next in nearness to her nest, and scrutinized it. After this minute examination, she dropped down upon the earth and walked in an almost perfect circle around the nest, not all at once, but in arcs, and at the termination of each arc she would waltz about in tiny circles, sometimes one whirl, and sometimes two or even three times around, and then proceed with the next arc, without once becoming confused in her directions or missing the lines of her well-defined circle. The little waltzing whirls were almost always from left to right, but once she circled from right to left. The accompanying crude diagram (fig. 48) will aid in making clear this remarkable performance. While we had no measure of the length of the arcs, it seemed to us they were wonderfully uniform in size. This precision is only in harmony with the other instances of fine physical judgment which we so often see in the conduct of this wasp. At the conclusion of the first circle, she commenced a second of increasing radius, but as she progressed she got to running and hopping, and soon flew away to the vegetation beyond. A moment later we saw her climbing up a ragweed in the rôle of a forager.

She left at ro o'clock and we could not wait for her return, 
but at 4:30 p. m. we examined the nest and were surprised to find it just as we had left it. We removed the little lumps of clay with which she had covered it, but the hole was empty, so we replaced them; no prey after six and one-half hours! We began to wonder if she had gotten lost in spite of her accurate orientation.

Early the next morning, we again examined the spot and found it tightly filled in. A little careful digging soon revealed the cut-worm, with the delicate egg on its "side. Hence she must have returned to the nest with the prey some time between 4:30 and sunset, after an absence and a search of six hours or more. Her locality study served the purpose of her accurate return, although many marks were required to guide our return.

In another case, the burrow was ready for use and the wasp proceeded to close it temporarily, as described elsewhere, while she went foraging. Here her judgment must somehow have been amiss, for the first two pellets which she brought were so small that they fell down into the hole; but the third was large enough to rest on top nicely like a lid. Then she concealed the spot deftly by adding some other bits of earth and a kick or two of dust, and departed for green fields. She did not take the usual flight of orientation, but began by searching in the weeds nearby. She flitted or hopped from plant to plant, but while doing this her path described a circle around the hole. Suddenly she flew directly away out of our sight. Five minutes later, she returned and continued scanning the weeds in this region, and at one time even walked over her own nest and stopped short on her pile of pellets for a moment, then flew away.

In observing pictipennis, the fact is demonstrated again and again, that the insects, when returning to the object of their search, are not guided by any special sense, but in all probability, as the Peckhams, Turner and others have shown for 
other Hymenoptera, by place-memory. In contrast to the nicety with which they often return to their holes with the caterpillars, witness their difficulty in regaining their prey when they are compelled suddenly to leave it. Recently we suddenly came thus upon one as she was carrying her prey across the low grass, so that we could not check our footsteps in time and she abruptly flew away. We drew back and, though we watched her search for an hour and a half, she never succeeded in regaining it. Sometimes she was very near to it, but seemed entirely unaware of this, and finally she gave up the search.

Another Ammophila left her hole as we came by, but not in apparent alarm. She seemed in search of something and presently picked up a pellet, but she had walked three feet from her hole in her wandering search for a suitable one. During her absence, we marked the location of the nest in the usual method, by pinning a bit of paper near it. This evidently confused her when she returned; she spent five minutes walking to and fro within a radius of a foot of her hole, and many times within an inch of it, without perceiving it. She even walked across the opening three times without recognizing it as her own. On the fourth crossing, she paused and was about to the drop the pellet when she seemed to change her mind; she left the pellet an inch from the hole while she first ventured into the burrow with an inquiring air-an unusual performance; then she promptly reappeared and dropped this pellet and another into the hole, and then went off in the same direction as before in quest of another. The earth here was smooth and sun-baked, and she had to go long distances for clods. She brought the next one from a distance of seven yards and returned, readily enough, to the general region of her nest, but here, within a few inches of her burrow, she sought nervously, for a half-hour, for her hole, sometimes carrying her property 
with her and sometimes laying it down. At last she seemed to stumble upon it, and then turned back to get her burden which was nearby. In her confusion by this time, however, she pulled loose from the earth another little clod and used that as a covering for her burrow. Thus it seems that even a little scrap of paper beside the nest so altered the topography as to utterly confuse this wasp.

Another, which left likewise under provocation, roamed about in the region of her prey for an hour, while we waited at a safe distance, with the camera focused upon her caterpillar. After a tedious hour we both left in disgust, she without her caterpillar and we without our picture.

Instances of this sort only substantiate the "place-memory" idea. When she suddenly leaves her prey in the midst of her journey and has no opportunity of studying the landmarks, even though she be in the immediate vicinity, this wasp is unable, or able only with great difficuly, to find her prey. When she does find it, as she occasionally does, we believe it is due merely to her stumbling upon it by chance as she scours the region, and if the same element of chance leads her footsteps one inch to the right or left of it, it is as lost to her as if she were a mile away. It does not seem that scent or even sight plays a very great part-at least the sight of the object of her search-although probably she must depend upon the visual sense in establishing her placememories. It is barely possible that this might have developed a condition of far-sightedness.

Pictipennis is very select in the choice and treatment of her prey. We have never known her to use more than a single individual for the provisioning of a nest, but these are sleek, fat and meaty, usually of the cut-worm type. Some of them have been identified for us by Dr. Barnes and Dr. McDonnough as Agrostis C. nigrum, and a Hesperid larva Pholisora catullus. Another species often used is identical 
with the illustration in Holland's Moth Book of Lycia cognataria, Guenée. This is a Geometrid that is known to be protectively colored and stiffens out to resemble a dead twig when attacked, yet somehow pictipennis gets it. Another Lepidopterous larva used by this wasp is Prodenia ornithogalli Guen. [S. B. Fracker]. One green caterpillar of the Noctuidae [S. B. Fracker], taken from pictipennis while in transportation, lived eight days.

The impression exists that the cut-worms used by Ammophila are subterranean caterpillars. Kellogg says :" "Almost all cut-worms hide in cracks in the ground by day, feeding during the night," and, since cut-worms are so often used by pictipennis, it would seem that she would be obliged to acquire the subterranean hunting habits of her European cousins. In fact, Turner ${ }^{8}$ describes the behavior of an American Ammophila sp. that digs in the ground for caterpillars with which to stock the nest. This leads him to conclude that "some of our American Ammophilas resemble those studied by Fabre in storing their nests with subterranean caterpillars."

We have never been so fortunate as to observe these wasps at the moment of capture of the prey, but, on one occasion, we saw one whose behavior was such as might easily arouse suspicion. This insect was running about a small plot of ground, in so strange a manner that our interest was at once attracted. It would take short flights in the air just above the ground and suddenly drop to the ground, with a sort of thump, landing on all its legs as if sounding the earth. Here it would walk slowly about the spot for a few seconds, then wheel round in another short flight and repeat the performance. This it continued to do for twenty minutes, until at length it seemed to decide upon

5 Am. Insects, p. 402. 1905.

6 Psyche I8: I4. I9II. 
a certain spot in the broad, barren area, where it began to dig. It would stand squarely on its head and hum a high-pitched little tune while at work. In digging, the mandibles and forelegs were used to chop and break the dry earth while the middle legs were used to brush the dust away at both sides. At first there was nothing to be brushed away, yet this pair of legs worked automatically and prettily. There was no sign of the usual habit of carrying the excavated dirt away to a pile, as is always done when the burrow is being dug. With the hind legs alone the wasp held firmly to the ground. It left the spot several times, as if in doubt or dissatisfied about something, but returned. In a few minutes a neat depression was made; then without provocation or without warning or flight of orientation, it arose and flew far away, never to return. Was it in quest of prey, which in this instance it did not find, or are we misjudging it in this suspicion?

We have never found $A$. pictipennis to provision her nest with more than one caterpillar, although the Peckhams found that $A$. urmaria stores two caterpillars in each nest. Williston ${ }^{7}$ finds that $A$. yarrowi $\mathrm{Cr}$. stores four or five caterpillars, and Hartman ${ }^{8}$ says that the large $A$. procera "capture and store but one immense green tomato caterpillar, while the smaller specimens of procera bring in three caterpillars. Kellogg ${ }^{9}$ finds that an Ammophila sp. which inhabits the salt marshes near Stanford University uses from five to ten paralyzed inch-worms for each young wasp. According to Sharp, ${ }^{10} \mathrm{~A}$. hirsuta chooses a single larva, of considerable size, belonging to one of the nocturnal Lepidoptera. Fabre ${ }^{11}$ finds that $A$. julii stocks each

7 Bull. Wis. Geol. \& Nat. Hist. Surv. 2: $25 . \quad 1898$.

8 Bull. Univ. Tex. 66: I3. 1905.

9 Am. Insects, p. 494.

${ }^{10}$ Insects, Pt. 2, p. II I. 1895.

${ }^{11}$ Hunting Wasps, pp. 259, 419. I9I7. 
cell with two medium-sized caterpillars, and that the silky Ammophila, $A$. holosericea, puts as many as five caterpillars in the burrow, although much smaller ones than those taken by $A$. sabulosa, $A$. argentata and $A$. hirsuta. These last three species use only one for each cell, but here bulk makes up for numbers, for the game selected is large, plump, and capable of amply satisfying the grub's appetite. Martineau, ${ }^{12}$ too, finds that $A$. sabulosa uses but one caterpillar. Parker ${ }^{13}$ found a nest of Sphex urnaria containing four larvae of Geometrid moths and one large caterpillar. Peckhams find that Ammophila polita Cress. uses five or six caterpillars. This wasp, they say, has an especial interest in that it shows a transition stage between the wasps that provide a store of food for their larva all at once and those which feed their young all through the larval period. Latter, ${ }^{14}$ however, finds that $A$. sabulosa provisions the nest with two large caterpillars, and he also finds that $A$. campestris returns to the nest, bringing a fresh caterpillar every morning for several days. Thus we see that there are other species of Ammophila besides pictipennis that provision each cell with but one caterpillar.

What a privilege it would be to see the actual capture and first paralyzing of the prey! We have never yet been so fortunate. We have only seen the huntress come trudging homeward across the grass or bare earth with her game already stilled and ready for burial. On one occasion, however, we had the opportunity of seeing a performance which was probably very similar to the first attack of the wasp upon the caterpillar. We saw an Ammophila out, evidently in quest of prey, and placed in her path a large, plump caterpillar which had shortly before been abandoned by another

12 Entomologist 28: 375 . 1896.

13 Proc. Ent. Soc. Wash. 17: 75. 1915.

14 Bees and Wasps, p. 23. I913. 
wasp in her long, hopeless struggle to reach her burrow. The second or foraging wasp became aware of its presence when she was within an inch or two of it, "sniffed all around with her antennae," and at once located it. She did not pounce upon the caterpillar with violence, as we had expected, but paused and examined it closely, running to and fro, eagerly examining first one end and then the other alternately several times, then pinched it in a number of places along the ventral surface, and bit it on the throat close under its head several times so viciously that we thought that she was deliberately decapitating it. Then she released her grip and turned it over, dorsum up, mounted its back and curved her abdomen deftly around it until she planted her sting behind the first pair of pro-legs. The caterpillar, which had heretofore lain motionless, drew up quivering. Then the wasp withdrew and inserted her sting behind the second pair, administering a prolonged and most deliberate sting, and also behind the third and fourth-four slow, sure stings. Then she lifted and inquisitively shook its head and then shook its tail a bit, as if to make sure that it was really done for, turned it over on its back, straddled it and, with some difficulty (for it was an exceptionally large and heavy caterpillar), got started with it across the smooth ground. She grasped it with a terrible grip of her mandibles, and part of the time with her first legs too. She dragged it in the usual fashion, dorsal side down. Then followed the endless chase; she seemed now to be hunting for her nest in this locality, and sometimes appeared to be preparing to dig as if to uncover it, but it may have been destroyed, or she may have been badly mistaken in her location. She trailed here, there and yonder, sometimes several feet away, and then came back to this vicinity only to wander off again. She ran around so much with that caterpillar that we thought surely it would be worn to shreds 
before she would use it. As time passed by, her journeys away from the original point became longer. A thunderstorm was approaching, but neither the dark clouds nor the first pattering drops of rain drove her to desist. This wandering and vain search had continued relentlessly for over two hours under the August sun and the dark clouds; and we wonder how much longer she would have continued it, had not a horde of romping boys passed by and frightened her away.

Thus she apparently accepted this proffered caterpillar and treated it as her own. The stinging certainly could not have been done with more precision. The malaxation is said to be a regular part of Ammophila's treatment of her prey, and occasionally, if a victim does not seem wholly and completely submissive, she will pause in her journey and administer some more pinching, kneading and shaking.

Again and again we have been astonished at the remarkable tameness of Ammophila when building, provisioning or closing her nest. This cannot be attributed, as we thought at one time, to defective eye-sight, for when she is alone, without a caterpillar or a nest to detain her, she is very evasive, and usually many attempts to approach her are futile. But when her interest is absorbed in home duties, she seems self-forgetful and one can usually approach very near to her without her giving heed. On several occasions, when a wasp was in difficulties in moving her caterpillar, we assisted her with her burden with our forceps, and she seemed to take it all as a matter of course, as if we were friendly collaborators. Once, in order to see how she would respond to teasing, we took hold of a caterpillar which an Ammophila was bringing to her hole. She would not relinquish her hold, but gripped the other end, braced herself with spread legs and pulled with all her might. A tiny "tug-o'-war" ensued, until we lifted her clear off the ground, 
still clinging to her treasure. Several times we thus lifted the caterpillar and the clinging wasp into mid-air, and each time she felt herself once more on firm earth she again dragged her prey over to the brink of her hole. On another sunny September morning the feminine partner in these observations was sitting upon the ground, busily writing up the notes of the morning's observations, when an Ammophila came and began industriously digging a burrow right beside her knee, while another, homeward bound with its prey, climbed up on her dress and trundled its caterpillar down the full length of her bare forearm, pausing once and laying the cut-worm down on her hand while it washed its face and looked about inquiringly, then moving calmly on to the burrow beyond.

Finally one day we went so far as to take the caterpillar away from a wasp and place it in the hollow of the hand, flat on the ground, perhaps eight inches away from her. The wasp came without hesitation and got it; in fact, she betrayed less nervousness than we, for she seemed to fear nothing, while we remembered very vividly how wasps often re-sting caterpillars which misbehave, and feared that her aim might not always be accurate.

Later, we removed the caterpillar from the mouth of another wasp, placed it in the bottom of a two-inch vial and laid it flat upon the ground. The wasp soon found it, flew in circles just above the vial and finally rested on top of it for a time, then again flew above it in circles. It was evident that she saw her property, but either she did not find the opening, or feared to go so far into a mysterious place for her prey. We then placed her caterpillar in the neck of the vial, whereupon she promptly went into the bottle, turned around to get her customary grip upon the caterpillar, and happily trundled it off homeward. After she had gone some distance we again robbed her and placed her treasure 
in the neck of the vial; she promptly repeated the performance. Next we placed it at the middle of the vial; again she returned at once, hesitated but finally went in and took her booty homeward. At last we placed the caterpillar in the extreme end of the vial; she certainly appeared to be learning by this time, for she returned promptly, entered unflinchingly and dragged her property out. Once more we tried her, but it is little wonder that, after so much annoyance, she flew away in disgust. The reader may give whatever interpretation he chooses to this experiment, but one who saw the wasp would say that she was a very apt learner in the school of experience.

It is difficult indeed to refrain from using the term "practical judgment" in the discussion of some of Ammophila's ways. It is truly marvellous to see her choosing, with such care and nicety, a little clod with which temporarily to cover her hole while she goes away in quest of prey. She passes by one after another, pausing a moment to look at or sometimes to turn over one which may be a trifle too large or too small, but finally selecting one, perhaps from among a dozen or forty others, which is just right to serve as a lid. If, after adjusting this lid, the nest is still noticeable on the landscape, she sometimes scratches one or two throws of loose dirt or dust around it to render it less conspicuous. We have only twice seen an Ammophila use anything which was small enough to fall into the hole. One of these was a wasp which abandoned her burrow when it was half-dug, and, for some unknown reason, scratched several tiny clods and leaf-fragments into it before leaving. The other case was that of a wasp which certainly appeared to be actually experimenting, and learning eventually by her experience. Her conduct was so interesting that perhaps the details of it will not be out of place here. We found her running to and fro over the bare ground of the 
baseball diamond, at first rather nervously with twitching wings, then calmly as if her mind were all on her quiet home duties. Then we saw that she was carrying little clods, about as large as her head. It seemed that she was trying to lay them on top of the hole, but they all went inside. She did not, however, drop them in with a thump, but she went in with them and came out at once in search of more. She walked all the time (never flew), and seemed to become more calm and serious as the work progressed. She walked here and there, seizing every protuberance on the surface of the hard-packed earth that might serve her, and giving it a vigorous jerk to dislodge it. Presently she reversed her action, took out the clods one by one and threw them away until she had discarded seven clods of the size of her head; then she brought in their place one large clod which was about twice the size of the first ones, and of precisely the size needed. She laid it over the opening and brushed up a little loose dirt-oh, so nicely-over and around it, and departed. In taking her leave, she walked around the nest at first, then circled around by short jumps gradually lengthening into one-, two- and three-foot flights, then a continuous flight in a wider circle, and away she soared to the weeds. We can see no explanation of this juggling with the clods other than that either this was her first nest, or she was not gifted with the usual instinct or skill in judging exactly the right size of clod, and she learned it only by experimenting. At a later stage in the nest-building, clods are regularly taken down into the burrow; is it not possible that this female, who was probably possessed of defective instinct in one phase or another, had momentarily confused this temporary closing with the permanent closing?

After the caterpillar has been stored in the chamber at the bottom of the burrow, a plug of clods is always placed in the mouth of the chamber to prevent the dirt falling in 
around it when the gallery is filled. This, too, is fitted in with pretty accuracy. Sometimes a single clod is used; sometimes two or three form the partition. In one nest which we dug out, the mother had utilized a round pellet of rabbit's dung for this purpose. It fitted the hole so nicely that it must have been forced in with considerable energy.

Even in their ways of meeting obstacles which chance to come in their way, Ammophilas display more than the average good sense. They do not merely kick the objects back out of their way temporarily, but they pick them up and carry them away, or, in the case of straws or leaf-fragments, they fly with them to a safe place to deposit them. How unlike this is to the stupid Pompilus marginatus which we saw digging in the bottom of a little funnel-shaped depression where a clod rolled in upon it and seriously hindered it. Six times the silly creature carried that clod up and laid it on the brink of the depression, from where, as soon as her back was turned, it rolled down again and bumped her. Thus A.pictipennis seems to be a tidy and exact housekeeper in all details; she always carries out the dirt and piles it up in a neat mound at a certain distance from the hole, and in the direction opposite the horizontal chamber at the bottom. In one case which we noticed, the site of the hole was surrounded by grass, but even this difficulty did not defeat her; she carried all her diggings to the appointed spot, even though she had to carry them through a tangled tuft of grass which must have been to her a veritable jungle.

Another abnormal instance which caught our attention was an unusually large nest. It was already about two inches deep, a little beyond normal depth, when we found it, and the wasp was continuing the excavating. There were two piles of dirt; one, the smaller, was almost at the brink of the hole, and the other twelve inches away. She was carrying all her diggings to the more distant pile all the time 
we watched her. She carried large loads, and the soil was sandy and crumbled readily; so she bore each load with both front legs around it. Some species of wasps reserve near at hand just enough dirt to fill up the channels of their burrows when they close them, and throw away all that comes from the deeper chamber. It is possible that this individual showed a reversion to this type, or was a sport just developing it, but we fancy that it is more probable that she was merely a freak, since when we dug up the hole we found the horizontal chamber much larger than usual. The caterpillar, one of only medium size, seemed quite lost in it. It might be that the pile near the orifice had been accidentally dropped when she emerged from so great a depth. It may seem to some that we give an undue amount of attention to petty details of this order, but we want to record every point and search every detail which might lead or contribute to knowledge of the origin of new habits.

The duration of the period of development of the larva of Ammophila, or the time from the deposition of the egg until the pupation of the larva, is brief but somewhat variable. One usually finds the egg hatched on the second day, unless it has been deposited late in the day, in which event the little larva, about five $\mathrm{mm}$. in length, is not present until two days after oviposition. By the fifth day of its existence, the larva usually becomes large, fat and white, and the next day, or at most two days thereafter, it spins its white, silky cocoon. During the growing stages, the larva seems only to suck the juices of its host; but, if it is hungry on the last day of its gormandizing, it sometimes devours even the tough, withered carcass of the caterpillar. When it has attained its full growth and is ready to spin, it announces the fact by a peculiar way of writhing to and fro. We have not yet ascertained the real reason for these contortions. However, it is interesting to note that Ammophila always pupates 
with its head towards the opening or exit, whether it be in a glass vial or in the natural earthen nest.

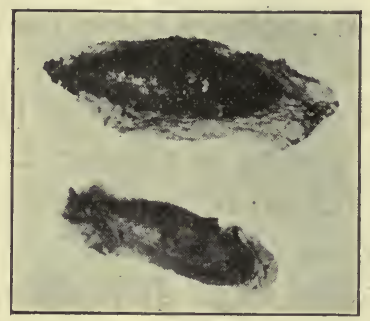

FIG. 49. The pupal cases of Sphex pictipennis. Natural size.

We have the exact record of the duration of the pupal period in three cases. The two summer larvae, which pupated June 5 and July $2 \mathrm{I}$, emerged as adults on June 28 and August 9, after pupal periods of 23 and 19 days respectively, while one which spun its cocoon a little later in the season, September Io, remained dormant until the surprisingly late date of September 24 of the following year, or through a pupal period of one year and two weeks.

The newly-spun cocoons (see fig. 49), like that of Odynerus dorsale and $O$. geminus, are at first beautifully milky white; later they become brown, sometimes of a light shade, and sometimes dark. However, when these larvae spin in glass vials, their cocoons are not symmetrical as in their native habitats, and, after the silken part is done, some thick strings of black substance remain. This is probably the excrement which normally is spread or thrown over the silken cocoon to darken and reinforce it.

Sometimes the larva seems very greedy in devouring the last dried bits of its shrivelled caterpillar, but, although it appears hungry, it seems discriminating in the choice of its food. We have been unable to induce it to take other food, although we have offered it a tempting variety-Cecropia 
caterpillars, flies, tent-caterpillars, spiders taken from mud nests, or pupae of Trypoxylon.

Ammophila, like all the others, is haunted by persistent parasites. One little Dipteron often follows her like a bad conscience, persisting unwaveringly for two hours or more at a time as she drags her caterpillar here and yonder in search of her hole, poising in mid-air, always about twelve or fourteen inches behind her, advancing, retreating, turning with every movement of her leader, as if firmly attached to her in some invisible way. If pictipennis lays her caterpillar down and leaves it for a time while she searches, this parasite will sit down at her usual safe distance and watch it until the owner comes back and claims it. Like parasites of other wasps, it seems to have no interest in a host left lying thus exposed, but is eager about it as soon as it is taken away with a prospect of being buried properly.

We are unprepared to make any statements regarding the frequency of parasitization, but it is not uncommon, for we have several times dug up nests only to find the caterpillar heavily infested with Dipterous or Hymenopterous larvae instead of serving as nourishment for Ammophila's larva.

The adults, too, have their enemies. We once rescued a pictipennis which was being carried off in the mouth of a robber-fly, Proctacanthus milberti Macq., and Mr. George M. Greene records ${ }^{15}$ that he found the adults stylopized by Eupathocera sp.

The adults have been seen feeding on the nectar of the dandelion, and Robertson ${ }^{16}$ records them frequenting about eight species of flowers.

We have only once caught a glimpse of the mating of this species. In the dooryard of a farm-house one June

15 Ent. News 28: 94 . 1917.

16 Trans. Acad. Sci. St. Louis 6: 455. 1894. 
day we were watching an $A$. pictipennis taking her caterpillar home at a galloping speed. Suddenly, we knew not whence, a male swooped down upon her. She was knocked from her caterpillar, but at once resumed her work; she appeared much confused and bothered by his persistent intrusion, but she did not pay him any particular heed. To our surprise, another male in great agitation dashed down and violently bumped the first one, and for a few seconds fought for her possession; then it departed. After perhaps three minutes the first male departed unceremoniously. The female showed no concern for either his presence or his departure, but went ahead with her work, as though glad to be at peace again.

Sphex (Ammophila) procera Dahlb. [S. A. Rohwer].

A three-mile walk along a country road on September 9 gave us many glimpses of Ammophila procera along the way. We soon learned that when we saw a member of this species in the sunny spots in the road, we would presently see the second nearby. They seem always to play and frolic in pairs. The two would whirl about each other in the air, in a playful manner, then one would suddenly fly in a straight line along the wagon-track in the road, with the other close behind it. The leader would then come to a rest on the road or on a stone, and the other would at once do the same some distance away. Sometimes they would sit thus ignoring one another for from three to five minutes, when one would rise and hover or poise over the other resting individual; this seemed to be a signal to follow, and so it usually did. Sometimes, however, like playful children, they could not readily be coaxed away in this manner, but the leader would make a few circuits in the air a few inches 
from the resting body. Occasionally it proved difficult to arouse the playmate, and sometimes it was necessary to administer a few hard blows with the abdomen on the abdomen of the loiterer to make it wake up. This is not mating. This performance of dancing in the air less than five feet from the ground, chasing one another on the wing, resting flat upon the ground near together, has happened so often in our observations in various times and places that we feel confident that this play is a constant and characteristic habit of $A$. procera, and not the antics of an individual or group. We are also sure that it is play and not courtship, for among the one hundred or more seen that day, only two were females.

At Fox Creek, on August 2, we saw different aspects of the mating of $A$. procera on the sandbar. Here there were about a hundred males and only three females. The males were chasing one another and flying about near the ground so wildly and playfully that we could not tell what they were until we took them in the net. But the females' behavior was different. They would walk about slowly in a small space as if under the pretext of looking for something. Sometimes, during a brief period of this, a number of males would, at different times, swoop down for an instantaneous mating, then fly away again and join the others in the dance, seldom or never returning to her. This behavior is somewhat different from the one case observed a few years ago at Lake View, Kansas. Three procera, two males and a female, clinging together in a mass, were flying slowly from plant to plant.

At Moselle, Mo., many large $A$. procera were flying about in courtship, not on the hot sand but usually in the low, wet places near a stream. They never rested long enough for us to ascertain the species without capturing them. One would follow another in a straight line for a long distance; 
when it overtook the leader, the two would describe circles and figure eights about each other in a vertical plane about six feet high.

Although $A$. procera were abundant at this place, only two females were seen making burrows. The females seem to be of a frivolous sort, in comparison with $A$. pictipennis. Perhaps at the time when they were observed, they were in that restless stage of courtship. It may be that, after they are properly fertilized, they begin work with real earnestness. However, since our observations on this point are the same for July, August and September in three different localities, without their improvement towards industry, we are skeptical toward this excuse.

The one $A$. procera which we found digging her burrow was at Moselle. The hole was one-half inch in diameter and, when we found it, was deep enough to include half the length of her body. The wasp would dig, head downward, for a time, then back out of the hole and fly a short distance to drop the load of dirt. In five minutes' digging, she doubled its depth; then she flew away to a pile of rocks, as if looking for prey, and never returned. October I we saw an $A$. procera temporarily closing, with chips and clods, her new hole which she had made in the soil among the roots of an uprooted tree.

One was seen digging in the friable soil of a small, barren area amid low vegetation. Later in the day, the nest was dug out and found to be the characteristic "L"shaped nest of $A$. pictipennis, but larger. This burrow was one-half inch wide, went down vertically with only a slight slant for one and one-half inches and terminated in a horizontal pocket one inch in length. The proprietor was out foraging, and had left the hole temporarily covered. Loose soil filled the tunnel at the orifice to a depth of one-quarter inch; beneath this was a large clod dextrously placed to hold up the loose earth. 
At Allenton, Mo., July II, I9I6, one of these wasps was searching for something half-way up an almost vertical clay bank, five feet high. Soon she discovered her big green caterpillar, Nadata gibbosa [S. B. Fracker] which was lying there; she took it up between her legs and continued her journey straight up this steep bank, with astonishing rapidity. She held it just as $A$. pictipennis does, with the dorsum of the caterpillar toward the ground, although in this case such a position seemed unnecessary since she held the caterpillar, which must have weighed about eight times as much as she, high enough from the ground to make friction impossible. It was difficult to follow her among the weeds on top of the bank. It is doubtful if she knew where she was going, since three times in course of her rambling travels she climbed the trunks of trees to the height of three to five feet, as if she were getting her bearings; then she would fly down with her burden and continue her journey. Presently she abandoned her caterpillar, seeming unable to reach her destination.

When the caterpillar, Nadata gibbosa, was picked up after she had discarded it, it seemed unable to respond to stimuli in any but the last segment of the body. The third day it was still alive and responded with both anterior and posterior extremities.

When one walks along the road and sees, as described above, $A$. proceras fly ahead of one in a straight line, pause a moment, then fly further on, etc., one thinks that this might serve as a method for dissemination, and that wasps continuing this for a number of hours each day, for several days, might soon be far from their fatherland. But, after observing their ways carefully, we are sure that they do not roam very far from home, although they appear to. On that day in particular we followed many wasps. They would fly along the road in a straight line and lure us 
on, but since they could not outdistance us, we soon found that, after they had travelled thus from three hundred to five hundred feet, they invariably turned back. If we continued to follow them on their return, we would arrive nearly at, and sometimes beyond, the starting-point, where they would usually disappear in the weeds. We could see no females at work along the roadsides. Even though the males should migrate along the highways, this alone would not be a factor in their dissemination while the females remain near the old home, since the female alone decides the home site. The abundance of males shows that they do not die off as early as do the males of Bembix mubilipennis.

We have been able to examine only two species of $A m m o-$ phila in the field, $A$. pictipennis and $A$. procera, but we feel that there is some little evidence to indicate that $A$. pictipennis is phylogenetically older than $A$. procera. A. pictipennis ingeniously carries her prey underneath her body with the smooth, dorsal side against the earth. She is so small that the prey must drag on the ground, and, if the ventral surface were against the ground, the legs would offer resistance; so we invariably find her carrying it with the smooth, rounded surface downward. A procera carries her prey in precisely the same manner, but the point that we would make here is that the wasp is so large and its legs so long that, when the caterpillar is hugged up close to the body, it is well off the ground, so here we see the uselessness of turning the scratchy legs from the ground. Yet the habit persists, and we can see in the habit only the vestige of one which was a necessity in the older species. A. procera often seems only a giant variety of $A$. pictipennis, since it is practically the same in color, form and all respects excepting size. One can easily imagine certain individuals of the pictipennis group, a little larger in size, getting larger caterpillars, and the consequent effect of a superabundance of 
food upon the emerging wasp and its resultant ability to grapple in turn with large prey. Then when the intermediate forms had dropped off, there would be left only the two distinct forms, $A$. pictipennis, which uses one mediumsized caterpillar, and $A$. procera, which uses one large one, with the instincts of nest-building and carrying prey not at all changed.

A. procera seems to be one of our most husky species for enduring the cold of autumn. On October 28, at Clifton, Illinois, we took three specimens and saw many others on the bluffs of the Mississippi. The days were sunny, but the nights were very cold.

They have many times been seen feeding on the flowers of white snakeroot and Melilotus, and the species is reported by Banks to frequent the flowers of Ceanothus. The only enemy mentioned for this wasp is the tivisted-wing parasite recorded by Pierce.

The behavior of this insect has been worked out by Hartman. ${ }^{17}$ He finds her very tolerant of human company, which our Missouri wasps are not. The work of excavating occupies about thirty-five minutes; the gallery is nearly vertical at the top and runs down in a gentle curve until it becomes almost horizontal where it widens out into a spacious pocket. The large individuals, he says, store but one immense green tomato caterpillar, and the smaller ones several caterpillars. He tells how a pair of females had a duel over a caterpillar, and relates various pretty incidents.

After the custom of many wasps of her group, $A$. procera does not sleep in individual nests, but assembles in small groups to sleep. The reason for this gregariousness in sleep has not been ascertained. We watched one such group of these wasps which returned, night after night, to the same dried stem, about three feet tall, which stood in the midst of abundant green vegetation. Their mandibles were locked 17 Bull. Univ. Tex. 6: II-20. 1905. 
in the stem; the body and legs were extended and rigid. Sometimes the legs touched the plant, and sometimes they

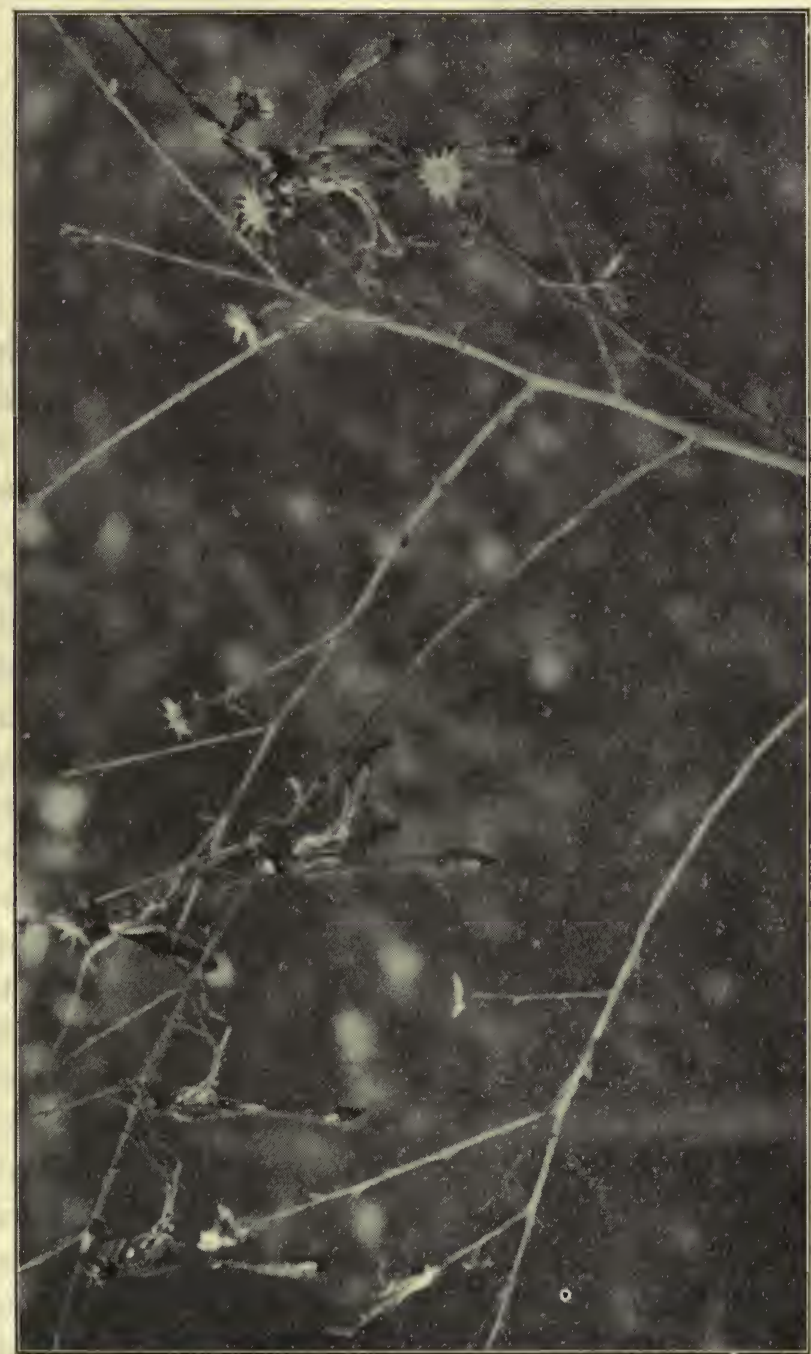

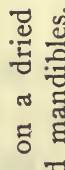

ఫิ సี

แั

๘

ปั

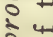

है

올 들

है.

इ :

ॠ

फ

ป ํํㅇ

है

.

के

$\geqq \cdot \frac{00}{4}$

(1)

윰

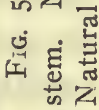

were spread free in the air. (See fig. 50.) This group varied in number from five to fifty according to the time of the season. 


\title{
CHAPTER XII
}

\author{
Some Social Wasps
}

Experiments on the Homing of Polistes pallipes

The ability of Polistes pallipes to find its way home to the nest when carried in complete darkness and liberated at distant points has proved a fascinating and fruitful experimental study. Fabre found that Cerceris tubercula returns home in a fair proportion of instances, when liberated two, or even three, kilometres from the nesting site. $\mathrm{He}$ also found that a mason-bee exhibits similar ability. These, of course, are solitary Hymenoptera. It is indeed marvellous that even a few of them should return, in consideration of the fact that these insects do their foraging near home and, in all probability, had never before visited the spot from whence they were liberated. Fabre lays undue stress upon the fact that some of these insects returned, but fails to explain why the others did not do so. He cannot attribute their return to memory; but, to use his own words: "to some special faculty, which we must content ourselves with recognizing by its astonishing effects without prețending to explain it, so greatly does it transcend our own psychology." We suppose, however, that he is willing to apply this last statement only to those which made the successful return, for this explanation, vague as it is, does not apply to those which dropped by the wayside; for them he offers no theory. He neglects also to consider the age, experience and probably the sex of his subjects, and to make the markings of identifi- 
cation on the insects of a permanent nature, so that it could be certain that any one wasp was not accidentally used in more than one experiment.

In our work on the homing of Polistes pallipes, these factors are all carefully considered; with permanent markings, with consideration of the age, experience and sex of the subject, the results that these experiments show can be explained without transcending human psychology.

Polistes pallipes is a social wasp having three forms of individuals in a colony; the queen or female, males and workers. They are natural paper-makers, manufacturing the paper for their nests from weathered wood. They mix the woody pulp with a fluid substance from their mouths and form it into the cells of their nests. The nests are made by a single colony in one season, and all but the fertilized queen perish with the cold of autumn. At the approach of winter the fertilized females crawl into sheltered nooks and remain there, in a dormant condition, until the warm weather of spring awakens them. They at once construct a nest, lay an egg in each cell, and, when the larvae hatch, they feed and care for them until they transform into perfect insects. The first brood consists of workers only, and these at once take up the task of enlarging the nest and caring for the larvae, for after this first brood has developed, the queen does nothing but lay eggs. The workers are undeveloped females, and, if the queen dies, the burden of egg-laying is assumed by one or more of the workers. Later in the season, the queens lay eggs which develop into perfect males and queens. These mate, the males and workers die and the females hibernate. (Lewis.)

Throughout these experiments it is well to remember this important point: that the queens spend the winter in some sheltered nook, and hence have had some experience not only in the previous autumn's roaming, but also in flying about 
looking for a place of hibernation, and during the sunny days of autumn they often come out of their nooks for play and sunshine (see page 282). Furthermore, in spring, when nidification begins, they fly about in search of pulp for the nest, insect food for the larvae, and nectar for themselves. All of these things are mentioned merely to show how it is possible for these activities to add to the topographical experiences of the wasps, and how age is a factor worthy of consideration in experiments of this sort. After hibernating, the queens begin nest-building in April or early May, and work all alone until the workers emerge about the end of June. During these two months, it is of life-and-death significance to the brood that the queen learn the environs of her nest.

The first series of experiments were made with queens. At this time, June I9-30, the nests were in an ideal condition; each nest had from twelve to sixteen cells, some with pupae, some with large larvae, some with an egg and still others unfilled. All of this is an index to the queen's activities outside the home.

An item of value, too, was that, with one queen on each nest and the nests distributed in the dozen outbuildings usual to a farm yard, no markings were needed, and a series of markings was used only in later experiments, after the workers had emerged. The queens were usually gently shaken, without handling, into a wire fly-trap and, in complete darkness, carried to a distant point; hence the factor of possible injury was eliminated.

In all of the experiments but one, the mass of cages was given, while moving and still in complete darkness, a series of turns in every conceivable direction, the more to confuse the inmates' sense of direction or location.

The work was carried on at a hill-top farm twenty miles south of St. Louis. A half-mile east of the house ran the 
Mississippi river; the Meramec river was one-half mile to the north; two miles southward was the town of Kimmswick, and to the northwest, by a winding road of two and one-half miles, lay the village of Becks.

The experiments will follow in chronological order, instead of a more appropriate order, since many of the wasps were used in more than one experiment.

\section{Experiment $I$}

June 19; weather bright and sunny. Queens from nests $\mathrm{I}, 2,3,4,5$ and 6 were taken at $4.53 \mathrm{p}$. $\mathrm{m}$. and carried in complete darkness along the level road for one-eighth mile, in a northerly direction, to the rural mail-box. This road led through a wheat-field and corn-patch with a strip of dense woods midway, over which the returning wasps would have to fly. The wind was blowing toward the south, a direction favorable to their homeward journey.

All of the wasps returned to their nests; no. I made the trip in $25^{\mathrm{T}} / 2$ minutes, 2 in 25 minutes, 3 in 22 minutes, 4 in 24 minutes, 5 in 49 minutes and no. 6 in 72 minutes. Their behavior upon being released was as interesting as it was ، varied. The wasps, in order to reach home, must fly directly toward the south. No. I flew into the air to a height of six feet, made a complete circle and flew toward the west and was lost in the glare of the sun; no. 2 went up for about seven feet, made a quarter-circle from the west to the north, and landed in a tree fifteen feet beyond the point of release; after a minute it left the tree and flew southeast for about five hundred feet, when it was lost to view. No. 3 went east and alighted on an oak tree; no. 4 went southwest for about one hundred and fifty feet and then dropped into the wheatfield. No. 5 went west for two hundred feet, then made a complete circle, flew northeast for one hundred and fifty feet, landed in a tree and remained there for a few seconds; 
leaving here it described a quarter-circle and travelled three hundred feet in a northwesterly direction, where it alighted in another tree and was lost to sight. No. 6 went directly northward and landed in an oak tree; in leaving here it turned its course abruptly toward the southeast and was soon lost to sight.

The great variation in the initial directions of their flight, and the marked difference in the intervals at which these queens returned would tend to show that the point of release one-eighth mile from their home was new to their experience, and that they reached home by virtue of the method of trial and error, or perseverance.

Of course, if they flew above the tree-tops they could have seen, if they had so great a range of vision, the conspicuous group of farm buildings which was their home; but at that height they could also have seen a strikingly similar group of buildings at the same distance westward, which they might easily have mistaken for their own. But, regardless of the cause or the method, it is wonderful to know that every one of these six queens made the return flight in from 22 to 72 minutes. This experiment shows, at least, that if some unknown force draws them back to the nest, this force does not act by the most economical method as to either time or space.

\section{Experiment II}

June 20. This experiment was made with nine wasps which were carried to Becks. The distance along the road was about $2 \frac{1}{2}$ miles, but the distance as a bird flies was approximately $\mathrm{I} / 2$ miles. Both the home and the point of release were on about the same level; this eliminated the factor of varied elevations. Five of the wasps, nos. 2, 3, 4, 5 and 6 , had been used in experiment I, where they had been eminently successful in making the one-eighth-mile 
flight; the other four wasps, 7,8 , I0, and I2, had never before been used.

These nine wasps were gathered between 8:50 and 9:25 a. $\mathrm{m}$. and placed in individual large test-tubes plugged with loose cotton, the tubes placed under cover and carried along the road to Becks. The contortions of the winding road were even increased by the usual turns of confusion. All were released at one place and time, between 10:50 and I I : I 2 a. $\mathrm{m}$. The temperature was about $92^{\circ} \mathrm{F}$. with no perceptible wind. In order to reach home, they would have to fly southeast.

The return of the five wasps which had had previous experience in the first trial was as follows: no. 2, when released, flew north-northwest and alighted on a telegraph pole, then it made a large circle and dashed away southeast, toward home, but it never arrived at its nest during the eight days we kept watch for it. No. 3 flew southeast for fifteen feet and alighted on a bush, then circled about and flew away north-northwest, in quite the opposite direction from her home. She returned to the nest at 4:05 p. m., having made the trip in five hours and being the first to reach the nest in this experiment, as well as the preceding one. No. 4 flew south-southeast to a bush fifteen feet away, rested for a few seconds and then flew directly eastward, almost the proper direction for reaching home. This one did not arrive at the nest until 9:30 the next morning, after an absence from home of 23 hours. No. 5 when liberated flew for twelve feet south-southeast and alighted for a moment on a bush, then turned its course northeastward. This one did not return that day, but the next day, when our patience was almost exhausted, she came in at 5:45 p. m., after an absence of approximately one and one-half days. No. 6 flew directly westward to a bush twenty feet away. This one never returned, although it too was sought for eight days. 
Thus, of the five queens that had made the one-eighthmile trip, three successfully made the one and one-half-mile flight. What these three did, the other two should have done also, since their domestic interests were alike; each had from a twelve- to a sixteen-celled nest at home to care for, which really indicates that all had had about equal experience abroad. For an explanation of the non-appearance of these two, we can only suspect that they failed in a case in trial and error. The facts that no. 2 made the first flight speedily, that she left the tube apparently in good health and vigor, and that, by reason of the aggressive coloration and severe sting, enemies are few, would all indicate that her nonreturn was probably due to her simply having gotten lost. In the case of no. 6 , however, one might justly suspect that her failure to return was due to her subnormality, since, if she had really been normal, she could probably have made the flight in Experiment I in the same time as the others, instead of thrice the time. Whether or not the three which returned did so by reason of their previous experience will be indicated by the behavior of queens no. 7,8 , Io and 12 , none of which had been used in flights previously.

No. 7, when released at I I :02, alighted on a bush fifteen feet away, and then flew away to the southeast. It returned to its nest the next day at 9 a. m., after an absence of almost one day.

No. 8 flew north-northwest and alighted on a bush fifty feet away. It also reappeared at the nest the next day at $9: 45$, having made the journey in practically the same time as the previous one.

No. Io when liberated alighted on the finger and remained there for fifteen minutes, when it was placed on a flowerhead. This one never returned to its nest, but its languor indicated an illness.

No. 12, when released, sat on the neck of the bottle for 
six minutes, cleaning its antennae with its legs; then fell to the flower-heads below, where it remained. This one did not return the same day, nor the next, but on the third evening at $5: 50 \mathrm{p} . \mathrm{m}$. it dragged itself wearily into the nest, after an absence of almost two and a quarter days.

Thus of the four queens that had not made the preliminary flight, three returned to their nests; two of them did it in the same time as some queens used in Experiment $I$, and one of them in about twice the time. The fact of some evidence of defect in wasp no. Io practically eliminates her from the experiment.

This experiment shows that the short flight near home as a preliminary training is not necessary to insure a successful long flight. The evidence also increases with increased experimentation that the wasps do not return during the night.

\section{Experiment III}

June 2I. Six queens were used in this test, four of which, nos. II, I3, I 5 and I6, were used for the first time. No. I had been used in the one-eighth-mile flight from the mailbox and had been successful; No. 3 had done the same and, in addition, had made the return flight from Becks over a distance of one and one-half miles.

In the previous experiments, the releasing point and the home were at the same elevation. This time the wasps were taken down the hill to an altitude about I 50 feet lower than the home point, carried along the railroad tracks for a distance of two miles, in darkened wire cages, with many turns of confusion on the way, and released at Kimmswick. They were taken from their nests at $8: 45$ and released at $10: 30$ a. $m$. When they were liberated, a very gentle breeze was blowing toward the south, against which they would have to travel to reach home. If they were to return by the curving railroad track, they would have clear sailing, but if they deviated from this, their route would be most difficult be- 
cause on one side were heavily-wooded hills and on the other the bottom-lands between the track and the river were cultivated fields and forest.

The wasps were released on the railroad track just at the edge of the town.

No. I flew north thirty feet, made a circle to the northeast and landed high in a cotton-wood tree. This one never returned to the nest.

No. 3 was released at Io:25; it flew north-northwest and settled in the weeds at the foot of the railroad embankment. It returned to the nest the next day at $2: 30 \mathrm{p} . \mathrm{m}$.

No. I I disappeared down the steep embankment as did no. 3 , but never returned to the nest.

No. I 3 circled above our heads, flew southwest and alighted in a thicket of sweet clover. This one never returned to the nest.

No. I6 behaved in the same manner as I3 except that it made its toilet for four minutes, then flew northward and was lost to sight. It likewise did not return.

No. I 5 first flew southward for a few feet, then curved to a southwesterly course and was lost in the thicket of weeds at the foot of the embankment. This one reappeared at the nest the same day at 7:30 p. m., after only nine hours on the long journey.

Of the six wasps which were started in this two-mile race, two finished, no. 3, the one which had been out on two previous test flights, and no. I 5, out for the first time. It is interesting to note further that the novice made the flight in the shorter time, nine hours, whereas the other on this her third flight took more than a day for it. Of course the factor of fatigue may enter into the case of no. 3. Concerning the four which failed utterly, we can only suspect that they tried but lost their landmarks. ${ }^{1}$

1 We are indebted to Carl Eckart and Carl Witter for valuable assistance in the early part of this work. 


\section{Experiment IV}

June 25. The results of this experiment will have to be ignored, but are recorded here to save confusion later. In this test, queens 8,4 and I 5 were liberated from a moving train. Since they never came home, we do not know whether they died or got lost as did the others, or became entangled in the whirlwind and were drawn under the wheels. Nevertheless, like the novelist who must gracefully dispose of his characters when they are of no further use, so let this record dispose of queens 4,8 and $\mathrm{I}_{5}$. The nests which they left behind were, of course, thereafter orphan nests; we shall have more to say later of the orphan workers.

\section{The Homing of Workers and Queens}

The workers were beginning to emerge. This necessitated the adding of marks of identification on their bodies. This was very artfully done without injury to the insects. Fabre attributes the failure of many of his insects to return to the nest to injury in handling when being marked. By our method, injury was avoided, and, if an individual failed to return, there was no cause to blame but its own stupidity or its youthfulness. In taking the wasps for marking, a wire fly-trap was usually placed over the nest and the inmates shaken into it, carried thus to the laboratory, permitted to escape one at a time to a window pane where they were picked up with a wad of soft cotton and gently held between the fingers while paint was applied in the desired colors and number of dots. The markings on the thorax were most practical, for here they were retained for life, whereas on the abdomen it was possible for the wasps to clean them off after several days. 


\section{Experiment $V$}

June 25. The queen of nest 2 failed to return to her nest in Experiment II on June 20. The pupae were able to continue their development without her, however, and on June 24 two workers emerged and one on June 25 .

Of course, if these wasps find their way home instinctively or through the aid of a sixth sense, we have a right to expect the young wasps to return as readily as the old ones; if, however, age and experience are factors in directing them home, the fledglings would be unable to return to the nest since they lack both.

These three were placed in large test-tubes and, without the handicap of darkness so they could have every advantage of studying their landmarks, they were taken to the mailbox one-eighth mile distant along a level road (same as Experiment I) and liberated at 7:40 a. m. They left the tubes rather awkwardly (the direct activity and impatience for escape, so noticeable in the queens, was absent), and settled on the vegetation below.

Four days of careful watching at the nests showed the continuous absence of these workers. They were all unable to find their way home, despite the short distance and the free use of their sense of sight.

\section{Experiment $V I$}

July 7. No further experimental work was done on the wasps between the last test on June 25 and the present one on July 7. In the interval, several workers had emerged from the various nests. This experiment is the same as Experiment $V$, except that a larger number of wasps was used, which ought to give more conclusive evidence as to whether the homing process is one of learning or of instinct, or of some unknown sense. Thus ten workers and 
two queens, ${ }^{2}$ all clearly marked, were taken to the mail-box exactly as before and liberated at $8: 40 \mathrm{a} . \mathrm{m}$. The route was in all respects the same as previously, except that the wheat in the field had just been cut and was now in shocks, thus altering the aspect of the landscape.

When the nests were examined at noon for any returns, the queens had already arrived at nests 19 and 20, but not one of the ten workers returned during the five succeeding days. Some of these orphans were perhaps two days old, while some might have been a week or ten days. old. One would at least expect a week-old worker to give positive results in so simple an experiment, but since these workers were all members of fairly large family groups, it may well be that they had had little responsibility or practice in foraging, and hence were mere infants in experience.

Before going further with the experiments, some factors in the biology and behavior of Polistes pallipes must be introduced.

When once a queen is lost, strayed or stolen from the nest, one or more of the workers that are left, or, if there be none at the time, of those that come afterwards, will instinctively take up the duties of the queen, lay eggs and constantly remain on the nest: Then, as is very generally known, the eggs of the foster-mother give forth only male wasps. This condition we now face-nests ruled over by an adopted mother. ${ }^{3}$

One other item in their behavior is at once noticeable: when one attempts to take queens or old workers from the nest, the slightest approach will cause their alertness, sharp, nervous movements, antennae in motion and heads

2 Nest 19, I queen and 3 workers; nest 20 , I queen; nest 8,3 workers, and nests $I_{3}, K_{4}, I I$ and I8, I worker each.

${ }^{3}$ In Experiments V and VII they may have been too young to have commenced their duties. 
erect; at a nearer approach they fly downward about the head of the intruder and often are free with stings. After a few seconds of aggressive buzzing, most of them escape to return later; those which remain are usually the queen and the youngest workers. It seems that the young workers are slow to learn to defend themselves by offensive actions. True, they can sting if handled, but they do not fly away from the nest when it is in danger, nor do they attack an observer, but remain on the nest. When teased with a straw, they walk a short distance and stop; when followed, they escape by the first crack in the wall. In our observations, these newly-hatched ones, when ousted in this manner, seldom were able to return to the nest, this failure to return evidently being due to their lack of knowledge of their environment.

Now this was precisely the condition in nest I9 in Experiment VI; the old workers flew at our approach and the queen and three young workers remained and were taken for the experiment. The queen returned and these new workers were all lost. (See Experiment VII for additional observations on workers of nest I9.)

\section{Experiment VII}

July 7. This is merely a repetition of the foregoing experiment. A second lot of wasps were liberated at the same place and date as before, but two hours later, at IO: 30 a. m.

Nest 19. After the first lot had been taken and released, the older workers which escaped us returned to the nest. Three of these were taken and marked differently, to distinguish them with certainty from those from this nest used in previous experiments, and released as per account.

When the nests were examined at I I : o I o'clock, two of these workers had already returned, which satisfies us in this 
case, as in others to follow, that the worker wasp which is old and experienced enough to escape or show bellicosity when taken has by that time the ability to return to the nest.

Nest I3. This queen was lost on June 2I in Experiment III, and on this date some half-dozen orphans had charge of the nest. So alert were they that only one of them could be taken. It never returned to the nest.

Nest I5. From this nest we have some interesting data. The queen was lost in Experiment IV on June 25. The queenless nest with its potential life was taken from the barn on June 27 and pinned to the wall in the laboratory near the table where we could watch the maneuvers of the young when they emerged. It also happened that on or about June 22, we had been experimenting on wasps in applying paint to various parts of the body and observing its effect upon the insects. On that day, two workers, probably a day or two old, were taken from nest 12 in the barn, carried into the laboratory directly in front of the barn, at a distance of fifty feet. There, two dots of paint were applied to the pro-thorax of each, and after noting the method of handling, their ability to clean off the paint, etc., they were liberated, seven hours later, by being allowed to walk about on the sill of the open window nearest the barn. We expected that of course they would find their way back to the nest in the barn directly in front of the window and only fifty feet distant, but somehow these workers did not find nest I2. We little suspected that this new environment, as they could see it through the wire fly-cage during the seven hours of imprisonment and their subsequent freedom about the room, was making such an impression upon their senses that they would regard it as their habitat rather than the barn. Five days later, orphan nests 8 and I 5 were pinned to the wall near the laboratory table where these workers had 
been handled. Then it became evident that they must have been lingering about this building while we looked elsewhere for them, for on the same day that these two nests were pinned to the wall side by side, both of these especially marked wasps were found at rest on nest 8 , where they remained persistently for three days, when one shifted to nest $\mathrm{I}_{5}$, and each held its respective nest continuously thereafter. This self-appointed queen on nest I 5 took care of the brood, deposited eggs, fed the larvae, tore down parts of the nest and rebuilt other sections. On June 29, one worker emerged and on the following day another. When all three of these were used in this experiment on July 8 the worker-mother was at least seventeen days old and the workers ten and nine days old respectively. Owing to the smallness of the colony, they must have had wider out-ofdoor experiences than the workers of larger colonies.

Here it is well to mention, in anticipation of what we shall see in later experiments, that age and experience should not be taken as synonymous. We think of course that old workers would be more experienced than young ones, but this is true only up to a certain point. When the colony is growing, a supply of pulp for the nest and food for the many young mouths makes intensive work for the small number of workers. After the season has passed its height, or the young are few in number, with an abundance of workers, they may spend more and more time on the nest, and when occasionally they fly abroad, they remain in the general vicinity of the nest seeking liquid refreshment. Finally, in the early autumn, one sees the cells entirely devoid of young, and workers, males and later females, clinging languidly to the carcass of a nest.

But now, to resume the narrative of Experiment VII : the three pioneers on nest I 5 were released with the others at the mail-box at Io:30 o'clock. All three of these returned 
promptly to the nest, one at II o'clock, one at II : 25 and one at I I :40.

Here we find a striking condition in the ability of one individual which, as a youthful worker, could not return to her nest in the barn fifty feet away, but as a queen at the age of seventeen days, performed her homing task nicely over a distance of one-eighth mile. This experiment likewise shows that, while other workers in other experiments were lost at the same distance, these two workers nine and ten days old made the trip promptly.

From nest II, one orphan worker was taken. The queen of this nest had been lost in Experiment III, on June $2 \mathrm{I}$; soon after this the nest was transferred to the wall of the laboratory. This one wasp never returned to the nest.

$\mathrm{K}_{4}$ and $\mathrm{K} 6$ were two orphan nests carried from Kimmswick, two miles distant, and pinned to the laboratory wall. Two workers, one from each nest, which skubsequently emerged, were properly marked and used upon this occasion. Neither of them returned.

Nest 6. The queen from this nest was lost on June 20 (Exp. II). One of the first orphans to emerge soon thereafter was marked, and soon took up the duties of workerqueen. This one was now used in this experiment, together with four workers of uncertain age differently marked. The five were released along with the others at IO: 30 o'clock.

At Io:55 the worker-queen had already returned, but up to I o'clock the workers had not appeared. The next examination of the nest at $3: 30$ o'clock found two workers besides the queen on the nest. This constitutes additional evidence of experience being a factor in aiding the return flight, since of the eight that returned in this experiment, five were old workers and three were of unknown age, while none of the young workers returned. 


\section{Experiment VIII}

July 9. This test, in all essentials the same as Experiment VII, was performed with five workers from two orphan nests : three workers from nest I8, which emerged June 29 to July I, and two from nest II which also emerged June 29 and July I. These were taken to the mail-box and released at $10: 25$.

Two of the workers from nest 18 returned at II : IO and I I : 50 , and two from nest II, one at II : $55 \mathrm{a} . \mathrm{m}$. and the other at $\mathrm{I}: 35 \mathrm{p}$. $\mathrm{m}$. Here we see workers returning with eminent success. We shall note two things in passing: they were all eight to eleven days old, and they were solely responsible for the maintenance of the home, and hence had probably had wider experience in the world than indolent youngsters. The reader will remember that young workers readily lose themselves even though liberated near the nest.

Up to the present point in our studies, old workers have successfully made the trip over one-eighth mile distance, and queens have returned from a two-mile trip, but the old workers have not yet been experimentally tested in long flights. Hence the following experiment was carried on with the purpose of trying workers both old and young in a flight of longer distance.

\section{Experiment IX}

July I 7. The wasps were taken from the buildings about the farm, and two lots, nest 24 and 25 , were brought from a shed near the railroad track and carried up a hill of perhaps 150 feet elevation, to the laboratory to be marked. This was done at noon. Later they were taken down the gently sloping hillside by an entirely different route to the railroad track, and then carried to Montesano Park on the 
outskirts of Kimmswick. The wasps all experienced the same conditions, except that those from nests 24 and 25 had, in addition to the trip to Kimmswick, a trip by a tortuous route up the hill to the laboratory. At 3:45 p. m., twentytwo wasps were liberated at Montesano Park, one and eighttenths miles south of their homes, and I50 feet lower for all but those from nests 24 and 25. The cages were darkened and turned about repeatedly the more to confuse the inmates.

Three wasps from nest 25 were taken. This nest was large, having ten larvae ready to spin their cocoons, six with sealed cocoons, and numerous young. One would suspect that by the time the proprietors had accomplished this much work, they would have had sufficient foraging experience to be able to get to their homes from a point one and eight-tenths miles distant on the same level. Only one of them returned; it appeared on the next day at $2 \mathrm{p}$. $\mathrm{m}$. We suspected that this one was the queen, but had no proof of the fact. ${ }^{4}$ The ages of the other two were unknown.

Nest 24 was near nest 25 in the shanty by the railroad track. Five wasps were taken from this, each marked with two white dots on the pro-thorax. Of these, only one returned; it appeared the next day at I2:30 p. m. ${ }^{4}$

Nest 15. The workers from this nest were the three wasps which had taken over the queenly duties, and had successfully made the one-eighth-mile trip in Experiment VII. This had been about ten days previously; the additional time for becoming acquainted with the neighborhood should have been a factor to aid them in making a prompt

${ }^{4}$ Since during later work these two wasps were so constantly on the nests, we have fully decided that they were queens; and in later experiments refer to them as queens. 
return. However, none returned from this greater distance.

Nest I9 gave us two workers of unknown age but each bearing a white mark, indicating that it had made the oneeighth-mile flight previously. Neither of them came back.

Nest II. The one wasp which was taken from this nest still bore the marks which identified it as the one used in the mail-box trial on July 9 (Exp. VIII). Despite its previous successful trip in Experiment VIII, it did not return to the nest this time.

Nest I8. Just as in the preceding instance, one worker which had successfully made the trip in Experiment VIII was again taken, but this time it never reappeared at the nest.

Nest 22 was a newly discovered nest in the smoke-house, which had only one adult, two sealed cells and a half-dozen other young. This sole proprietor, presumably the queen, was taken on this journey, but never returned.

Nest 20. A young worker, five days old, was taken on this long trip, but, as was to be expected, it did not reappear.

From nest 6 , three wasps whose markings proved that they had successfully made the one-eighth-mile trip on July 8 (Exp. VII), were again used in this experiment, but not one returned this time.

Nest I3. Two workers, of unknown age, were both lost. In this experiment it is at once evident that no worker taken out for the first time was able to find its way home over a distance of one and eight-tenths miles, and even other workers and worker queens, although they had successfully made other return flights, were unable to do so at this distance. It might be suggested that the meteorological conditions on that day were peculiar, in some way hindering their activity, but we must not lose sight of the fact that the queens from nests 24 and 25, acting as a check upon 
the others, gave no evidence of such an impediment. These two queens returned to the nest, even under the handicap of being carried up the hill to the laboratory and down again, quite out of the direct route to the point of release.

\section{Experiment $X a$}

July i8. We have heard somewhere that bee-keepers choose a hill-top for the location of an apiary because bees when foraging will descend a hill, but, if the hive is in a valley, they will never go to the hill-tops for nectar. Material was available for an experiment to see if this principle holds in Polistes pallipes. Three wasps were taken on top of the hill and liberated in the valley I 50 feet below and one-eighth mile distant, while from an out-house near the point of their release, four wasps were taken and carried to the top of the hill and liberated near the point where the first lot had their nests.

From the hill-top, the queen from nest I9 was used, the one which in Experiment VI had made the one-eighth-mile flight successfully over a country of level topography. This wasp never returned; despite her previous success on a level plane, she failed to find her way home for the same distance when it was uphill work.

From nest 18 two workers, whose ages were i7 and I4 days respectively, were carried to the bottom of the hill with the queen mentioned above, but neither of them returned.

We are surprised that queen 19 failed to make the return flight for so short a distance, and since the other two old workers failed to return, we can readily suspect that the hillside was a barrier, or that the region below their home was completely unknown to them.

Now "we shall consider the wasps which were taken in the valley and carried to the hill-top. 


\section{Experiment $X b$}

The wasps from nests 24 and 25 for Experiment IX had been removed on the preceding day; they were all still absent from the nest at 7 o'clock on the morning of July I8. But those which had escaped the first collection had by this time returned, and four of these were taken. The very fact that these escaped from the nest on the previous day when the catch was made indicates that they were the older and wiser heads, and the results should be regarded in this light. One was taken from nest 24 and three from nest 25. These were released on the hill-top at 8 o'clock, and when we arrived at the shed below at $8: 50$, they had all returned more speedily than we.

It is too great a deduction from limited data to say that it is easier for the wasps whose home is in the valley to reach it from a hill-top than vice versa, but the experiment does show that it is possible for wasps to find their way home from hill-tops if they are taken from their homes below, regardless of what bees do. ${ }^{5}$ In Experiment IX, where they returned from a lower plane to the same hill-top, the route was by a two-mile flight and the ascent was a gradual one up the gently-sloping side of the hill, whereas in this experiment the ascent would have been up the steepest side of the hill.

\section{Experiment $X I$}

While we were eager to make some experiments on the homing flight of these wasps from greater distances, these had to be postponed as the material available at this time was unsuitable.

It seemed fitting, therefore, to devote the available material to experiments attempting to ascertain by what sense they

${ }^{5}$ Experiment XIII shows that antennaeless wasps are capable of making the downward flight successfully. 
find their way home. It was our intention to deprive them of the use of their eyes or antennae, and then test their ability to make return flights which normal individuals had proved themselves capable of making. The antennae were removed in part or whole, one or both. To take such advantage of the fascinating creatures which seem almost pets, is degrading indeed; one could do no more, and the further trick of blinding the eyes of such highly endowed beings was abandoned.

\section{Experiment XIa}

July 23. The object of this experiment was to test the ability of antennaeless wasps, as compared with normal individuals, to make the homing flight. For this purpose, we desired a random sample of the population, from which all the naturally unfit individuals were eliminated. This end we accomplished by merely sending a lot of marked wasps on the flight from the mail-box and then taking those which were successful in this one-eighth-mile flight for further experimentation. It seemed a poor reward indeed for their faithfulness and merit-merely to be permitted again to make the involuntary journey plus mutilations, or rather minus parts of the antennae.

All of these unmutilated wasps were taken between 8 and 9 o'clock, marked, carried to the mail-box in the usual manner and liberated at 9:45 a. m.

Three workers were taken from nest Io. The queen from this colony had been lost on June 20 , but the workers had done wonderfully well, and, under their care, the nest had reached very fine proportions. Under these circumstances, it is not surprising that these three workers had returned to the nest by the time we arrived to examine it at I I : 30 .

Nest 26 contributed three workers and a queen. We suspect that the workers may have been young, because the 
older and more experienced ones were agile in escaping when we approached to make a catch. At I I : 30 only one (the queen ${ }^{6}$ ) had returned. The next day at 2:00 p. m., while waiting for the mail, we saw one of the marked workers sitting on a post fifty feet from the place where it had been liberated. We thought at first that it was ill or injured, but when approached it darted nimbly away in apparent good health. It may have been young or too indifferent even to start back home. In any event, it never reached home.

The one worker two days old from nest i 3 did not return. The queen from nest 20 returned at 2:00 p. $\mathrm{m}$.

\section{Experiment $X I b$}

We were now ready for the second step in the experiment. For this purpose, the above-mentioned successful competitors, and a few others which had proved capable in previous flights, together with a small number of entirely new and inexperienced wasps, all distinctly marked and with variously modified antennae, were liberated as usual at the mail-box, on the same afternoon at 5: I 5. This allowed them ample time to return before nightfall three hours later. When these wasps were released, they all flew away with the usual alertness and energy, so one seeing them would suspect that the loss of their antennae made no difference to them.

From nest I8, two workers were taken and the left antenna removed near the base. One of them bore a white mark proving that it had been successful in a previous flight; the other was new in the work. The next day between $7: 30$ and $8: 30$ both of these had returned.

Two workers from nest II, with previous experience, were each deprived of the right antenna and sent out on ${ }^{6}$ Later observations proved this one to be the queen. 
the flight. The nest was anxiously watched all that evening, but not until the next morning between 9:30 and 10:30 did they return.

Nest no. Io gave us three workers: one was without the right antenna, one lacked the entire left antenna, and the third lacked the right antenna and in addition bore the white mark which proved that it had done the flight only that morning. The next morning at $7: 45$ the first of the above-named wasps returned, and between II and II : 20 the other two appeared.

Nest I2 afforded us one worker with the left antenna off. This one returned promptly, probably the same evening, for at $6: 30 \mathrm{p}$. m. she was still out, but at 6 o'clock the next morning she was on the nest. This one made the flight in the shortest time of all the competitors.

This experiment shows very clearly that wasps in a normal condition and wasps minus one or the other of their antennae, regardless of whether or not they have made the same flight before in a normal condition, or whether their first trip is made under handicap, find their way back to the nest for this distance.

It should be made clear that, in effecting the mutilations, the antennae were cut as close to the base as it was possible with a very fine dissecting-scissors. A tiny stump remained, perhaps $3 / 1000$ of an inch in length, from which a transparent fluid oozed out. Critics might say that this stump of an antenna may factor as a true sense organ.

\section{Experiment XII}

July 24. Wasps with various antennal mutilations were taken to the mail-box and liberated, in the same way as in Experiment XIb. They were taken at $7 \mathrm{a}$. $\mathrm{m}$. and set free at $7: 30$ a. m.

From nest 12 we took one wasp, tried for the first time, 
with both antennae amputated at the base, and another which had been successful in returning with one antenna, in Experiment XI; its other antenna was now cut off. The one used for the first time did not return to the nest, but the other now repeated the trip deprived of both these organs. She did not arrive at the nest, however, until I : oo p. $\mathrm{m}$.

Nest 20 gave us one queen which had successfully made this distance in Experiment XI. She was now handicapped by having one-half of each antenna cut off, and liberated with the others for the same flight. She never returned.

From nest Io, two wasps were taken which had previously made the one-eighth-mile flight successfully when in a normal condition. Now they were liberated again with one-half of each antenna removed. Both of them returned between II and II : 30 a. $\mathrm{m}$. A third worker from this nest, a fledgling, also with one-half of each antenna removed, did not return.

From nest I9, a worker which had been successful in one of the previous tests was tried in this experiment with its entire right antenna gone. This one returned to the nest at 9: ro a. m.

The insects in the foregoing tests were all liberated at $7: 30$ a. m.; those which follow were released on the same day and place at $3: 50$ p. $\mathrm{m}$.

The two wasps from nest II used in Experiment XI, where the right antenna was removed, were now sent out with both organs gone. Both returned to their nest during the early part of the afternoon of the following day.

The worker from nest ig which successfully returned minus the right antenna in the first part of this experiment, was now again tried in the same flight with the other remored. It reappeared at the nest, seeming very sprightly and unhampered, in only forty minutes!

The same treatment was now accorded to the two wasps 
from nest Io which, with one antenna, had been successful in Experiment XI. When the nest was examined at 4:30, one of these had already returned; the other did not arrive home.

To summarize, then: the wasps in this lot which had been previously successful in the flight with only one antenna, now proved themselves equally capable with both antennae amputated. These were subjected to all the confusion that the others endured, i.e., the darkness and the turning about. The time in which they made the flight was a little longer than the time required by the first lot of queens in Experiment I; the minimum time for these workers was 40 minutes, and two were out about 20 hours.

We had planned to experiment upon these wasps, entirely or partly antennaless, with flights of greater distance, but were called away from July 25 to 30 . We thought, furthermore, that a rest for these overworked individuals would eliminate the factor of fatigue from the results of long flight experiments. We assumed that, since most of them returned very properly to the nest even under handicap, they would of course continue their normal activities until our return. But at the end of the week, when the various nests were examined, not one of either the partly or entirely mutilated wasps was to be found. Whether they had perished, or had been driven from the nests by the normal inhabitants, or had lost themselves in foraging expeditions. we do not know. Thus ended the plans for their long distance flights under handicap.

\section{Experiment XIII}

July 30. In Experiment $\mathrm{X}$, the wasps in normal condition were taken from their outbuilding at the foot of the hill and carried to the crest of it, whence they all speedily 
made their way home. The experiment was now repeated with wasps which had the antennae cut off at the base.

Four wasps were taken from nests 24 and 25 and released at I2.o'clock. Two were unmarked, showing that they had not been used previously; a yellow dot was placed on the thorax of each. Two others already bore the white mark, which showed them to have had some previous acquaintance with their tormentors. Two of the four wasps returned to the nest; one with a white mark reappeared at $4 \mathrm{p} . \mathrm{m}$. and the other, a novice, returned home at $5: 30$.

\section{Experiment $X I V$}

September 3. During the preceding week males had been appearing on the nests. These, with what workers were available, composed the material for this experiment. Since the males had no interest in their nests, one would only expect them to get lost under such treatment. After the males have emerged from the nest, they are practically done with it, since their function is merely the fertilization of the females, and for this purpose they undoubtedly go elsewhere and do not need to remember the home nest.

The wasps were captured at 2 p. m., carried to the laboratory and marked, but, on account of rain, their release at the mail-box was postponed until 4 o'clock. After that hour, it was cloudy and dreary and much rain fell during the night; the next morning also was cloudy, but in the afternoon the sun shone out brightly.

Nest 27 was out-of-doors on a rose-bush at the foot of the hill. This gave us one queen and one worker, all used for the first time. These were taken to the top of the hill, again marked, and released. Both worker and queen were found to have returned the next day at 9: I5 a. $\mathrm{m}$.

Nest 28 was under the porch beside 27. Two workers were taken from this and marked yellow. One had returned 
by $9: 15$ the next morning; the other did not appear until $2: 30$. The wasps from nests $2 \mathrm{I}$ and 28 may have returned the same day, but the follow-up did not occur until the next morning at 9: 15 .

From nest I9 one worker and two males, used for the first time, were taken and marked in yellow. At $4 \mathrm{p}$. $\mathrm{m}$. the same day the worker arrived home; the males did not return.

Nest I3, one male which did not return.

Nest 26, three workers, none of which returned.

Nest Io, ten males and five workers. None came back.

Late in the season, when the cells are empty and workers, males and queens abound, one would not expect the wasps to maintain any interest in the nest or to exert themselves to return to it, but the problem is worthy of careful investigation. In this experiment, none of the males returned. If the young workers easily get lost, how much more likely are the males to do the same.

If some unknown factor automatically draws the workers back to the hive in the sense of Bethe's theory, it should likewise possess the same chemical or physical affinity for the males.

\section{Experiment $X V$}

September 4. This experiment is the same as Experiment XIV, except that the material was such as could be gotten at the end of the season, and the wasps were held captive over night. They were gathered at 5 p. m. on September 3 , fed on honey, of which they ate ravenously, and liberated at the mail-box at 8:30 a. m. It rained during the intervening night and the morning was cloudy, but the afternoon was bright and sunny.

Nest 25 contributed five workers and two males, all new to the experiment, one queen with a white dot used 
in Experiment $\mathrm{X}$, and one worker with a yellow mark, used in Experiment XIII, on July 30. At II a. m. the white-marked queen returned; at $2 \mathrm{p}$. m. the. one with the yellow mark appeared, and at $2: 30$ another worker, which had never before made the test flight, returned.

Nest 27, one worker, used for the first time, returned at II : Io a. m.

Nest 24, three workers new to these experiments, of which one returned at $2 \mathrm{p} . \mathrm{m}$.

Nest 28, one male and four workers used for the first time; none of these $\cdot$ returned.

\section{Experiment XVI}

September 5. This was an experiment in long distance flight with whatever material the lateness of the season afforded. The wasps were gathered between 4 and $5: 30$ p. m., September 4 , taken to the laboratory on the hill-top, marked, fed on honey, of which they ate greedily, kept in wire cages over night and liberated the next day. The material from nests 29 to 33 was taken from an old shed near the railroad track one-fourth mile south of the laboratory; these had not been used experimentally before. On the morning of September 5, under proper wrappings, they were all taken on board the $7: 25$ train to a station 2.7 miles to the north, removed from the train and released at 8 o'clock. ${ }^{7} \quad$ The sun was shining warm and bright, and a

${ }^{7}$ The material was as follows: Nest 25: One queen marked in white, used successfully in Exp. XV and X, now marked with an extra yellow dot; Nest 27: 2 workers, I used successfully in Exp. $X V$ and $I$ in Exp. XIV; Nest 23: 3 workers, I yellow used successfully in Exp. XIV, and 2 never before used; Nest 24: 2 workers, I used previously in Exp. XV; Nest 19: I worker used succesfully in Exp. XIV; Nest 2: 3 workers now used for first time; Nest 26: I worker, not used before, and I queen with dot on thorax and on abdomen, used successfully in Exp. XI on July 23; from nests 29 to 33,9 workers and I male were used, all for the first time. 
breeze, so gentle as to be almost imperceptible, came from the south. All of the wasps were from places at the railroad level, the same elevation as the point of release, excepting those from nests 2, 19 and 26; these were hill-top nests, at an altitude of 150 feet higher. The Meramec River intersected their course of flight near home.

These twenty-four wasps, many of which had records of successful flights (see footnote, page 272 ) were liberated at 8 a. m. On account of the distance, we expected that none would return; hence we were almost shocked to find that one from nest 26 had come back. It was the queen which had finished in the preliminary flight in Experiment XI. A distance of 2.7 miles plus an elevation of 150 feet is indeed an astonishing feat for so small a creature. At 6: Io that evening, one queen appeared on nest 25. This wasp had already made two successful flights, Experiments $\mathrm{X}$ and $X V$. Subsequently, the nests were watched for a week, but out of the abundance used in this experiment only these two ever returned. It seems that the oldest and most experienced ones were the most expert in finding their way home, or the most successful under adverse circumstances. If magic or some impelling power drew the wasps to their nests, as Bethe thinks of the bees, then surely a different type of behavior would be manifested.

\section{Summary and Conclusions}

To summarize, then, we find (table A) that out of 33 queens which were taken for various distances from oneeighth mile to two and seven-tenths miles, 24 returned to the nest.

Of the 22 taken out for the first time, 17 reached home; of the II which had made previous test flights, 7 successfully returned. 
TABle A.

Homing of queens.

\begin{tabular}{|c|c|c|c|c|c|c|c|c|c|}
\hline 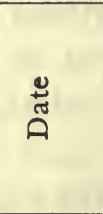 & $\begin{array}{l}\dot{0} \\
z \\
\dot{0} \\
\dot{x} \\
\dot{10}\end{array}$ & 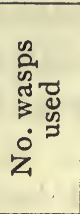 & 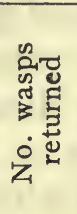 & 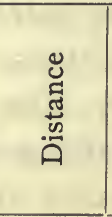 & 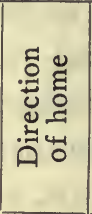 & 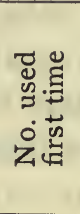 & 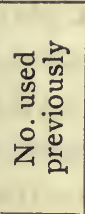 & 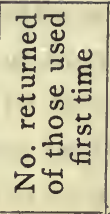 & 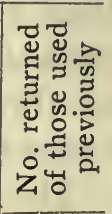 \\
\hline $6 / 19$ & I & 6 & 6 & $1 / 8 \mathrm{mi}$ & S. & 6 & - & 6 & - \\
\hline $6 / 20$ & II & 9 & 6 & $\mathrm{I} 1 / 2 \mathrm{mi}$. & S. E. & 4 & 5 & 3 & 3 \\
\hline $6 / 21$ & III & 6 & 2 & $2 \mathrm{mi}$ & N. & 4 & 2 & I & I \\
\hline $7 / 7$ & VI & . 2 & 2 & $\mathrm{x} / 8 \mathrm{mi}$ & S. & 2 & - & 2 & - \\
\hline $7 / 17$ & IX & 3 & 2 & $\mathrm{I} \frac{8}{10} \mathrm{mi}$. & N. & 3 & - & 2 & - \\
\hline $7 / 18$ & $\mathrm{Xa}$ & I & ० & $1 / 8 \mathrm{mi}^{*}$ & W. & - & I & - & $\circ$ \\
\hline $7 / 23$ & $\mathrm{XIa}$ & 2 & 2 & $\mathrm{x} / 8 \mathrm{mi}$ & S. & 2 & - & 2 & - \\
\hline $9 / 3$ & XIV & I & I & $1 / 8 \mathrm{mi}$. & E. & I & - & I & - \\
\hline $9 / 4$ & $X V$ & I & I & $1 / 8 \mathrm{mi}$ & E. & - & I & - & I \\
\hline $9 / 5$ & XVI & 2 & 2 & $2 \frac{7}{10} \mathrm{mi}$. & S. & - & 2 & 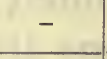 & 2 \\
\hline Totals & & 33 & 24 & & & 22 & II & I7 & 7 \\
\hline
\end{tabular}

*To valley below.

With the workers, the results are quite different.

Of II 2 workers that were used, only 28 returned, and those which returned did so only in the short flights. The long distance tests always gave negative results. Let us go into detail in regard to these I I 2 workers, and the 28 that returned home in this lot. Out of the $I 7$ new workers that were experimented upon, none returned; of the 33 old workers, I 4 came back; of the 62 workers of unknown age, I 4 returned. According to the law of chance, it is easily possible that these I 4 out of 62 workers of unknown age may have been old ones. The last four columns show that 


\begin{tabular}{|c|c|c|c|c|c|c|c|c|c|c|c|c|c|}
\hline & 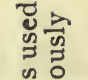 & $\dot{z}$ & 11 & 1 & 1 & 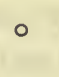 & 1 & 1 & 1 & & & & T \\
\hline & 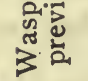 & $\dot{0}$ & 11 & 1 & 1 & $\stackrel{\circ}{=}$ & 1 & 1 & 1 & 1 & 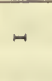 & & 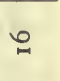 \\
\hline & 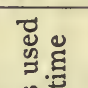 & $\dot{\partial}$ & $\circ \quad 0$ & $\infty$ & in & $\circ$ & $\circ$ & $\sigma$ & m & + & $m$ & & $\hat{a}$ \\
\hline & 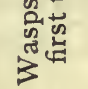 & 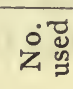 & 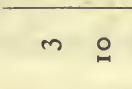 & $\because$ & in & $a$ & $a$ & $\sigma$ & $\wedge$ & $\cong$ & & ㄴ. & \& \\
\hline & 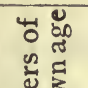 & $\dot{\gamma}^{\circ}$ & 11 & $m$ & 1 & $\circ$ & 1 & 1 & $m$ & + & + & $\circ$ & \pm \\
\hline & 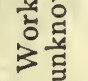 & 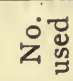 & 11 & 0 & 1 & $\infty$ & 1 & 1 & 0 & $\cong$ & \pm & 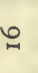 & హี \\
\hline & $\overline{0}$ & $\dot{0}$ & 11 & n & in & $\circ$ & $\circ$ & + & 1 & 1 & & $\circ$ & \pm \\
\hline & $\overline{0} \frac{\bar{t}}{0}$ & $\dot{0}$ & 11 & $n$ & in & $\circ$ & $a$ & + & 1 & 1 & 1 & in & $m$ \\
\hline & $\stackrel{800}{=}$ & z & $\circ \quad \circ$ & $\circ$ & 1 & $\circ$ & 1 & 1 & $\circ$ & 1 & 1 & 1 & $\circ$ \\
\hline & 雪 & 宽苟 & $m$ & $N$ & 1 & - & 1 & 1 & - & 1 & & 1 & $=$ \\
\hline & jo $\stackrel{2}{\mathrm{uc}}$ & & $n \sim s$ & 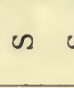 & $\backsim$ & z & 3 & (디 & n & $\begin{array}{l}\mathscr{2} \\
\text { के } \\
\text { Ix| }\end{array}$ & w & & \\
\hline & & & $x_{\infty}^{\infty}$ & $\propto^{\infty}$ & $\varkappa^{\infty}$ & $\stackrel{\infty}{\circ}$ & $\infty$ & $\infty$ & $x^{\infty}$ & $\propto$ & $\propto^{\infty}$ & a & \\
\hline & $\begin{array}{c}\text { pau } \\
\text { sdse. }\end{array}$ & & $\circ \quad 0$ & $\infty$ & in & $\circ$ & $\circ$ & + & $m$ & 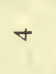 & & $\circ$ & $\stackrel{\infty}{\sim}$ \\
\hline & $\begin{array}{r}\mathrm{pe}^{2} \\
\text { sdset }\end{array}$ & & $m$ 잉 & $\approx$ & in & $\Omega$ & N & + & - & $\cong$ & \pm & $\vec{\wedge}$ & $\Xi$ \\
\hline & ${ }^{\circ} \mathrm{N}$ & ×马 & $>5$ & 5 & $\Xi$ & $\underset{u}{u}$ & $\ddot{x}$ & $\ddot{x}$ & $\frac{\pi}{x}$ & $\vec{x}$ & $\vec{x}$ & & \\
\hline & $\begin{array}{l}41 \\
\text { ग1 }\end{array}$ & & $\frac{n}{6} \lesssim$ & $\hat{n}$ & $\therefore$ & $N$ & N & $\stackrel{\infty}{\curvearrowright}$ & 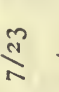 & నू & $\stackrel{+}{\Delta}$ & & 先 \\
\hline
\end{tabular}


previous experience is not necessary to successful flights. There we see that 27 successful returns out of 96 were made by wasps used for the first time, and that only I out of I6 wasps that had had previous flights made a successful second trip. With the queens, this is not the case.

Table $\mathrm{C}$ shows that not one of the $\mathrm{I} 7$ males returned to their former nests, even though the distance for 16 of them was only one-eighth mile.

Table D shows that the function of the antennae is not the sole factor in bringing them home, for out of 24 mutilated wasps, i8 successfully returned.

Thus, by the elimination of other faculties, the evidence grows stronger that vision is the sense whereby the insects regain their homes.

TABLE C.

Homing of males.

\begin{tabular}{|c|c|c|c|c|}
\hline 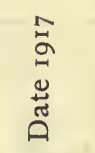 & $\begin{array}{l}\dot{0} \\
z \\
\dot{x} \\
\dot{x} \\
\dot{I}\end{array}$ & 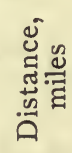 & 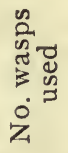 & 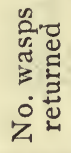 \\
\hline $9 / 3$ & XIV & $\frac{1}{8}$ & 13 & o \\
\hline $9 / 4$ & XV & $\frac{1}{8}$ & 3 & 0 \\
\hline $9 / 5$ & XVI & $2 \frac{7}{10}$ & I & 0 \\
\hline Totals & & & 17 & 0 \\
\hline
\end{tabular}

The evidence here shows that Polistes pallipes find their way home in the manner which Lubbock ${ }^{8}$ describes for his bees: "If a hive bee is taken to a distance she behaves as a pigeon does under similar circumstances; that is to say, she flies round and round, gradually rising higher and

8 Senses, Instincts and Intelligence of Animals, p. 265. 1888. 
TABLE D.

Homing of mutilated wasps.

\begin{tabular}{|c|c|c|c|c|c|c|c|c|c|c|}
\hline $\begin{array}{l}\hat{\sigma} \\
\tilde{\sigma} \\
\tilde{\sigma}\end{array}$ & $\begin{array}{l}\dot{0} \\
z \\
\dot{\alpha} \\
\dot{x} \\
\dot{a l}\end{array}$ & 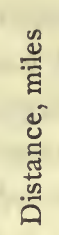 & 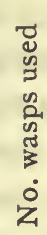 & 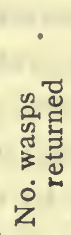 & 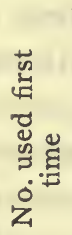 & 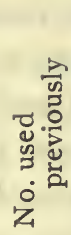 & 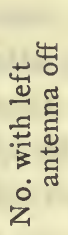 & 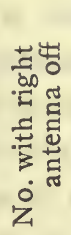 & 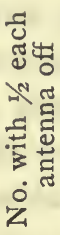 & 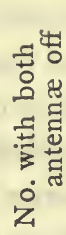 \\
\hline $7 / 23$ & $X I$ & $1 / 8$ & 8 & 8 & 4 & 4 & 4 & 4 & 0 & \\
\hline $7 / 24$ & XII & $1 / 8$ & I 2 & 8 & 2 & $10^{*}$ & 0 & I & 4 & 7 \\
\hline $7 / 30$ & XIII & $1 / 8$ & 4 & 2 & 2 & 2 & o & ○ & 0 & 4 \\
\hline tal & & & 24 & 18 & 8 & 16 & 4 & 5 & 4 & I I \\
\hline
\end{tabular}

* One of these was a queen.

higher and enlarging her circle, until we suppose her strength fails or she comes within sight of some known object.

"Again if the bees had returned by a sense of direction, they would have been back in a few minutes. To fly one and a half or two miles would not take five minutes. One bee out of the 147 did it in that time; but the others took one, two, three or even five hours. Surely then it is reasonable to suppose that these lost some time before they came in sight of any object known to them."

Fabre $^{9}$ has done some work on the Cerceris wasp and on two species of Osmia bees-insects which, while living in communities, are solitary in habit. In all three species a certain proportion of those experimented upon returned to the nest after having been liberated at distances varying from two to three miles from their homes. He cannot comprehend the possibility of these creatures returning for such distances when liberated in regions remote from their

9 The Mason Bees, p. 55. I9r4. 
habitat. He cannot attribute their return to memory, for he says: "It was certainly not memory, but some special faculty which we must content ourselves with recognizing by its astonishing effects without pretending to explain it, so greatly does it transcend our own psychology."

Bethe thinks that bees returning to the nest "follow a force which is entirely unknown to us, and which causes them to return to the place in space from which they flew." Buttel-Reepen ${ }^{10}$ tries to show that Bethe's experiments furnish "such excellent proof of the existence of memory for location that we can hardly wish for anything better," and in a footnote to his paper he shows that Fabre's unknown sense theory was abolished as early as I 895 by some experiments by Weissmann, who finds that "the only correct solution of the enigma of path-finding by Chalicodoma is that the insects find their way back with their eyes." So persistent is Fabre in clinging to his unknown sense theory that again in his chapter on red ants he asks why, "if they issue from the same mold, has one a sense which the other has not, an additional sense constituting a much more overpowering factor than structural details. I will wait until evolutionists give me a valid reason."

Thus one can see how ever-ready some naturalists are to attribute any unusual behavior to an additional sense or some unknown power. So fearful are they of being branded as individuals ready to attribute some aspect of behavior to an anthropomorphic conception that they prefer to call in some unknown influence to account for conditions.

In the chapter on Homing in "Mind in Animals," $\mathrm{Mr}$. E. M. Smith says: "At one time the return of bees to the hive or pigeons to the cote after foraging or explorative exhibitions was attributed to instinct, and this implied that the act is little short of miraculous and absolutely in${ }^{10}$ Buttel-Reepen, The Natural History of the Honey-Bee, p. 26. 
explicable. A somewhat similar view is still held by those scientists who invoke a mysterious unknown inner or 'sixth' sense, but the evidence in favor of such an assumption is very slight. More and more it becomes evident that acquaintance with the position of the home-hive, nest, shell or cote as the case may be-and the path by which the return may be made is only acquired gradually, even laboriously, by means of individual experience; in fact in practically all homing reactions individual memory must play a rôle and one which is by no means insignificant. It follows that all that can be properly understood by the homing instinct is the basic impulse to regain home after an absence, together with a tendency to make use of certain sense data or impressions and of associations between them to achieve that end.

"In confirmation of this view of the necessity for individual experience certain facts may be cited. First, birds and insects appear unable to find their way home even when quite near if from youth or through removal to a strange neighborhood they are unfamiliar with their surroundings. Secondly, bees are said to be unable to regain the hive in the dark. These insects it would seem depend chiefly upon visual impressions and recognition of visual landmarks for finding their way. If they possess an unknown homing sense, their inability to return in the dark becomes incomprehensible."

The conclusions of Smith apply very fittingly to this investigation. And since his deductions are of a general nature, garnered from the observations of workers in various fields, such as C. H. Turner, Peckhams, Buttel-Reepen, it merely shows that Polistes, in principle, differs in nowise from most other comparable organisms.

In Polistes the proportion that return to the nest is in inverse ratio to the distance that they must travel to regain 
the home. There is, as the experiments seem to show, a limit to the distance from which they have the power to return. If a wasp is taken far enough away from home it can be lost, even though it be within the range of its physical endurance. Now if they were endowed with some mysterious power, or sixth sense, or magic or unknown force or what not, they should return to the nest, regardless of the distance they have to traverse, so long as it is easily within their physical power. Furthermore, since Polistes do not return at night, as Smith says, then the suggested unknown power is proved of known impotence. Again, if the mysterious sixth sense were adequate, we should see all of the wasps drawn, as if by magic, at the same time to the nest, and we would not find such vast variations in the time for their return as from twenty-two minutes to two and one-fourth days. This unknown force of Bethe and others should transcend time and space, but our experiments throughout leave every indication that age, experience, memory and perseverance are the factors that bring Polistes pallipes back to their homes, and when they are removed beyond the distance within which these faculties are adequate, they are lost. Their case is, in fact, quite analogous to that of human beings, who, when lacking these factors of age and experience, perseverance and memory, are easily lost.

Polistes rubiginosus Lept.

We have seen these wasps out, on various occasions, from April 2 to October I3, and yet we have only a few desultory stories out of their whole life history.

One April morning, while looking down from a clay bank into a pond ten feet below, we saw a $P$. rubiginosus attempting to alight on the surface of the stale water. We 
have often seen them stand in the midst of a body of water, without any disaster, to drink. While intently watching her alight, we were startled to hear a shrill shriek as a frog from under the bank pounced upon her and disappeared under the water. The frog had been at rest on the shore twelve inches from the spot where the wasp sought anchorage, and he jumped, captured her, shrieked and dived all in less time than it takes to tell. It all went so quickly that one could not tell whether the frog shrieked before or after it captured the wasp, but anyone who might have heard it would agree with us that there was agony almost human in that scream, and we do not think we are asking too much license in letting our fancy explain the case for us.

At Meramec Highlands, on August I7, I915, we saw a $P$. rubiginosus behaving queerly on the ground. We watched it for a few seconds, when suddenly she pounced upon a green caterpillar on the under side of a leaf above her head, invisible to us but clearly within her view, from her position on the ground. She carried it to the upper side of the leaf and began to malaxate it all along its body, for several seconds, and then continued to bite, chew and eat its anterior portion. After she had eaten about onefifth of the caterpillar, she again practiced malaxation on the remainder; then, after resting quietly on the leaf for some minutes, she flew away. After she had eaten her fill and had taken the pains to knead the remainder, we were surprised that she did not carry it to the nest.

On a sunny afternoon at the very end of the wasp season, October $\mathrm{I} 3$, a number of $P$. rubiginosus and $P$. annularis were observed on the south side of the old rock ice-house at Meramec Highlands. It seemed as though they were at play, flying to and fro against the building, resting a while and occasionally chasing one another. Most of them 
seemed larger than usual. What surprised us very much was to see so many at leisure, for one never sees a Polistes but it is either on the nest or nervously flitting from bush to bush in quest of prey, and at this date they ought to be in hibernation.

We watched these Polistes, perhaps twenty-five of them, for about three hours, and decided, from their manner, that the warm sunshine had lured them from their hibernatingplaces, and that they were enjoying some activity before again entering their cold, gloomy holes.

The dilapidated stone building had numerous crevices between the stones, but most of them were small; a very few were large enough to permit the wasps to enter and disappear from view. The wasps were flying against the wall in various places, examining a number of crevices in rapid succession, all much too small. Often they would fly away for some distance, wheel around and return, and eventually enter one that was large enough and remain therein.

Presently we saw that soon all of them would be gone, so, one by one, we took eighteen of them for study. It is a strange fact that of these every one of the $P$. annularis were males, and all of the $P$. rubiginosus were queens. We have often wondered if this condition was the same throughout the flock.

They continued to play, sometimes only one on the wall and sometimes as many as six, until all had found sheltering crevices or had been captured. All seemed to have the same end in view, to find a suitable lodging-place. The entire performance was confined to the sunny side of the building, although the other walls offered every inducement excepting the sunshine.

Of the eighteen which were taken home and kept in the laboratory, only ten were living a week later. They all 
seemed to be in a state of torpor, and would move only when prodded. They were divided and part placed in a box of excelsior out-of-doors under the south porch, part in the laboratory, and part back under the eaves in the attic where the temperature was intermediate between the other two places. But one by one all died; it could not be ascertained among these limited numbers that any one location was more favorable to them than the others. The $P$. annularis survived for less than two days, but the last of the rubiginosus females did not die until December 20.

One June morning, a P. rubiginosus alighted on a potato plant in the garden and immediately pounced upon a large larva of a striped potato beetle, mumbled it in her jaws and seemed to try to turn it over. After about forty seconds, she suddenly dashed away, perhaps alarmed at our intrusion. The larva was apparently uninjured, and remained on the leaf.

They also feed upon flower heads, and are known to cut open the fruits of Opuntia and other cacti and feed upon the juices. ${ }^{11}$

Polistes anmularis Linn. [S. A. Rohwer].

When, on April 7, 1915, we found P. anmularis out in great numbers, we were both astonished and delighted at the propitious opening of the wasp season. They were queens that had wintered over, and were taking advantage of the first warmth of spring.

The site of this first appearance of the wasps was the east face of the high, rocky bluff overhanging the Mississippi River at Cliff Cave, near St. Louis. Along this bluff, in the warm morning sunshine, were hundreds of queen ${ }^{11}$ Bull. U. S. Dept. Agr. No. II3: 36, 45. 1912. 
wasps. They were resting or flying idly around among the rocks and along the sunny railroad track below; by far the greatest numbers were to be seen in the sheltering crevices of rocks in the cliff. Careful examination of the swarms proved that the wasps were all of the one species, all queens, and-most interesting of all points-that they were all gregarious. We did not on that day find a single solitary individual. Many of the groups were small, from three to ten queens, and others were larger; we estimated three colonies to contain from twenty-five to fifty wasps each, and one about a hundred resting quietly together, while a fourth colony was enormous-we do not think an estimate of a thousand would be excessive. Even the members of this large group were so docile that we could easily approach near enough to them to ascertain the sex. At the side of the stream below, many were drinking water. It was, of course, too early in the season for nest-building, but we were elated with the thought that a little later in the season we should find a wonderful supply of material for observing how they begin to build their nests.

A few dead wasps were found scattered about the ledges, and frequently, when we chipped off a piece of loose rock, a dead queen was to be found in the cranny behind it. In two spots there was evidence that this elimination had been particularly heavy. On the ledge behind two colonies of mason-bees were a great many wings of these insects, but no bodies. These two sites were probably good places for anmularis to spend the winter, and also good places for a lizard, a mole or a bat to come and feed. It was evident that the wasps had not died a natural death. since only the wings remained. Whatever may have been their fate, it seems that their severe sting has availed nothing in giving them protection.

Later in the season, June 25, we returned to this place 
with visions of wondrous wasp activities. Imagine our surprise when not one $P$. anmularis was to be seen, and no nests on the rocks, as we had expected. Only two Polistes were seen that day, and they were $P$. pallipes. We cannot account for this strange disappearance, unless they had dispersed or migrated. Several lizards were seen along the railroad track at the foot of the bluff, but we cannot believe that they could annihilate so large a population of insects which are so well equipped for flight and defense. Yet again on this date, in one crevice in the bluff which seemed an ideal hibernating-nook, we found upwards of fifty queens of $P$. anmularis, dead. This shows that we must count upon heavy elimination.

The interest of this April congregation of $P$. annularis was only increased when, on October 25, 1916, we found an assemblage of one hundred or more queens behind a closed shutter of an old abandoned building at Clifton Terrace, Illinois. This particular window was the most sheltered nook on the building, sunny and well protected from the raw winds. We searched at all the other shutters, but no wasps were behind them. Whether the love of companionship, or the mere attraction of physical comfort had drawn them thus together cannot be declared; we only know that they all had the ability to congregate in the warmest spot, and not one was to be found elsewhere in that vicinity. The group comprised three species of Polistes; perhaps seventy-five per cent of them were pallipes, twenty per cent anmularis and five per cent bellicosus. It appeared that the entire population of the neighborhood was here assembled, yet there was not a male among them.

At Raleigh, North Carolina, Brimley ${ }^{12}$ has taken males all winter, from the end of November to the end of March; but, while we have looked for males during the winter, we 12 Ent. News 19: 107. 190S. 
have never succeeded in finding them. It seems as though it is normal for the males to die of exhaustion after fertilizing the queens, but it might be possible for some unfortunate ones, with no opportunity to function sexually, to retain sufficient vitality to prolong their longevity.

While all species of Polistes customarily place their nests in buildings, we found several very large last-year's nests on shrubs in a small, uncultivated patch of ground, about fifty by one hundred feet, in the Illinois valley. (See fig. 5I.) Wheat-fields surrounded it on all sides. The nests were attached to the bushes about four or five feet from the ground. The striking feature was that several of these old nests had a number of queens of $P$. anmularis clustering upon them. It was April 24, I9I4, just the time in the spring when the wasp queens would be likely to go househunting. They may have been only resting on these old nests, but we have long had a notion, and so have other writers, that they sometimes use old nests, and that more than one queen sometimes finds a nome on such a nest; hence we accepted this evidence in partial confirmation of our impressions. The following table shows the number of queens that were at rest on each nest:

No. nests

I

3

3

I

I
No. queens on each

o

I

5

6

I6

Besides this, we found several new nests in the making, of three or four cells each, some containing eggs, and presided over by queens as follows: 


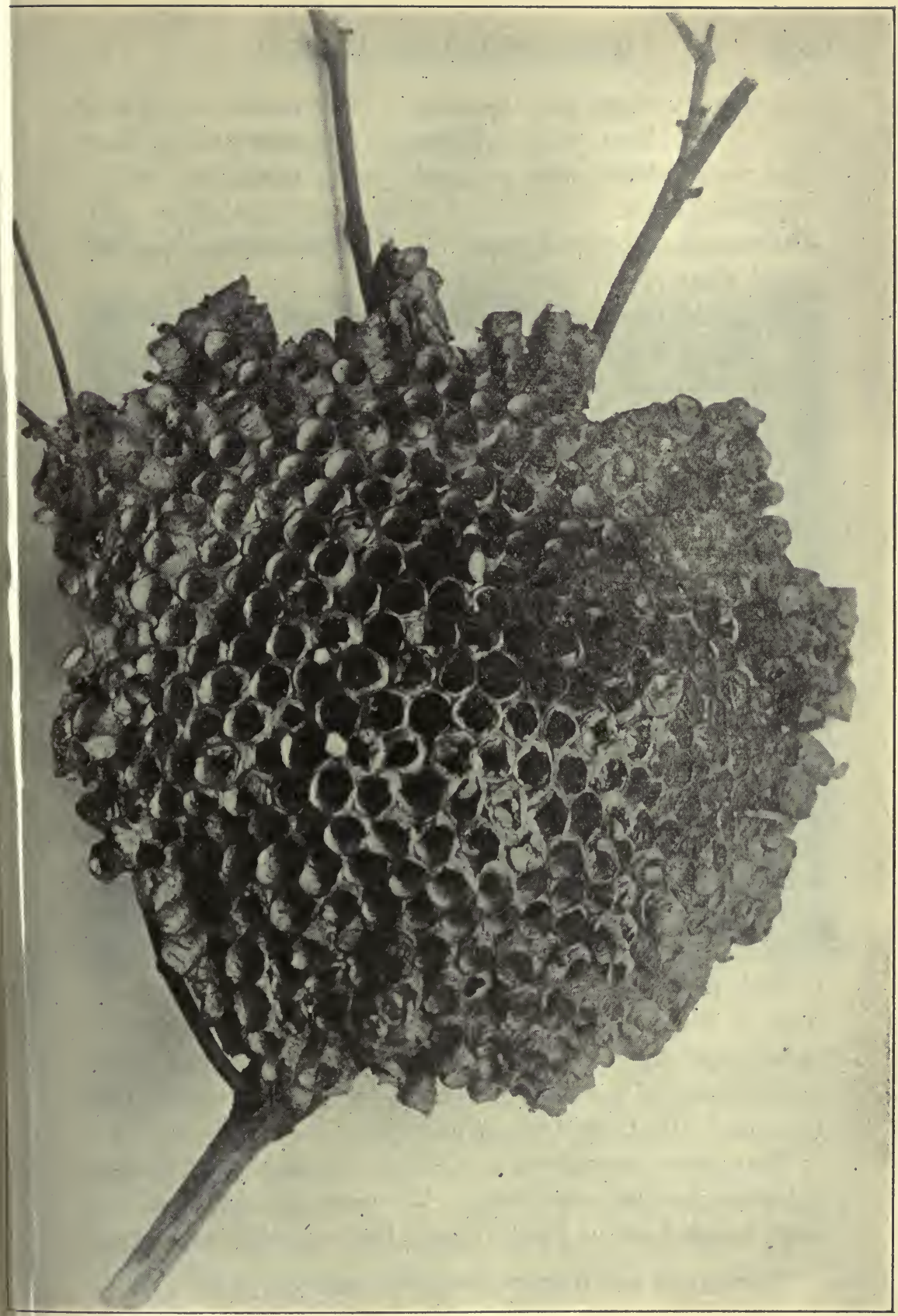

FiG. 5I. Nest of Polistes sp. Slightly reduced. 
Nests with I queen,

I nest

Nests with 2 queens,

I nest

Nests with 4 queens,

2 nests

There were also some queens in clusters, without any evidence whatever of nests being built.

That old nests are sometimes used, but usually not the old cells, is evidenced by the fact that flourishing Polistes nests are often found with bright, clean cells along the periphery and a center of soiled, partly disintegrated cells. However, one should not attach to this fact too much assumption of intelligent choice, for we often find nests in strange situations which are probably accidental, as, for instance, the mud nests of Chalybion and Pclopocus often found plastered upon Polistes nests, or, like one curiosity which we saw, a pipe-organ nest and two mud nests all subjoining a large paper nest. Whether the queen falls upon old nests as accidentally as she does upon the rafters of a barn or other site, is a problem worth study; but, whether through luck or foresight, we must admit that the queen enlarging an old nest, with the stem and foundation already built and the material at hand which may be again used, has much of her work already done at a time of year when she is without assistants.

We usually think of Polistes as inhabitants of sheds, and in such places they are most abundant, but their nests are built in trees as well, where there is no shelter whatever from wind and rain. Judging by the large size of these nests, which of course denotes strong colonies, we see that they are little affected by the elements.

They seem, moreover, to be able to adapt their nesting habits to unusual conditions. We once found a nest in a rusty tomato can in a city rubbish heap. Polistes variatus ${ }^{13}$

${ }^{13}$ Hungerford and Williams, Ent. News 23: 255. 1912. 
in Kansas, when without trees and buildings, suspend their nests in the tunnels of rodents.

The nests of $P$. annularis sometimes attain great size. The following data recorded by Pierce $^{14}$ are of interest: Of two nests taken in Texas, one had I 575 cells, and the

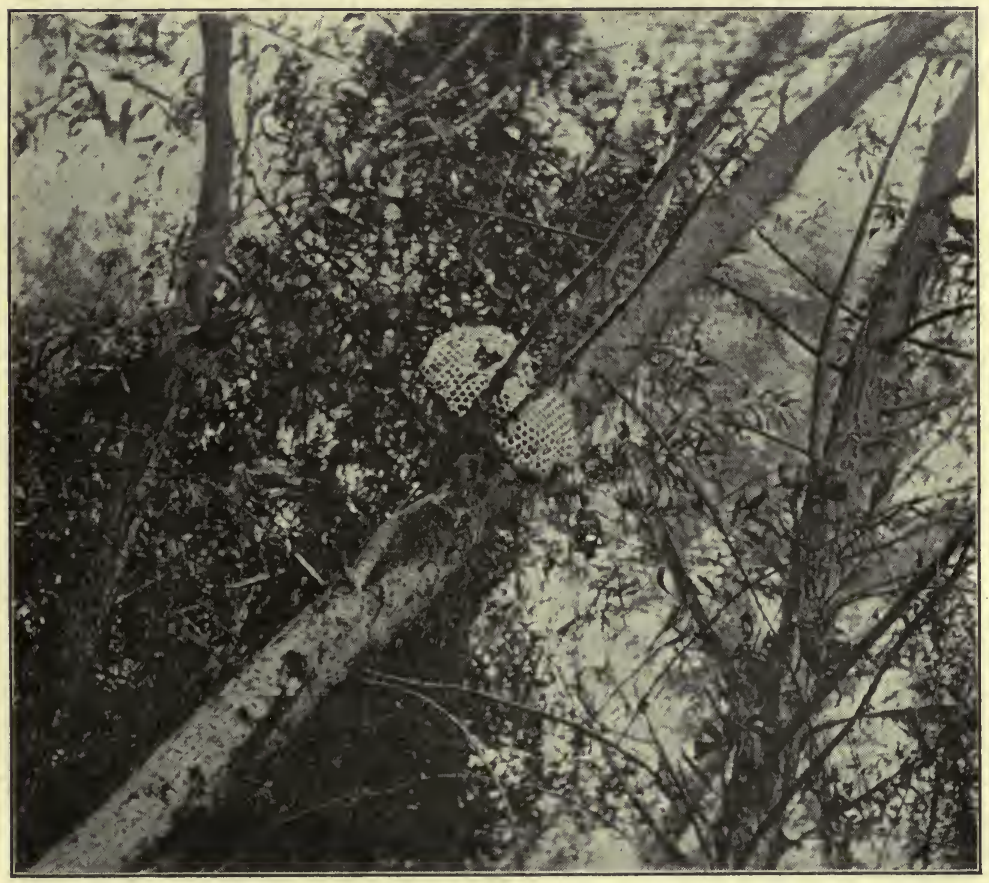

FIG. 52. A nest of Polistes annularis among the branches.

other had I2I 2 cells. These 2787 cells gave forth I 553 wasps of which I3II were males and 242 were females. Two hundred sixty-six wasps were stylopized by Acroschismus pallidus Brues. He says further that stylopized $P$. annularis are not so active as normal individuals, but are often seen feeding on flowers, and some lived from I 3 to

14 Bull. U. S. Nat. Mus. No. 66: 17. 1909. 
I6 days after the exit of the male parasites from their bodies. Some were even found hibernating thus. Fox ${ }^{15}$ found, at Denison, Texas, a nest of $P$. annularis which measured eleven by sixteen inches.

The large nest of $P$. annularis illustrated in figure 52 was found overhanging a dry creek-bed near St. Louis. It was almost on edge among the branches, eight feet from the ground, and bore about twenty queens. They were all frightened away by the removal of some of the leaves in order that the nest might be photographed. The nest had probably been built elsewhere, and either the wind or high water had lodged it here in an unusual position apparently without having caused any change in the life of the progeny.

In one case we noticed a strange phenomenon: one cell in a $P$. anmularis nest contained two eggs. The second egg was additional-not merely a misplaced one-for the 28 cells of the nest contained 29 eggs. Ten days later we noticed, however, that only one egg in this cell was developing; the other seemed not to have hatched.

One $P$. annularis returned several times to our out-door dinner table in the country, to eat the juice from a bowl of apple-sauce. It drank long and steadily, standing kneedeep in the juice.

Miss Murtfelt records the fact that these wasps removed strips of paper from the bags that were used to protect clusters of grapes. After chewing the material into pulp, they carried it away for the building of the nest. Pierce (loc. cit. p. 22) finds that this wasp is the host of three species of stylops. Robertson mentions it as feeding upon various flower-heads, and we have observed it feeding upon flowers of the madeira vine and goldenrod. 
Polistes pallipes Lepel.

We had long been possessed of an idle curiosity to know how Polistes would behave if their nests were turned upside down, so the experiment was tried of inverting several of the nests of $P$. pallipes. This was done by taking down the nest, passing a long hat-pin through the center and stem of the nest, and thus pinning it back in its place upside down, with ample space allowed above for the easy entrance and exit of the wasps to the cells.

After one of the Polistes nests had been inverted, the inmates removed much of the material from the nest and commenced to build another nest on the ceiling at the identical spot where this one had been. At last only one wasp at a time was to be seen working at this spot, while the others remained below and cared for the inverted nestlings. In time, the wasps abandoned this new project and all worked on the inverted nest, carrying on the household affairs in the usual way, excepting that they removed the material from the middle of the nest and from it this time built other normal cells beneath, using the roof of the old nest, now inverted, for the ceiling of the new cells.

In another colony, the duties went on normally, and none of the new cells were placed vertically on the old roof (now ceiling), but the new cells around the periphery were so built as to be almost horizontal, radiating from the stem of the nest.

In two other inverted colonies, the affairs of the household went on normally, but no attempt was made to add new cells.

A year later, in June, when turning over a large stone. we found a queen of $P$. variatus Cress. with her nest of a dozen cells, two of which were sealed and the others with wasplings in various stages of development. We inverted 
this stone, to observe the behavior of the queen, taking precautions, however, to lay another broad stone of the same color above it, in order to give her the roof and the shelter from the light and weather to which she was accustomed. She remained on the upturned nest until 3 p. m.. about five hours, and then deserted it. The next day the little black ants were stealing the goodies from the exposed nest. Watch was kept at frequent intervals for the next two days, but the queen never returned.

Another small nest of $P$. pallipes, built on the sheltered side of a loose door which leaned against the side of a barn, was exposed, by turning the door, to the direct rays of the August sun. The nest was soon deserted by the owners. Shortly afterward we found that the larvae, too, had been torn out, probably by birds.

All wasps are usually so diligent about their domestic duties that we seldom catch them doing so commonplace a thing as eating - in fact; we are almost surprised when we find them pausing to take nourishment for themselves.

Early one August morning, we found a $P$. pallipes visiting a small wound in a willow tree. It remained for perhaps a half-hour, with its head buried in the soft, moist tissues, but when it left we could see that it carried away no wood-pulp. Hence we concluded it was only breakfasting off the juice and pulp.

A cottonwood tree bore a decayed spot on the top of a projecting root. Two $P$. pallipes were busying themselves about it when we discovered it at 9:40 a. $\mathrm{m}$. Thinking it would be a good chance to see them gather pulp for nidification, we watched their every movement. A few minutes later a black and yellow Eumenid came to the same place as if returning to a familiar spot. During the next hour while we remained, they came and went at intervals. often pausing on the rotted wood for ten minutes or more, 
When they departed; we could see clearly that they never carried away any pulp. They spent their time with their heads buried in the rotted wood, with their abdomens pulsating in and out, which movement in the wasp generally denotes contentment. We thought that they might be merely seeking moisture, so we placed near them a piece of juicy peach, from our lunch. This they stolidly ignored, however, although they seemed to be aware of it and even climbed over it on their way to the much preferred rotten pulp. Hence we again concluded that instead of gathering the wood-pulp for the construction of their nests, they were merely enjoying their own repast.

They are not always vegetable-feeders, however. On a nest hung above the laboratory door, one worker brought in a caterpillar. A second immediately cooperated with the first, and together they soon divided it into two equal parts; then each took his portion and complacently chewed it to pulp.

We have previously recorded ${ }^{16}$ how, when one comes upon a Polistes nest at night, one finds the inhabitants quietly at rest, their bodies and legs spread flat against the under surface of the nest. They seem to be fully asleep, for one may hold a strong light near them for several minutes before they show the slightest response. Early last year, when the queens were nesting alone, we wondered what became of them at night. It seemed that they went elsewhere to sleep, until a careful examination of fifteer: nests of $P$. pallipes revealed them in hiding during the night on top of the nest, and completely invisible from below. There they clung to the stem of the nest, between their roof and the ceiling of the barn. This condition was constant for all the queens at that stage of nidification, and 16 Ann. Ent. Soc. Amer. 9: 24I. I9I6. 
brings to light the interesting variation of position in sleep when the queen is alone and when the numbers are great.

Dr. C. H. Turner ${ }^{17}$ has published a very interesting and detailed account of the feeding, homing and hunting behavior of an orphan colony of $P$. pallipes. Tower ${ }^{18}$ has done some work on the ontogeny of the color pattern in this wasp. Pierce finds $P$. pallipes stylopized by the twisted-wing parasite, Acroschismus bowdichi, and says that a female was taken by Mr. Dury "so laden with parasites that it could not move." It contained nine male pupae. Robertson finds them feeding on various flower heads. Packard ${ }^{19}$ says says that a male with the abdomen removed lived for five and one-half hours, while a female with the head removed lived actively for forty-one hours. Snyder ${ }^{20}$ says that, in the Bermuda Islands, $P$. pallipes is of a lighter shade than in the United States. Bermuda has coral roads and white calsomined roofs, and he suggests that selective elimination has been a factor in causing the survival of the light colored individual.

\section{Polistes bellicosus Cress. [S. A. Rohwer].}

Two specimens of Polistes bellicosus, a yellow-striped wasp, and also another Hymenopteron often came down to the water to drink. Occasionally they stopped at the water's edge, but more often they would fly to the middle of the puddle of still water and there alight upon the surface, spread their legs in the fashion of the water strider and drink long and deep, apparently in full enjoyment. They

17 Psyche I9: I84-T90. I9I2.

18 Decen. Publ. Univ. Chicago Io: 21. Fig. 72-74. 1903.

19 Psyche 2: 17. 1877.

20 Ent. News 19: 147. 1908. 
did not swim nor spin about, as do the water striders, but rested calmly on the water with legs spread; and when they had finished they arose lightly on the wing and flew off. Sometimes they spent a long time there, probably for the purpose of cooling off.

On one occasion, a Pelopoeus was lying on its side, motionless and partly submerged. At first we suspected a tragedy - that the insect had come to the water exhausted or had made a false step in alighting and had been drowned -but when we approached and essayed to pick it up, it darted away. However, two Ammophila sp. were taken from the pond drowned. We do not know whether the water really has its dangers for them, or whether these had merely come to this spot when already injured or exhausted and ready to drop.

Vespula germanica Fabr. [S. A. Rohwer].

We hesitate to call this little wasp a scavenger, and yet we have seen it enjoying discarded fragments of our food so often that we have grown to expect to see it on the deserted picnic ground, feasting on the remains left from the lunch-baskets. On one day, August 2I, we captured twenty workers, and many more were present, feeding on grape-jelly, greasy chicken-bones and other fragments left by the picnickers of the previous day. While feeding, they are as intent as bees on a water-melon rind, and may be captured with ease. They seem practically omnivorous. We have seen them eating of an astonishing variety, including grapes, pears, apple-sauce, paw-paw, dead roach, juice in salmon can, cold broth, flowers of buck-brush, madeira vine, banana, eyes of a dead rat. Several were seen sipping water at the spring. A few hours after a young rooster 
had lost his head at the chopping-block, the head was found teeming with these greedy scavengers. They jostled and swarmed over the tongue, eyes and all exposed moist surfaces (fig. 53).

In early spring, the queens always keep close to the ground in flight, and often enter openings like mole-holes or crevices in the rocks. We could easily understand their low flight and hunting behavior, since it is well known that this species builds paper nests underground; they were probably not foraging but nest-seeking or site-hunting. On May I I, I9I5, we saw many in the fields at Meramec Highlands conducting themselves in this manner.

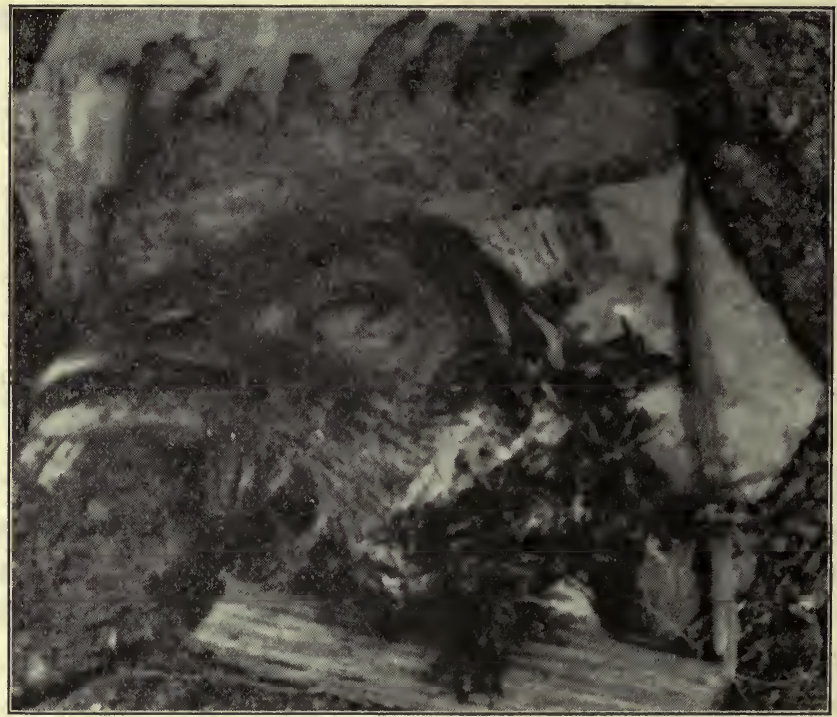

FIG. 53. Vespula germanica were as thick as flies on a freshly removed rooster's head.

While they usually build their nests underground, we once found one in a hollow log lying on the ground. It was 
discovered early in June, and then comprised three empty cells, six covered ones and about a dozen with larvae. From the covered cells, four adults emerged on June 28 and 29 and July 3. The nest was small and had four layers of covering over the top and partly overlapping on the sides.

\section{Vespa maculata}

A pair of insects, tumbling violently about on the doorstep, attracted our attention. Closer observation revealed Vespa maculata in deadly combat with a large gray fly. Soon one wing of the fly flew off; then the head popped off. Even then, more tumbling ensued, until presently the wasp triumphantly adjusted the fly under her body and flew to the grape-arbor nearby. Here she paused to complete the preparation of her prey, which consisted of much malaxation of the fly and biting off its other wing; then she flew away with it.

For days thereafter she chased flies at the kitchen door and at our out-door dinner table. Other wasps were often there, too, sharing our food-drinking our fruit-juice, stealing our cake, even pillaging our sausage-but Vespa maculata never bothered anything but the flies which congregated there. With a swiftness exceeding that of a chickenhawk in its onset upon a barn-yard, she would appear above the table, pounce upon an unsuspecting fly either on the wing or resting on the table, and carry it up to the grapearbor overhead. There she would either snip off its wings and head preparatory to carrying it away, or, as is her custom, hang herself up by one hind leg and swing to and fro up-side-down while devouring the prey.

They are large, boisterous and decidedly terrifying in their manner. However, they themselves do not always 
escape, for we once found one dead, ensnared in a spider's web.

Wasps of all kinds are almost always a hot-weather population; hence we were much surprised, on November 16 , to find a $V$. maculata, very active, upon the windowpane. It was left there, that its voluntary course of action might be observed. That day was unusually warm; on the cooler days, the wasp was only slightly active. On November 28 , it was placed in a jelly-glass containing cotton, but either the confinement did not suit it, or its days were near an end, for it survived less than two days more.

In January, I9ro, a large nest was taken at Kimmswick, Missouri, having several dead wasps lying between the tiers of the paper. 


\section{CHAPTER XIII}

\section{The Mining and Other Wasps of the family Eumenidae}

Odynerus geminus Cress. [S. A. Rohwer].

Certainly one of the daintiest pieces of work executed by the solitary wasps is the little turret built by Odynerus geminus. This is a neat little chimney, built of pellets of mud plastered one upon another, surmounting the wasp's burrow in the ground. It is a little less than three-eighths inch in diameter, outside measurement, very thin and delicate, rough on the outside, showing the delineation of each pellet of mud as it was superimposed upon the other, but smooth on the inside; the interior diameter of one-fourth inch is just the same as the hole in the earth beneath itin fact, it is merely a built-up continuation of this hole. The turret rises to a height of about three-fourths inch above the surface of the ground, then turns at a right angle and extends in a horizontal course for the same length. The completed turret looks just like a miniature "elbow" of a stovepipe (see fig. 54).

The wasp has a pretty way of entering this novel tunnel; she stands beneath the turret, gently lifts the front part of her body until the first pair of legs can reach the edges of the chimney, and thus holding on she deftly raises the body and climbs in.

The gallery beneath this quaint architecture is clear-cut, 


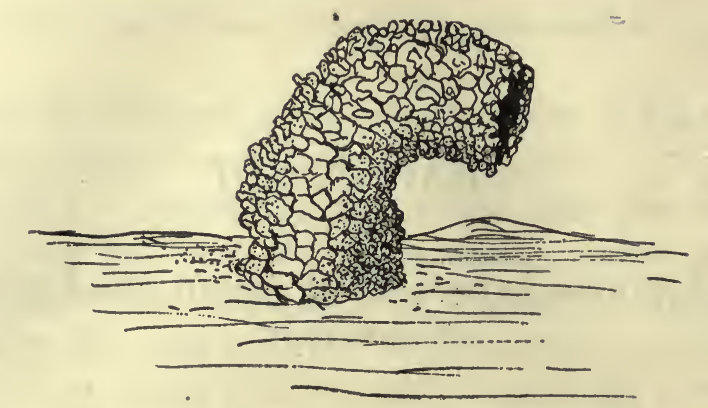

FIG. 54. The turret over the burrow of Odynerus geminus. Twice natural size.

about one-fourth inch in diameter and two inches in total length. It goes straight downward for half its length, then turns abruptly, usually forming an angle of approximately $60^{\circ}$ with the perpendicular, although occasionally this angle approaches a right angle. The end of this channel is very slightly wider than the upper portion, and forms one of the "pockets" which make up the nest (see fig. 55). Other channels, with a similar pocket, may branch off from the main burrow at the point of the sharp bend. We have found from one to four pockets to a single nest, but we do not know whether the wasps vary so in their habits of nest-building, or whether the smaller nests were only incomplete. We suspect that the construction of a single cluster of cells extends over a considerable length of time. because, in one nest of four pockets which we excavated, one cell contained a larva of considerable size, while tho others contained smaller larvae or egg and caterpillars.

Hungerford and Williams ${ }^{1}$ find no mud tubes over the tunnels of 0 . geminus, and a part if not all of the pellets of earth are deposited within two or three inches of the entrance to the hole. We find that $O$. geminus drops her

1 Ent. News 23: 253. I912. 
pellets nearer to the entrance than does $O$. dorsalis, the latter scattering them over a much larger area. We too have seen an occasional nest of geminus without the turret, but we attributed these cases to some accident, the intrusion of man or beast. We watched three such nests, whose turrets had been destroyed, to see whether they would be reconstructed, but no attempt was ever made by the wasps to repair them.

F1G. 55. Photograph of the nest of $O$. geminus, showing the mandiblemarks on the wall of the vertical channel. Natural size.

Of course such a piece of work as this perfect little chimney would be impossible without mud, whereas they are usually built in dry, barren places. Hence this wasp, like her sister $O$. dorsalis, carries water and disgorges it a little at a time, to wet the soil, making just enough mud at a time for one pellet.

We have never been so fortunate as to witness the beginning of this pretty tower, but we have seen the builder carrying out the pellets of mud through the chimney and 
dropping them a few inches from the burrow." The accompanying figure (fig. 56) illustrates a number of these pellets, which nicely show the marks left by the manipulation of the mandibles.

We suspected that the dirt taken out of the hole was applied to the chimney, but we were perplexed that the wasp should apply part of her excavated clay to the turret, and, with the same careful precision, carry out and discard other pellets. Finally, near the end of the season, on September I6, we got a clue to the answer to the question. We found a turret which seemed incomplete; it went straight up for one-third inch and had no curve or horizontal portion. The wasp was carrying out moist pellets: but instead of applying them to the turret she was taking them out a few inches from the hole and discarding them. When we returned the next afternoon the turret stood at precisely the height at which we had left it. The wasp was no longer carrying out pellets, but she emerged every few minutes and played about the mouth of the chimney. Imagine our surprise when closer scrutiny revealed to us that she was at these times biting off a mouthful of clay from the margin of the chimney, after having moistened the spot with water just as she does in digging her hole, and carrying it down into the burrow! Her work was methodical and accurate-really charming to see. She would come up to the top of the turret, spread a drop of water, bite off and knead together a large mouthful and carry it down, head first, into the hole, and come up in a moment to repeat the performance precisely. The fact that she moistened only enough clay at each trip to make the desired chunk indicates again that she must carry the supply of water in some other way than in the mouth; perhaps deep down in her throat. When her supply of water was exhausted, she flew away for more, Returning after a 
few moments, she first went down into her hole to see if all was well, then came up and promptly resumed her work of breaking down the little wall, mouthful by mouthful, and carrying it down into the cell. The supply of water

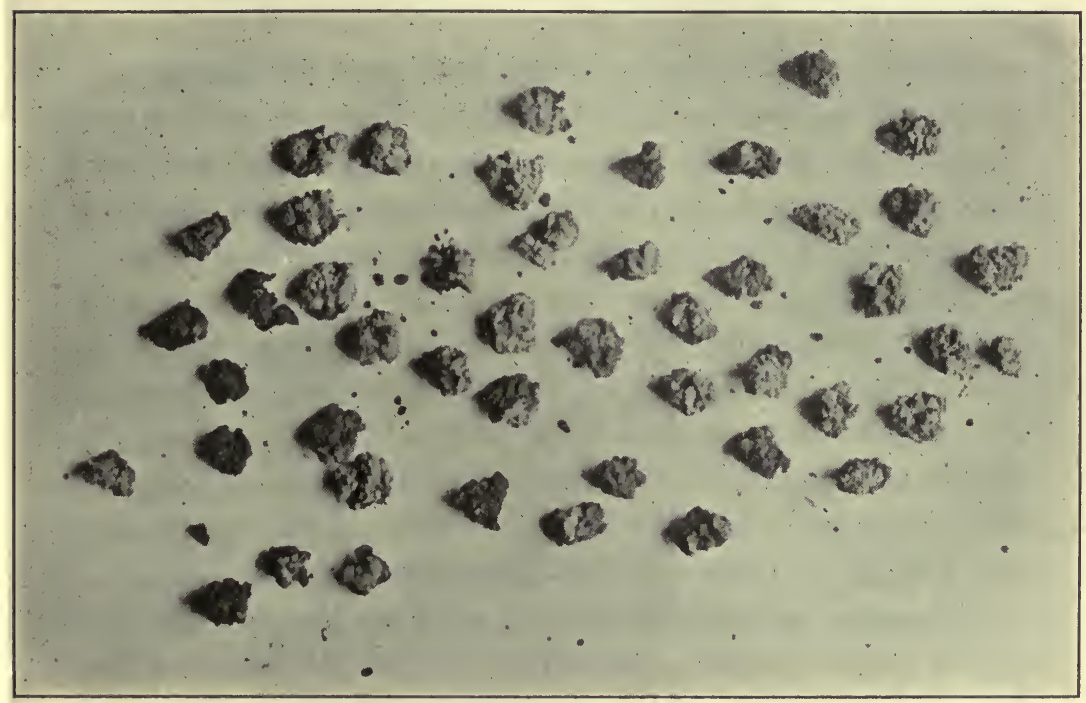

FIG. 56. A collection of mud pellets carried out in the mouth by Odynerus geminus and dropped near the nest. Natural size.

sufficed for eight loads of mud. When it was gone, she came out and paused on the brink for a moment to clean herself and then flew away, in the same direction as before, for water. This quantity was disposed of in precisely the same inanner as before; she first went down to examine the cell immediately after her return, then came out on top and paused to clean herself before going for more water.

Now the turret was almost gone, and as the work progressed the rear portion of her body protruded more and more. This gave us a direct clue to what was happening; 
down below. Sure enough, when all the turret was gone, it was proved that the material in the chimney was exactly the amount required to fill and seal up the burrow flush with the surface of the ground. Here then was our explanation: the wasp digs her burrow and carries out the earth in moist pellets; all the dirt from the gallery she carefully saves and constructs into a chimney, while that from the chamber or pocket she carries out and discards. When the nest is provisioned she plugs up the mouth of the chamber and packs back into the gallery the very same clay which she took out and has at hand exactly the required amount of filler, and also material of the right color to render the plug in her hole indistinguishable from the surrounding earth. By this method the security of the young is well safeguarded also, for the entire channel is so firmly packed that it is impossible to probe it or even to trace it when digging, as one can often easily do with the nests of the wasps that kick the dry dirt loosely into their burrows.

This wasp worked arduously in packing down the last dirt on the top of the hole, moistening it with the remainder of her load of water. After she had finished applying more "earth, she fetched one more load of water and applied it to the plug, presumably to make it more firm and compact. She stood pounding and smoothing the seal down with her head, her body curled almost in a circle so her abdomen nearly touched her head, and her folded wings sticking up vertically.

Thus, it seems, wasps vie with one another in wonderful ways of effecting the security of their young, and each new method seems more marvellous than the last.

Another turret-building Eumenid and its little chimney came under our notice at about $2 \mathrm{p}$. $\mathrm{m}$. The nest underground could not have been an extensive one, as could be seen by the paucity of the pellets strewn nearby, so when 
we saw the wasp carrying in caterpillars, we suspected that it was her first cell that she was provisioning.

The top soil in that place was black loam to a depth of one-fourth inch, while the subsoil was of red clay. The basal half of the turret was made of black earth and the upper half of red clay, and all of the pellets strewn about were of red clay. This color-arrangement proves that the wasp begins, immediately upon commencing her burrow, to construct her turret out of the first soil excavated, and adds the deeper mouthfuls of clay, in their turn, higher on the turret until the required size is attained (or the required amount of material reserved), and throws away the remaining pellets taken out of the chamber or such portions of the nest as will not need to be refilled with earth. This chimney was of the standard form and dimensions.

The proprietress was carrying in caterpillars. The first one was procured in five minutes, and the second one in twenty-five minutes. While she was gone we made a scratch on the surface of the ground to help us to locate the nest. This confused or alarmed her so that she flew about for several minutes before entering. Finally she ventured into the nest but flew out again and away, carrying her caterpillar with her. Not until a half-hour had elapsed did she return, and then she came empty-handed. Once more she entered her hole and flew out again uneasily, and began to dismember the turret, pellet by pellet, and carry the clay into the hole. We have noted previously how they plug up their holes by removing all of the turret and carrying it in for filler, so we thought that she was now doing the same, although we were surprised that she should finally seal up the tunnel, when apparently only one cell was finished below. When about one-fourth of her chimney had been taken down we caught her to make sure of her identity and proceeded to open the burrow. Great was our sur- 
prise upon finding that she had placed a plug of mud in the mouth of the cell that she had filled with caterpillars, and another thin layer over the top of the hole flush with the surface of the ground, while the tunnel, which for permanent sealing is always completely filled, was empty. Here we see that when danger threatened, and insufficient time was at hand to seal the burrow normally, she did the best thing possible to safeguard the young in the shortest possible time. Since we often find from two to four cells emanating in all directions from the central tunnel, it might be that in this case, since this nest had only one cell, her intentions were to return and construct other branch galleries and cells from the bottom of this empty main channel, when she felt that an intruder was not lurking near. Such behavior ought to make man feel like a vain pretender when he presumes to lay an exclusive claim to intelligence.

The burrow was the regular vertical tunnel with the chamber at the bottom turning to one side, as we have already photographed (see fig. 55). There were seven caterpillars in the chamber, of the species of Loxostege, discussed fully elsewhere. They were all actively moving, and could even walk about.

The egg was hanging by a tiny thread from the wall. It had been deposited at 3 p. m. on September ro, and it hatched at 7:30 a. m. on September 13 , thus having a period of incubation of about two and one-half days. The miniature larva wriggled out through one end of its shell and fell right down among the squirming caterpillars. Their activity seemed to do it no harm, however, for it thrived for ten days and became large and husky, until one morning it was found dead. Fabre thinks that the egg would be injured by the wriggling mass of caterpillars, if it were not hung up out of their reach, but here we think, as with $O$. dorsalis, the egg might be placed among the caterpillars 
with safety. In this instance we dug up the whole nest in a lump of earth, leaving the arrangement intact, so the fragile larva dropped to the food-mass below.

An interesting little experiment on the homing of $O$. geminus was carried on. We had thought that the little chimney might be of service to the wasp by aiding her to locate her hole upon her return to the nest. One turret was kicked away by an animal, but she showed no more confusion in locating her nest when the chimney was gone than when it stood at its full height.

For our own convenience, on the first day we marked one turret with a piece of paper an inch square pinned to the earth beside the hole. This was of course very conspicuous on the bare ground, and we wondered if it might have anything to do with the perfect ease with which, for three days, the mother wasp unfailingly came straight to her nest. So, while she was away for water, we moved the paper to a point three inches away from the nest, in the direction from which she always came with water. When she returned, she alighted very near to the paper, paused, walked around it, took a short flight and again alighted on the paper and for five minutes seemed interested solely in the paper. Then she arose for another brief flight, during which we hastened to replace the paper in its original position beside the burrow, and stepped back; she immediately alighted on the spot and continued her/work, as if nothing had happened. Whether she found her nest by aid of the short flight or by the guidance of the paper cannot be determined positively, but this much is certain: that she returned to the paper twice, and then gave it five minutes of her attention because it was associated with her nest, and, even though her home was only three inches away, she was compelled to take a second flight of orientation in order to locate it. 
In the vicinity of the turret just described, we found in the bare ground some plugs of mud sealing former holes. These were no longer a mystery to us after we had seen $O$. geminus break down her chimney, make mud of it and
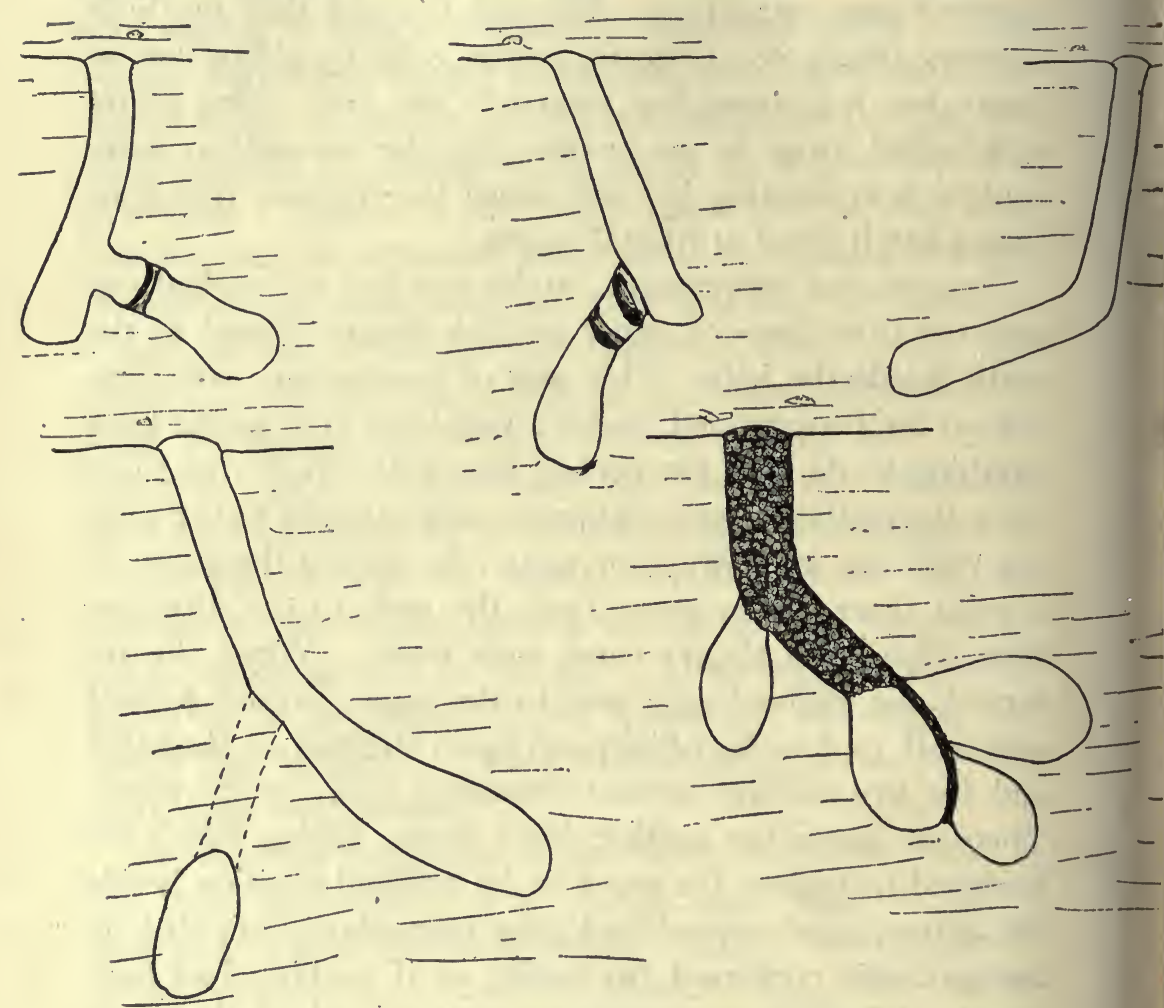

Fig. 57. Burrows of Odynerus geminus in various stages of construction. Natural size.

close the hole flush with the surface. Near each of these were strewn twelve or fifteen old pellets of mud of the type which geminus always throws away when excavating her chamber. The first nest which we dug out seemed a perfect piece of work. Clustered around the base of the vertical 
channel were four pockets, all alike and all containing caterpillars of the species used exclusively by O. geminus. (See figure in lower right-hand corner of fig. 57). There were fifty-two caterpillars in all, or an average of thirteen to a cell. They were writhing briskly and seemed very much alive, but they were unable to walk. The larvae were small but apparently healthy. Another of the sealed burrows near by had precisely the same external appearance, but had only one cell below ground (upper right-hand figure). This contained eleven caterpillars of the same species of Loxostege as the others, and the egg was hanging from the wall by a short but strong silken thread.

One certain incomplete turret surmounting an open hole was watched for three days, but it neither increased nor decreased in height, and since we saw no signs of activity about it, we dug it up. The main channel went down as usual for an inch, where it branched and terminated in two pockets (see fig. 57, lower left figure). One of these contained a large $O$. geminus larva and was well sealed with a plug of mud in the mouth of the chamber, while the second was open and contained only four caterpillars, and apparently was unfinished. Probably the mother wasp had met with an accident which had prevented her from finishing the nest, but the incomplete nest gives us the evidence that the turret is left standing until the pockets below are all finished.

Hungerford and Williams have some evidence that the cells are often used more than once as brood chambers. They also illustrate many galleries and cells to one nest, apparently made by one mother. The most complex nest in our experience is that shown in figure 57 , in which the cells diverge from the central gallery in a shower.

When we opened one new nest, we were surprised to find in its single cell one lone caterpillar and the mother wasp 
This burrow was dug out at about 5 p. m.; perhaps the little owner had merely gone into her burrow for a night's lodging, or it may be that we had only caught her there when busy with nidification. While we suspect that $O$. geminus sleeps in her hole the same as does $O$. dorsalis, we found one insect asleep on Melilotus, clinging to the stalk. However the sex of this individual was not noted.

The very first $O$. geminus worker of the year was seen in the field on June 5, but they were not at all common until August, and most of the above notes were made in the first half of September. Some which we reared at home emerged as adults in June. On September 24, we noted that during that week the turrets of geminus had been scarce. This disappearance of wasps was probably due to the increasing coolness and the fact that their normal season was over; but it may also have been due to the fact that all the puddles of water in the vicinity had dried up in the long-continued drought.

Of the hundreds of caterpillars exhumed from the nests of $O$. geminus, every one was of the same species. They were identified by Dr. S. B. Fracker as belonging to the genus Loxostege, of the family Pyraustidae. Dr. Fracker writes further that it was difficult to be sure of the species since the alcohol had taken out all the color, but in all probability they were $L$. similalis. Thus the two species of Odynerus, $O$. geminus and $O$. dorsalis, dwelt together in this field (fig. 2) and found plentiful food for their young. yet each adhered strictly to her own choice of prey, the one using only Loxostege and the other taking exclusively Pholisora catullus. Since the two species are so similar, it seems to us surprising that they should be so strict in their choice of prey as never to accept what is entirely pleasing to the other. Hungerford and Williams ${ }^{2}$ note a similar

2 Ent. News 23 : 254. 
behavior. They find that "Odynerus annulatus and O. geminus occur in the same locality, but differ widely in habits. Annulatus provisions its nest with the larva of Loxostege sticticalis (Pyralidina), geminus with the larva of Pholisora catullus (Hesperidae) although the larva of L. sticticalis was common for geminus."

We have found wide variation in the number of these caterpillars used by $O$. geminus; all the way.from four to fourteen in the cells. This difference must be due to faulty instinct on the part of the mother wasps. We do not see how the larvae could thrive equally well on such varied provision. In rearing some larvae from egg to adulthood, we offered them additional caterpillars when they had eaten all that their mothers had provided for them, and they gladly accepted and devoured many more.

A study of the longevity of a large number of these caterpillars which had been entombed in the cells showed great variation.

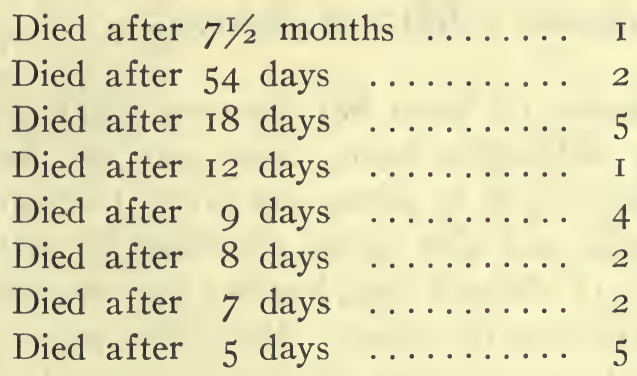

The great majority of them lived from five to eighteen days after having been exhumed; this is not of course exactly the same as the length of time they survived the stinging, but corresponds roughly to it. They were for the most part very active when the space permitted it, squirming and writhing vigorously and doing everything but walking away. One seeing this activity could under- 
stand at once why it might be safer for the delicate egg to be fastened up to the wall by a strong thread than to be dropped ruthlessly into a writhing mass like this, although we suspect that in most cases it would survive.

A few of the caterpillars showed exceptional longevity. Two remained active for fifty-four days, and one astonished us by continuing to live from September to the following April, or seven and a half months. After the first three months, it ceased spontaneous writhing and moved only upon stimulation, but remained plump and healthylooking until the last. Does the poison of the sting act as a preservative? It must have some such potency, for without it under natural conditions these caterpillars, imprisoned without food, would have died and decayed in a day or two, or pupated, but it seems that after the wasps have finished with them, they can do neither.

Odynerus dorsalis Fab. [S. A. Rohwer].

Each species of wasp has its own highly specialized method of building its nest. Some bite out the earth in chunks, some dig it to pieces and carry it out in armfuls, others scratch and kick it out according to various fixed habits. So O. dorsalis, too, has her own peculiar method which differs from the others. She carries water, mouthful by mouthful, and moistens the spot of hard, dry earth, so converting it into mud which she carries out in pellets. We have never chanced to see her working, except when the earth was dry and hard; we should like much to know whether she continues to carry water when she digs her nest after a rain. Perhaps their method of work may well be gleaned from the detailed description of the behavior of a single individual which seemed to us typical in practically all points. 
When we discovered this wasp at work at 8:50 on the morning of July $3 \mathrm{I}$, her hole was already begun and about one-half the length of her body in depth. She would stand on her head in the hole and bite out a little clod, at the same time turning around, screw-like, about one-quarter or one-half a revolution, in order to work from all directions alike. Then she would back out of the hole with her round, well-formed pellet of mud in her mandibles, always fly from two to fifteen inches with it, and drop it. These mud-balls were fairly uniform in size, and round-not mere clods of dirt bitten out. (See the pellets strewn about in fig. 58).

After working thus for about ten minutes, she went away, probably for a fresh supply of water. We waited so long for her return that we began to think that she had abandoned the enterprise; but, after fifteen minutes, she reappeared and began her work afresh. She worked almost incessantly, and took out I 5 pellets in 8 minutes. When she emerged from the hole with the last pellet and flew away a few inches to drop it, she did not return immediately to continue her burrowing, but continued her flight at a high speed and in a direct line toward the northwest. She was gone from our sight just one and a half minutes, when we saw her returning, straight from the same direction. Iseley $^{3}$ says that when they return from their wateringplaces he can see their mouth-parts glistening; we were unable to see so much, but she resumed her work as before, so we suppose she carried the water in her gullet. This time she worked 8 minutes, the same as before, and in that period took out 12 pellets; upon emerging to cast away the last she flew straight and swiftly off to the northwest, just as before, and returned in $\mathrm{I} / 4$ minutes. Thus she seemed to work with pretty precision and accuracy, yet we doubt ${ }^{3}$ Kan. Univ. Sci. Bull. 8: 287. 1913. 
the economy of this elaborate method of work. In a halfhour she had deepened her hole just the length of her own body; other wasps, such as Priononyx or Sphex, digging and kicking out the dirt, would have progressed much faster.

With this supply of water, she worked 7 minutes and took out I I loads of earth, after which she surprised us by flying off toward the northeast. A quarter of an hour elapsed before she returned. She must have found a supply of water somewhere in that direction, however, for she resumed work normally, taking out 12 mud-balls in just eight minutes. On the next two journeys, she resumed her northwesterly course; the first time she made the trip in one minute and the next time in only one-half minute. Can it be that she was learning by experience to make her trips more quickly or directly?

By this time we were sufficiently familiar with her usual course to make it comparatively easy to follow her in her flight to her watering-place, except that it required such sprinting as was neither becoming to our mature figures nor befitting to a July day. The pond, a mere puddle of rain-water which remained in a small depression, was some 200 feet distant. When she arrived she went direct to the edge of the clearest part of the puddle, took a long drink, and when she arose in flight she seemed very heavy on the wing, probably because of being gorged with water. We were surprised to find that even after she had made so many trips to the pond, her course was not quite direct. Instead, her going out and her return to the nest followed the course indicated in the little diagram, the left in figure 59. She flew west-by-northwest to the railroad track, down the track to a point even with her tiny pond, then to the pond and home again, with only a minor detour in her return route, as indicated.

This time she worked only 5 minutes and removed 7 


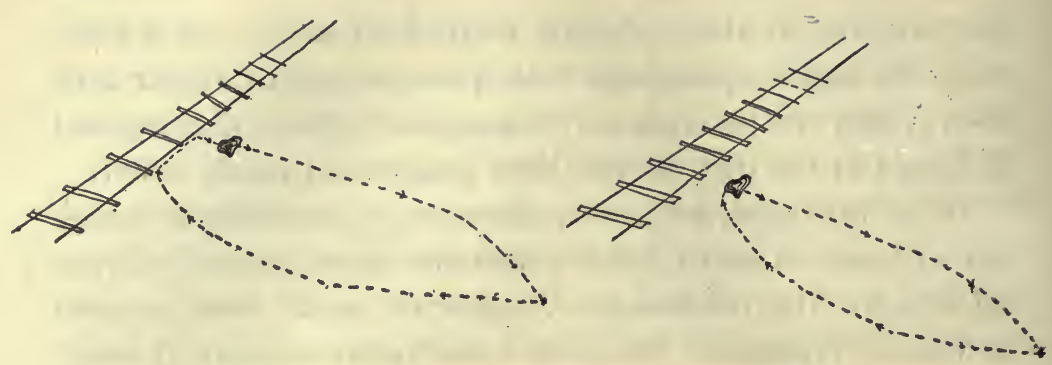

FIG. 59. The course of flght of Odynerus dorsalis to the puddle of water.

pellets, when she soared off to the northeast. We waited for her at her old pond, and, although she had flown in the opposite direction, she eventually appeared there, paused a moment for a load of water and hurried on back to her hole, following her habitual route precisely, and arriving after an absence of just $61 / 2$ minutes. Why these roundabout courses? We do not know, but this shows that, even though these wasps are familiar with the direct route, they do not always adhere to it. The hole was now about two inches deep; the pellets were larger and fewer to each mouthful of water. Either the work was becoming more arduous or it was telling on her strength, for she moved more heavily and occasionally staggered when she dropped a ball. The next three working periods were 8,6 and 5 minutes, and in them she took out only 8, 9 and 9 pellets. Our St. Louis wasps generally worked at a different pace from Iseley's Kansas $O$. dorsalis; the latter made the trip for water in less than a minute, but with each load of water they removed only 5 or 6 pellets of earth, while ours always took out from 7 to 15 pellets.

In making her trip toward the northwest she now simplified her course somewhat to a more nearly direct route, similar to the right-hand diagram in figure 59. Once more 
she went off on her northeasterly tour and was gone I 5 minutes-in fact, so long that she had trouble in locating her burrow. Previously she had come to it directly every time without a moment's confusion, but as unhesitatingly as a man returns to his own home. She flew about, as if confused, within twelve or eighteen inches of the burrow for over a minute; then she gave up the search, went back to the weeds about twenty-five feet away in the direction from which she usually came, and from there came back to it directly, showing again the necessity of going back to her starting-point for her bearings. It was then necessary for us to go. When we left her, she was continuing her northwest trips by the oval route last described. In deserting this wasp, we probably missed a most excellent opportunity of seeing the complete nidification, for this nest was probably nearing completion.

FIG. 6o. The burrow of Odynerus dorsalis. Natural size.

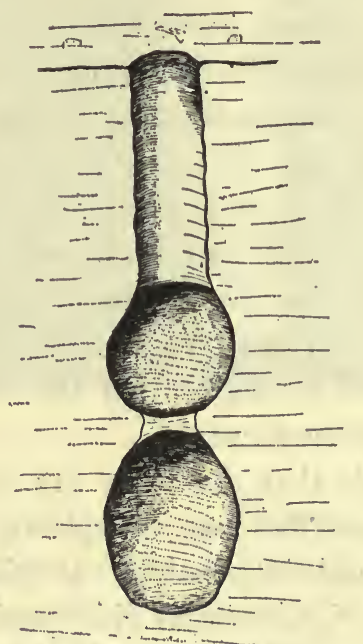

The nests are always about two or two and one-half inches in depth, and a quarter to three-eighths inch in diam- 
eter at the top. The hole goes straight down for one-quarter to one-half an inch and then widens to form a spherical chamber a half-inch in diameter (see figs. 60, 6I ). From the bottom of this the gallery continues, the same diameter as before, for a short distance and expands into a second chamber similar to the one above. The lower cell is filled with caterpillars, the egg is left swinging by a delicate thread from the wall of the cell, and the mouth of the compartment is sealed up with a plug of mud; then the upper cell is similarly filled and sealed with a mud plug in the neck of the cell. Finally a closure of mud is inserted in the top of the hole flush with the surface, sometimes artfully constructed so as to be indistinguishable from the surrounding earth, but more often there is the saucer-like depression, caused by biting out earth to fill the hole, which Iseley has so well described. But right here is a very interesting and curious point: the entire gallery from the top of the upper cell to the surface plug is not filled in solid for its entire length, as are the holes of other burrowing wasps, although often it is a short channel (fig. 6r) ; but it has only the firm plug at the top and bottom and an air-chamber between. The purpose of this arrangement leads one into pretty speculation. Does the air-chamber in the channel help to maintain a more uniform temperature in the cells beneath? The depth is sometimes so slight that the difference could not amount to much at any event.

Iseley, too, finds that the nests are vertical with one or two cells. He describes one exception, however, which is very surprising and interesting: a colony of eight nests built in the face of a vertical clay bank, with from three to seven cells to each burrow. We have never yet found more than two cells-except in one nest which was apparently abnormal, which had an extra (small) cell between the two normal ones (figure 62) ; neither have we found these 
insects building in the face of clay banks. It is surprising indeed to find one small group of individuals digressing so far from the established custom of the species, yet adhering

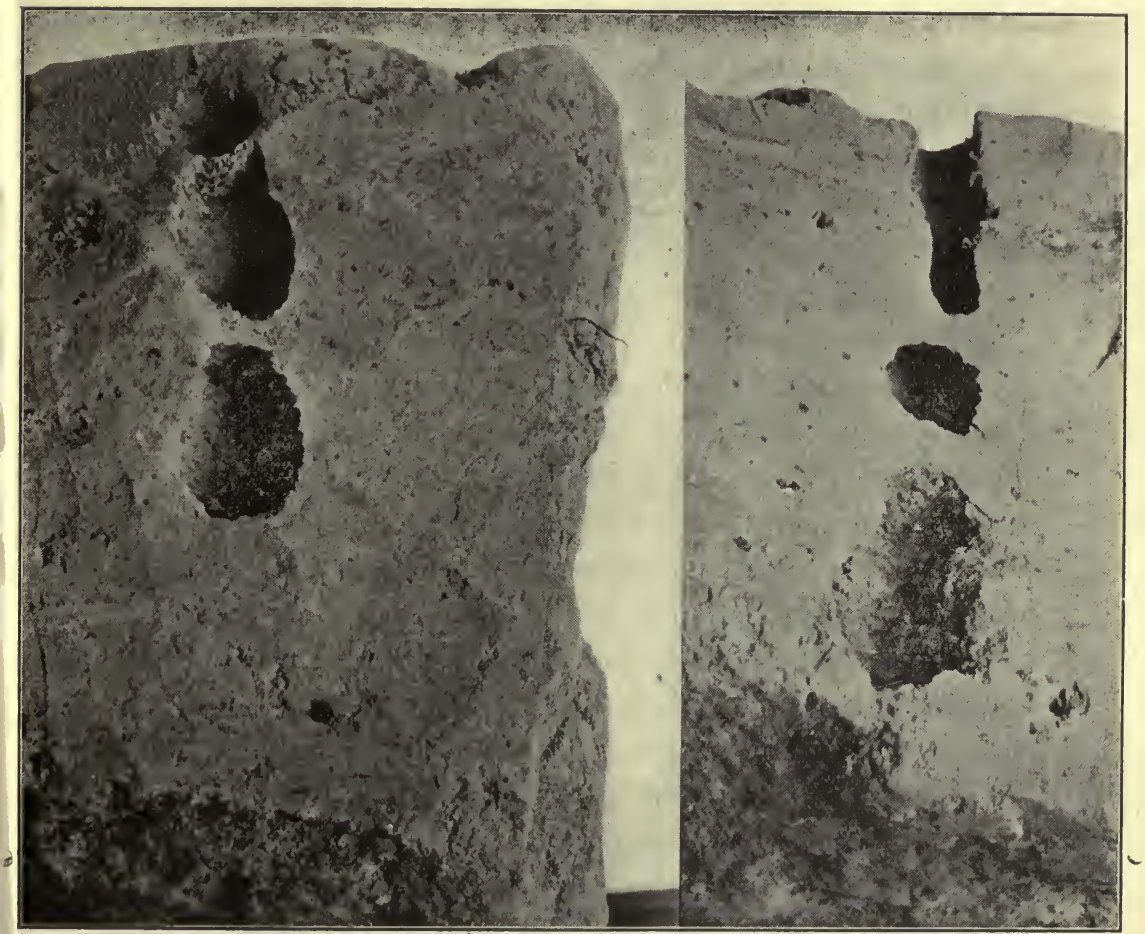

FIG. 6I. Two burrows of Odynerus dorsalis. Natural size.

to a more or less uniform scheme of their own among themselves. As he suggests, these excavated burrows show a sharp contrast to the earthen cells under a tuft of grass, described by Hartman. ${ }^{4}$ Mr. Hartman tells us, however, in a letter, that he suspects that probably his species was erroneously identified for him.

4 Bull. Univ. Texas, No. 66. 
In all of the channels and nests may be seen, on the sidewalls, the mandible-marks, in lateral strokes, or half-rings, where bites were taken out horizontally, not up and down. (See fig. 63.) The figure also betrays the method of procedure in nest-digging: as the length of the burrow increases, the width also increases, so that at the bottom there is a start on the first globular cell. When this has been completed and provisioned and the egg deposited, undoubtedly the widening of the second cell occurs, and perhaps the soil removed in this widening goes to form the plug for the lower cell.

When the home is at last in order and Madam Odynerus goes a-marketing, she does precisely what most other wasps scrupulously avoid: she leaves her nest wide open. To be sure, there is yet nothing in it to attract or reward marauders, but neither is there in the newly-finished burrows of other species, so one is again left wondering what may have been the origin of such an instinct-what condition can have brought such pressure upon the species as to establish in them so fixed a habit.

Iseley (loc. cit. p. 289) was very fortunate to observe her hunting in a patch of mallow. When $O$. dorsalis comes upon a crumpled leaf containing the larva of the spotted skipper, she commences tearing energetically at the silken nest, first at one end and then at the other. Sometimes more than five minutes is required to dislodge a caterpillar, but more often the victim is jerked from its cover in less than a minute, seized by the neck and stung two or three times under the thorax. Vigorous malaxation follows the stinging, after which the caterpillar is carried to the nest without delay.

These wasps, when returning from the field, seem to experience no difficulty whatever in locating their burrows. They carry their prey on the wing, usually with com- 


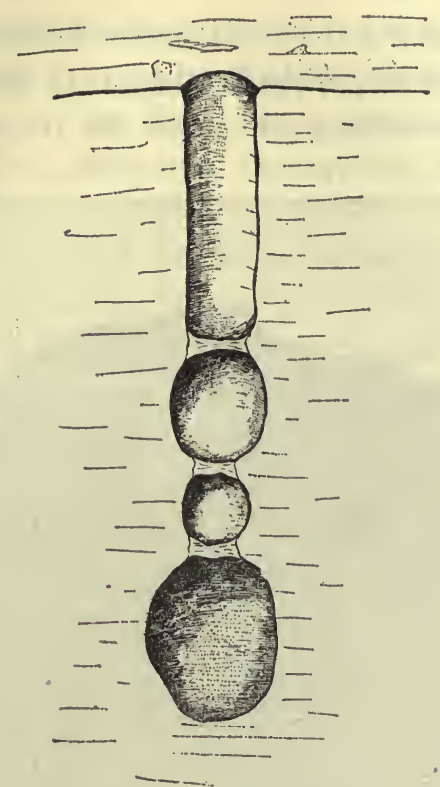

Fig. 62. An unusual burrow of Odynerus dorsalis. Natural size.

parative ease, hugging it tightly all the while, alight at the brink of the hole and push it in ahead of them, holding to it as they lower it (see fig. 58 ) ; then they follow it into the hole, remain inside for a few seconds-perhaps a halfminute--and then come backing out. Sometimes the wasp soars away directly in quest of other game; at other times she sits down and washes her face for a moment, then rises and poises on vibrating wings an inch or two above the hole, turns around on the wing as if inspecting the site, then circles about and flies away. She is calm, gentle and composed in all the maneuvers, betrays no nervousness and wastes no time in blustering.

We had long suspected that this wasp builds not one burrow but a group of burrows, and were glad to read Iseley's statement of having seen one begin a second hole 
immedately after the first was finished, and close beside it. On several occasions, when we began to dig up a nest and scooped off the surface soil with the trowel, the removal

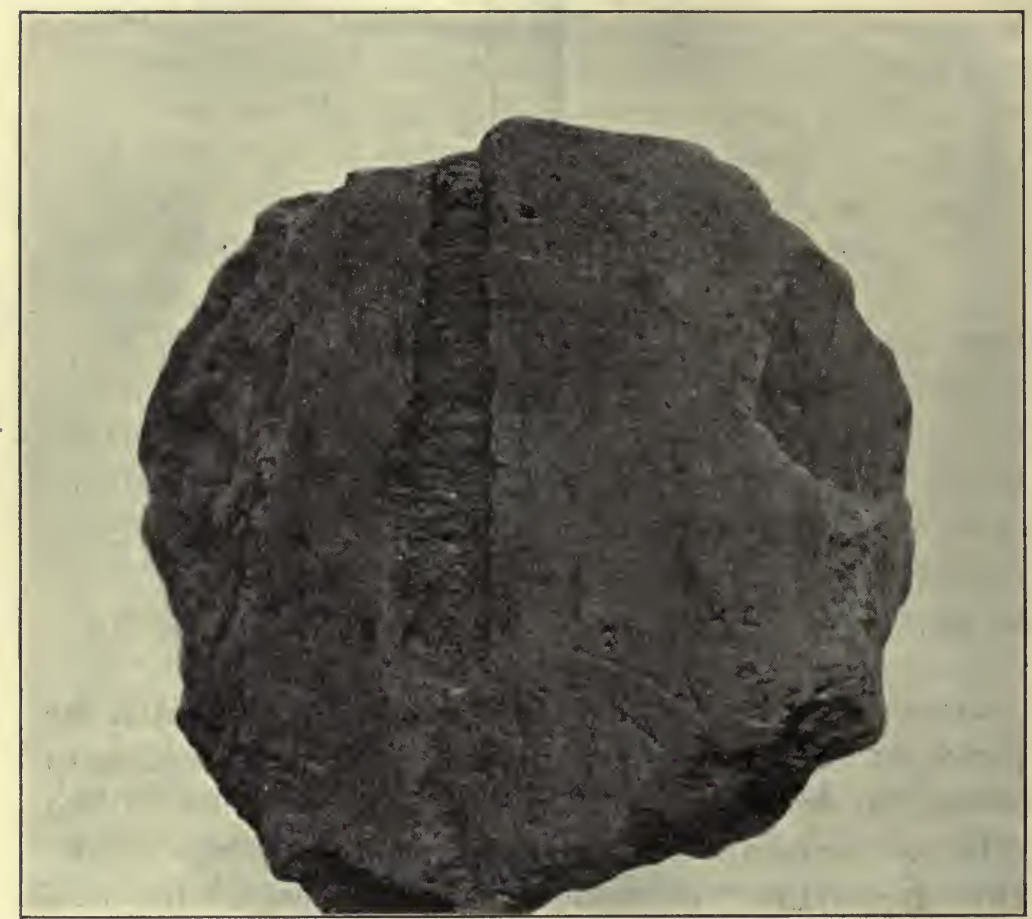

FIG. 63. The mandible-marks on the tunnel of Odynerus dorsalis. Natural size.

of the thin layer revealed three or four nests near together. We have only occasionally noticed, in our St. Louis waspfield, the pretty saucer-like depressions which betray the location of the closed nests.

One such group of nests particularly impressed us. For a week at least we had been watching a certain $O$. dorsalis as we crossed the field each morning. On every occasion 
she was busily engaged in digging her burrow, yet day after day the hole seemed ever unfinished. One evening we determined to open it to see if the wasp used it for sleepingquarters. The first stroke of the trowel revealed three similar nests, all close together in a row. It has always been our custom to place our little markers one inch west of the burrow. A closer examination showed the marker to be just one inch west of the first covered one, while it was three inches west of the open or unfinished one. Hence we have every reason to believe that the one mother had really dug all three, and we had been too dull to perceive that she was not working on the same one all the time. These three nests had but one cell or chamber each. One-celled nests were rare in the previous year as well as this year, in our vicinity. Can it be that this trait of habit or instinct is heritable, that this individual should show a rare trait so persistently in her work?

Incidentally, we found the wasp sleeping in the upper part of the unfinished burrow. The sealed chamber beneath her and the cell of the middle nest contained eggs and green Hesperid caterpillars, sixteen in all, while the oldest and original hole had a full-grown larva together with the remains of one-third of a caterpillar and some excrement. With it in the cell were fifteen white pupal cases of an Hymenopterous parasite, clustered in one corner. Since the larva was full-grown and healthy, and apparently had not been disturbed by them, one can only'suspect that the Hymenoptera had been parasitic upon the caterpillars before their capture, instead of upon the wasp larva.

The number of caterpillars used by these wasps varies greatly; occasionally as few as three are tossing about in the compartment, and in other cases the cell is crammed full with eight or ten. We, too, have found that the wasp does 
not oviposit at the conclusion of the provisioning, as do other species, but whenever it suits her fancy-or physiology. We sometimes find the little egg swinging from the wall on its thread when the provisioning is only begun or half done.

Among the St. Louis population of dorsalis we have found only the one species of caterpillar used as prey, viz., the Hesperid larva, Pholisora catullus [Drs. Barnes and McDunnough], while Iseley has found two species of Lepidopterous larvae used by the Kansas $O$. dorsalis, the species mentioned above and Pyrgus tesselata. ${ }^{5}$

We are not positive that $O$. dorsalis always sleeps in her burrows, but we have found her in the unfinished holes at twilight and on dark, cloudy days a sufficient number of times to make us certain that at least the females do so frequently while the digging is in progress. Of course the problems remain of where the males sleep, and where the females find shelter when they have not open holes at their disposal.

It has always seemed to us remarkable that the nests of $O$. dorsalis are not more often ravaged by parasites or enemies, since the owner always leaves the burrows wide open during her long absences. Yet we believe she suffers less at the hands of such impostors (at least in the nests which have come under our notice) than do some of her sister species which always close their burrows behind them with such exacting care.

From one open hole we saw an $O$. dorsalis emerging and watched her closely to ascertain her method of egress. Imagine our surprise when we, saw her carry out a $P$. catullus caterpillar in her front and middle pairs of legs, pause at the brink of the hole for several seconds to adjust the 5 We have observed $O$. dorsalis in three widely separated areas but never yet have we found her using caterpillars other than Pholisora catullus. 
caterpillar properly between forelegs and mandibles, and fly away with it. Was she a deliberate robber, or was she only a home-seeker who had by error entered the wrong nest and was removing only that which she had brought with, her and which was rightfully hers? These wasps are usually very careful in finding their nests, and while they sometimes peep into two or three others before arriving at their own, we have seen only this one go so far as to enter the hole of another.

One day we saw a black wasp running and hopping about in the region of the holes of $O$. dorsalis for about five minutes; finally it entered one of the holes, and we captured it, as it emerged, to ascertain its identity. It was a Notogonidea argentata Bve. [S. A. Rohwer]: In this case, too, we were uncertain whether Notogonidea was invading the nest of Odynerus through a blunder or through mal-intent. This wasp hunts crickets, and she probably entered this hole in search of them.

Certain Diptera sometimes pester Odynerus. One twocelled nest, which we found apparently securely sealed, contained eight Diptera pupae.

On the same day on which we made the above discovery, September 18, we watched a small gray Dipteron, Hilarella n. sp. [C. H. T. Townsend], following an O. dorsalis which was homeward bound with her green caterpillar. The little fly tagged behind her most persistently, keeping just at a safe distance, a few inches to the rear of the wasp. It followed and poised in the air with all the skill which insects of their profession usually display. Both flew near to the ground, and if $O$. dorsalis rested for an instant, the fly would hover or poise on vibrating wings a few inches away; if the rest was prolonged, the fly would rest on the ground or a grass-blade nearby. It was pretty to see the shadow on the whitened earth of the two insects in the bright sun- 
light, moving in unison as if they-were invisibly united. The wasp flew hither and thither in an evasive way in the region of her nest for fully twenty minutes before finally entering her hole. We have never seen another of these wasps experience such difficulty in locating her nest; can it be that this one spent this time and effort flying to and fro in an effort to evade her pursuer?

We have never witnessed the attack of the wasp upon the caterpillar, but, as Iseley says, they are stung and paralyzed. They keep fresh, plump and green, and usually respond to stimulus, writhe and void excrement for from three days to a week after their entombment; and we have had some which continued to live and remain plump for two or three weeks or even more. Following are some typical records which show the longevity' of the prey (all caterpillars moving actively about when taken from the nest):

Nest A. I died after 8 days $^{6}$ 3 died after 15 days I died after 25 days. Nest $B$. I died after I 2 days Nest $D$. I died after 25 days I died after I 4 days I died after 27 days Nest $E$. I died after 6 days I died after 8 days I died after I 4 days I died after I9 days I died after 20 days Nest $F$. I died after 3 days I died after 5 days Nest $C$. I died after 3 days I died after 6 days 2 died after 6 days I died after 9 days 2 died after 9 days 2 died after Io days I died after I 4 days I died after I 2 days I died after I 5 days I died after 22 days I died after I 8 days

I died after 26 days

I died after 29 days

- The number of days after the nests were exhumed. Of course the number of days since their capture somewhat exceeds this. 
The question arises apropos of this: does the acid of the sting serve in any way as a preserving fluid to keep the flesh in good condition? For certainly if we were to gather these caterpillars and shut them up without food they would starve to death and putrefy long before the length of time noted above had elapsed.

The delicate little egg is suspended by a short silken thread from the top or wall of the cell. Fabre would have us believe that this ingenious contrivance saves the egg from being crushed among the mass of heavy, writhing caterpillars in the lower part of the nest. This explanation appears very plausible, but we have found repeatedly that this protection is not absolutely necessary, for we have recklessly removed the egg from the cell and dropped it into a mass of squirming caterpillars in a vial; these eggs have always hatched and made thrifty larvae, often growing to adulthood. Although the tiny thread appears very delicate, it is astonishingly strong.

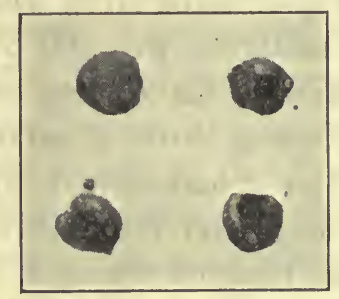

FIG. 64. After the feast. Empty heads of Pholisora catullus caterpillars-all that the Odynerus infant leaves.

By the day following oviposition, the egg has enlarged to twice its size and is of a golden yellow color, and usually it hatches on the second day. The little larva is then about Io $\mathrm{mm}$. in length, with transparent body walls and clear pale green contents, a very pretty little organism. It drops down upon the caterpillars and greedily devours them, one after 
another, not only sucking out the juices, but consuming the entire carcass, excepting the dry shell of the little black heads (see fig. 64, the remains of a feast). The supply of food provided by the mother for the growing infant varies greatly, but we have never ascertained whether that supply is sometimes actually inadequate or excessive, or whether the young merely accepts whatever is given it and gets through somehow. In our eagerness to keep alive all that we had at home for observation, we gave all of them additional food and it was almost always accepted greedily. Once we were so daring as to offer a fat, prosperous larva a small brown caterpillar instead of the customary green ones. The larva turned at once to this new fresh food, but mumbled about it mincingly for only a minute and then went back to resume chewing at its old half-eaten green carcass. We suspect that some of them are in real need of more food before they pupate, especially since some have as few as three little caterpillars upon which to subsist. We chanced to find one good-sized larva which must have been eating dirt, for the abdomen was full of earth. Yet overfeeding probably tends to make them overfat and delicate. We had one which was a thriving infant and promised to be a fine adult. After it had sucked dry seven caterpillars it was enormously large and fat. As we transferred it to a clean bottle, in the hope of seeing it spin its cocoon, we let the vial fall to the table, and the jar caused the body walls of the fatling to burst. Of course, in nature the larva runs no risk of such a catastrophe, and yet the circumstance suggests that overfeeding may make them, as well as other organisms, soft.

There is an astonishing degree of variation in the duration of the different periods of development in this species. There seems to be no fixed time for hatching, spinning or any of the functions. Moreover, we have not yet ascer- 
tained any causes, climatic, environmental or hereditary, to account for such variations. This variability will be easily noted from the tabulaton of a few typical cases, as follows:

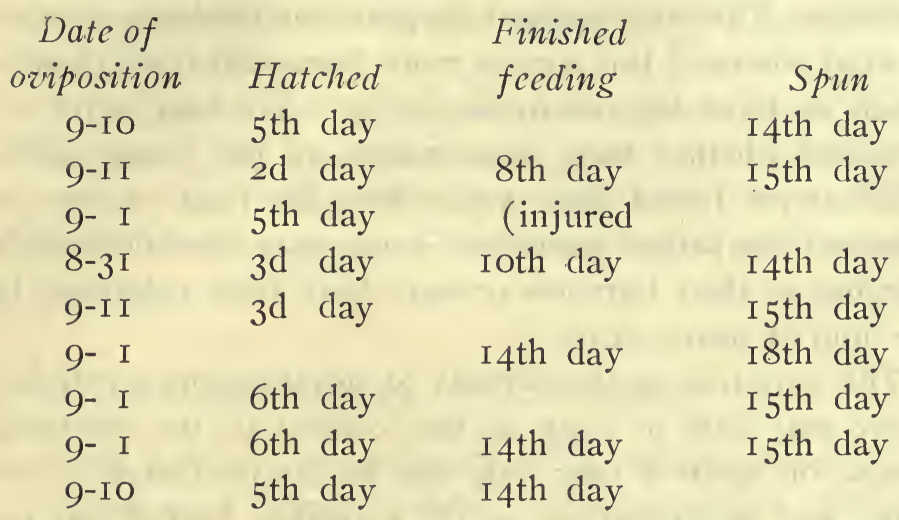

On August 2 we exhumed a three-fourths grown larva, with its last caterpillar. We gave it three more, which it eagerly devoured. After five days more it began to spin. It was unable to construct its cocoon normally in the tin box; so we made in the box a nest of tiny bits of soft paper. After that it succeeded better in covering itseli, but we could still see the insect within. Not until August 19, or twelve days after first spinning, did it transform into a mummy-like pupa within the web. On September I2, after a pupal period of thirty-six days, an adult female emerged. There is a possibility that the transformation of this individual may have been delayed by the impeded construction of the cocoon. This adult was kept in a cage and lived on sugar-water for eight days. This, too, would indicate that at least two generations emerge each year.

One of the perplexing problems is the question of how the wasp in the lower cell, when adult, can emerge without injuring its younger brother in the cell above. To be sure, they probably lie dormant all winter and are ready for 
emergence at approximately the same time in the following spring; and yet we cannot see how even then they could make their way out without often coming into disastrous collision. This may account, in part, for the large number of dead adults of this species more than of $B$. nubilipennis, which we have dug out in the spring. We have never ascertained whether these dead wasps are the young adults which never found their way out to the light of day, or wasps of the parent generation which may have died while sleeping in their burrows or may have been entombed by the mud of heavy rains.

The variation in the periods of development mentioned above may help to clear up this conflict of the emerging wasps, or again it may only add to the confusion. This point was suggested to us by a certain burrow, an exceptional nest in this vicinity in that it had three cells (fig. 62). We dug it up just after the top cell had been closed. One would logically expect to find the occupant of the lowermost cell of the tier the largest, but we were surprised to find the larva in the middle cell large, the bottom one small and the uppermost still of course in the egg stage. How this state of affairs could have come about remains a mystery. ${ }^{7}$ We wanted to follow up this development, but the lowest larva died. However, when they arrived at the stage of pupation, the middle or largest one spun its cocoon only three days earlier than the smallest one (which was still in the egg stage when we found it). Hence we may believe that the difference in the date of maturation of these and the intermediate one would have been even less.

Fabre finds that, in certain bees, one sex hatches earlier than the other, and the mother can control the sex of the

${ }^{7}$ The fact that the foregoing table shows the incubation of the egg to vary from 2 to 6 days may mean a correlation of the period to the sex of the developing larva. 
eggs so that the one to emerge first is deposited in the uppermost cell; - thus it can emerge first and leave the way clear for the second inmate of the nest. We have as yet no intimation as to whether or not such a condition may hold in Odynerus.

The season for $O$. dorsalis seems to be from about the middle of July or the first of August to the middle of September, but stragglers are occasionally seen outside the limits of those dates. The earliest individual seen was out on July 2.

Odynerils anormis Say [S. A. Rohwer].

On July z2, we carried home a hollow stem which bore evidence of being occupied. Mud partitions divided the pith-chamber in the stem into five cells. From these cells, five Odynerus anormis emerged, from July 24 to 26 . The top of the cavity was not sealed, but was open for about an inch; in this space we found Diptera puparia, which on the next day gave forth adults of Sarcomacronychia trivittata Townsend [C.H. T. Townsend]. We could not tell whether these were there accidentally or whether the life history of this fly is interlinked with that of O. anormis.

At Lake 'View, Kansas, a little later in the season,' we saw two specimens of this wasp, and watched them for over a half-hour, as they ran about constantly prying into holes in the sand and often entering them. They showed no discrimination regarding the size of the hole; sometimes the holes were those of very small bees, and sometimes quite large like Bembix burrows. We suspect that they were foraging.

The Peckhams. find this species making nests in stalks and using caterpillars for provisions, although the species

${ }^{8}$ Wasps, Social and Solitary, p. 9I. 1905. 
of the prey is not mentioned; it might be that she uses subterranean caterpillars, since our notes show that she enters numerous holes in a foraging manner.

Robertson finds the adults frequenting many species of flowers.

Odynerus designatus Cress. [S. A. Rohwer].

Two of these Eumenid wasps were found fast asleep on a pig-weed at 4:30 p. m. on August 28. Both were curled around leaf petioles. At 4 a. $m$. the following day, it rained, and rain continued to fall until Io o'clock. At $9: 30$ in the morning, they were in the identical places and positions, and dripping wet. The rain had not aroused them to activity in the least; on the contrary, they were in a kind of stupor which rendered them very easy to pick up. They were not alone in their misery. Nearby were found a number of other insects, Pelopoeus caementarium, May beetles and others, behaving similarly.

Odynerus pedestris Sauss. [S. A. Rohwer].

On a clay bank (see fig. 27), rising about six feet above the level of the ground, we saw, on October 3, this Eumenid entering and leaving an open hole at intervals. After catching her, we dug up the nest; this was of the exact size of the drawing in figure 65 .

This wasp makes a gallery and, from time to time, constructs chambers beneath it, as they are needed, similar to the manner of Philanthus sp., except that the latter usually builds them from the sides of the gallery, whereas this one builds the gallery, drops a branch of it to a chamber, continues the gallery and makes another chamber therefrom, and so on. 
The first cell that this one had made, the one nearest the orifice, contained a half-grown larva and four greenish-blue caterpillars, all of one species of Gelechiidae [S. B. Fracker], (the larva was too immature to determine the species). The next cell contained six specimens of the same Lepidopterous larva, and hanging by a tiny thread from

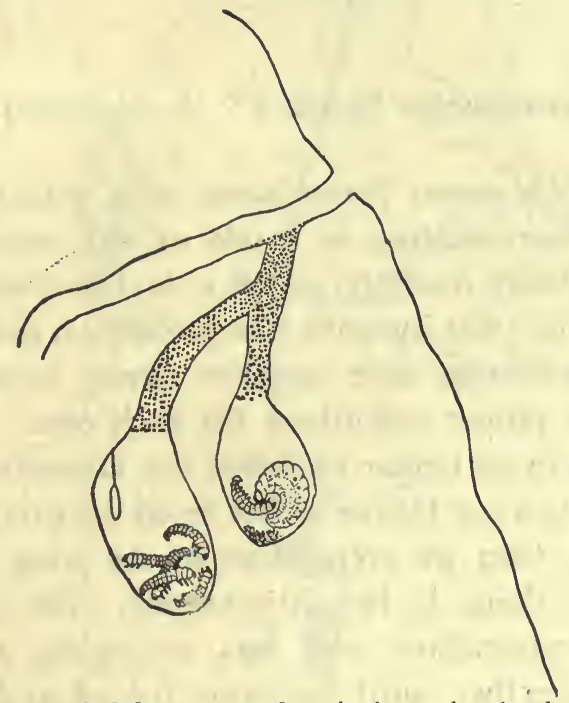

FIG. 65. The nest of Odynerus pedestris, in a clay bank. Natural size.

the wall was the egg. The small, petiole-like gallery that led from the main gallery to this was tightly packed with soil, and the continuation of the main channel in a parallel direction led us to think that a third cell was about to be hollowed out of the end of this gallery. One has not far to seek to suspect that the earth that is removed in the digging of the new gallery and cell is used for the filling of the short neck of the cell just provisioned.

The fat larva which we captured in the first cell ate all it could find, and also two caterpillars that we gave it from the other cell. The next day, when we introduced a large 
one we found in the field, it made a brave effort to eat this; but its strength proved unequal to coping with its tough skin and its wriggling activity. Two days later the larva died.

No details of biological significance could be found in the literature on this wasp.

Odynerus foraminatus Sauss. [S. A. Rohwer].

The first Odynerus foraminatus with which we became acquainted were nesting in a pile of old, weathered logs. They are solitary dwellers, and it is highly doubtful if they live in colonies; this instance was probably a case of a number of them nesting near together merely because the site afforded the proper conditions for each one.

One wasp in particular attracted our attention. She had her burrow in a log twelve inches from the ground. Twice she entered; then we crept close to see what she was so mysteriously doing in her little cranny. She had about a half-dozen caterpillars, and was arranging and packing them close together, until they were forced so deep into the hole that they were out of sight. Then she left, and soon returned with a moist pellet of gray fire-clay and used it inside the hole, probably for a partition. She brought a second load; then we took her, to ascertain her identity.

Nearby were other nests of this kind (see fig. 66), which were similarly situated. As we watched one, the wasp's behavior took a most remarkable form. We are certain that our presence did not cause it, for we were careful not to intrude. Without apparent cause, she carried out four caterpillars, one at a time, and dropped them in the road six feet away. We followed and found one of them; it was Enarmonia sp., of the family Tortricidae. [S. B. 
Fracker]. In bringing out the last caterpillar, another, the fifth, was dislodged and jostled to the opening of the hole. When she returned, she carefully took this back into the

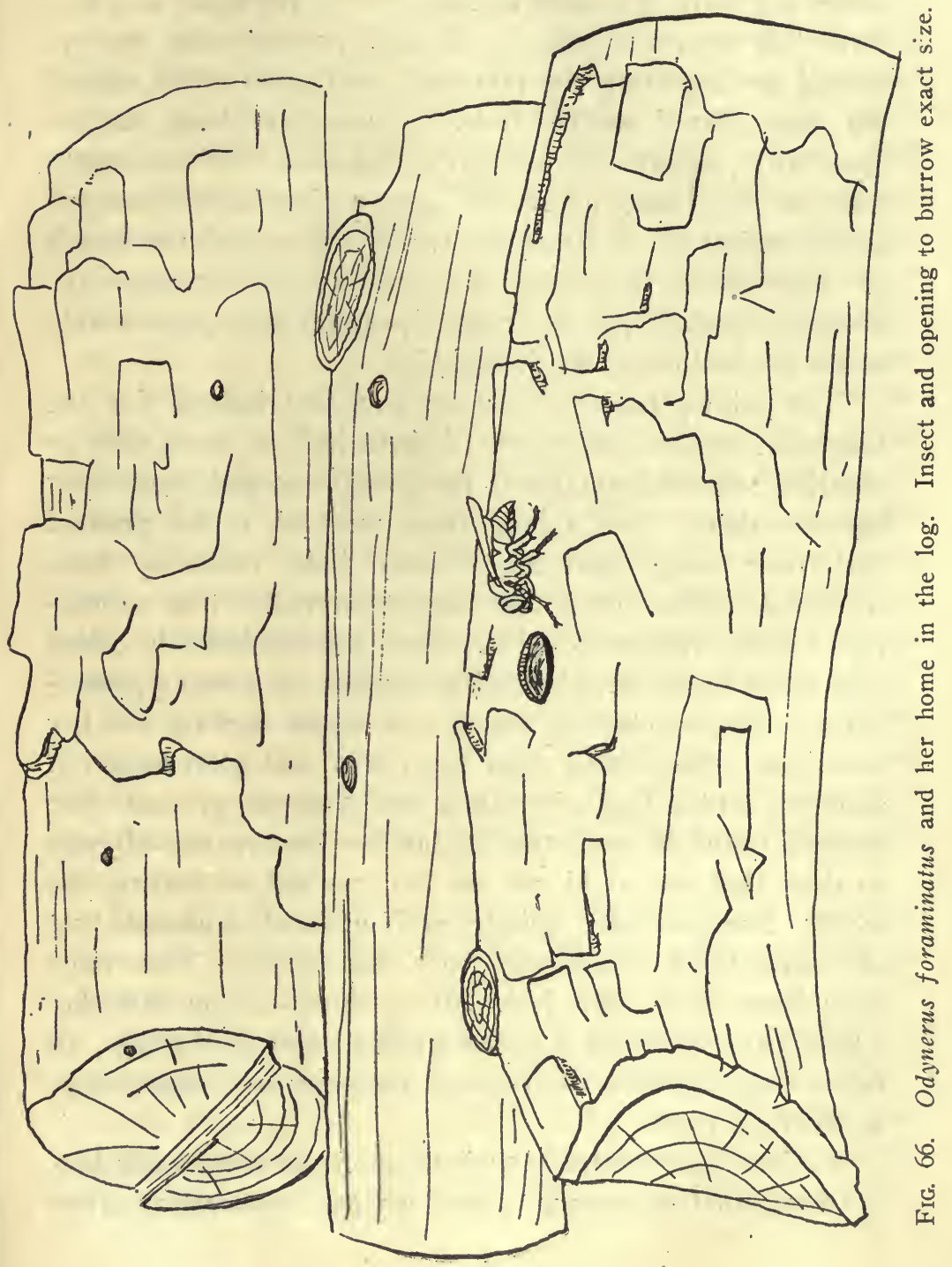


burrow, replaced it with the others and continued for some time arranging and packing them.

One day one of these wasps, carrying a green caterpillar under her body, was seen to enter one of the holes in a log. After all efforts to dig it out had proved vain, we removed the log from the pile and, with great effort, shook the caterpillar from the hole. It was not dead, but responded to stimuli. On another occasion an O. foraminatus was carrying home, under her body, a Gnorimoschema gallaesolidaginis [S. B. Fracker], while just beneath the mouth of her burrow in the log was another, a Loxostege sp., probably similalis [S. B. Fracker], caught in a spider's web, where she had evidently dropped it.

This old log-heap formed an excellent habitat for the longicorn beetles, and many of them had, at some time or another, taken advantage of the conditions and made their burrows there. For a long time, we took it for granted that these wasps used the deserted holes made by these powerful beetles, for it was almost incredible that so delicate a little creature could cut deep, smooth holes in oaken logs which broke one blade after another of a heavy pocketknife. But one day we found one surely carving out her own hole. She would enter head-first and soon back out and drop a little load of fresh saw-dust on the ground. She worked faithfully and steadily, but her burrow was already so deep that we could not see her method of cutting the wood. She proceeded quietly, as if modestly unaware that she was doing something truly marvellous. This must have been about their hole-cutting time, for on that day (July 22), we found a dozen similar holes in the logs, all newly-cut, although we did not intercept any other wasps at work on them.

We have commented elsewhere upon the remarkable lack of dissemination among many wasps. Generation after 
generation they remain persistently in the place where they were born, and frequently an entire population in a locality is exterminated just because of their inability or unwillingness to move from a chosen spot, even when it appears to us that migration would be very easy. And so it was with this particular group of $O$. foraminatus. It seems they were introduced into this locality about eight years ago, at a time when the brick manufacturing company piled several carloads of logs in the field. These logs have been hauled away, from time to time, by cartloads and used for starting the kiln fires. It is possible that they were introduced in some stage of their development with the logs, and, finding everything to their liking, have occupied the site generation after generation, never going even to the fence-posts or other wooden structures near by. As a result of this inability to go even a little way from the place of their birth, their numbers have grown less and less, as the logs have been used; and now, when the last load will have gone to feed the flames, there seems no hope of anything but extermination for this lot. We have made diligent search about the region to find even a few of them taking up their abode in some more permanent structure, but without success. If, like our Bembix nubilipennis and Scolia dubia, they cannot disseminate over different parts of a restricted area, how is it possible for them to cover distinct or remote areas?

Hungerford and Williams dug them out of a stump in Decatur County, Kansas, and found the cells separated by partitions of mud.

After so recently deploring the probable extermination of many of these wasps on account of their lack of adaptation to other places of abode than the logs, we were gratified to have discovered in another area at least one case in which this insect had used a hollow twig. This elderberry 


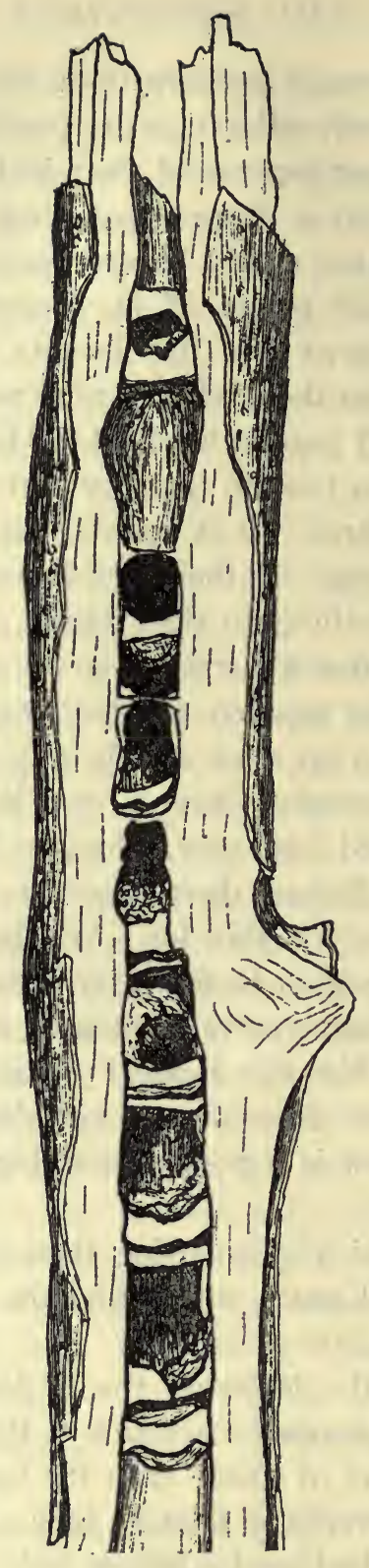

FIG. 67. The nest of Odynerus foraminatus in an elder stem. Natural size. 
stalk was about eighteen inches high and seven-eighths inch in external diameter, while the diameter of the hollow within was a little more than three-eighths inch. One must admit that this is quite a cavity for so small a mason to partition off. The top was broken off, thus offering easy access to the mother wasp. The inside was weathered, and some rings of mud about the periphery disclosed the fact that last year was not the first season that the stem had been in use. Not the entire gallery in the stem, but only the upper porion, was partitioned. The nest at present occupying it commenced at a point six inches from the top, where a heavy bottom of mud, one-half inch thick, had been placed for a foundation or floor; below this the hollow was empty and unused, and weathered from previous erposure. This shows conclusively that in this case the mother had not been compelled to do any tunnelling, but the elder stalk as she found it was already tenantable.

The figure shows (see fig. 68) the single solid chunk of mud for a platform at the bottom, another layer near to this base and so close in some places as almost to touch the platform layer. Similarly, each partition was composed of two separate'walls. The intervening space was usually sufficient to admit a fine pin, but in one case the two walls were one-fourth inch apart. The cells, as the figure shows, were three-eighths to one-half inch in length.

Upon opening the twig in May, we found three wasps completely developed, wings and all. They moved about and, with a little prodding, walked out of the cell. While we were speculating as to whether they had become mature very early in the season, or possibly the previous autumn, and were only awaiting the warmth of spring to come forth, we opened two other cells and there found the wasps completely developed except that the wings were not inflated. Hence, it is logical to conclude that these specimens had just 
completed or were completing their development at about this time and were ready to emerge. When taken from their cocoons in the twig and placed on cotton saturated with sweetened water, they immediately partook eagerly of the nourishment.

Another O. foraminatus was seen one June day carrying a dark gray caterpillar into an old log smoke-house. She hid it in a burrow in the lowermost $\log$, and then sealed the hole with mud.

It was impossible to investigate the nests of this species, to see whether they, too, suffer from the ravages of parasites. On more than one occasion, however, we saw Chrysis bees, Chrysis (Hexachrysis) intricata Br. [S. A. Rohwer] flying about the pile of wood wherein the wasps nested, as if looking for the burrows of some host; hence we should not be at all surprised if they sometimes meddled in the homes of $O$. foraminatus also. Pierce finds the females to be the host of the twisted-wing parasite. Strepsiptera.

Robertson found O. foraminatus females to go from flower to flower of Pentstemon laevigatus Solond. and, "turning to the base of the tube, cut a hole in one side with her sharp jaws and insert her tongue, then she cut a hole in the other side and again inserted her tongue. The nectar is lodged on each side of the base of the sterile filament, and the wasp showed remarkable intelligence in making a hole on each side." We saw them repeatedly feeding at the flowers of Melilotus alba, and Robertson records various other flowers upon which they feed.

Ancistrocerus fulvipes Sauss. [S. A. Rohwer].

This wasp, which we had previously observed entering holes in $\log$ s, was seen at the edge of a corn-field near 
Creve Coeur Lake, digging up mouthfuls of mud. Later in the day another individual was seen, at the same place, doing precisely the same thing. We suppose it was carrying mud to make partitions and plugs in its burrow somewhere, perhaps in wood. Several others were entering holes in old logs piled a short distance away. Some of them were digging in the wood. One in particular entered a shallow hole and, with the body partly protruding, turned itself around so that it was inverted, and cut away the wood at the ceiling of the burrow. Hence we see that they do not use old tunnels of other insects, but mine their own or enlarge those already at hand.

We found ${ }^{9}$ that this species makes good use of the old cells of mud-daubing wasps. They use these old cells without modification, filling them with caterpillars for their young and then sealing the aperture with mud. Ashmead cites Walsh, who saw one nest-building in a spool.

Not alone does this wasp use the tunnels in wood with or without modification; she also digs burrows of her own. In a small clay bank, protected overhead by a porch, three specimens of this wasp were seen at work as early as June 28. As the season advanced, others appeared.

The interesting feature of this bank was that its face was completely riddled with the old tunnels of a miningbee, Entechnia taurea Say (see fig. 68), any one of which would have made an ample domicile for this wasp. Instead of appropriating one of these, however, she always built her own tunnels in the clay bank, although in so doing she often broke into the barrel-shaped cells left by this bee.

One of these wasps was seen in the morning bringing in a caterpillar and in the afternoon sealing the cell with a plug of wet earth. The burrow, when opened, was found to have two cells, separated by a partition of mud. The tunnel was

${ }^{9}$ Journ. Animal Behavior 6: 27-63. I916. 
about one-fourth inch in diameter, and each of the two cells was three-fourths inch long. The plug at the orifice was thicker than the partition. Most interesting of all was the fact that the last cell had broken into an old bee cell, and this, too, had not been used but, on the contrary, had

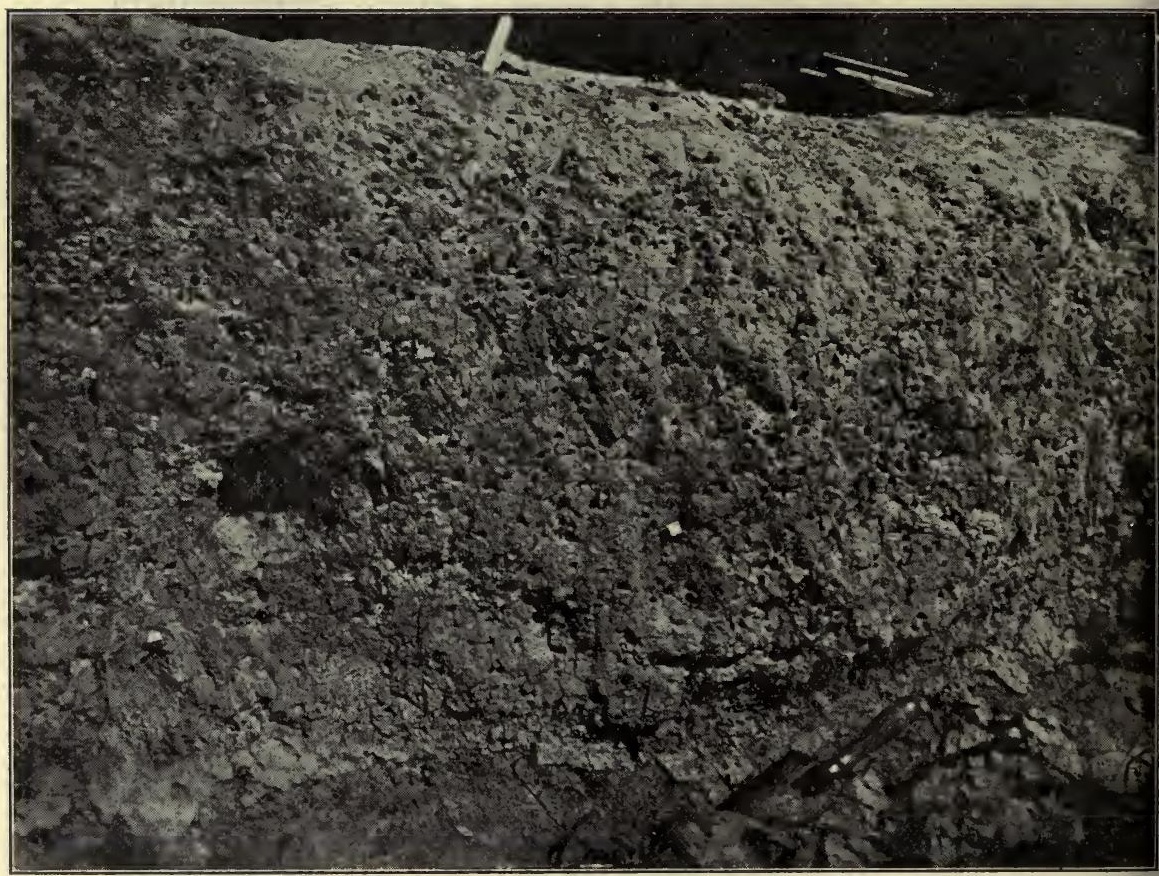

FIG. 68. Abandoned holes of the mining bee. Ignoring the opportunity of ready made homes, Ancistrocerus fulvipes found space in the interstices to dig her own burrows.

been partitioned off with mud. The cell nearest the surface of the ground contained seven caterpillars, all of the same size and species, and the egg aftached to the wall by the usual short thread. It hatched within the succeeding twentyfour hours. The caterpillars, too, were all alive at that time, and had been letting out silk. 
In the lower cell, the egg or larva must have been lost in removing the soil, but eight caterpillars were unearthed. All but one responded to stimuli; the exceptional one was discolored. Thirty-six hours later, these caterpillars were beginning to pupate. Hence it appears that the caterpillars are either placed in the cell with so slight a sting or mere crushing of the abdomen that they can survive and pupate, or else they are placed there fully alive. It seems improbable that the caterpillars would pupate if very roughly handled. The caterpillars used are so small, in comparison with the size of the wasp, that it seems that stinging would be quite unnecessary to keep them from resisting. One of the caterpillars in this cell pupated, and, nine days later, emerged an adult butterfly, which was identified as Characoma nilotica Rogen [H. G. Dyar]. This gives proof that, if the prey is stung at all, the sting is so slight that it has little or no effect upon the transforming creature.

Another nest was opened which differed essentially from the first. This one was closed at the orifice with a mud plug. Below this was an empty chamber, possibly an airspace, for three-quarters of an inch, and beyond this the lower or true chamber, nine-sixteenths inch in length and one-quarter inch in width, containing the prey and the larva: while the empty egg-shell swung upon its thread. The ten caterpillars were in these various conditions: two were dead and discolored, five were absolutely normal pupae, and three were live caterpillars, one of which was feeding upon one of the pupae.

Still another nest comprised three cells plus the airchamber; the wasp's channel had two cells, very similar to the first described above, and the third or bottom cell was the chamber of a mining-bee which was broken into and afterward utilized. The three cells contained nine, seven and six caterpillars. The air-chamber was three-fourths 
inch in length, and the other three cells were one and onehalf inches in total length.

The next nest opened was unlike any of the others; it had but a single cell and no air-chamber. We had watched the mother-wasp close the burrow with mud, and expected to find the egg quite new. But the larva was already hatched and was beginning to partake of its supply of provisions (thirteen caterpillars identified by S. B. Fracker as Exertema sp.). This is significant in showing that the nest is not fully provisioned before the egg is laid, but the egg is deposited before or during provisioning.

She does not make her burrow by kicking out the soil, but, like certain species of Odynerus, she carries water, softens the earth into mud which she gathers into a pellet, carries out and discards. She enters her hole head first, gets her load, backs out and flies backward for about six inches, then drops the load and re-enters. We once counted that with one mouthful of water she brought out nine pellets of mud; the succeeding mouthful made exactly the same number. Another took out six loads of mud in three minutes.

The holes are left open during the proprietor's absence. A large, blue cuckoo-bee once entered a cell and remained within for several minutes.

Thus we see her, a versatile creature who can adapt herself to various conditions with equal success.

Ancistrocerus tigris Sauss. [S. A. Rohwer].

A mud nest was found on the outside of a schoolhouse at Lake View, Kansas. The nest seemed newly-made, and, from its appearance, we thought that it belonged to a Chalybion or a Sceliphron. When we broke it open, how- 
ever, we found that eac!n long cell had two partitions making of it three cells, each of which was lined with a papery substance. Most of the pupae were injured by the jar when the nest fell, so that only two came to maturity and emerged as adult $A$. tigris, on August 5 and 6, 1916. The caterpillars remaining in the cells were so dried up that their species was indeterminable.

At first it seemed possible that this Eumenid had made her own nest, instead of being a renter, but later we found evidence of the cells having been resealed; so, in all probability, it had been previously occupied by one of the muddaubers.

Mrs. Slosson finds this insect to inhabit the Alpine region of Mt. Washington. Banks ${ }^{10}$ finds that it frequents the flowers of Ceanothus, and Robertson records it as having been taken while feeding on various flower heads.

Two specimens of this species were taken dead from a spider's web. They linger until late in the fall; on October 27 several of them were out, feeding upon the few remaining flowers of the goldenrod, at Clifton Terrace, Illinois.

Ancistrocerus capra Sauss. [S. A. Rohwer].

A woody elder twig of the previous season was picked up from near the ground, at Eureka, Missouri, on July I2, I9I6. It was kept indoors all winter, and on April 23-27, I9I7, four wasps of the above species and one cuckoo-bee, Chrysis (Tetrachrysis) sp., [S. A. Rohwer], emerged therefrom.

The first cell, the bottom of which was on a level with the ground, was one and a quarter inches in length and sealed at the top with a mud partition. The cocoon therein

10 Ent. News 23: 107. I9I2. 
was very light tan, almost white, thin and papery. The second cell was three-fourths inch in length, unfilled and likewise closed at the top with a wall of mud. Above this was another cell only one-fourth inch in length, occupied by $A$. capra. The next cell, one-half inch long, contained a dead larva. The remaining four cells measured one-half inch or less, and gave forth adult wasps or parasites.

Ashmead $^{11}$ says, on the authority of Rev. T. W. Fyles, that this wasp provisions its cells with larvae of the larch saw-fly, Nematus erichsonii, and is economically valuable, destroying tineina, geometrina, tortricina, pryalina and noctuina larvae in great numbers.

Monobia quadridens Linn. [S. A. Rohwer].

The "carpenter mud wasp," Monobia quadridens, has been widely known for years, but little has been noted on its life history. That it is a mud wasp is true; that it is a carpenter wasp is doubtful, since the authors who attribute this habit to this wasp bring forward no positive evidence except that the nests are found in wood-bores. This point will bear further investigation, and until it is determined, some more appropriate name should be applied to the insect. The few known facts of its life history may be summed up as in the following paragraphs.

Ashmead $^{12}$. says that $M$. quadridens preys upon large cut-worms which she carries to her cells. These cells are made in the old burrows of the carpenter-bee, Xylocopa virginica, by first renovating the sides of the old tunnel with a thin veneering of clay and then dividing the space into cells with clay partitions, working from the bottom

11 Psyche 7: 77. 1896.

12 Psyche 7: 77. 1896. 
upwards. He saw more than one wasp entering and leaving a single burrow, and thinks that undoubtedly several individuals live and work in harmony together. Ashmead says nothing of their burrowing habits, but Comstock $^{13}$ and Iseley $^{14}$ say. that this species bores in solid wood. Tandy ${ }^{15}$ found a nest in a groove in the lower side of a block of cypress wood as it lay in a lumber pile. On the upper side of the block he found "six small partly decayed places" which he says bear evidence of the wasp's efforts to make its own tunnels for its home, but each of these burrows in turn had been abandoned because of the silicified layers in cypress wood. His data offer no guaranty that these six places had been made by this insect, but we are glad to know that it had readily conformed its work to its splendid opportunity and adopted the long mechanically-made groove for its fine twelve-celled nest. This behavior is, we think, in no wise exceptional, but it is in perfect harmony with the cases which we have observed, which will be discussed later.

Following are our observations on the mud-carrying activities of this wasp.

On a sandy area beside Fox Creek, near Allenton, Missouri, our attention fell upon a small spot of loam, where a few plants were sparsely growing. In the middle of an afternoon in July, a $M$. quadridens came to this earthy area, bit at the dirt and flew away leaving a most spot. It appeared at first that she was digging a hole there and had flown away for more water. She returned five times, at intervals of from five to ten minutes, and repeated this performance precisely, each time in a different spot; she wet the ground with water or saliva, bit out a chunk of dirt, rolled it into a ball with her mandibles and with

13 According to Kellogg, Am. Insects, p. 502, fig. 702. 1905.

${ }^{14}$ Kans. Univ. Sci. Bull. 8: 245. 1913.

15 Ent. News 19: 231. 1908. 
them carried it away just as the mud-daubers do. She stood on her head and struggled with the stiff mud, as if only with great effort could she remove the clay, while mud-daubing Pelopoeus at the edge of their watering-places carefully select their mud of just the right consistency and then gather it up with comparative ease and grace.

A year later, August 7, I9I7, we saw three instances of the mud-carrying propensities of this ingenious wasp. One came from afar to the dirt bank under the porch where we were loitering, moistened a spot of the earth until it became mud, which she gathered in a big ball and carried away. A second one, which had her nest in a board in the porch above the clay bank, went out for a load of water, came back and alighted on the turret made by a burrowing bee, and, after soaking it, appropriated a huge mouthful of her neighbor's pretty dwelling in a manner most nonchalant. A third, thanks to our vandalism, had not so far to go for her partitioning mud. For about two days we had been noticing this one entering an abandoned carpenter-bee hole in the joist, and were eager to see the internal structure of the burrow. With a pocket-knife, we attempted to remove enough of the wood to expose the cells, but after expending much energy in whittling, we decided it could not be done. Suddenly it dawned upon us that to leave this fresh cut in the weather-worn porch prop would spell the doom of the few privileges which we enjoyed of prowling about people's premises, since our erratic behavior was already regarded with grave suspicion by the populace of this rustic community. Then we remembered the saving grace of protective coloration. We hastily gathered a few handfuls of mud and besmeared the bright cuts, to render all the woodwork a uniform gray color. The wasp continued her work, however, and profited at once by her new convenience. Although she had been going elsewhere for 
her mud for ten days or more, she at once changed her course of action and gathered this mud which we had just placed near to her door. We have never seen another wasp so quick to alter her activity in order to avail herself of a new and strange convenience or economy.

The several nests which have been examined internally showed much variation in the nesting-habits and provisioning. While Comstock indicates that these wasps use vertical holes in trees, we have found them to occur in various other situations.

The first one opened was in the under side of a porch floor. With much effort, sufficient wood was cut away to expose three cells of a large tunnel that went into the joist horizontally. The sides of the tunnel bore marks of previous partitions, not alone of this wasp, but also of the carpenter-bee; hence, it seemed evident that this hole had been used several times by both the bee and the wasp. There was no veneering of mud such as Ashmead describes. In one cell was a fat, growing larva with sixteen large caterpillars, all identified by Dr: Fracker as Epipaschiinae, probably Epipaschia sp. The other cell contained eighteen caterpillars of the same species. This seems indeed an astonishing number, considering their size, to be stored for a single infant.

Another mother which was utilizing an abandoned burrowing-bee hole in the clay bank for its domicile, was caught in her task of carrying in caterpillars and sealing the cell. The first one she brought in fifteen minutes, the second one in twenty-five minutes. These large caterpillars were carried very deftly under the body; the long trunk was not allowed to dangle awkwardly, but one end was clutched in the mandibles while the other end was clasped close to the abdomen with the legs. When next observed at I I o'clock she was carrying in either mud or water and 
sealing up the hole; the aperture was already closed and she was occupied with biting out mud alongside the burrow and adding it to the plug. Suddenly she flew away and returned in five minutes without mud but with water, and moistened the earth beside the plug. We eagerly pressed too close, to study her method, and she fled. Three minutes later she returned, bringing a pellet of mud from afar, and applied it, went out and got another ball in the same way and added that; then, with the surplus water in her mouth; she soaked up more earth beside the hole, dug it out and plastered it also over the closure. Here both methods were used : bringing in water and making mud near at hand, and carrying mud from afar. In applying this mud, she revolved about the hole, taking every position describing a circle. After two minutes, she brought in still another ball of mud. For a few moments our attention was drawn to another little wasp nearby, and when we turned back, the first had torn out all her carefully constructed masonry, opened her seal and was busy inside the burrow. What she was doing there we could not ascertain, but when we returned to the scene at $4 \mathrm{p}$. m. the burrow was once more nicely sealed. A large, freshly-made depression beside the hole gave evidence that much of the material for the plug had been gathered right on the premises. Upon opening this nest, we found it had first an air-space of one-half inch depth, then a partition and, a little way behind this; the remains of another partition-the one evidently broken into when she demolished the front door. Through poor manipulation in opening the nest, we got the contents of two cells together, which comprised thirty-six caterpillars of the kind already mentioned, and an egg for each compartment. Almost all of the caterpillars spontaneously exhibited signs of life. The eggs were not carelessly tucked in among the writhing caterpillars, but in true Eumenid 
fashion they were neatly suspended from the walls by a short silken thread. The egg was $5 \mathrm{~mm}$. long, and the thread about one-half of that length. The two bee cells used for this nest had originally been built at right angles to each other, and had been utilized by $M$. quadridens without alteration. One of the eggs, deposited between ro a. $\mathrm{m}$. and 4 p. m. on July $\mathrm{r} 6$, was placed in a vial together with its portion of the caterpillars, eighteen in number. The larva devoured all of them, pupated, and on August 19 emerged as an adult male, after a period of one month and three days for the three stages. It left no evidence of having spun a cocoon. This would indicate two generations per year.

In another cell which was opened, the empty egg-shell was still hanging from the wall, thus showing that the larva had crawled out of the egg-shell, instead of behaving as some Hymenoptera do, where the egg merely assumes form and eventually imbibes at one end. Most of the caterpillars, when the larva is done with them, are merely sucked dry: but a few bear marks where the chitin has been eaten. Obviously, where so enormous an amount of food is supplied, there is no necessity for the larva to consume the undesirable parts of the carcass.

Once, when digging up some burrows in the clay bank, we accidentally broke into the nest of a $M$. quadridens, which was in course of construction. The wasp returned and spent a long time evidently either looking for a lost hole or prospecting for one, poking her head into many holes, deep and shallow. The next morning at ro o'clock, she was busy enlarging a shallow opening by carrying out wet pellets of dirt. Her trip for each mouthful of water took four minutes. While the hole was yet shallow, she carried out the pellets by flying backwards; later she usually walked to the orifice backwards, released the pellet at the brink where it would roll down the steep surface of the bank, and 
re-entered the hole without turning around." An old bee cocoon she pulled out bodily and cast aside thus. Here we see an additional activity of this wasp; enlarging holes to make them suitable for her habitation.

Thus far in the observations, we had never seen one of these wasps actually cutting wood, but in all of the instances mentioned above and a number of others, they had merely utilized the old holes of carpenter-bees or other borers. Hence we were growing suspicious that these so-called carpenter-wasps are not wood-cutters at all. At this juncture our surmise was strengthened by finding a nest in the hollow roller-holder of an old iron bed-post on a junk-heap. Of course we could not open up the nest to examine its structure, but with the forceps we removed the caterpillars, six in number. Two were of the species mentioned heretofore, and four were of two other species not noted before; a mishap prevented their identification, but this record will show that $M$. quadridens uses more than one species of prey.

On July 25 one of these wasps was noticed in the outdoor laboratory, where she had appropriated an old nest of the Pelopoeus mud-dauber. This nest was lying on the shelf, and had been used also by a Trypoxylon clavatum for nidus. The cell in the top row of the nest was empty and open, and Monobia had enormously enlarged its opening. It already contained two caterpillars and the egg was hanging on its thread. This nicely shows that $M$. quadridens does not first provision the nest and then oviposit, as do some Hymenoptera, but that she lays the egg before or during provisioning. That night she slept in the cell with her face toward the opening, and by July 29, when I returned to the farm, she had completed and sealed the cell. Between August 5 and I5 one male wasp emerged. The cell when opened contained no evidence of a cocoon, but 
two crumpled, light-brown shedding-skins remained, one resembling the pupa, and the other more larva-like. This is the second instance of the absence of a cocoon; perhaps they do not spin one.

The behavior of insects in the event of rain is a point seldom noted, but we once had the opportunity of watching these under such circumstances. From our place of shelter under the porch and beside their nests, we could observe them to advantage. The first to come home in the rain was very shy in attempting to enter her nest, and when we persisted in lingering near to see if she carried anything, she flew angrily away in all the rain. Soon another came in, all wet and with slow flight, but when we attempted to capture it, it too wheeled about and went out into the storm. After ten minutes it returned, all drenched, in the most terrific downpour, went direct to the hole and crept in. During the hour, three others were seen to come home in the heavy rain in the same manner. The carpenter-bees nesting in the same place did not come home, but after the shower many came in.

Further observations must show whether this wasp uses saliva or water for making her mortar, and if she ever does the work of excavating her own tunnel in wood. If she actually carries water, it is remarkable that she does not gather the mud itself directly from the water's edge, unless indeed the streams thereabout are all so sandy or gravelly that there is no mud about them and she must carry water to an earthy area, like the spot on the sandbar in Fox Creek, to get her plaster. At least one can hardly imagine streams mudless to such an extent that the development of this habit would be forced. Thus the evolution of such a habit as this remains a wonder and mystery, but since the wasp is so apt in adapting certain conveniences to her needs, in all probability some day she or her descendants will be found using more eccinomical building or renovating methods. 
The habit of this insect of carrying water to moisten the earth is indeed a wonderful instinct. It is even more simple for Odynerus dorsale to carry water to moisten the earth where she digs her burrow than it is for Monobia to make a burrow in a log or bank, or even appropriate an old hole, go elsewhere for water and carry it to a distant dry spot in the earth, make the mud a mouthful at a time and carry it back to her nest for partitions and plugs. That would combine the methods of a water-carrier wasp, a mud-daubing wasp and a wood-cutter, plus a renovator or enlarger of old burrows. This would be indeed the most complex list of accomplishments and one of the most complicated methods of nest-building found among wasps. 


\section{CHAPTER XIV}

\section{Some General Considerations}

The behavior of wasps clearly contributes much evidence to the study of instinct and its plasticity or fixedness, the aptitude of organisms for learning, and their psychical adaptability.

One must surely be impressed with the vast variety of types of phychic phenomena found within the taxonomic limits for Sphegidae and Vespidae. When one goes into the field to study their habits, he must be always prepared to witness some unexpected type of behavior, and hold the mind as well as the eye open for new revelations, unbiased by what other individuals may have done and unprejudiced by any notions of what one should expect to see happen. Marvellous displays of instinct, intelligence and their variations greet one on every hand. The types of behavior are not exhausted with a few observations, but additional phenomena are revealed with every species-in fact, almost every individual-studied.

American investigators, foremost among whom are the Peckhams, Williams, Iseley, Hartman, Barth and Parker, have made known various aspects of the life-history of approximately IIO species. The foregoing pages describe the behavior of 6o-odd species. This gives us a total of some I70 species of whose behavior something is known. One can safely say that the ecological life-histories of about half of this number have not been worked to completion, but still await the deft hand of a Fabre or a 
Peckham. One may safely say, too, that the work of the European naturalists will not greatly exceed this number, and that, approximately, less than 200 species of wasps have anything like a complete report to their credit. When we compare this with the number of known species of Vespidae up to I894 and Sphegidae to I897 ( ide Dalla Torre's Catalogus Hymenopterorum), which is approximately 9900, we get an idea of the vast amount of work yet to be done before we dare attempt to construct a synthetic genetic psycholcgy of wasps.

The social and solitary wasps afford especially fine material with which to work out such problems as the correlation of habit to structure, the origin of socialization among insects, the development of intelligence from instinct, as Whitman would have it, or the independent origins of instinct and intelligence, the problem of the inheritance of psychic acquisitions as per Lamarck, the position of natural selection as a factor in preserving and accumulating favorable variations in behavior, problems of distribution etc.

Throughout this work the data have given evidence of four very definite attitudes of behavior:

I. That there are very definite and iron-clad instincts.

2. That, despite these instincts which are constant in each species, there is much variation in the behavior of the individuals.

3. That there is a display of the expression of emotions in these creatures.

4. That, in many instances, there is much aptitude for learning, display of memory, profiting by experience and what seems to us rational conduct.

Before giving details showing examples of the above four types of behavior, it is well to point out that there are extant two very important interpretations of behavior which these observations clearly do not support. The first is the 
theory of Bethe, who thinks that we have not the right to admit either sensations, perceptions or memories in animals. He refuses to allow animals any psychic qualities whatever, and considers the presence of consciousness, even in animals that can learn by experience, as a highly problematic and improper assumption. The other theory is the tropism theory of Loeb. However well Loeb's theory may apply to certain organisms in the plant or animal world, his mechanical interpretation is nil, in so far as the movements of wasps are concerned, when he says:" "The tropisms are identical for animals and plants. The explanation of them depends first upon the specific irritability of certain elements of the body surface, and second upon the relation of symmetry of the body. Symmetrical elements at the surface of the body have the same irritability, unsymmetrical elements have a different irritability. Those nearer the oral pole possess an irritability greater than that of those near the aboral pole. These circumstances force an animal to orient itself in such a way that symmetrical points on the surface of the body are stimulated equally. In this way the animals are led without will of their own, either toward the source of stimulus or away from it. Thus there remains nothing for the ganglion cells to do but to conduct the stimulus, and this may be accomplished by protoplasm in any form."

The theories of Loeb² and Bethe make not a beginning of an explanation of the activities in Waspdom. Had either of the gentlemen spent some time in the field with these creatures, his mechanical theory, if formulated at all, would

1 Holmes, Evolution of Animal Intelligence, p. 20. I9I I.

${ }^{2}$ It must be remembered, however, that Loeb does not claim that all the reactions of animals are tropisms. He recognizes three types of behavior: tropisms, differential sensibility and associative memory. He even states that he thinks he must admit that ants, wasps and bees have associative memory. 
presumably have been so modified as not to be all-embracing in its scope.

We know that there are established instincts. It would be superfluous to do more than to mention a few of the most patent of these, e.g., the instinct of every species of wasp to hunt certain prey; the instinct for mating; the instinct for getting food for itself; the instinct for stinging, for nest-building, etc. These are all established and fundamental instincts which will admit of no marked digression. There are, however, an unlimited number of habits which seem to be constant which probably are not fixed by such stern necessity as those mentioned above. These may be mere habits which have become fixed in the species, even as our habits become fixed without either the compulsion of necessity or the urge of advantage. Nevertheless, these ways seem to be constant within the species and seem to be followed instinctively. As examples of this condition, we may note the following cases:

The method of digging or of building is fairly constant among the members of a species and is pursued instinctively.

The way of Bembix mubilipennis in bringing in soft, delicate flies for the first meal for her young is probably an act of instinct - at least it will have to be so classified until otherwise proved. The large chamber at the bottom of the burrow of this species, also, is not so planned by a knowledge of the need of the babe, nor is the work invariably directed to this end by tropisms, but guided again by instinct. The constancy with which this species closes her hole when going out on a foraging trip classes this habit also with instincts. The persistence of several species of wasps in carrying their prey always in the same way, sometimes even going through the motions of dragging or tugging at it when it is so small that it is all the while lifted 
clear off the ground, is evidently pure instinct. Wasps of some species are persistent in making a final examination of the interior of the burrow before taking in the prey; other species are as determined upon plunging into the burrow with their burden immediately upon their arrival at the nest. Instinctive behavior is exhibited by Scolia dubia in that it flies only about the barn where its prey can be found. In the case of Alyson melleus, which uses delicate leaf-hoppers that easily become dry and hard, the habit of nesting always in moist places now seems general for this species.

The above cases are only a few instances from the long list of instinctive activities of wasps which might be mentioned. While all of these habits are, in some such form, either necessary or advantageous to the well-being of the species, most of them would admit of minor digressionsindividual variations, if you please-in the way of carrying them out or of doing them under the difficulty of abnormal conditions. Many such deviations have been discovered in our field work; more of them are ferreted out, of course, with an increased scope of the number of observations. Almost more interesting and important than the instincts themselves are the variations and modifications of the usual habit. These details of the behavior of members of a species, these modifications, slight though they may appear, are probabiy the handle upon which Natural Selection works-the evidence of evolution in some form in progress before our eyes. Among these variations in instinct which we have fortunately espied in wasp life we may cite the following from the preceding pages:

Bembix nubilipennis occasionally rob one another of their prey, when instinctively they ought to find their own provisions.

While nest-building is probably instinctive, we have 
found occasional pronounced variations in the type of nests under our own observation. In other instances, the nests described by us were different in rertain details from those of the same species described by other writers from other localities.

Parker tells us that Microbembix first lays the egg and then provisions the nest, while we found one which had brought in five insects and still the egg had not been deposited.

A Pompiloides tropicus took a spider, presumably for her young; but when she could not find her nest and decided to abandon it, she first made an incision in the body wall and sucked the juices. Some species seem to have quite unvarying habits in the manner of carrying their prey, but Pompiloides marginatus exhibits some degree of variation in this respect; one walked backwards with a spider larger than herself, holding it in a vertical position with her mandibles inserted in the ventral surface between its legs; another grasped the spider by one of its coxae; a third had a spider which was so small that it was well above the ground, yet she walked backwards with it with an air of being obliged to exert herself; still others flew backwards with their prey.

Wasps are nectar-feeding insects, yet we find $P$. tropicus and $P$. marginatus sometimes indulging in animal food. Both species of Pompiloides sting with varying intensities; sometimes the prey is stung to death, sometimes the victim lingers for some days, or in other instances it recovers.

$P$. scelestus introduces a novel method of removing the soil from her burrow by dropping her forelegs to form a rake and then walking backwards, thus dragging out the soil, which is usually kicked under the body.

Priocnemis pompilus is not a stickler for conventionality; she takes such prey as she can get, uses such holes as she 
can find, and only sometimes modifies them to suit her needs; if she cannot ascend a precipitous slope directly, she will in time contrive some indirect way to scale it. In carrying her prey, she walks backwards dragging her burden, but also sometimes walks sidewise dragging it at right angles to her own body. She seizes it by any of its members that may offer themselves as a convenient handle at the moment. Other wasps, described in the preceding pages, presented various digressions from the customary way of the species of transporting their prey.

Some wasps are very exacting in their construction or selection of a nest; others admit a considerable variety, as for instance Trypoxylon clavatum, which is thus far known to use for its cells the made-over cells of the mud-dauber, holes in logs or fence-posts, or to tunnel deftly into wood to make its own burrows.

Tachysphex terminatus, originally a digger in sand, seemed to be adapting itself to the loose dirt on a clay bank, but the nests were crude in shape and subnormal in size.

While Priononyx thomae carries the prey to the orifice of the burrow, enters, comes up, grasps it by the antennae and pulls it in, on one occasion she hastily dumped it into the hole immediately upon arriving and crowded in after it.

This list of individual digressions from the customary ways of the species might be continued indefinitely. Whether these truants from conventionality show by their independent actions a type of degeneration or a degree of development superior to that of their fellow-beings we shall not now venture to surmise; at least not until that moot point has been decided for the human species. However, be that as it may, the first requisite for improvement of the species or even of its ability to hold its own in a constantly changing environment is precisely this variability, this capacity to adopt or contrive new ways. 
Under the next heading we come to the expression of emotions in these wasps. It is exceedingly difficult, in witnessing demonstrations like the following to think of these creatures as mere automata or mechanical instruments.

In the sun-dance of Bembix nubilipennis, sufficient emotion is displayed when the dancing males leave their aerial flight and masses of them struggle on the ground to gain possession of the female and then pursue the mated pair on the wing until they overtake them and form the teeming mass again.

Pompiloides tropicus, upon regaining her spider after a long search, pounced upon it with unmistakable viciousness. Later, when some ants came near to her burrow she bit at them, kicked at them angrily and curled up her sting at them menacingly until they withdrew, either of their own accord or in consequence of her threats.

Pompiloides marginatus displayed decided agitation when she came to a spider's turret, lingered about it for some time in vain, then violently rammed her head against the turret.

If wasps are capable of the expression of the emotion of anger, Pseudagenia pulchripennis certainly made the display when the spider which she was pursuing gave one leap and escaped. The wasp became frantic; the sight of the spider and the fact that she had been fooled so excited her that she acted madly, walking, flying, running about the ground in indescribable directions until she tumbled headlong into a mole's hole. The play of Trypoxylon clavatum might probably be classified as the expression of some emotion or other.

Stizus unicinctus, after examining near a dozen spots of broken soil, arrived at a certain inconspicuous pile of loose earth. Instantly her manner changed when she had "struck pay dirt"; she became greatly excited, nervous, quivering 
with eagerness, expressing in every movement and attitude the furious eagerness and excitement which agitated her.

Finally, we arrive at the items of behavior evidencing intelligence, or let it be called plastic judgment, practical judgment, place-memory, associative memory or aptitude for learning. Only a few instances, to be sure, may be recalled here.

Late in the mating season of Bembix mubilipennis, the males mate with the females quietly, right on the dancing area, whereas only a few days earlier, when males are abundant and females few, the marriage flight consists of a wild dash far out over the grass outside the dance area and away from the mobs that were ready to sever the mating pair.

One Bembix started one hole after another, while frequently others would fly down and alight with a thump and violently bump her. Each time she was bumped she flew a short distance and began a new hole. After eight such attempts, she learned not to mind intruders further and continued to dig the last hole while twenty-four other wasps one by one flew down and butted her.

While the temporary closing of the burrow of Bembix by kicking up loose soil is probably instinctive, we believe the insect uses plastic judgment in meeting some conditions. When the ground is packed hard by dashing rains, she laboriously bites out with her mandibles the filing, and after permanently closing her burrow, she sweeps the dirt so as to remove from the surface all traces of her nest. Her conduct here varies with conditions; if there is a surplus of loose dirt near the hole, she sweeps it away and scatters it evenly over a considerable area; if it is bald so that traces of the filled hole are evident, she sweeps other dust back over it for a distance until no trace of a scar can be seen.

The behavior of Sphex pictipennis in overcoming unusual difficulties in getting her caterpillar through a tangle 
of grass indicated practical judgment, to say the least. She managed it very ingeniously by lifting one end of the burden and propping it high in a fork of grass, then swinging the lower end around to a slightly higher point, and thus continued lifting alternately the ends of the caterpillar until she had hoisted it out of the chasm in the grass thicket, exactly as a man, working alone, would hoist a heavy timber little by little.

The fact that $S$. pictipennis could not be induced to use the tamping tool until the burrow had been nearly filled shows a marvellous instinct, but the fact that Sphex sometimes uses a pebble, a hard clod, a bit of wood or even the leg of a grasshopper, is evidence of highly plastic intellectual powers. When she throws in a clod to be ground to dust, she breaks it up; when it is her intention to use it as a tool, she holds it between the mandibles and pounds and rubs it about with a circular motion. Again, when she had left her tool in the depression and had so far forgotten herself as to kick loose soil over it and bury it, when she was next ready to use it she went back and, with her mandibles, fished out this same clod to use as a hammer on the final layer.

We have wondered, as have many others, by what sense the wasp locates the proper spot for stinging her prey. We shall not attempt to say how she knows the spot, but the observation of $S$. pictipennis at this critical moment shows that the spot is located by the sense of touch, for she passed the tip of her abdomen on the under-side of the caterpillar, feeling or rather probing in a half-dozen places, sliding her sting continuously backward until she reached the point just to the rear of the last pair of pro-legs and there administered the long, deliberate thrust.

The flight of orientation as S. pictipennis leaves the nest and the usual return, in contrast to the difficulty and some- 
times the inability when she leaves the nest or prey so suddenly that no study of the landmarks can be made, again demonstrate place-memory.

Odynerus geminus usually fills up her burrow solid with mud, but on one occasion when danger threatened, she removed enough mud from her chimney barely to seal the cell below and then placed a thin layer of mud flush with the surface of the earth. The time was too short for the

A little piece of paper pinned to the ground to assist us in finding the nest of O.geminus proved soon to be a landmark for this mother. After a few days we removed the scrap of paper; the mother could not find the nest until the paper was replaced.

Odynerus dorsale, in going for water, follows landmarks. One individual repeatedly flew to the railroad track, travelled parallel to it for a short distance, then back in the direction from which she came to her pool. The railroad track was undoubtedly associated in her mind with the direction of her flight.

Fabre lays much stress upon the fact that Bembix will stupidly tolerate dipterous parasites about the nest when she has the power to dispose of them. But Stizus unicinctus is not so slow, for she was able to recognize at a glance the infestation of the hopper in the Priononyx hole and fled from the place without laying her egg.

An Arachnophoctonus ferrugineus dragging her prey left it several times, to fly to the old log house some distance away, and then returned very directly to her spider. She undoubtedly travelled from the spider to the walls so often to ascertain if she was going in the right direction, since eventually the nest was made between its logs.

In Priocnemis pompilus the instinct to enter the hole each time before bringing in the spider was strong, despite the fact that it meant disaster to do so, for the ledge before her 
door was so narrow that every time she came out of the burrow she knocked the spider down the hill. After prolonged struggles her better judgment overcame this instinct for a moment, for she finally carried her prey to a point where the bank sloped gradually, then dragged it back horizontally and let it rest on a ledge three inches above the burrow. But here the conflict between instinct and intelligence recurred, for when again she tried to take the spider into her burrow she returned to her old habit of a final inspection of the nest, and lost her prey as before

With these few facts as examples of types of variation in behavior, plasticity of instinct, memory, etc., we can see at once how little the theory of Bethe and the tropism theory have to offer toward satisfactorily explaining the phenomena. Forel, ${ }^{3}$ conservative as he is, explains the actions of such creatures far better in these words:

"Insects, therefore, reason, and the most intelligent among them, the social Hymenoptera, especially the wasps and ants, even reason much more than one is tempted to believe when one observes the regularly recurring mechanism of their instincts. To observe and understand these reasonings well, it is necessary to mislead their instinct. . . Further, one may remark little bursts of plastic judgment. of combinations-extremely limited, it is true-which, in forcing them an instant from the beaten track of their automatism, helps them to overcome difficulties, to decide between two dangers, etc.

"From the point of view of instinct and intelligence or rather of reason, there are not, therefore, absolute contrasts between the insect, the mammal and the man. In the insect, the inherited automatisms play by far the preponderating part, developed and specialized to an unheard-of point, and, curiously enough, often coming to produce very analo-

${ }^{3}$ The Senses of Insects. Translation, p. II9. London. 1908. 
gous effects to that which man has found with his plastic judgment. . . The most intelligent insects are generally, but not always, those which have the most varied instincts. In my opinión, there is no necessary relation. . . Instinct is reasoning, organized, systematized, automatized. It seems to require much less nervous substance for fixed or instinctive reasoning, than for reasoning actual, individual, new and combinative; these two factors occur in all animals which possess a nervous system, but in the insect, plastic reasoning is only a spark which serves as a base for each new complement of its so highly developed instincts." Again," "It must be admitted, therefore, that insects are capable of perceiving, of learning, of recollecting, of associating their recollections and of utilizing them to accomplish their ends. They have various emotions, and their will is not purely instinctive, but offers individual plastic modifications adapted to circumstances."

Forel's words apply aptly to the behavior of these creatures as we viewed them in sunny fields for four years. Hence, why should we apologize for the use of terms which seem anthropomorphic? Why spend the sunny summer days in green fields where Nature places no boundaries to her wonders, unless it be the limits of her other creatures already existing, and then withdraw to some far-away study to coin a new terminology with which to try to compass the actions of these organisms, branding them as automata, reflex machines and what not? We surely cannor see the manifestations of the inner nature of these creatures and think of them as automatic machines any more than we can look at the statue of The Thinker and characterize Rodin with Bethe terminology. ${ }^{5}$ With Clifford. Huxley and

4 Loc. cit. p. 274.

5 "To be consistent, one must recognize that, since each man has only his subjective knowledge of himself one must disallow every 'anthro- 
others, we realize that the student of animal behavior must ever be on his guard against making faulty ejects; yet, when confronted with abundant confirmatory evidence, to refuse

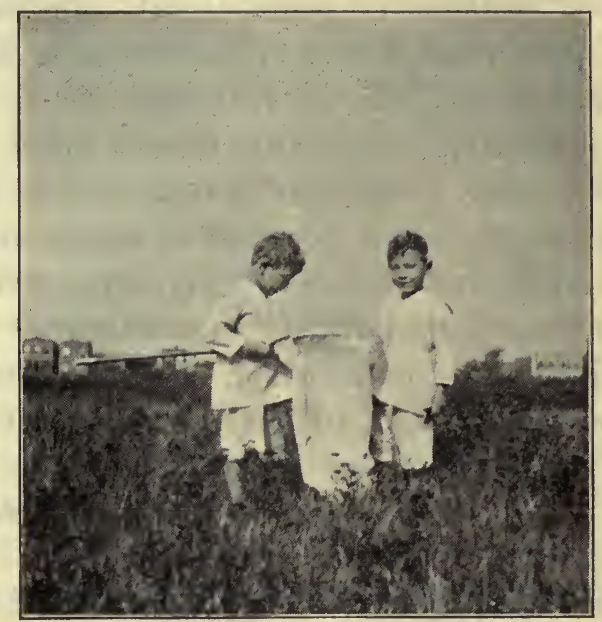

to ascribe a certain psychic trait to an animal merely because it. is not a human being seems to us as great an anthropomorphism as those of which the older comparative psychologists were guilty.

pomorphic,' that is to say egocentric term, not only to what concerns animals, but also to all other men. Indeed by supposing that other men have the same sensations as ourselves we attribute to them, without exact proof, our own subjectivism. If we wish to renounce it consistently. . . . we could no longer say 'my wife has a headache.' We should have to say: 'This animal machine which I believe to be my wife makes certain facial contortions and emits certain sonorous articulations which correspond to those which I emit when I have a headache. It may therefore be possible that she may have analogous sensations to mine in like cases, but I have not a right to call them headache.' "-Forel. 
others, we realize that the student of animal behavior must ever be on his guard against making faulty ejects; yet, when confronted with abundant confirmatory evidence, to refuse

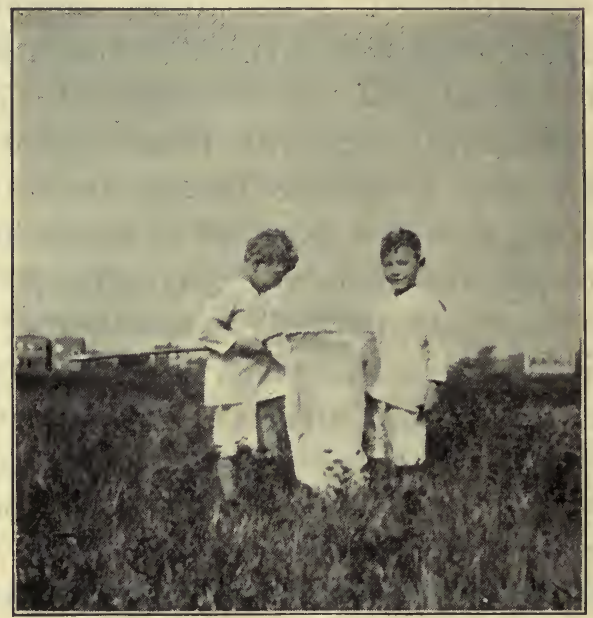

to ascribe a certain psychic trait to an animal merely because it is not a human being seems to us as great an anthrop anicm as those of which the older comparative psych
pomo
anim:
have
exac
siste
shor
wif,
lati
ach
ser
he 


\section{INDEX}

Achaetoneura, 92.

Acridean nymphs, 148.

Acroschismus bowdichi, 294. pallidus, 289.

ADAMs, I7I.

Agallia novella, 143.

Agenia architecta, 83-84, fig. I6.

Agrostis C. nigrum, 224.

Alyson melleus, 140-144, 359, fig. 33.

Ammobia bridwelli, 206.

Ammophila argentata, 227.

campestris, 227.

hirsuta, 226-227.

holosericea, 227. julii, 226-227.

pictipennis, 19, 24, 62, 191, 207$237,295,364-365$, fig. 2, figs. 45-49.

polita, 227 .

procera, 215, 226, 237-243,

fig. 50 .

sabulosa, 227.

urnaria, 215, 226-227.

yarrowi, 215, 226.

Amphitornus, 178.

Ancistrocerus capra, 245-246.

fulvipes, $340-344$, fig. 68 .

tigris, BDD-CDE.

Anthrax lateralis, 94.

Aphis setariae, 105-106.

Arachnophoctonus ferrugineus, $78-83,366$, fig. 15.

Argilis objectus, 127.

Arphia corinata, 173-174.

xanthoptera, 178.

AsHMEAD, 84, I08, I23, 124, I29, I32, 156,346 .

Athysanus exitiosus, I43.

Atlanticus dorsalis, 198.

Atrophopoda singularis, 91.

Aulocara, 165, I78.

BARTH, 4I, 96.

BATES, 27.

Bees, prey, I09-II7, I33.
Beetles, prey, I26-I32.

Belonogaster, 2.

Bembix ciliata, 27. nubilipennis, 9-37, 62, 358, 360363 , figs. $2-7$.

spinolae, 19, 23, 37-38, 147 .

BERGSON, I, 6.

BETHE, 6, 278, 357-358, 366.

Bicyrtes quadifasciata, 4I-43, fig. 8.

BlackBURN and CAMERON, I23.

BoH N, 6.

Buprestis lineata, 129.

BUTTEL-REEPEN, 278.

Camptonotus .carolinensis, 206.

Caspidae, I35.

Centhophilus, 202.

Ceratophorus tenax, 108.

Cerceris finitima, $\mathbf{1} 33$.

fumipennis, I26-I29, fig. 3I. ornata, 8.

tubercula, 244, 277.

Chalicodoma, experiments with, 278.

Chalybion caeruleum, I21, 124-125, I $35-137,288$, figs. $30-32$.

Characoma nilotica, 343 .

Chlorion auripes, 203-206.

caeruleum, 44.

calcaratum, I96.

cyaneum, I80-181, 200-203.

ichneumoneum, I93-198, fig. 43.

Chortophaga viridifasciata, 149.

Chrysis, 345. coerulans, 124. intricata, 340. perpulchra, 124

Chrysobothris deutipes, 129 .

floricola, 129.

4-impressa, I29.

Clubonia abbotti, 76 .

COCKERELL, I24.

Coloptenus spretus, 173.

Сомsтоск, 349.

Conocephalus triops, 198.

Conotrachelus neocrategi, 128.

Cotinis nitida, I3I. 
Crabro montanus, 96 . obscurus, 96 . sexmaculatus, 96 .

Cresson, 94.

DAVIDSON, 202.

Davis, I98.

Dicerca punctulata, 129.

Dichromorpha viridis, I48.

Diodontus Americanus, 108. corniger, 107. gracilis, 107. minutus, 108. tristis, 107-108.

Diomorus, 94.

Dissosteira carolina, І6г, I68, I73, I75.

Dolomedes, 64.

Draeculacephala mollipes, 39.

Emphanopteryx eumyothyroides, 92.

Empoasca mali, 143.

Enarmonia, 335.

Epipaschia, 349.

Eumenidae, 2, 5, 299-354.

Eupathocera, 236.

Exertema, 344.

FABRE, 6-8, I9I, 245, 277-278.

FERNALD, I97.

Flies, parasitic, 38, 46-47, I63-I64, I70-172, 197, 212, 236, 325 .

Flies, prey, 34, 90-1or.

FOREL, 366-368.

Gelechiidae, 333.

Gnorimoschema gallaesolidaginis, 336.

GROSBECK, I29.

Gryllus abbreviatus, 20I-203. pennsylvanicus, I53-I55.

Halictus disparalis, II5. pruinosus, II5. sparsus, II 5. versatus, II 5 .

HANCOCK, 58, I96.

HANDLIRSCH, 2.

HaRTMAN, 39, 60-63, I28, I43, I78, 2I5, 24I, 3I9.

Hemiptera, prey, I35.

Hilarella, 325.

Hippodamia I3-punctata, 39.

HoLmes, 216.

HUBBARD, I29.

Hungerford, and Williams, 44, 202, 288, 309-3II, 337 .
Hypocrabro chrysarginus, 94-96. stirpicolus, 90-94, figs. 21-23.

ISELEY, 3I6-32I, 324.

LAMARCK, 356.

Larra argentata, 156. terminata, $\mathrm{I} 49$.

LATTER, 227.

LEWIS, 245.

LOEB, 6, 357-358.

Loxostege, 306, 310, 336 .

LUBBOCK, 276-277.

Lucilia, 92. caesar, 34,38 .

Lycia cognataria, 225.

Lycosa carolinensis, 55 . domifex, 58. frondicola, 45 48, fig. 9. helluo, 76.

Lycosidae, 76-79.

McDougall, I.

Macrosiphum rudbeckiae, 108.

MARCHAL, 8.

MARTINEAU, 227:

Melanoplus, $\mathbf{1} 48$. differentialis, 165, 169. femur-rubrum, I73, 190, 199. lakinus, 165.

Mermiria neomexicana, 165 .

Metopia, 197. leucocephala, I72.

Microbembix monodonta, 39-4I, 360 , figs. 7-8.

Monobia quadridens, 346-354.

MORGAN, 216.

Murtfelt, Miss Mary E., 290.

Mutillidae, 2.

Nadata gibbosa, 240.

NeEDHA and LLOYd, 77-78.

Nemobius fasciatus, 153.

Neoharmonia velutina, 39.

Niteliopsis fossor, I35. inerme, I34.

Notogonidea argentata, I52-I58, 325 , fig. 35 .

Odynerus anormis, 331-332. designatus, 332. dorsalis, 62, 312-331, 365, fig. 2, figs. $58-64$. foraminatus, 334-340, figs. 66-67. geminus, 299-312, 365, figs. 2, 54, 57. pedestris, 332-334, fig. 65 . Oedipode, I35. 
Ophthalmochlus duryi, I74.

Orchelimum delicatum, 196. gracile, 198. vulgare, I94, I96, 198.

Orthoptera, prey, I35, I39-206.

Osmia bees, 277.

Osprynochotus junceus, 84.

Oxybelus quadrinotatus, IOI.

PACKARD, 94, I73, 205.

Paralimna appendiculata, 98.

Paranothyreus cingulatis, 96-IOI, figs. 24-26.

Pardosa canadensis, 76 . minima, 76. nigripalpis, 76 .

PARKER, 22-24, 37, 40-4I, 227.

Pecknams, $19,23,36-37,60-63$, $67,83,94$, I08, I 16-І19, I23, I29, I65, 202, 227, 332 .

Pellenes coecatus, 57-58.

Pelopoeus caementarium, II8-I24, I35-I $37,288,295,332$, figs. I8, 30. 32 . coeruleus, II9-I20.

Pentatomidae, 42.

Pepsis dubitata, 67-7I.

Pheidole vinelandica, 39.

Phidippus, 60 . andax, 84-85, fig. I7.

Philanthus punctatus, I07-II7, figs. $2,29$. vertilabris, II6.

Phlepsius irroratus, 39.

Pholisora catullus, 224, 3II, 324, 327.

Phorbia, 92.

Phormia regina, 92.

PierCe, I74, I97, 289, 294, 340.

Plant-lice, prey, I02-108.

Polistes, 4-5, 286-288, fig. 5I. annularis, 28I-285, 289-290, fig. 52.

bellicosus, 285, 294.

pallipes, BDD-BRJ, 29I-294.

rubiginosus, 280-283.

variatus, 288-289, 29 I.

.Pompilidae, 45-63.

Pompiloides marginatus, 58-63, 360 , 362, fig. I2.

tropicus, 45-58, 360, 362, figs.

9-II.

Pompilus scelestus, 64, 67, 361.

Priocnemis flavicornis, 77-78. pompilus, 7I-78, 36I, 366, fig. I4. Priononyx atratum, 24, 62, 159I75, figs. 2, 36-39.

thomae, 62, I75-193, 361, fig. 40-42.

Prodenia ornithogalli, 225.

Promusca domestica, 96.

Psammochares scelestus, 64-67, fig. I3.

Psammocharidae, 5.

Pseudagenia architecta, 83-84, fig. I6.

mellipes, 86-89, figs. I8-20B.

pulchripennis, 84-85, 362, fig. I7.

Pseudanthophilus vertilabris, I I6II 7.

Psilopus sipho, 92.

Pteromalus, 84.

Pyrgus tesselata, 324.

Ravinia quadrisetosa, 9I.

RILEY, 44,I72.

Roubaud, 2.

Salius pompilus, 7I.

Sarcodexia sternodontis, 92, 94.

Sarcophaga, 34.

Sarcomacronychia trivittata, 33I.

Scarabaeidae, I32.

Sceliphron-see Pelopoeus.

SCHWARZ, I24-I25.

Scolia dubia, I29-I32, 359.

Scoliidae, 2.

SHARP, 226.

Silaon niger, I34-I35.

SмITH, 278-280.

SNYDER, 294.

Sparnopolius brevirostris, 34, 38.

Sphaerophthalma scaeva, 89.

Sphecius speciosus, 44.

Sphegidae, 2, 5.

Sphex-see Ammophila.

Sphex elegans, 203, 206. tibialis, 205.

Spiders, prey, 67-68, 72-78, 83, II9125, I39.

Spogostylum anale, 32, 34 .

Solva pallipes, 92.

Stifus unicinctus, 4, I80-I93, 363, 365 , figs. 2, $4 \mathrm{I}$.

Strepsiptera, 340 .

Synagris, 2.

Syrbula admirabilis, 148.

Tachysphex fuscus, I49-I50.

obductus, I50-I5I. 
obscurus, I 50-I5.

terminatus, I44-I49, 36I, fig. 34 .

Tettigidae, I5I.

Tettigonia bifida, I43.

Thammotettix clitellarius, I43.

Theridium tepidariorum, 123.

Tномаs, 173.

Thomisid spider, 62 .

Thyreopus, 96.

Trachelas tranquilla, 84 .

Trochosa avara, 60, fig. I2. cinera, $\mathrm{I} 5 \mathrm{I}$.

Trypoxylon clavatum, 361,363 , fig. 32 . johnsoni, I37-I39. tridentatum, 134 .

Tryxalid, I49.

TURNER, I24, 225.

Vespa, 5. maculata, 297-298.

Vespula germanica, 295-297, fig. 53.

WALSH and RILEY, 84.

WEISSMANN, 278.

WESTWOOD, 107.

WHEELER, I-8, I 29.

WhitMAN, 356.

WICК НА, 83.

WILLIA MS, I35, I49, I5I, I57, I65, I 72, I78, I89.

I35-I37, WILlistoN, 215, 226.

Xyocelia metathoracicus, 102-108, figs. 27-28.

Xylocopa virginica, 205, 346-347.

Xylomya pallipes, 92.

Xysticus nervosus, 39. 


\section{The Princeton University Press}

invites attention to the volumes described in this and the following pages. They represent modern bookmaking at its best, in respect of scholarly and useful content, careful typography and durable binding. The aim throughout has been to produce, at a reasonable price, books worth writing, printing, publishing - and reading-in these days of national stress and economy.

Heredity and Environment in the Development of Men. By Edwin Grant Conklin. \$2 net; by mail, \$2.10.

Is a man ruled by his chromosomes? Is it useless to revolt against the predestination and foreordination of heredity? Professor Conklin is too human a scholar to counsel surrender. His book has not only had a notably large sale among general readers, but has been adopted as a textbook or for collateral reading by more than thirty colleges and universities. Its science is correct and advanced, its text is eminently readable, and its conclusions are positive and helpful.

A Critique of the Theory of Evolution. By Thomas Hunt Morgan. $\$ 1.50$ net; by mail, \$1.58. 
A survey and valuation of the older evidence and an appreciation of the new. The Journal of Heredity says: "It furnishes the first authoritative account of Morgan's work which is available to anyone but the specialist." And the Yale Reviere: "Darwin gave us a knowledge of the fact of evolution, Mendel introduced us to the method of inheritance, and Morgan advances us a long way in understanding the mechanism."

Above the French Lines. Letters of Stuart

Walcott, American aviator. \$1 net; by mail, $\$ 1.06$.

Walcott, son of Dr. Charles D. Walcott, Secretary of the Smithsonian Institution, was a college senior when he enlisted in the French Flying Corps. He was killed in combat in December of 1917. His letters give one of the best accounts ever published of the life of an airman in training.

England and Germany, 1740-1914. By Bernadotte Everly Schmitt. \$2 net; by mail, $\$ 2.10$.

An accurate, impartial history, written before the war, this volume presents an impressive mass of evidence against Germany, the self-outlawed nation.

The World Peril. By members of the Faculty of Princeton University. $\$ 1$ net; by mail, \$1.06.

Germany's violation of American rights; of democracy; of international law. Interests in the war 
of the two Americas and the Far East. Guarantees of international peace, in elimination of the Prussian system.

Protestantism in Germany. By Kerr D. Macmillan. $\$ 1.50$ net; by mail, $\$ 1.58$.

Luther and Lutheranism, and German national character, which have made it possible for the militarist German Government to plunge the world into this war "made in Germany."

The President's Control of Foreign RelaTions. By Edward S. Corwin. $\$ 1.50$ net; by mail, $\$ 1.58$.

A complete summary of the long rivalry between the executive and legislative branches of our government in foreign affairs.

Cooperative Marketing. By W. W. Cumberland. $\$ 1.50$ net; by mail, $\$ 1.58$.

A comprehensive survey of cooperative production and marketing among the citrus fruit growers of California which illuminates the whole field of cooperation.

Crime Prevention. By Arthur Woods. \$1 net; by mail, $\$ 1.06$.

Col. Woods, who was Mayor Mitchel's Police Commissioner, treats briefly but cogently these topics: Constitutional Methods; Educating the 
Public; Diminishing the Supply; Poverty; Mental Defectives; Drink and Drugs; Convicts; Juvenile Delinquency.

Financing the War. By A. Barton Hepburn. 50 cents net; by mail, 55 cents.

Mr. Hepburn's text covers but a small area of good white paper, but that area is cultivated intensively and bears a generous fruitage of sensible and helpful views of the nation's problem in war finance, bonds and taxes.

Simplified Italian Manual. By A. L. Frothingham. 50 cents net; by mail, 55 cents.

A little book that will be useful to all who wish to learn Italian quickly; especially, to Y. M. C. A. men and other war workers.

The Professional Re-education of Maimed Soldiers. By Leion de Peauw. \$1.25 net; by mail, $\$ 1.33$.

A complete description of Belgium's endeavor to restore to civic usefulness the victims of war. 




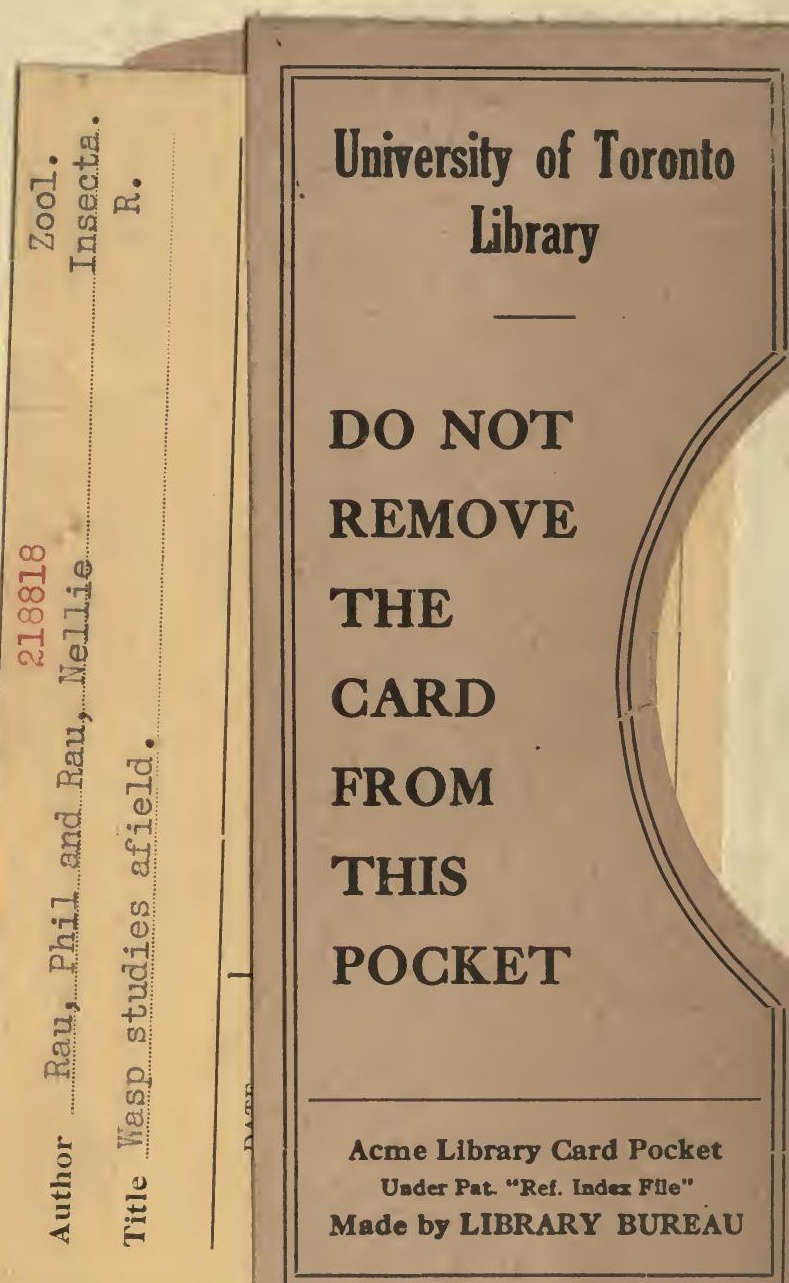


